\title{
Daily physical activity and COPD
}

Citation for published version (APA):

Vaes, A. W. (2015). Daily physical activity and COPD. [Doctoral Thesis, Maastricht University]. Maastricht University. https://doi.org/10.26481/dis.20150130av

Document status and date:

Published: 01/01/2015

DOI:

10.26481/dis.20150130av

Document Version:

Publisher's PDF, also known as Version of record

\section{Please check the document version of this publication:}

- A submitted manuscript is the version of the article upon submission and before peer-review. There can be important differences between the submitted version and the official published version of record.

People interested in the research are advised to contact the author for the final version of the publication, or visit the DOI to the publisher's website.

- The final author version and the galley proof are versions of the publication after peer review.

- The final published version features the final layout of the paper including the volume, issue and page numbers.

Link to publication

\footnotetext{
General rights rights.

- You may freely distribute the URL identifying the publication in the public portal. please follow below link for the End User Agreement:

www.umlib.nl/taverne-license

Take down policy

If you believe that this document breaches copyright please contact us at:

repository@maastrichtuniversity.nl

providing details and we will investigate your claim.
}

Copyright and moral rights for the publications made accessible in the public portal are retained by the authors and/or other copyright owners and it is a condition of accessing publications that users recognise and abide by the legal requirements associated with these

- Users may download and print one copy of any publication from the public portal for the purpose of private study or research.

- You may not further distribute the material or use it for any profit-making activity or commercial gain

If the publication is distributed under the terms of Article $25 \mathrm{fa}$ of the Dutch Copyright Act, indicated by the "Taverne" license above, 


\section{DAILY PHYSICAL}

ACTIVITY AND COPD

Anouk Vaes 
Copyright (C) Anouk Vaes, Maastricht 2015

ISBN 9789461593931

Lay out: Datawyse | Universitaire Pers Maastricht Cover Design: ArtCRDesign

Production: Datawyse | Universitaire Pers Maastricht

This thesis was financially supported by $\mathrm{ClRO}+$, center of expertise for chronic organ failure, the Netherlands and the Weijerhorst Foundation, Maastricht, the Netherlands.

Printing and distribution of this thesis was financially supported by $\mathrm{CIRO}+$, center of expertise for chronic organ failure, the Netherlands; Stichting Astmabestrijding, Amsterdam, the Netherlands; GlaxoSmithKline, Zeist, the Netherlands and Chiesi Pharmaceuticals B.V., Rijswijk, the Netherlands. 


\title{
'Daily physical activity and COPD'
}

\author{
PROEFSCHRIFT \\ ter verkrijging van de graad van doctor \\ aan de Universiteit Maastricht, \\ op gezag van de Rector Magnificus, Prof. Dr. L.L.G. Soete, \\ volgens het besluit van het College van Decanen, \\ in het openbaar te verdedigen op \\ vrijdag 30 januari 2015 om 10.00 uur
}

door

Anouk Wilhelmina Vaes

Geboren op 30 december 1982 te Weert

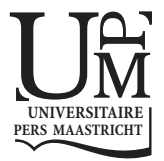




\section{Promotor}

Prof. dr. E.F.M. Wouters

\section{Copromotores}

Dr. M.A. Spruit (CIRO+, Horn)

Dr. K. Meijer

\section{Beoordelingscommissie}

Prof. dr. F.J.W.M. Smeenk (voorzitter)

Prof. dr. R.A. de Bie

Prof. dr. F. Pitta, State University of Londrina, Brasil

Dr. H. Savelberg

Prof. Dr. A. Schmidt-Trucksäss, University Basel, Switzerland 


\section{Table of contents}

Chapter 1 General introduction 7

Chapter 2 Task-related oxygen uptake during domestic activities of daily life in $\quad 21$ patients with COPD and healthy elderly subjects

Chapter 3 Effects of body mass index on task-related oxygen uptake and dyspnea 51 during activities of daily life in COPD

Chapter 4 Effect of new walking aid on functional exercise capacity in patients with chronic obstructive pulmonary disease

Chapter 5 Efficacy of walking aids on self-paced outdoor walking in individuals with COPD: A randomized cross-over trial

Chapter 6 Changes in physical activity and all-cause mortality in chronic obstructive pulmonary disease

Chapter 7 Effect of 'activity monitor-based' counseling on physical activity and health-related outcomes in patients with chronic diseases: $A$ systematic review and meta-analysis

Chapter 8 General discussion

Chapter 9 Summary of this thesis

Samenvatting van dit proefschrift

Valorization addendum

Acknowledgments

Curriculum vitae

List of publications 

Chapter 1

General introduction 



\section{Chronic Obstructive Pulmonary Disease (COPD)}

COPD is defined as 'a common preventable and treatable disease, characterized by persistent airflow limitation that is usually progressive and associated with an enhanced chronic inflammatory response in the airways and the lung to noxious particles or gases' (1). The chronic airflow limitation characteristic of COPD is caused by a mixture of small airways disease (obstructive bronchiolitis) and parenchymal destruction (emphysema) (1).

Worldwide, tobacco smoke is the most important single risk factor for the development of COPD (1-3). However, there is consistent evidence that nonsmokers may also develop COPD $(4,5)$. Indeed, a substantive burden of disease is attributable to risk factors other than smoking such as age, gender, genes, occupational dust and fumes, lung growth and development, and socioeconomic status $(1,3,6)$.

The characteristic symptoms of COPD are chronic and progressive dyspnea, cough and sputum production, which can be variable day-to-day (1-3). Other common symptoms include wheezing and chest tightness, and fatigue, weight loss and anorexia in the severe stages of COPD $(1,2)$. Nowadays, it is increasingly recognized that COPD is associated with several systemic manifestations, such as skeletal muscle dysfunction, osteoporosis, cardiovascular diseases, diabetes, anemia, and symptoms of anxiety and depression $(2,7)$.

The clinical diagnosis of COPD is based on spirometry, confirming a ratio of postbronchodilator forced expiratory volume in 1 second $\left(\mathrm{FEV}_{1}\right)$ and forced vital capacity (FVC) below $0.70(1,2)$. In the last decade it has become clear that there is a considerable heterogeneity between COPD patients, regarding respiratory symptoms, frequency of exacerbations, lung function decline, response to therapy and survival $(1,8,9)$. Therefore, the updated Global Initiative for Chronic Obstructive Lung Disease (GOLD) guidelines recommend not only to use the degree of airflow obstruction, but also determine the current level of patient's symptoms and risk of exacerbation for classifying COPD patients (figure 1) $(1,3)$.

\section{Prevalence and burden of COPD}

The prevalence of COPD varies considerably between countries, not only because of the widespread underrecognition and underdiagnosis of COPD, but also due to differences in study population, survey methods, diagnostic criteria and analytic approaches (1, 2, 10). A systematic review and meta-analysis using data from 26 studies showed that the 
prevalence of spirometry-defined COPD in adults of 40 years and older is approximately 9-10\% (10). A study in Maastricht, the Netherlands showed that the prevalence of GOLD-defined COPD in the general population aged 40 years and older is $24 \%$ (11).

The prevalence of COPD is projected to increase in the coming decades due to continued exposure to COPD risk factors and the demographic shift of an aging population. Future scenarios expect that between 2000 and 2025 the prevalence of COPD in the Dutch population of all ages will increase from 24 to 33 per 1,000 male inhabitants and from 15 to 27 per 1,000 female inhabitants(12). The Rotterdam study showed that the lifetime risk for developing COPD over the coming 40 years is $24 \%$ for a 55 -year old man and $16 \%$ for a 55 -year old woman (13).

COPD is one of the most important causes of death worldwide. In 2005, more than 3 million people died of COPD, corresponding to $5 \%$ of total deaths globally. It is estimated that COPD will become the fourth leading cause of death worldwide by 2030 (14).

In addition, COPD is associated with a significant economic burden. The economic costs include both direct costs associated with diagnoses and management of COPD and indirect costs such as disability, lost income from giving up employment, and caregiver or family costs associated with caring for COPD patients (15). In the European Union, the total costs of respiratory disease are estimated to $€ 380$ billion annually, of which $€ 48.4$ billion can be assigned to COPD (2). In addition, the social burden of COPD, estimated by disability-adjusted life-years (DALYs) lost for COPD, is another €93.0 billion per year (2). COPD is projected to be the seventh leading cause of DALYs lost worldwide by 2030 (14). In the Netherlands, the total annual costs of COPD are estimated at $€ 415$ million, including $€ 1,400$ per patient for healthcare use, and an additional $€ 1,200$ and $€ 1,900$ per patient for disability and sickness absence, respectively (16). COPD exacerbations account for the greatest proportion of the total health care costs and there is a direct relationship between the severity of COPD and the cost of care (1).

\section{Exercise limitation in COPD}

It is known that patients with COPD have an impaired exercise capacity compared to healthy controls $(17,18)$, often limited by dyspnea. Indeed, patients commonly report dyspnea as the main reason for reducing or stop exercise (19). Exercise intolerance in COPD may result from a complex interaction between ventilatory, peripheral muscle, pulmonary gas exchange, and cardiovascular abnormalities, which vary considerably per patient and also per exercise modality (20-23).

In the majority of the patients with severe COPD, the ventilatory limitation is often the predominant contributor to exercise intolerance, resulting from an imbalance between ventilatory demand and ventilatory capacity (24). In addition, dynamic hyperinflation, 
defined as a temporary and variable increase in the volume of air remaining in the lung at the end of spontaneous expiration (i.e. end-expiratory lung volume), contributes significantly to the sensations of dyspnea and impaired exercise capacity (25).

Furthermore, lower limb muscle dysfunction, frequently prevalent in patients with COPD, contributes significantly to exercise limitation (26-28). Indeed, 40 to $45 \%$ of patients with COPD report leg fatigue as the main limiting symptom during exercise, without reaching physiologic constraints (29). This could be related to the fact that peripheral muscle alterations, such as poor oxidative capacity, atrophy, and weakness, increase the susceptibility to contractile fatigue (26). In addition, increased lactic acid production for a given exercise work rate, which is common in patients with COPD, results in an increased ventilatory requirement (30). This imposes an additional burden on the respiratory muscles, which are already facing increased impedance to breathing (30). This rise in lactic acid is exacerbated by a tendency to retain carbon dioxide during exercise, further increasing acidosis and resulting ventilatory burden.

\section{Physical activity and COPD}

Physical activity is defined as any bodily movement produced by skeletal muscles that requires energy expenditure (31). It is a complex behavior, characterized by type, intensity, duration, patterns, and symptom experience. Physical activity also includes leisuretime, domestic and occupational activities $(31,32)$. Activities of daily living are a subset of physical activity and refer to a set of basic, everyday tasks required for personal selfcare and independent living $(33,34)$.

In the general population, regular physical activity has substantial health benefits, including a reduced risk for the development and progression of various diseases, such as cardiovascular disease, stroke, hypertension, type 2 diabetes mellitus, COPD, osteoporosis, obesity, some forms of cancer, anxiety and depression and a reduced all-cause mortality (35-38). In addition, there is strong evidence that regular physical activity results in increased cardiorespiratory and muscular fitness, improved body mass index and body composition, improved bone health, increased functional health and improved cognitive function $(36,38)$.

Health recommendations state that healthy adults aged 18-65 years should perform 30 minutes of at least moderate-intensity physical activity on five or more days every week or 20 minutes of vigorous-intensity physical activity on at least three days every week, or an equivalent combination(37, 39, 40). These recommendations have also been shown to be applicable in older adults ( $>65$ years) and in adults aged 50-64 years with clinically significant chronic conditions $(35,40)$.

Despite the important health benefits, many healthy adults do not meet the recommended amount of physical activity. Worldwide, more than $30 \%$ of the adults are physically inactive (39). However, the frequency of physical inactivity varies greatly between 
different regions, from $17.0 \%$ in southeast Asia to $43.3 \%$ in the Americas (39). In 2009, physical inactivity was identified as the fourth leading global risk factor for mortality and accounted for 3.2 million preventable deaths in 2004 (41).

The level of physical activity seriously declines with increasing age $(39,42)$ and having a chronic disease most probably accelerates this decline in physical activity. The prevalence of physical inactivity in patients with COPD is remarkably higher compared to healthy age-matched individuals, but also compared to patients with other chronic diseases such as diabetes mellitus and rheumatoid arthritis (43-49). Lower levels of physical activity are present even in the earliest stages of disease, and an increasing COPD severity is associated with a further decrease in physical activity (43).

\section{Activities of daily life}

A major contributor to physical inactivity in COPD is the perception of dyspnea (50). Indeed, many patients with COPD reported dyspnea as a limiting factor for performance of daily physical activities $(3,18,51-53)$, and it is most probably the starting point of the vicious circle of physical inactivity in $\operatorname{COPD}(44,54)$. Moreover, patients with COPD may experience more inconveniences during the performance of daily physical activities, because of a poor exercise tolerance (50). Both factors will also adversely affect the performance of activities of daily life (ADLs) in COPD, such as dressing, showering, walking and housework (55). Previously it was shown that patients with COPD have an enormous variety of problematic ADLs (55). Indeed, 820 patients with COPD reported 2999 problematic ADLs, of which walking was the most prevalent (55). In addition, a huge proportion of patients was not satisfied at all with the performance of one or more problematic ADLs. Therefore, it is important to study domestic problematic ADLs in more detail.

At the start of the current PhD project, the metabolic load and symptom perception during domestic ADLs were studied rarely in patients with COPD. Earlier studies showed that patients with COPD perform domestic ADLs at a higher proportion of their peak aerobic capacity compared to healthy subjects accompanied by a higher degree of dyspnea $(52,56,57)$. Nevertheless, it still remains unknown whether and to what extent differences may exist in task-related oxygen uptake and task-related symptoms in patients with COPD after stratification for gender, GOLD stage, Medical Research Council (MRC) dyspnea grade or score on BODE (body mass index, bronchial obstruction, dyspnea, exercise) index.

Strategies to improve exercise tolerance and symptom burden during daily physical activities may be useful for increasing the level of physical activity in COPD. In addition to exercise programs, strategies such as learning and applying energy conservation techniques and the use of walking aids may be beneficial. Indeed, earlier it was shown 
that the use of energy conservation techniques in COPD patients during ADL reduces energy cost and dyspnea perception $(58,59)$. In addition, the use of a rollator results in clinically relevant improvements in six-minute walk distance and a reduction in exerciseinduced dyspnea in patients with COPD (60-63). However, not all patients benefit from its use, and many patients feel embarrassed about using it. Therefore, it would be interesting to consider other walking aids.

\section{Physical inactivity and mortality}

Physical inactivity is known as a predictor of mortality in patients with COPD (64-66). In addition, low levels of physical activity have been associated with a higher risk of hospitalization $(64,65,67,68)$. Studies have shown that patients with COPD are severely inactive during and after hospitalization for an acute exacerbation $(69,70)$, and this physical inactivity results in an increased probability for readmission $(64,69)$.

Furthermore, low physical activity levels are associated with poor outcomes, including accelerated lung function decline, exercise intolerance, muscle weakness and reduced muscle mass and reduced health-related quality of life $(65,66,69,71-73)$. It is reasonable to assume that changes in physical activity behavior over time may affect these clinical outcomes. However, to date, studies on longitudinal changes in physical activity in patients with COPD are rarely. It would be interesting to compare longitudinal changes in physical activity between patients with COPD and healthy controls and their impact on mortality.

\section{Treatment of physical inactivity}

Because of the many adverse health outcomes of low physical activity levels, increasing physical activity is an important desirable outcome in patient with COPD. The 2013 Global Initiative for Chronic Obstructive Lung Disease (GOLD) guidelines recommend that patients with COPD should participate in daily physical activity (1). In addition, the latest statement from the American Thoracic Society and the European Respiratory Society on Pulmonary Rehabilitation stresses the importance of increasing physical activity, although, there are no COPD-specific recommendations for an adequate physical activity level (27).

Most evidence of increasing physical activity is based on structured exercise programs embedded in pulmonary rehabilitation (74-81). However, these programs do not guarantee an enhanced participation in daily activities and long term effects of these programs are limited. Therefore, it is important to develop and optimize physical activity programs aimed at integrating physical activity in daily life and adaptation to a physical active lifestyle. 
Since reduced physical activity levels may have a behavioral component $(82,83)$, interventions using behavioral modification and counseling are becoming more common. Indeed, a previous review showed that physical activity counseling was associated with a significant increase in self-reported daily physical activity levels in sedentary adults (84). In addition, activity monitors are increasingly used to promote physical activity (84, 85). They are easy to use and have been shown to be suitable for increasing physical activity (85). Studies combining the use of an activity monitor with behavioral modification on long term changes in physical activity are promising. However, the effects of these interventions in adults with a chronic disease have not been systematically evaluated yet.

\section{Aims of this PhD thesis}

Patients with COPD are limited in their ability to perform daily physical activities, even in the earliest stages of their disease. These lower levels of physical activity have a tremendous impact on many health related outcomes and progression of the disease. Therefore, the general aim of this thesis was to study daily physical activity in patients with COPD.

The specific aims of this thesis were to:

- Investigate differences in oxygen uptake, ventilation and Borg symptom scores between COPD patients and healthy elderly subjects during the performance of 5 activities of daily life; and differences in task-related oxygen uptake, ventilation and Borg symptom scores in COPD patients after stratification for gender, GOLD stage, MRC dyspnea grade or score on BODE index.

- Determine the effects of body mass index on oxygen uptake, ventilation and Borg symptom scores during the performance of 5 consecutive domestic activities of daily life in patients with COPD.

- Determine the effects of a rollator and a modern draisine on 6MWD, walking pattern, exercise-induced symptoms, metabolic requirements and user satisfaction in patients with COPD.

- Determine the efficacy of a rollator and draisine on self-paced outdoor walk distance, time and speed, walking pattern, exercise-induced symptoms and user satisfaction in patients with COPD.

- Study longitudinal changes in the level of self-reported regular physical activity between subjects with and without COPD and their impact on all-cause mortality risk.

- Systematically evaluate the effect of activity monitor-based counseling on physical activity levels, generic and disease-specific health-related outcomes in adults with a highly prevalent chronic disease, such as diabetes mellitus type II (DMII), COPD or chronic heart failure (CHF). 


\section{Outline of this thesis}

Chapter 2 provides more insight in differences in metabolic load and symptoms during the performance of activities of daily living between patients with COPD and healthy controls

Chapter 3 describes the effect of body mass index on the metabolic load during the performance of five consecutive ADLs in patients with COPD.

Chapter 4 describes the effect of a new walking aid on functional exercise capacity compared to a rollator in patients with COPD.

Chapter 5 describes the efficacy of walking aids on self-paced outdoor walking distance, time and speed in patients with COPD.

Chapter 6 includes data from the Copenhagen City Heart Study, describing longitudinal changes in physical activity between subjects with and without COPD, determinants of changes in physical activity and the association with all-cause mortality.

Chapter 7 presents a systematic review and meta-analysis on the effects of activity monitor-based counseling on physical activity and generic and disease-specific healthrelated outcomes in adults with DMII, COPD, or CHF.

Chapter 8 discusses the previous chapters and future directions for research. 


\section{References}

1. Vestbo J, Hurd SS, Agusti AG, Jones PW, Vogelmeier C, Anzueto A, et al. Global strategy for the diagnosis, management, and prevention of chronic obstructive pulmonary disease: GOLD executive summary. Am J Respir Crit Care Med. 2013;187(4):347-65.

2. Gibson G, Loddenkemper R, Sibille Y, Lundbäck B. The European Lung White Book. Sheffield: European Respiratory Society; 2013.

3. www.goldcopd.org.

4. Lamprecht B, McBurnie MA, Vollmer WM, Gudmundsson G, Welte T, Nizankowska-Mogilnicka E, et al. COPD in never smokers: results from the population-based burden of obstructive lung disease study. Chest. 2011;139(4):752-63.

5. Eisner MD, Anthonisen N, Coultas D, Kuenzli N, Perez-Padilla R, Postma D, et al. An official American Thoracic Society public policy statement: Novel risk factors and the global burden of chronic obstructive pulmonary disease. Am J Respir Crit Care Med. 2010;182(5):693-718.

6. Mannino DM, Buist AS. Global burden of COPD: risk factors, prevalence, and future trends. Lancet. 2007;370(9589):765-73.

7. Barnes PJ, Celli BR. Systemic manifestations and comorbidities of COPD. Eur Respir J. 2009;33(5):116585.

8. Agusti A, Calverley PM, Celli B, Coxson HO, Edwards LD, Lomas DA, et al. Characterisation of COPD heterogeneity in the ECLIPSE cohort. Respir Res. 2010;11:122.

9. Vestbo J, Agusti A, Wouters EF, Bakke P, Calverley PM, Celli B, et al. Should we view COPD Differently after ECLIPSE? A Clinical Perspective from the Study Team. Am J Respir Crit Care Med. 2014.

10. Halbert RJ, Natoli JL, Gano A, Badamgarav E, Buist AS, Mannino DM. Global burden of COPD: systematic review and meta-analysis. Eur Respir J. 2006;28(3):523-32.

11. Vanfleteren LE, Franssen FM, Wesseling G, Wouters EF. The prevalence of chronic obstructive pulmonary disease in Maastricht, the Netherlands. Respir Med. 2012;106(6):871-4.

12. Hoogendoorn M, Rutten-van Molken MP, Hoogenveen RT, van Genugten ML, Buist AS, Wouters EF, et al. A dynamic population model of disease progression in COPD. Eur Respir J. 2005;26(2):223-33.

13. van Durme YM, Verhamme KM, Stijnen T, van Rooij FJ, Van Pottelberge GR, Hofman A, et al. Prevalence, incidence, and lifetime risk for the development of COPD in the elderly: the Rotterdam study. Chest. 2009;135(2):368-77.

14. Mathers CD, Loncar D. Projections of global mortality and burden of disease from 2002 to 2030. PLoS Med. 2006;3(11):e442.

15. Wouters EF. The burden of COPD in The Netherlands: results from the Confronting COPD survey. Respir Med. 2003;97 Suppl C:S51-9.

16. Suijkerbuijk AWM, de Wit GA, Wijga AH, Heijmans MJWM, Hoogendoorn M, Rutten-van Mölken MPMH, et al. Maatschappelijke kosten van astma, COPD en respiratoire allergie. Ned Tijdschr Geneeskd. 2013;157(A6562).

17. Gosker HR, Lencer NH, Franssen FM, van der Vusse GJ, Wouters EF, Schols AM. Striking similarities in systemic factors contributing to decreased exercise capacity in patients with severe chronic heart failure or COPD. Chest. 2003;123(5):1416-24.

18. Annegarn J, Spruit MA, Savelberg HH, Willems PJ, van de Bool C, Schols AM, et al. Differences in walking pattern during 6-min walk test between patients with COPD and healthy subjects. PLoS ONE. 2012;7(5):e37329.

19. Hamilton AL, Killian KJ, Summers E, Jones NL. Symptom intensity and subjective limitation to exercise in patients with cardiorespiratory disorders. Chest. 1996;110(5):1255-63.

20. O'Donnell DE, Webb KA. The major limitation to exercise performance in COPD is dynamic hyperinflation. Journal of applied physiology (Bethesda, Md : 1985). 2008;105(2):753-5; discussion 5-7.

21. Debigare R, Maltais F. The major limitation to exercise performance in COPD is lower limb muscle dysfunction. Journal of applied physiology (Bethesda, Md : 1985). 2008;105(2):751-3; discussion 5-7. 
22. Aliverti A, Macklem PT. The major limitation to exercise performance in COPD is inadequate energy supply to the respiratory and locomotor muscles. Journal of applied physiology (Bethesda, Md : 1985). 2008;105(2):749-51; discussion 55-7.

23. Man WD, Soliman MG, Gearing J, Radford SG, Rafferty GF, Gray BJ, et al. Symptoms and quadriceps fatigability after walking and cycling in chronic obstructive pulmonary disease. Am J Respir Crit Care Med. 2003;168(5):562-7.

24. Vogiatzis I, Zakynthinos G, Andrianopoulos V. Mechanisms of physical activity limitation in chronic lung diseases. Pulmonary medicine. 2012;2012:634761.

25. O’Donnell DE, Revill SM, Webb KA. Dynamic hyperinflation and exercise intolerance in chronic obstructive pulmonary disease. Am J Respir Crit Care Med. 2001;164(5):770-7.

26. Maltais F, Decramer M, Casaburi R, Barreiro E, Burelle Y, Debigare R, et al. An official American Thoracic Society/European Respiratory Society statement: update on limb muscle dysfunction in chronic obstructive pulmonary disease. Am J Respir Crit Care Med. 2014;189(9):e15-62.

27. Spruit MA, Singh SJ, Garvey C, Zuwallack R, Nici L, Rochester C, et al. An official american thoracic society/european respiratory society statement: key concepts and advances in pulmonary rehabilitation. Am J Respir Crit Care Med. 2013;188(8):e13-64.

28. Gosselink R, Troosters T, Decramer M. Peripheral muscle weakness contributes to exercise limitation in COPD. Am J Respir Crit Care Med. 1996;153(3):976-80.

29. Killian KJ, Leblanc P, Martin DH, Summers E, Jones NL, Campbell EJ. Exercise capacity and ventilatory, circulatory, and symptom limitation in patients with chronic airflow limitation. Am Rev Respir Dis. 1992;146(4):935-40.

30. Casaburi R, Patessio A, Ioli F, Zanaboni S, Donner CF, Wasserman K. Reductions in exercise lactic acidosis and ventilation as a result of exercise training in patients with obstructive lung disease. Am Rev Respir Dis. 1991;143(1):9-18.

31. Caspersen CJ, Powell KE, Christenson GM. Physical activity, exercise, and physical fitness: definitions and distinctions for health-related research. Public Health Rep. 1985;100(2):126-31. Epub 1985/03/01.

32. Howley ET. Type of activity: resistance, aerobic and leisure versus occupational physical activity. Med Sci Sports Exerc. 2001;33(6 Suppl):S364-9; discussion S419-20.

33. Katz S. Assessing self-maintenance: activities of daily living, mobility, and instrumental activities of daily living. J Am Geriatr Soc. 1983;31(12):721-7.

34. Fricke J. 2013. Activities of Daily Living. In: JH Stone, M Blouin, editors. International Encyclopedia of Rehabilitation. International Encyclopedia of Rehabilitation. Available online: http://cirrie.buffalo.edu/encyclopedia/en/article/37/.

35. Nelson ME, Rejeski WJ, Blair SN, Duncan PW, Judge JO, King AC, et al. Physical activity and public health in older adults: recommendation from the American College of Sports Medicine and the American Heart Association. Med Sci Sports Exerc. 2007;39(8):1435-45.

36. Lee IM, Shiroma EJ, Lobelo F, Puska P, Blair SN, Katzmarzyk PT. Effect of physical inactivity on major noncommunicable diseases worldwide: an analysis of burden of disease and life expectancy. Lancet. 2012;380(9838):219-29.

37. Global Recommendations on Physical activity for Health. Geneva, World Health Organization. 2010.

38. Warburton DE, Nicol CW, Bredin SS. Health benefits of physical activity: the evidence. CMAJ. 2006;174(6):801-9.

39. Hallal PC, Andersen LB, Bull FC, Guthold R, Haskell W, Ekelund U. Global physical activity levels: surveillance progress, pitfalls, and prospects. Lancet. 2012;380(9838):247-57.

40. Chodzko-Zajko WJ, Proctor DN, Fiatarone Singh MA, Minson CT, Nigg CR, Salem GJ, et al. American College of Sports Medicine position stand. Exercise and physical activity for older adults. Med Sci Sports Exerc. 2009;41(7):1510-30.

41. Global health risks: mortality and burden of disease attributable to selected major risks Geneva, World Health Organization. 2009.

42. Caspersen CJ, Pereira MA, Curran KM. Changes in physical activity patterns in the United States, by sex and cross-sectional age. Med Sci Sports Exerc. 2000;32(9):1601-9. 
43. Watz H, Waschki B, Meyer T, Magnussen H. Physical activity in patients with COPD. Eur Respir J. 2009;33(2):262-72.

44. Pitta F, Troosters T, Spruit MA, Probst VS, Decramer M, Gosselink R. Characteristics of physical activities in daily life in chronic obstructive pulmonary disease. Am J Respir Crit Care Med. 2005;171(9):972-7.

45. Troosters T, Sciurba F, Battaglia S, Langer D, Valluri SR, Martino L, et al. Physical inactivity in patients with COPD, a controlled multi-center pilot-study. Respir Med. 2010;104(7):1005-11.

46. Hernandes NA, Teixeira Dde C, Probst VS, Brunetto AF, Ramos EM, Pitta F. Profile of the level of physical activity in the daily lives of patients with COPD in Brazil. Jornal brasileiro de pneumologia : publicacao oficial da Sociedade Brasileira de Pneumologia e Tisilogia. 2009;35(10):949-56.

47. Vorrink SN, Kort HS, Troosters T, Lammers JW. Level of daily physical activity in individuals with COPD compared with healthy controls. Respir Res. 2011;12:33.

48. Bossenbroek L, de Greef MH, Wempe JB, Krijnen WP, Ten Hacken NH. Daily physical activity in patients with chronic obstructive pulmonary disease: a systematic review. COPD. 2011;8(4):306-19.

49. Arne M, Janson C, Janson S, Boman G, Lindqvist $U$, Berne C, et al. Physical activity and quality of life in subjects with chronic disease: chronic obstructive pulmonary disease compared with rheumatoid arthritis and diabetes mellitus. Scand J Prim Health Care. 2009;27(3):141-7.

50. Roche N. Activity limitation: a major consequence of dyspnoea in COPD. European respiratory review : an official journal of the European Respiratory Society. 2009;18(112):54-7.

51. Rodriguez Gonzalez-Moro JM, de Lucas Ramos P, Izquierdo Alonso JL, Lopez-Muniz Ballesteros B, Anton Diaz E, Ribera X, et al. Impact of COPD severity on physical disability and daily living activities: EDIP-EPOC I and EDIP-EPOC II studies. Int J Clin Pract. 2009;63(5):742-50.

52. Jeng C, Chang W, Wai PM, Chou CL. Comparison of oxygen consumption in performing daily activities between patients with chronic obstructive pulmonary disease and a healthy population. Heart Lung. 2003;32(2):121-30

53. Lahaije A, van Helvoort $H$, Dekhuijzen P, Heijdra Y. Physiologic limitations during daily life activities in COPD patients. Respir Med. 2010;104(8):1152-9.

54. Polkey MI, Moxham J. Attacking the disease spiral in chronic obstructive pulmonary disease. Clin Med. 2006;6(2):190-6.

55. Annegarn J, Meijer K, Passos VL, Stute K, Wiechert J, Savelberg HH, et al. Problematic activities of daily life are weakly associated with clinical characteristics in COPD. J Am Med Dir Assoc. 2012;13(3):284-90.

56. Velloso M, Stella SG, Cendon S, Silva AC, Jardim JR. Metabolic and ventilatory parameters of four activities of daily living accomplished with arms in COPD patients. Chest. 2003;123(4):1047-53.

57. Lahaije A, van Helvoort H, Dekhuijzen P, Heijdra Y. Physiologic limitations during daily life activities in COPD patients. Respir Med.104(8):1152-9.

58. Velloso M, Jardim JR. Study of energy expenditure during activities of daily living using and not using body position recommended by energy conservation techniques in patients with COPD. Chest. 2006;130(1):126-32.

59. Velloso M, Jardim JR. Functionality of patients with chronic obstructive pulmonary disease: energy conservation techniques. Jornal brasileiro de pneumologia : publicacao oficial da Sociedade Brasileira de Pneumologia e Tisilogia. 2006;32(6):580-6.

60. Solway S, Brooks D, Lau L, Goldstein R. The short-term effect of a rollator on functional exercise capacity among individuals with severe COPD. Chest. 2002;122(1):56-65.

61. Probst VS, Troosters T, Coosemans I, Spruit MA, Pitta Fde O, Decramer M, et al. Mechanisms of improvement in exercise capacity using a rollator in patients with COPD. Chest. 2004;126(4):1102-7.

62. Gupta R, Goldstein R, Brooks D. The acute effects of a rollator in individuals with COPD. J Cardiopulm Rehabil. 2006;26(2):107-11.

63. Crisafulli E, Costi S, De Blasio F, Biscione G, Americi F, Penza S, et al. Effects of a walking aid in COPD patients receiving oxygen therapy. Chest. 2007;131(4):1068-74..

64. Garcia-Rio F, Rojo B, Casitas R, Lores V, Madero R, Romero D, et al. Prognostic value of the objective measurement of daily physical activity in patients with COPD. Chest. 2012;142(2):338-46. 
65. Garcia-Aymerich J, Lange P, Benet M, Schnohr P, Anto JM. Regular physical activity reduces hospital admission and mortality in chronic obstructive pulmonary disease: a population based cohort study. Thorax. 2006;61(9):772-8.

66. Waschki B, Kirsten A, Holz O, Muller KC, Meyer T, Watz H, et al. Physical activity is the strongest predictor of all-cause mortality in patients with COPD: a prospective cohort study. Chest. 2011;140(2):331-42.

67. Bahadori K, FitzGerald JM. Risk factors of hospitalization and readmission of patients with COPD exacerbation--systematic review. Int J Chron Obstruct Pulmon Dis. 2007;2(3):241-51.

68. Esteban C, Arostegui I, Aburto M, Moraza J, Quintana JM, Aizpiri S, et al. Influence of changes in physical activity on frequency of hospitalization in chronic obstructive pulmonary disease. Respirology. 2014.

69. Pitta F, Troosters T, Probst VS, Spruit MA, Decramer M, Gosselink R. Physical activity and hospitalization for exacerbation of COPD. Chest. 2006;129(3):536-44.

70. Ehsan M, Khan R, Wakefield D, Qureshi A, Murray L, Zuwallack R, et al. A Longitudinal Study Evaluating the Effect of Exacerbations on Physical Activity in Patients with Chronic Obstructive Pulmonary Disease. Ann Am Thorac Soc. 2013.

71. Garcia-Aymerich J, Lange P, Benet M, Schnohr P, Anto JM. Regular physical activity modifies smokingrelated lung function decline and reduces risk of chronic obstructive pulmonary disease: a populationbased cohort study. Am J Respir Crit Care Med. 2007;175(5):458-63.

72. Waschki B, Spruit MA, Watz H, Albert PS, Shrikrishna D, Groenen M, et al. Physical activity monitoring in COPD: compliance and associations with clinical characteristics in a multicenter study. Respir Med. 2012;106(4):522-30.

73. Esteban C, Quintana JM, Aburto M, Moraza J, Egurrola M, Perez-Izquierdo J, et al. Impact of changes in physical activity on health-related quality of life among patients with COPD. Eur Respir J. 2010;36(2):292-300.

74. Pitta F, Troosters T, Probst VS, Langer D, Decramer M, Gosselink R. Are patients with COPD more active after pulmonary rehabilitation? Chest. 2008;134(2):273-80.

75. Steele BG, Belza B, Hunziker J, Holt L, Legro M, Coppersmith J, et al. Monitoring daily activity during pulmonary rehabilitation using a triaxial accelerometer. J Cardiopulm Rehabil. 2003;23(2):139-42.

76. Sewell L, Singh SJ, Williams JE, Collier R, Morgan MD. Can individualized rehabilitation improve functional independence in elderly patients with COPD? Chest. 2005;128(3):1194-200..

77. Coronado M, Janssens JP, de Muralt B, Terrier P, Schutz Y, Fitting JW. Walking activity measured by accelerometry during respiratory rehabilitation. J Cardiopulm Rehabil. 2003;23(5):357-64.

78. Mercken EM, Hageman GJ, Schols AM, Akkermans MA, Bast A, Wouters EF. Rehabilitation decreases exercise-induced oxidative stress in chronic obstructive pulmonary disease. Am J Respir Crit Care Med. 2005;172(8):994-1001..

79. Egan C, Deering BM, Blake C, Fullen BM, McCormack NM, Spruit MA, et al. Short term and long term effects of pulmonary rehabilitation on physical activity in COPD. Respir Med. 2012;106(12):1671-9.

80. Dallas MI, McCusker C, Haggerty MC, Rochester CL, Zuwallack R. Using pedometers to monitor walking activity in outcome assessment for pulmonary rehabilitation. Chron Respir Dis. 2009;6(4):217-24.

81. Mador MJ, Patel AN, Nadler J. Effects of pulmonary rehabilitation on activity levels in patients with chronic obstructive pulmonary disease. J Cardiopulm Rehabil Prev.31(1):52-9.

82. Bauman AE, Reis RS, Sallis JF, Wells JC, Loos RJ, Martin BW. Correlates of physical activity: why are some people physically active and others not? Lancet. 2012;380(9838):258-71..

83. Polkey MI, Rabe KF. Chicken or egg: physical activity in COPD revisited. Eur Respir J. 2009;33(2):227-9.

84. Orrow G, Kinmonth AL, Sanderson S, Sutton S. Effectiveness of physical activity promotion based in primary care: systematic review and meta-analysis of randomised controlled trials. BMJ. 2012;344:e1389.

85. Bravata DM, Smith-Spangler C, Sundaram V, Gienger AL, Lin N, Lewis R, et al. Using pedometers to increase physical activity and improve health: a systematic review. JAMA. 2007;298(19):2296-304. 

Chapter 2

Task-related oxygen uptake during domestic activities of daily life in patients with COPD and healthy elderly subjects

Anouk W. Vaes, Emiel F.M. Wouters, Frits M.E. Franssen, Nicole H.M.K. Uszko-Lencer, Koen H.P. Stakenborg, Marlies Westra, Kenneth Meijer, Annemie M.W.J. Schols, Paul P. Janssen, Martijn A. Spruit

Chest. 2011;140(4):970-9. 


\section{ABSTRACT}

Background Patients with COPD generally have a poor peak aerobic capacity and may therefore experience more inconvenience during domestic activities of daily life (ADLs). Yet, task-related oxygen uptake and symptom perception during ADLs have been studied rarely in COPD. It therefore remains unknown whether and to what extent differences may exist in task-related oxygen uptake and symptom perception during ADLs in COPD patients after stratification for gender, GOLD stage, MRC dyspnea grade or score on BODE index.

Methods Ninety-seven COPD patients and 20 healthy subjects performed 5 self-paced domestic ADLs with 4-min rest intervals: putting on socks, shoes and vest; folding 8 towels; putting away groceries; washing up 4 dishes, cups and saucers; and sweeping the floor for $4 \mathrm{~min}$. Task-related oxygen uptake was assessed using a mobile oxycon, while Borg scores were used to assess task-related dyspnea and fatigue.

Results COPD patients used a significantly higher proportion of their peak aerobic capacity and ventilation to perform ADLs compared to healthy elderly subjects, accompanied by higher task-related Borg dyspnea scores. Patients with GOLD stage IV, MRC dyspnea grade 5 or BODE score of $\geq 6$ points had the highest task-related oxygen uptake and dyspnea perception during the performance of domestic ADLs. Results showed no gender-related differences.

Conclusion COPD patients experience a relatively high metabolic load and symptom perception during the performance of ADLs that is not the same as seen in their healthy peers, particularly in patients with GOLD stage IV, MRC dyspnea grade 5 or BODE score of $\geq 6$ points. 


\section{BACKGROUND}

Breathlessness is the most widespread complaint of patients with chronic obstructive pulmonary disease (COPD)(1) which worsens over time(2). It seriously compromises patients' capacity to do activities of daily life (ADL)(3-7), exercise performance $(8,9)$, health status(10) and survival(11-13). Indeed, dyspnea is most probably the starting point of the vicious circle of physical inactivity in COPD and its adverse extra-pulmonary consequences $(14,15)$.

In patients with COPD the degree and impact of dyspnea during ADLs have been assessed frequently by using questionnaires and are worse compared to healthy elderly(5, $10,16,17)$. This may, at least in part, be due to the impaired pulmonary function in combination with explicit physical deconditioning $(18,19)$. Indeed, oxygen uptake increases during the performance of simple ADLs and, in turn, laying claim to the aerobic capacity of individuals(20). COPD patients have a significantly lower peak aerobic capacity compared to age-matched healthy subjects(21), and may therefore experience more inconvenience during the performance of domestic ADLs, as was seen previously in chronic heart failure(22).

Currently, task-related oxygen uptake and symptom perception during simple selfpaced domestic ADLs have been studied rarely in COPD(23-25). These studies showed that COPD patients perform domestic ADLs at a higher proportion of their peak aerobic capacity compared to healthy subjects accompanied by higher dyspnea(23-25). Nevertheless, it still remains unknown whether and to what extent differences may exist in task-related oxygen uptake and task-related symptoms in COPD patients after stratification for gender, GOLD stage, MRC dyspnea grade or score on BODE index (12). For example, female COPD patients generally have a higher dyspnea perception than male patients(26). Moreover, GOLD stage IV patients, patients with MRC dyspnea grade 5 and patients with higher BODE scores generally have worst peak aerobic capacity(10, 27).

The present authors aimed to corroborate the differences in task-related oxygen uptake, ventilation and Borg symptom scores between COPD patients and healthy elderly subjects. Moreover, they tested the hypotheses that female patients, GOLD IV patients, patients with MRC dyspnea grade 5 and patients with higher BODE scores use a higher proportion of their peak aerobic capacity and peak ventilation to perform simple domestic ADLs accompanied by a higher dyspnea sensation compared to male patients, GOLD II/III patients, patients with MRC dyspnea grade $\leq 4$ or patients with lower BODE scores, respectively. 


\section{METHODS}

Details on the methods are provided in the online supplement.

One-hundred COPD patients and 20 healthy peers volunteered to participate in the present study, which was approved by the institutional review board of the Maastricht University Medical Centre (MEC08-3-032). Informed consent was obtained from potential participants and study eligibility was determined.

Patients were recruited at $\mathrm{CIRO}+(28)$. Patients were clinically stable (no exacerbation in past 4 weeks) and were on various (non-) pulmonary drug therapies (Table E1 of online supplement). Exclusion criteria were the use of long-term oxygen therapy, neuromuscular co-morbidities, a cardiac pacemaker and/or an implantable cardioverter defibrillator. Healthy volunteers were recruited by posters and amongst healthy subjects who participated in previous trials. None of the healthy subjects used physician-prescribed drugs. All tests were in accordance with the World Medical Association declaration of Helsin$\mathrm{ki}(29)$. The healthy elderly subjects were part of a previous manuscript(22).

\section{Clinical phenotyping}

General demographics, co-morbidities, pulmonary function, dyspnea, body composition and peak aerobic capacity were assessed as described previously(10).

\section{Domestic ADLs}

The metabolic load of 5 domestic ADLs were assessed using a mobile oxycon, as described before(22). In brief, online breath-by-breath calculations of oxygen uptake and ventilation were recorded by the portable metabolic system during the performance of 5 ADLs in the kitchen of the Dept. of Occupational Therapy at CIRO+: putting on 2 socks (sitting in chair), 2 shoes (sitting in chair) and a vest (standing, ADL1; Figure 1a); folding 8 towels (standing, ADL2; Figure 1b); putting away groceries (e.g., 6 cans of beans of 400 grams each) in cupboard (standing and walking, ADL3; Figure 1c); washing up 4 dishes, 4 cups and 4 saucers (standing, ADL4; Figure 1d); and sweeping the floor for 4 minutes (standing and walking, ADL5; Figure 1e). Indeed, these ADLs have all been identified as problematic valued life activities in patients with $\operatorname{COPD}(30)$.

Heart rate was monitored using a Polar belt. Moreover, all participants were asked to score the degree of dyspnea and fatigue at the beginning and end of all ADLs using a modified Borg symptom score ranging from 0 (no symptoms) to 10 points (worst symptoms). Participants were asked to perform ADLs at their own pace, with 4 minutes intervals of rest between each activity. For unknown reasons a download of the data failed in 3 patients. Therefore, the COPD group finally consisted of 97 patients. 
a

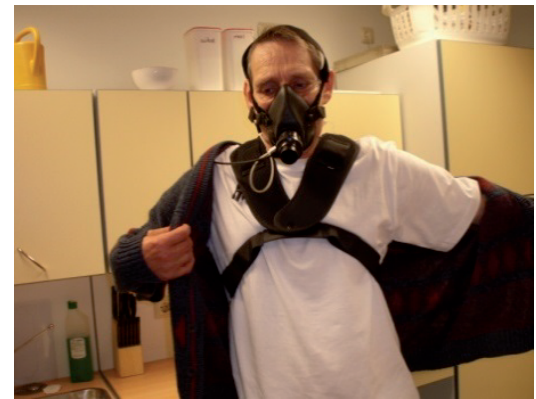

c

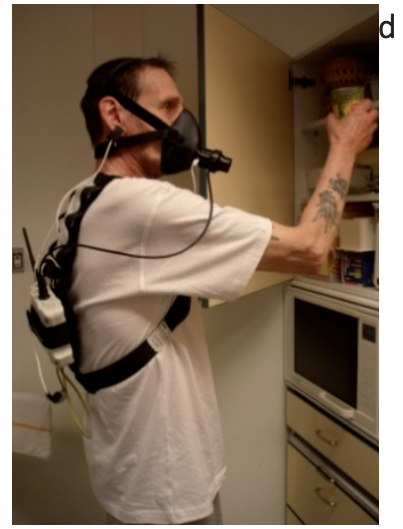

b
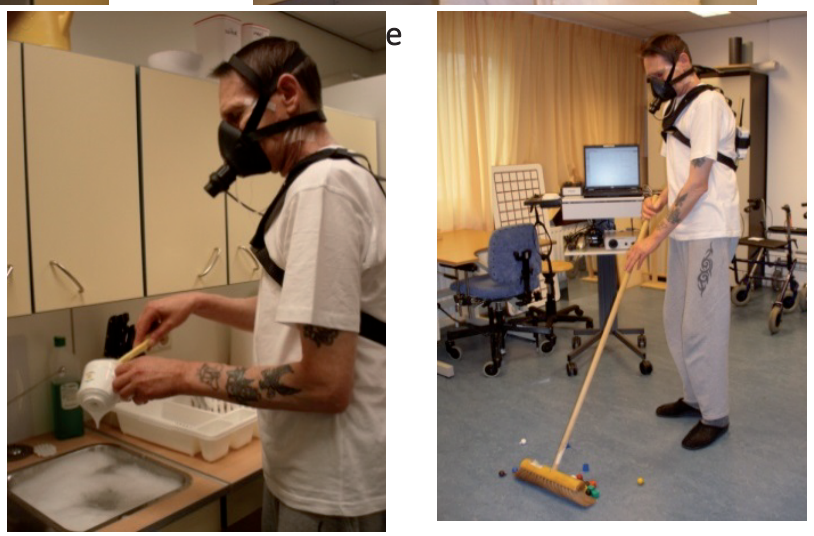

Figure 1. Male COPD patient wearing a mobile oxycon while performing 5 self-paced domestic activities of daily life ; a) putting on 2 socks, 2 shoes and a vest ; b) folding 8 towels; c) putting away groceries in the cupboard; d) washing up 4 dishes, 4 cups and 4 saucers; e) sweeping the floor for 4 minutes

A priori, relative task-related oxygen uptake during ADLs (i.e., task-related oxygen uptake as proportion of the peak aerobic capacity, \%peakVO $\mathrm{O}_{2}$ ) was chosen as primary outcome. Absolute task-related oxygen uptake $(\mathrm{mL} / \mathrm{min})$; task-related heart rate and ventilation (expressed as \% peakHR and \%peakVE, respectively); time to accomplish first 4 ADLs (ADL5 was always set at 4 minutes); task-related oxygen uptake ( $\mathrm{mL} / \mathrm{min})$ per kilogram fat-free mass (FFM); and Borg symptom scores for dyspnea and fatigue at the end of each ADL were chosen as secondary outcomes.

\section{Statistics}

Data are presented as mean and standard deviation, unless noted otherwise. Student's t-test was used to determine differences between patients with COPD and healthy subjects, between male and female COPD patients and between patients with and without co-morbidities. Chi squared (with Cramer's $V$ measure for strength of association) was used to assess the differences in gender distribution between groups. Differences between task-related requirements were compared using analysis of variance with Bon- 
ferroni post hoc comparisons. The level of significance was set at $\leq 0.05$. Data were analyzed with SPSS, version 17.0.

\section{RESULTS}

\section{Characteristics}

Patients had moderate to very severe COPD. The proportion men and the average age were comparable between patients and healthy subjects. Patients had a significantly lower BMI and FFM index compared to healthy subjects. Moreover, patients had higher scores on the (age-adjusted) Charlson co-morbidity index (Table 1). See also online supplement for details.

Patients obtained a significantly lower peak aerobic capacity $(\mathrm{mL} / \mathrm{min})$, peak heart rate (beats/minute) and peak ventilation ( $\mathrm{L}$ ) than healthy peers. Contrary, patients used a higher proportion of their maximum voluntary ventilation. Peak Borg dyspnea scores of patients were significantly higher compared to healthy elderly subjects, while peak Borg fatigue scores were comparable between groups (Table 1).

\section{Domestic ADLS}

\section{COPD versus healthy}

All subjects were able to complete ADL1 to ADL4 without stops during the performance of each ADL. Five patients were not able to complete ADL5 due to exertional dyspnea. COPD patients needed significantly more time to complete ADLs 1,2 , and 4 compared to healthy subjects $(85 \pm 26$ vs. $63 \pm 13 s ; 139 \pm 33$ vs. $115 \pm 21 s$; and $99 \pm 22$ vs. $72 \pm 20$ s; all $\mathrm{p}<0.001)$. Contrary, time to complete ADL3 was significantly shorter in COPD patients: $50 \pm 10$ vs. $63 \pm 16 s, p<0.01$.

Basal values for all variables before performance of the ADLs were similar. Moreover, task-related oxygen uptake $(\mathrm{ml} / \mathrm{min})$ at the end of the 5 ADLs was similar between COPD patients and healthy subjects (Figure 2a). Consequently, patients performed the domestic ADLs at a significantly higher proportion of their peak aerobic capacity compared to the healthy subjects: mean difference (95\%Cl) ADL1: 37.3 (28.4-46.1)\%; ADL2: 30.0 (21.7-38.3)\%; ADL3: 26.3 (18.4-34.3)\%; ADL4: 29.1 (21.7-36.4)\% and ADL5: 41.7 (31.9-51.5)\%; all $p<0.001$ (Figure 2b). Moreover, COPD patients had a significantly higher task-related oxygen uptake per kilogram FFM compared to the healthy subjects (Figure $2 \mathrm{c}$ ). 
Table 1. Characteristics

\begin{tabular}{|c|c|c|}
\hline & $\begin{array}{l}\text { Healthy subjects } \\
(n=20)\end{array}$ & $\begin{array}{l}\text { COPD patients } \\
(n=97)\end{array}$ \\
\hline Men (\%) & 60 & 60 \\
\hline Age (years) & $62.1(5.6)$ & $64.1(8.8)$ \\
\hline FEV1 (L) & $3.34(0.61)$ & $1.27(0.45)^{\dagger}$ \\
\hline FEV1 (\% predicted) & $119.4(24.2)$ & $47.3(14.8)^{\dagger}$ \\
\hline FEV1/FVC (\%) & $76.8(4.6)$ & $40.2(10.1)^{\dagger}$ \\
\hline TLCO (\% predicted) & - & $57.4(18.4)$ \\
\hline $\mathrm{PaO}_{2}(\mathrm{kPa}) *$ & - & $9.52(1.25)$ \\
\hline $\mathrm{PaCO}_{2}(\mathrm{kPa})$ & - & $5.14(0.59)$ \\
\hline $\mathrm{SaO}_{2}(\%)$ & - & $94.6(2.1)$ \\
\hline GOLD stage I/II/III/IV (n) & - & $0 / 41 / 42 / 17$ \\
\hline MRC grade $1 / 2 / 3 / 4 / 5(n)$ & - & $0 / 26 / 28 / 21 / 25$ \\
\hline BODE score (points) & - & $3.54(1.78)$ \\
\hline Body weight $(\mathrm{kg})^{* *}$ & $79.2(12.3)$ & $70.2(16.5)^{\dagger}$ \\
\hline Body mass index $\left(\mathrm{kg} / \mathrm{m}^{2}\right)$ & $27.0(3.0)$ & $24.7(5.1) \dagger$ \\
\hline $\mathrm{BMI}<21 \mathrm{~kg} / \mathrm{m}^{2}(\%)$ & 0.0 & 25.8 \\
\hline BMI $21-25 \mathrm{~kg} / \mathrm{m}^{2}(\%)$ & 25.0 & 28.9 \\
\hline BMI $25-30 \mathrm{~kg} / \mathrm{m}^{2}(\%)$ & 65.0 & 29.9 \\
\hline $\mathrm{BMI}>30 \mathrm{~kg} / \mathrm{m}^{2}(\%)$ & 10.0 & 15.5 \\
\hline FFM (kg) & $55.6(9.9)$ & $45.9(9.3)^{\dagger}$ \\
\hline FFMI $\left(\mathrm{kg} / \mathrm{m}^{2}\right)$ & $18.9(2.3)$ & $16.1(2.3)^{\dagger}$ \\
\hline Women <15 kg/m² (\%) & 25.0 & 53.8 \\
\hline Men $<16$ kg/m² $(\%)$ & 0.0 & 39.7 \\
\hline Charlson CMI (points) & 0.0 & $1.88(1.2)^{\dagger}$ \\
\hline Charlson CMI 2 (points) & $1.7(0.7)$ & $3.95(1.8)+$ \\
\hline$\geq 1$ co-morbidities (\%) & 0.0 & 50.5 \\
\hline Peak $\mathrm{VO}_{2}(\mathrm{~mL} / \mathrm{min})$ & $2155(770)$ & $1126(353)+$ \\
\hline Peak VO $2(\mathrm{~mL} / \mathrm{min} / \mathrm{kg} \mathrm{BW})$ & $27.5(10.2)$ & $16.4(4.4)^{\dagger}$ \\
\hline Peak $\mathrm{VO}_{2}(\mathrm{~mL} / \mathrm{min} / \mathrm{kg} F \mathrm{FM})$ & $38.8(12.2)$ & $24.6(5.8) \dagger$ \\
\hline Peak VE (L) & $87.3(28.2)$ & $44.6(14.6)^{\dagger}$ \\
\hline Peak VE (\% MVV) & $65.4(17.1)$ & $90.7(21.9)^{\dagger}$ \\
\hline Peak HR (bpm) & 154 (18.9) & $131(22)^{\dagger}$ \\
\hline Peak HR (\% max HR) & $97.5(10.7)$ & $83.7(12.9)^{\dagger}$ \\
\hline Borg dyspnoea (points) & $5.5(2.2)$ & $7.2(1.9)^{\dagger}$ \\
\hline Borg fatigue (points) & $5.7(2.2)$ & $5.7(2.5)$ \\
\hline
\end{tabular}

Results are presented as mean (standard deviation). $\mathrm{FEV}_{1}=$ forced expiratory volume in the first second; $\mathrm{L}=$ liter; $\mathrm{FVC}=$ forced vital capacity; $\mathrm{kg}=\mathrm{kilogram}$; $\mathrm{kg} / \mathrm{m}^{2}=\mathrm{kilogram}$ per squared meters; Charlson $\mathrm{CMI}=\mathrm{Charlson}$ co-morbidity index (45); Charlson CMI 2=Charlson age comorbidity index (46); $\mathrm{VO}_{2}=$ oxygen uptake; $\mathrm{mL}=$ milliliter; $\mathrm{min}=$ minute; $\mathrm{BW}=$ body weight; $\mathrm{FFM=fat} \mathrm{free} \mathrm{mass;} \mathrm{VE}=$ =ventilation; $\mathrm{MVV}=$ maximum voluntary ventilation; $\mathrm{HR}=$ heart rate; $\mathrm{bpm}=$ beats per minute.

$+p \leq 0.05$ versus healthy control subjects

* $1 \mathrm{kPa}=7.5 \mathrm{~mm} \mathrm{Hg}$; ** 1 kilogram $=2.2046$ pounds 
a

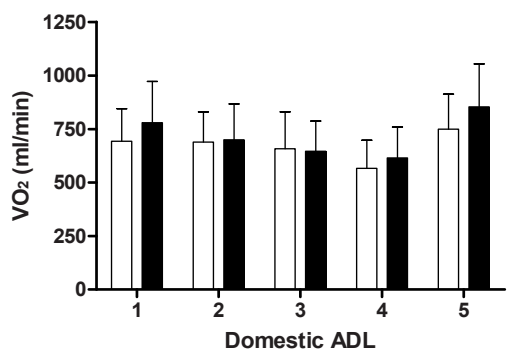

C

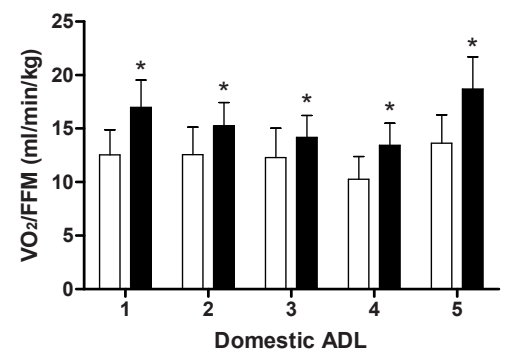

e

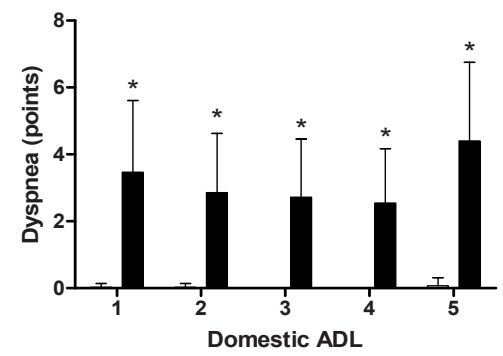

b

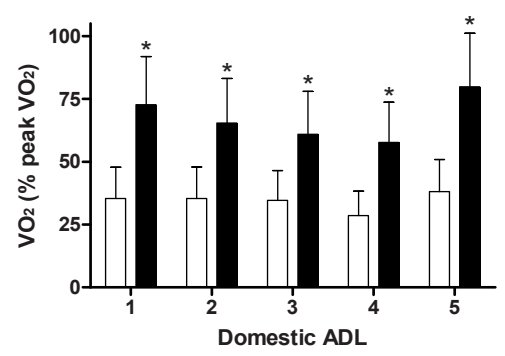

d

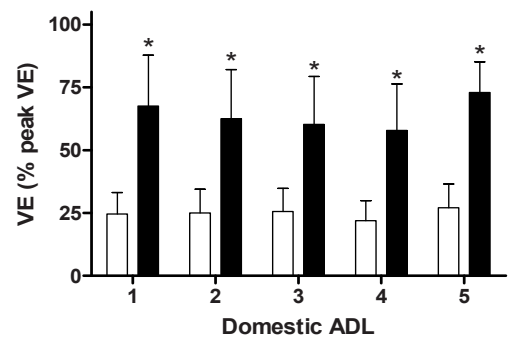

f

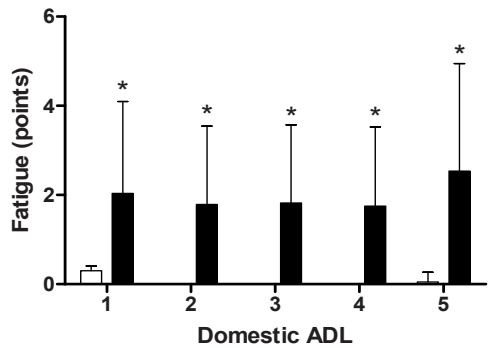

Figure 2. Results of patients with COPD (black) and healthy elderly subjects (white) after performance of 5 simple domestic activities of daily life.

a) Absolute task-related oxygen uptake; b) Task-related oxygen uptake (\% peak $\mathrm{VO}_{2}$ ); c) Task-related oxygen uptake per kg FFM; d) Task-related ventilation (\% peak VE); e) Borg dyspnea scores (points); f) Borg fatigue scores (points); * $p<0.001$ COPD versus healthy subjects

Patients also performed the ADLs at a higher proportion of their peak ventilation (mean difference $(95 \% \mathrm{Cl})$ with healthy subjects for ADL1: 42.9 (33.5-52.3)\%; ADL2: 37.4 (28.646.3)\%; ADL3: 34.5 (25.6-43.5)\%; ADL4: 36.0 (27.7-44.4)\%; and ADL5: 45.8 (36.2-55.4)\%; all $\mathrm{p}<0.001$; Figure $2 \mathrm{~d}$ ) and their peak heart rate (mean difference $(95 \% \mathrm{Cl}) \mathrm{ADL} 1: 18.6$ (11.8-25.4)\%; ADL2: 17.4 (11.1-23.6)\%; ADL3: 15.0 (7.7-22.2)\%; ADL 4: 17.3 (11.223.5)\%; and ADL5: 21.5 (15.1-27.9)\%, Figure E1 of online supplement). Patients reported higher Borg symptom scores for dyspnea and fatigue at the end of each ADL compared to the healthy peers (Figure 2e and 2f)

During ADL5 patients with COPD used a higher proportion of their peak aerobic capacity and peak ventilation compared to ADLs 1 to 4 . These differences were statistically sig- 
nificant $(p<0.05)$, also after stratification for gender, GOLD stage, MRC dyspnea grade or score on the BODE index. Differences between other ADLs were not significant.

\section{Sex-related differences in COPD group}

Task-related oxygen uptake, ventilation and heart rate (all expressed as a proportion of their peak values) and task-related symptoms were comparable after stratification by sex. See online supplement for details. Consequently, female and male patients were combined for further analyses.

\section{GOLD-related differences}

GOLD IV patients used a significantly higher proportion of the peak aerobic capacity compared to GOLD II/III patients (Figure 3a). Comparable findings were observed for task-related ventilation (Figure $3 \mathrm{~b}$ ) and task-related heart rate (Figure E3a of online supplement). Moreover, GOLD II patients still used a significantly higher proportion of the peak aerobic capacity, peak ventilation and peak heart rate compared to healthy controls (Figures 3a, 3b and E3a of the online supplement). Results show no significant differences in task-related oxygen uptake per kilogram FFM between GOLD stages; however GOLD II patients still have a significantly higher oxygen uptake per kilogram FFM compared to healthy subjects (Figure E3b of the online supplement). See online supplement for details.

GOLD IV patients had significantly higher Borg dyspnea scores after performance of all 5 ADLs compared to GOLD I//II patients. GOLD II patients still had a significantly higher perception of dyspnea compared to the control group (Figure 3c). There were no differences in Borg fatigue scores between GOLD stages (Figure E3c of the online supplement).

\section{MRC-related difference}

Patients with MRC dyspnea grade 5 used a higher proportion of their peak aerobic capacity compared to patients with lower MRC dyspnea grades (Figure 4a). Comparable findings were observed for task-related ventilation (Figure $4 \mathrm{~b}$ ) and heart rate (Figure E4a of the online supplement). Moreover, patients with MRC dyspnea grade 2 still used a significantly higher proportion of the peak aerobic capacity, peak ventilation and peak heart rate compared to healthy controls (Figures $4 a, 4 b$ and E4a of the online supplement). Results show no significant differences in task-related oxygen uptake per kilogram FFM between MRC dyspnea grades; however, MRC dyspnea grade II patients still have a significant higher oxygen uptake per kilogram FFM compared to healthy subjects (Figure E4b of the online supplement). See online supplement for details.

As expected, patients with the highest MRC dyspnea grades had the highest taskrelated Borg-scores for dyspnea and fatigue after completion of the each of the 5 ADLs. Again, patients with MRC dyspnea grade 2 still had a significantly higher symptom perception at the end of each ADL compared to the healthy control group (Figure $4 \mathrm{c}$ and Figure $\mathrm{E} 4 \mathrm{C}$ of the online supplement) 
a

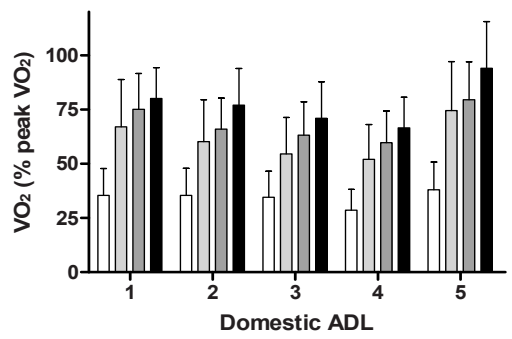

C

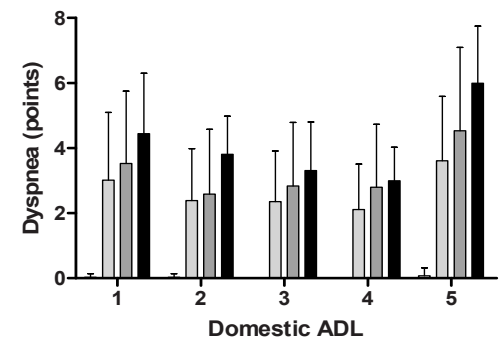

b

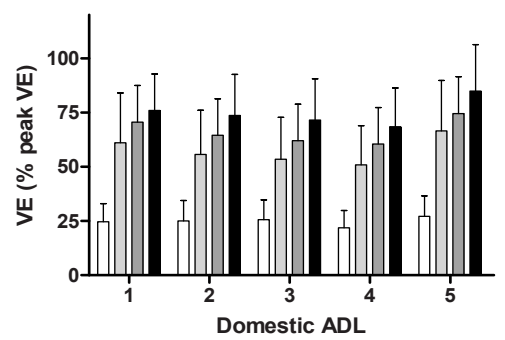

Figure 3. Results after performance of simple domestic activities of daily life in patients with COPD after stratification for GOLD stages.

a) Task-related oxygen uptake (\% peak $\mathrm{VO}_{2}$ ); all GOLD stages had a significantly higher task-related oxygen uptake compared to healthy controls $(p<0.05)$. GOLD stage IV was significantly higher compared to GOLD stage II and III for all ADLs (p<0.05). GOLD stage III was significantly higher compared to GOLD stage II for ADLs 1,3 and 4 ( $p<0.05$ ).; b) Task-related ventilation (\% peak VE); all GOLD stages had a significantly higher taskrelated ventilation compared to healthy controls $(p<0.05)$. GOLD stage IV was significantly higher compared to GOLD stage II for all ADLs $(p<0.05)$ and compared to GOLD stage III for ADL $5(p<0.05)$. GOLD stage III was significantly higher compared to GOLD stage II for ADL 1 and 3 ( $p<0.05)$. c) Dyspnea perception (points); all GOLD stages had a significantly higher Borg dyspnea score compared to healthy controls $(p<0.05)$. GOLD stage IV was significantly higher compared to GOLD stage II for all ADLs $(p<0.05)$ and compared to GOLD stage III for ADLs 1,2 and 5 ( $p<0.05)$. GOLD stage III was significantly higher compared to GOLD stage II for ADL $5(p<0.05)$. 
a

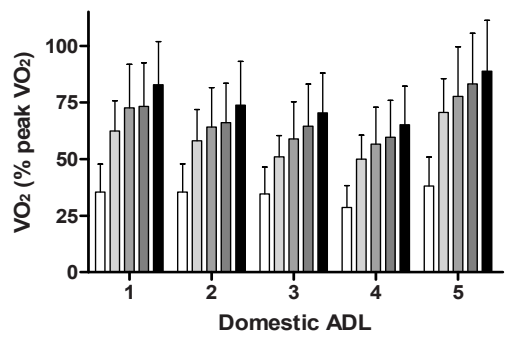

C

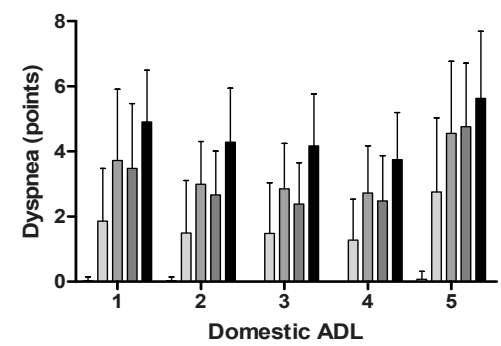

b

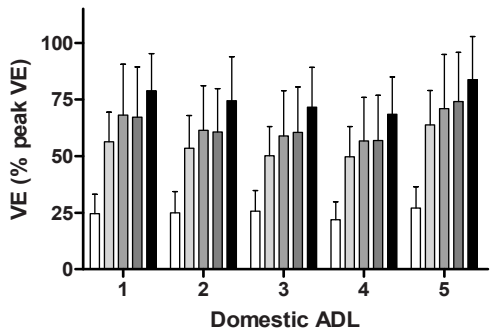

Figure 4. Results after performance of simple domestic activities of daily life in patients with COPD after stratification for MRC dyspnea grades.

a) Task-related oxygen uptake (\% peak $\mathrm{VO}_{2}$ ); all MRC dyspnea grades had a significantly higher task-related oxygen uptake compared to the healthy controls $(p<0.05)$. MRC grade 5 was significantly higher compared to MRC grades 2, 3 and 4 ( $p<0.05)$. MRC grade 4 was significantly higher compared to MRC grade 2 for all ADLs $(p<0.05)$. MRC grade 3 was significantly higher compared to MRC grade 2 for ADL $1(p<0.05)$. b) Task-related ventilation (\% peak VE); all MRC dyspnea grades had a significantly higher task-related ventilation compared to the healthy controls $(p<0.05)$. MRC grade 5 was significantly higher compared to MRC grades 2,3 and 4 for all ADLs ( $p<0.05)$. MRC grade 4 was significantly higher compared to MRC grade 2 for ADLs 1 and $3(p<0.05)$. MRC grade 3 was significantly higher compared to MRC grade 2 for ADL 1 ( $p<0.05$ ); $c)$ Dyspnea perception (points); all MRC dyspnea grades had significantly higher Borg dyspnea scores compared to the healthy controls $(p<0.05)$. MRC grade 5 was significantly higher compared with MRC grades 2, 3 and 4 for all ADLs $(p<0.05)$. MRC grades 3 and 4 were significantly higher compared to MRC grade 2 for all $A D L s(p<0.05)$ 
a

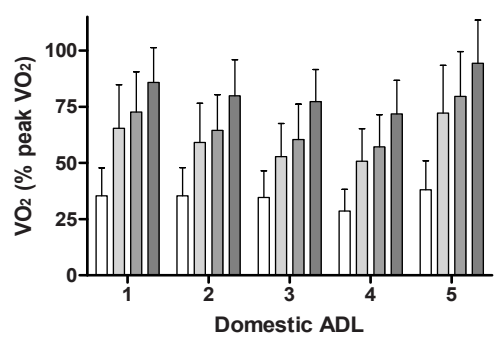

C

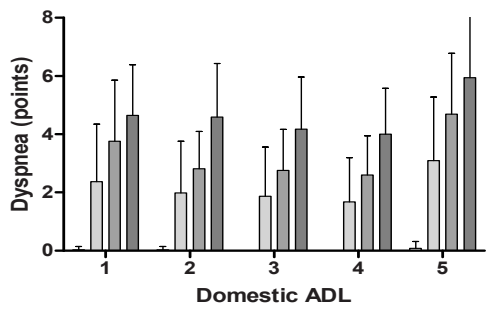

b

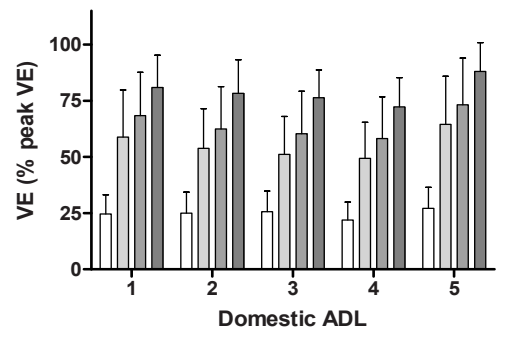

Figure 5. Results after performance of simple domestic activities of daily life in patients with COPD after stratification for BODE Index.

a) Task-related oxygen uptake (\% peak $\mathrm{VO}_{2}$ ); all BODE scores had a significantly higher task-related oxygen uptake compared to the healthy controls $(p<0.05)$. BODE scores of $\geq 6$ points were significantly higher compared to BODE scores of 3,4 and 5 points and $\leq 2$ points for all ADLs ( $p<0.05$ ). BODE scores of 3,4 and 5 points were significantly higher compared to BODE scores of $\leq 2$ points for ADL $2(p<0.05)$; b) Task-related ventilation (\% peak VE); all BODE scores had a significantly higher task-related ventilation compared to the healthy controls $(p<0.05)$. BODE scores of $\geq 6$ points were significantly higher compared to BODE scores of 3,4 and 5 points and $\leq 2$ for all ADLs $(p<0.05)$. BODE scores of 3,4 and 5 points were significantly higher compared to BODE scores of $\leq 2$ points for ADLs 1, 2, 3 and 4 ( $p<0.05$ ); c) Dyspnea perception (points); all BODE scores had significantly higher Borg dyspnea scores compared to the healthy controls $(p<0.05)$. BODE scores of $\geq 6$ points were significantly higher compared to BODE scores of 3,4 and 5 points and $\leq 2$ points for all ADLs $(p<0.05)$. BODE scores of 3,4 and 5 points were significantly higher compared to BODE scores of $\leq 2$ for $A D L s(p<0.05)$.

\section{BODE-related difference}

Patients with a BODE-index of 6 points or higher used a higher proportion of their peak aerobic capacity to perform the $5 \mathrm{ADLs}$ compared to patients with a lower BODE-index (Figure 5a). Comparable findings were observed for task-related ventilation (Figure 5b) and heart rate (Figure E5a of the online supplement). Moreover, patients with a BODE index of 2 points and lower still used a significantly higher proportion of the peak aerobic capacity, peak ventilation and peak heart rate compared to healthy elderly (Figures $5 a, 5 b$ and $E 5 a$ of the online supplement). Results show no significant differences in task-related oxygen uptake per kilogram FFM between BODE scores; however, patients with the lowest BODE scores still have a significant higher oxygen uptake per kilogram 
FFM compared to healthy subjects (Figure E5b of the online supplement). See online supplement for details.

\section{DISCUSSION}

The present study shows that COPD patients use a higher proportion of their peak aerobic capacity and peak ventilation to perform domestic ADLs as compared to healthy elderly subjects, particularly in patients with GOLD stage IV, MRC dyspnea grade 5 or BODE score of $\geq 6$ points, accompanied by higher task-related Borg dyspnea scores. Moreover, COPD patients have a significantly higher task-related oxygen uptake per kilogram FFM compared to the healthy peers, even in patients with GOLD stage II, MRC dyspnea grade 2 or BODE score $\leq 2$ points. No gender-related differences were found in task-related oxygen uptake or task-related symptom sensation in patients with COPD.

Previously, task-related oxygen uptake and ventilation were reported to be increased in COPD patients during performance of ADLs. For example, Lahaije and colleagues reported that COPD patients performed domestic ADLs at a mean task-related oxygen consumption of $86 \%$ of their peak aerobic capacity compared to $41 \%$ in healthy subjects(25). This is very consistent with our results (Figure $2 \mathrm{~b}$ ). Indeed, sweeping the floor resulted in a mean task-related oxygen uptake of $84 \%$ of peak aerobic capacity, which was even $94 \%$ in GOLD IV patients. Then again, Velloso and colleagues reported a taskrelated oxygen uptake of $52 \%$ of the peak aerobic capacity during sweeping the floor for 5 minutes(24). However, these authors estimated patients' peak aerobic capacity, which may have resulted in an overestimation of the peak aerobic capacity and, in turn, in an underestimation of the proportion of the peak aerobic capacity used to sweep the floor for 5 minutes(24). Jeng and colleagues also reported a relatively higher taskrelated oxygen uptake during walking (75\%) in COPD patients compared to healthy elderly(23). Then again, Jeng and colleagues only included male COPD patients of 65 years of age or older, which limits the external validity of their findings.

Lahaije and colleagues(25) were the first to study task-related oxygen uptake in female COPD patients. Regrettably, their sample size (i.e., 9 women and 12 men with COPD) was too limited to make a comparison between male and female patients. However, gender-differences in the performance of ADLs and in the perception of dyspnea may exist in COPD. Indeed, multiple studies have found that women with COPD report higher (worse) scores on the MRC dyspnea scale than men with $\operatorname{COPD}(26,31,32)$. Nevertheless, the MRC dyspnea scale is addressing only a small number of specific domestic ADLs (i.e., walking, and dressing or undressing). Moreover, Skumlien et al. reported no differences in dyspnea between women and men with COPD for 'home-management' and 'self-care' on the Pulmonary Functional Status and Dyspnea Questionnaire(33). The 
current study is the first to show that task-related dyspnea in real life is comparable between women and men with COPD. The lack of difference in task-related dyspnea may be due to the fact that women with COPD have reduced their 'house management' activities compared to the time before developing COPD to reduce task-related dyspnea (33).

As expected, patients with a severe degree of airflow obstruction, patients with severe dyspnea during daily life and patients with worse prognosis used the highest proportion of their peak oxygen uptake to perform simple domestic ADLs. This is line with our hypothesis. This may be due to the fact that these patients have the worst peak aerobic capacity $(10,27)$. Moreover, the present study clearly shows that GOLD II patients, MRC dyspnea grade II patients and patients with the lowest scores on the BODE index still use a significantly higher proportion of their peak aerobic capacity and peak ventilation compared to healthy elderly subjects (Figures 3 to 5). This may, at least partially, explain the fact that patients with less advanced disease may still experience symptoms in daily life.

Patients generally used a high proportion of their peak ventilation (Figure $2 \mathrm{~d}$ ), which may partially explain the daily experience of dyspnea during simple domestic ADLs in COPD. Indeed, mean task-related peak ventilation ranged between 50 and $85 \%$ of peak ventilation (Figures 3b and $4 b$, respectively). Moreover, Hannink et al. recently reported dynamic hyperinflation during the performance of ADLs in COPD patients(34), which will also contribute to a worsening of the task-related dyspnea. Therefore, various nonpharmacological interventions can be considered to reduce the task-related dyspnea sensation in COPD. Indeed, lower ventilation and a reduction in dynamic hyperinflation for the same constant work rate cycling load were found following exercise training and, in turn, resulted in lower dyspnea sensation(35-37). So, exercise-based pulmonary rehabilitation can lead to a better performance of ADLs in COPD(38). Indeed, COPD patients are likely to benefit from high-intensity interval training, which seems to resemble the physiological strain of domestic ADLs(39). In addition to exercise training, occupational therapy may also be a useful part of a comprehensive pulmonary rehabilitation program to reduce the burden of ADLs by learning and applying energy conservation techniques(40). These techniques aim to decrease energy expenditure during ADLs associated with a decrease in dyspnea, enabling better functional performance and quality of life in patients(41). Indeed, Velloso and Jardim showed a significant decrease in task-related oxygen uptake and dyspnea perception while using energy conservation techniques during the performance of domestic ADLs in COPD(42).

Several methodological limitations need to be addressed. Due to the portable metabolic system we were not able to measure patients with long-term oxygen therapy, who may even experience more problematic ADLs compared to those without long-term oxygen therapy(43). Moreover, the external validity of the present findings is limited to patients 
with GOLD stage II to IV and MRC dyspnea grade 2 to 5 . Thus the present data should be critically applied to subsets consisting of patients with long-term oxygen therapy, GOLD stage I patients or MRC dyspnea grade 1 patients.

About half of the COPD patients reported $\geq 1$ co-morbidities, which may have caused, at least in part, the difference in task-related oxygen uptake between COPD patients and healthy subjects. However, task-related oxygen uptake was similar between COPD patients with and without co-morbidities (see online supplement for details). This strengthens the validity of the current findings.

In the current study, the 5 ADLs were performed in the same order. The extent to which task-related oxygen uptake will change by altering the order of the tested 5 domestic ADLs remains uncertain and should be addressed in future studies.

Finally, the current findings need to be interpreted in the light of the number of comparisons that were made in the present study(44). Nonetheless, multiple findings in the same direction, rather than a single statistically significant result, suggest that these are not due to chance alone.

To conclude, COPD patients experience a relatively high metabolic load during the performance of self-paced domestic ADLs that is not the same as seen in their healthy peers, especially patients with GOLD stage IV, MRC dyspnea grade 5 or BODE score of $\geq 6$ points. The current findings generate a clear rationale to study the effects of occupational therapy in combination with high-intensity interval training on task-related oxygen uptake, ventilation and symptoms in COPD patients. 


\section{REFERENCES}

1. Rabe KF, Hurd S, Anzueto A, Barnes PJ, Buist SA, Calverley P, et al. Global strategy for the diagnosis, management, and prevention of chronic obstructive pulmonary disease: GOLD executive summary. Am J Respir Crit Care Med. 2007;176(6):532-55.

2. Janssen DJ, Spruit MA, Wouters EF, Schols JM. Daily symptom burden in end-stage chronic organ failure: a systematic review. Palliat Med. 2008;22(8):938-48.

3. Guccione AA, Felson DT, Anderson JJ, Anthony JM, Zhang Y, Wilson PW, et al. The effects of specific medical conditions on the functional limitations of elders in the Framingham Study. Am J Public Health. 1994;84(3):351-8.

4. Mannino DM, Ford ES, Redd SC. Obstructive and restrictive lung disease and functional limitation: data from the Third National Health and Nutrition Examination. J Intern Med. 2003;254(6):540-7.

5. Rodriguez Gonzalez-Moro JM, de Lucas Ramos P, Izquierdo Alonso JL, Lopez-Muniz Ballesteros B, Anton Diaz E, Ribera X, et al. Impact of COPD severity on physical disability and daily living activities: EDIP-EPOC I and EDIP-EPOC II studies. Int J Clin Pract. 2009;63(5):742-50.

6. Partridge MR, Karlsson N, Small IR. Patient insight into the impact of chronic obstructive pulmonary disease in the morning: an internet survey. Curr Med Res Opin. 2009;25(8):2043-8.

7. Annegarn J, Meijer K, Lima Passos V, Stute K, Wiechert J, Savelberg HHCM, et al. Problematic activities of daily life are weakly associated with clinical characteristics in COPD. J Am Med Dir Assoc. 2012;13(3):284-90.

8. Spruit MA, Watkins ML, Edwards LD, Vestbo J, Calverley PM, Pinto-Plata V, et al. Determinants of poor 6min walking distance in patients with COPD: the ECLIPSE cohort. Respir Med.104(6):849-57.

9. Hamilton AL, Killian KJ, Summers E, Jones NL. Symptom intensity and subjective limitation to exercise in patients with cardiorespiratory disorders. Chest. 1996;110(5):1255-63.

10. Spruit MA, Pennings HJ, Janssen PP, Does JD, Scroyen S, Akkermans MA, et al. Extra-pulmonary features in COPD patients entering rehabilitation after stratification for MRC dyspnea grade. Respir Med. 2007;101(12):2454-63.

11. Nishimura K, Izumi T, Tsukino M, Oga T. Dyspnea is a better predictor of 5-year survival than airway obstruction in patients with COPD. Chest. 2002;121(5):1434-40.

12. Celli BR, Cote CG, Marin JM, Casanova C, Montes de Oca M, Mendez RA, et al. The body-mass index, airflow obstruction, dyspnea, and exercise capacity index in chronic obstructive pulmonary disease. $\mathrm{N}$ Engl J Med. 2004;350(10):1005-12.

13. Puhan MA, Garcia-Aymerich J, Frey M, ter Riet G, Anto JM, Agusti AG, et al. Expansion of the prognostic assessment of patients with chronic obstructive pulmonary disease: the updated BODE index and the ADO index. Lancet. 2009;374(9691):704-11.

14. Polkey MI, Moxham J. Attacking the disease spiral in chronic obstructive pulmonary disease. Clin Med. 2006;6(2):190-6.

15. Pitta F, Troosters T, Spruit MA, Probst VS, Decramer M, Gosselink R. Characteristics of physical activities in daily life in chronic obstructive pulmonary disease. Am J Respir Crit Care Med. 2005;171(9):972-7.

16. Jones PW, Quirk FH, Baveystock CM, Littlejohns P. A self-complete measure of health status for chronic airflow limitation. The St. George's Respiratory Questionnaire. Am Rev Respir Dis. 1992;145(6):1321-7.

17. Guyatt GH, Berman LB, Townsend M, Pugsley SO, Chambers LW. A measure of quality of life for clinical trials in chronic lung disease. Thorax. 1987;42(10):773-8.

18. Pitta F, Takaki MY, Oliveira NH, Sant'anna TJ, Fontana AD, Kovelis D, et al. Relationship between pulmonary function and physical activity in daily life in patients with COPD. Respir Med. 2008;102(8):1203-7.

19. Mahler DA. Mechanisms and measurement of dyspnea in chronic obstructive pulmonary disease. Proc Am Thorac Soc. 2006;3(3):234-8. 
20. Ainsworth BE, Haskell WL, Whitt MC, Irwin ML, Swartz AM, Strath SJ, et al. Compendium of physical activities: an update of activity codes and MET intensities. Med Sci Sports Exerc. 2000;32(9 Suppl):S498504.

21. Gosker HR, Lencer NH, Franssen FM, van der Vusse GJ, Wouters EF, Schols AM. Striking similarities in systemic factors contributing to decreased exercise capacity in patients with severe chronic heart failure or COPD. Chest. 2003;123(5):1416-24.

22. Spruit MA, Eterman RMA, Wouters EFM, Meijer K, Wagers SS, Stakenborg K, et al. Task-related oxygen uptake and symptoms during activities of daily life in CHF patients and healthy subjects. Eur J Appl Physiol. 2011;111(8):1679-86.

23. Jeng C, Chang W, Wai PM, Chou CL. Comparison of oxygen consumption in performing daily activities between patients with chronic obstructive pulmonary disease and a healthy population. Heart Lung. 2003;32(2):121-30.

24. Velloso M, Stella SG, Cendon S, Silva AC, Jardim JR. Metabolic and ventilatory parameters of four activities of daily living accomplished with arms in COPD patients. Chest. 2003;123(4):1047-53.

25. Lahaije A, van Helvoort H, Dekhuijzen P, Heijdra Y. Physiologic limitations during daily life activities in COPD patients. Respir Med.104(8):1152-9.

26. Lopez Varela MV, Montes de Oca M, Halbert RJ, Muino A, Perez-Padilla R, Talamo C, et al. Sex-related differences in COPD in five Latin American cities: the PLATINO study. Eur Respir J. 2010;36(5):1034-41.

27. Huijsmans RJ, de Haan A, ten Hacken NN, Straver RV, van't Hul AJ. The clinical utility of the GOLD classification of COPD disease severity in pulmonary rehabilitation. Respir Med. 2008;102(1):162-71.

28. Spruit MA, Vanderhoven-Augustin I, Janssen PP, Wouters EF. Integration of pulmonary rehabilitation in COPD. Lancet. 2008;371(9606):12-3.

29. World Medical Association Declaration of Helsinki: ethical principles for medical research involving human subjects. J Int Bioethique. 2004;15(1):124-9.

30. Katz P, Chen H, Omachi TA, Gregorich SE, Julian L, Cisternas M, et al. The Role of Physical Inactivity in Increasing Disability Among Older Adults With Obstructive Airway Disease. Journal of cardiopulmonary rehabilitation and prevention. 2011;31(3):193-7.

31. de Torres JP, Casanova C, Hernandez C, Abreu J, Aguirre-Jaime A, Celli BR. Gender and COPD in patients attending a pulmonary clinic. Chest. 2005;128(4):2012-6.

32. Celli B, Vestbo J, Jenkins CR, Jones PW, Ferguson GT, Calverley PM, et al. Sex differences in mortality and clinical expressions of patients with chronic obstructive pulmonary disease. The TORCH experience. Am J Respir Crit Care Med. 2011;183(3):317-22.

33. Skumlien S, Haave E, Morland L, Bjortuft O, Ryg MS. Gender differences in the performance of activities of daily living among patients with chronic obstructive pulmonary disease. Chron Respir Dis. 2006;3(3):141-8.

34. Hannink JD, van Helvoort HA, Dekhuijzen PN, Heijdra YF. Dynamic hyperinflation during daily activities: does COPD global initiative for chronic obstructive lung disease stage matter? Chest.137(5):1116-21.

35. Puente-Maestu L, Abad YM, Pedraza F, Sanchez G, Stringer WW. A controlled trial of the effects of leg training on breathing pattern and dynamic hyperinflation in severe COPD. Lung. 2006;184(3):159-67.

36. Gigliotti F, Coli C, Bianchi R, Romagnoli I, Lanini B, Binazzi B, et al. Exercise training improves exertional dyspnea in patients with COPD: evidence of the role of mechanical factors. Chest. 2003;123(6):1794802.

37. Porszasz J, Emtner M, Goto S, Somfay A, Whipp BJ, Casaburi R. Exercise training decreases ventilatory requirements and exercise-induced hyperinflation at submaximal intensities in patients with COPD. Chest. 2005;128(4):2025-34.

38. Sewell L, Singh SJ, Williams JE, Collier R, Morgan MD. Can individualized rehabilitation improve functional independence in elderly patients with COPD? Chest. 2005;128(3):1194-200.

39. Butcher SJ, Jones RL. The impact of exercise training intensity on change in physiological function in patients with chronic obstructive pulmonary disease. Sports Med. 2006;36(4):307-25.

40. Hodgkin JE, Balchum OJ, Kass I, Glaser EM, Miller WF, Haas A, et al. Chronic obstructive airway diseases. Current concepts in diagnosis and comprehensive care. JAMA. 1975;232(12):1243-60. 
41. Branick L. Integrating the principles of energy conservation during everyday activities. Caring. 2003;22(1):30-1.

42. Velloso M, Jardim JR. Study of energy expenditure during activities of daily living using and not using body position recommended by energy conservation techniques in patients with COPD. Chest. 2006;130(1):126-32.

43. Sandland CJ, Morgan MD, Singh SJ. Patterns of domestic activity and ambulatory oxygen usage in COPD. Chest. 2008;134(4):753-60.

44. Perneger TV. What's wrong with Bonferroni adjustments. BMJ. 1998;316(7139):1236-8.

45. Charlson ME, Pompei $\mathrm{P}$, Ales KL, Mackenzie CR. A new method of classifying prognostic comorbidity in longitudinal studies: development and validation. J Chronic Dis. 1987;40(5):373-83.

46. Charlson M, Szatrowski TP, Peterson J, Gold J. Validation of a combined comorbidity index. J Clin Epidemiol. 1994;47(11):1245-51. 


\section{ONLINE SUPPLEMENT}

\section{METHODS}

\section{Clinical phenotyping}

Co-morbidities were scored using the Charlson Co-morbidity Index score and the Charlson Age Co-morbidity Index. The Charlson Co-morbidity Index consists of 19 medical conditions weighted according to the degree to which they predict mortality, with total scores ranging from 0-37. The Charlson Age Co-morbidity Index includes a factor for age by decade (1 point for each decade over 40 years) $(1,2)$. The scores were based on patients' self-reported co-morbidities and data from medical records.

Post bronchodilator forced expiratory volume in the first second (FEV1) and forced vital capacity were determined using spirometry (Master Screen PFT Pro, CareFusion, Houten, the Netherlands). Diffusion capacity of the lung for carbon monoxide $\left(T_{L} C O\right)$ was measured using single-breath method. Measurements were performed according to the guidelines of the European Respiratory Society (3). Arterial blood gas analysis was performed in all patients at rest.

Patients were asked about their perceived breathlessness using the Medical Research Council (MRC) dyspnea grades 1 to 5 according to their perceived disability: 'I only get breathless with strenuous exercise', MRC dyspnea grade 1; 'I get short of breath when hurrying on the level or up a slight hill', MRC dyspnea grade 2; 'I walk slower than people of the same age on the level because of breathlessness or have to stop for breath when walking at my own pace on the level', MRC dyspnea grade 3; 'I stop for breath after walking 100 yards or after a few minutes on the level', MRC dyspnea grade 4; and 'I am too breathless to leave the house or breathless when dressing or undressing', MRC dyspnea grade 5 (4).

Whole-body dual-energy x-ray absorptiometry (DEXA, GE Medical Systems Lunar Prodigy, Madison, USA) scanning was used to determine lean muscle mass. Body mass index was calculated as weight $(\mathrm{kg}) /$ height $(\mathrm{m})^{2}$. Peak aerobic exercise was determined using a symptom-limited cardiopulmonary exercise test (CPET) on a cycle ergometer (Ergoline 200P, Ergoline $\mathrm{GmbH}$, Bitz, Germany). The test was performed according to the international guidelines $(5,6)$. Predicted values were obtained from Jones and colleagues (7). 
The metabolic load of 5 self-paced ADLs was measured using a mobile oxycon (Oxycon Mobile, CareFusion, San Diego, USA), which provides reliable measurements of oxygen uptake and ventilation. A mobile oxycon has been used before in patients with moderate to very severe COPD and in patients with chronic heart failure without adverse events (8-10).

The Oxycon Mobile is a light-weighted system, allowing patients to move easily. The Oxycon Mobile consisted of a face mask with integrated oxygen and carbon dioxide electrodes, a data exchange unit, a transmitting unit and a receiving unit. The equipment had an acclimatization time of 15 minutes and was calibrated prior to each test. The system has been validated before (11).

Protocol domestic activities of daily life (ADLS)

Participants were asked to perform the ADLs at their own pace, with 4 minutes of rest before the first activity and in between each activity (e.g. sitting in a chair). The ADLs were performed in the kitchen of the Department of Occupational Therapy of $\mathrm{CIRO}+$ in Horn (the Netherlands).

The ADL protocol that was used:

- ADL1: Subject puts on 2 socks and 2 shoes with laces while sitting in a chair. Then subject stands up and puts on a vest.

- $\quad$ ADL2: Subject folds 8 towels (3 times fold per towel) while standing at a table.

- ADL3: Subject places an empty basket on the table and fills it with 6 cans of beans (400 grams each). Then subject takes the basket and walks to the kitchen, where the subject puts away the groceries in 6 different cupboards (height cupboard 1: $133 \mathrm{~cm}$, height cupboard 2, 3 and 4: $155 \mathrm{~cm}$, height cupboard 5: $140 \mathrm{~cm}$ and cupboard 6: $29 \mathrm{~cm}$; total distance walked $2.00 \mathrm{~m}$ ).

- ADL4: Subject washes up 4 dishes, 4 cups and 4 saucers in random order while standing at the sink (height: $90 \mathrm{~cm}$ ).

- $\quad$ ADL5: Subject sweeps the floor for 4 minutes while standing and walking.

The time was stopped as soon as the ADL was completed. The task-related degree of dyspnea and fatigue were scored at the beginning and end of all activities using a modified Borg symptom score ranging from 0 to 10 points. 


\section{RESULTS}

\section{Characteristics}

\section{Self-reported co-morbidities}

$50.5 \%$ of the patients with COPD had 1 or more co-morbidities (e.g. a score $>1$ point on Charlson Co-morbidity Index). Most common co-morbidities were cardiovascular diseases. Furthermore, $18 \%$ of the COPD patients had a history of orthopedic problems.

\section{Domestic ADLs}

Sex-related differences in COPD group

Comparison for sex shows that female patients are slightly younger, had a lower FFM and a better FEV1 than male patients. Female patients had a lower oxygen uptake (in $\mathrm{ml} / \mathrm{min}$ and \%predicted) compared to male patients. However, after correction for body mass results show no gender-related differences in oxygen uptake. Task-related oxygen uptake, ventilation and heart rate (all expressed as a proportion of their peak values) and task-related symptoms were comparable after stratification by sex. (Table E2, Figure E2).

GOLD-related differences in COPD group

Results after stratification for GOLD stage are listed in table E3 and figure E3.

MRC-related difference

Results after stratification for MRC dyspnea grade are listed in table E4 and figure E4.

\section{BODE-related difference}

Results after stratification for BODE-index are listed in table E5 and figure E5.

\section{Co-morbidity-related differences in COPD group}

After exclusion of COPD patients with $\geq 1$ co-morbidities (Charlson co-morbidity index score $\geq 2$ points), patients with COPD still used a significantly higher proportion of their peak aerobic capacity compared to healthy elderly subjects (Figure E6a). Indeed, taskrelated oxygen uptake, ventilation, heart rate and symptom perception were comparable between COPD patients with and without co-morbidities (Table E6, Figure E6). 


\section{REFERENCES}

1. Charlson M, Szatrowski TP, Peterson J, Gold J. Validation of a combined comorbidity index. J Clin Epidemiol. 1994;47(11):1245-51.

2. Charlson ME, Pompei $\mathrm{P}$, Ales KL, MacKenzie CR. A new method of classifying prognostic comorbidity in longitudinal studies: development and validation. J Chronic Dis. 1987;40(5):373-83.

3. Quanjer PH, Tammeling GJ, Cotes JE, Pedersen OF, Peslin R, Yernault JC. Lung volumes and forced ventilatory flows. Report Working Party Standardization of Lung Function Tests, European Community for Steel and Coal. Official Statement of the European Respiratory Society. Eur Respir J Suppl. 1993;16:540.

4. Bestall JC, Paul EA, Garrod R, Garnham R, Jones PW, Wedzicha JA. Usefulness of the Medical Research Council (MRC) dyspnoea scale as a measure of disability in patients with chronic obstructive pulmonary disease. Thorax. 1999;54(7):581-6.

5. ATS/ACCP Statement on cardiopulmonary exercise testing. Am J Respir Crit Care Med. 2003;167(2):21177.

6. Wasserman K, Hansen JE, Sue DY, Casaburi R, Whipp BJ. Principles of exercise testing and interpretation. 3 ed. Philadelphia: Lippincott: Williams \& Wilkins; 1999.

7. Jones NL, Makrides L, Hitchcock C, Chypchar T, McCartney N. Normal standards for an incremental progressive cycle ergometer test. Am Rev Respir Dis. 1985;131(5):700-8.

8. Spruit MA, Eterman RMA, Wouters EFM, Meijer K, Wagers SS, Stakenborg K, et al. Task-related oxygen uptake and symptoms during activities of daily life in CHF patients and healthy subjects. Eur J Appl Physiol. 2011;111(8):1679-86.

9. Lahaije A, van Helvoort H, Dekhuijzen P, Heijdra Y. Physiologic limitations during daily life activities in COPD patients. Respir Med.104(8):1152-9.

10. Hannink JD, van Helvoort HA, Dekhuijzen PN, Heijdra YF. Dynamic hyperinflation during daily activities: does COPD global initiative for chronic obstructive lung disease stage matter? Chest.137(5):1116-21.

11. van Helvoort HA, Heijdra YF, de Boer RC, Swinkels A, Thijs HM, Dekhuijzen PN. Six-minute walkinginduced systemic inflammation and oxidative stress in muscle-wasted COPD patients. Chest. 2007;131(2):439-45. 
Table E1. Pulmonary and non-pulmonary drugs

\begin{tabular}{|c|c|c|}
\hline & Name of drug & $\%$ of 97 COPD patients \\
\hline \multirow[t]{12}{*}{ Pulmonary drugs } & Short-acting beta2-agonists & 39.2 \\
\hline & Short-acting anticholinergics & 18.6 \\
\hline & Short-acting combinations & 15.5 \\
\hline & Long-acting beta2-agonists & 27.8 \\
\hline & Long-acting anticholinergics & 61.9 \\
\hline & Inhaled corticosteroids & 18.6 \\
\hline & Combination ICS and LABA & 66.0 \\
\hline & Theophylline & 17.5 \\
\hline & Fluimucil & 37.1 \\
\hline & Prednisone (maintenance) & 14.4 \\
\hline & Antibiotics & 1.0 \\
\hline & Singulair & 4.1 \\
\hline \multirow[t]{8}{*}{ Other drugs } & Antihypertensive agents & 38.1 \\
\hline & Diuretics & 20.6 \\
\hline & Anticoagulants & 21.6 \\
\hline & Cholesterol & 17.5 \\
\hline & Sedative/sleep medication & 29.9 \\
\hline & Stomach & 27.8 \\
\hline & Analgesic & 13.4 \\
\hline & Osteoporosis & 19.6 \\
\hline
\end{tabular}

Table E2. Results stratified for gender

\begin{tabular}{lll}
\hline & Male $(\mathrm{n}=58)$ & Female $(\mathrm{n}=39)$ \\
Age $($ years) & $66.1(8.5)$ & $61.1(8.6)^{\dagger}$ \\
$\mathrm{BMI}\left(\mathrm{kg} / \mathrm{m}^{2}\right)^{* *}$ & $25.0(4.9)$ & $24.3(5.4)$ \\
FFM (kg) & $51.1(7.8)$ & $38.1(4.8)^{\dagger}$ \\
FEV1 (\%predicted) & $44.9(14.4)$ & $50.9(14.8)^{\dagger}$ \\
GOLD II / III / IV (\%) & $36 / 41 / 23$ & $49 / 43 / 8$ \\
Peak VO $(\mathrm{mL} / \mathrm{min})$ & $1221(388)$ & $984(232)^{\dagger}$ \\
Peak VO $(\% p r e d i c t e d)$ & $54.0(14.7)$ & $89.5(24.8)^{\dagger}$ \\
Peak VO $(\mathrm{mL} / \mathrm{min} / \mathrm{kg})$ & $18.7(7.9)$ & $17.5(5.7)$ \\
Peak VE (L) & $48.7(14.9)$ & $38.6(11.9)^{\dagger}$ \\
Peak VE (\%MVV) & $91.3(20.7)$ & $89.8(23.7)$ \\
Peak HR (bpm) & $131.0(22.8)$ & $139.9(23.0)^{\dagger}$ \\
Peak HR (\%predicted) & $82.8(13.2)$ & $85.0(12.5)$ \\
\hline
\end{tabular}

Results are presented as mean (standard deviation); BMI=body mass index; FFM=fat free mass; FEV1=forced expiratory volume in the first second; $L=l i t e r ; \mathrm{kg}=\mathrm{kilogram} ; \mathrm{kg} / \mathrm{m}^{2}=\mathrm{kilogram}$ per squared meters; $\mathrm{VO}_{2}=\mathrm{oxygen}$ uptake; $\mathrm{mL}=$ milliliter; $\mathrm{min}=$ minute; $\mathrm{VE}=$ ventilation; $\mathrm{MVV}=$ maximum voluntary ventilation; $\mathrm{HR}=$ heart rate; bpm=beats per minute; ${ }^{\dagger} p \leq 0.05$ versus male; ${ }^{* *} 1$ kilogram $=2.2046$ pounds 
Table E3. Results stratified for GOLD classification

\begin{tabular}{|c|c|c|c|}
\hline & GOLD II $(n=40)$ & GOLD III (n=41) & GOLD IV $(n=16)$ \\
\hline Men (\%) & 52.5 & 58.5 & $81.3^{+*}$ \\
\hline Age (years) & $63.9(9.7)$ & $64.7(8.2)$ & $62.8(8.8)$ \\
\hline $\mathrm{BMI}\left(\mathrm{kg} / \mathrm{m}^{2}\right)^{* *}$ & $24.7(5.2)$ & $24.9(5.1)$ & $24.3(5.2)$ \\
\hline FFM (kg) & $45.1(9.4)$ & $45.7(9.7)$ & $48.5(8.0)$ \\
\hline FEV1 (\% predicted) & $61.2(10.0)$ & $41.4(5.3)^{\dagger}$ & $27.6(6.3)^{+*}$ \\
\hline Peak VO 2 (mL/min) & $1192(378)$ & $1093(343)$ & 1045 (298) \\
\hline Peak $\mathrm{VO}_{2}$ (\%predicted) & $77.2(28.9)$ & $66.9(22.0)$ & $49.1(16.6)^{+*}$ \\
\hline Peak VO $2(\mathrm{~mL} / \mathrm{min} / \mathrm{kg})$ & $17.6(4.9)$ & $15.8(3.7)$ & $14.5(3.6)$ \\
\hline Peak VE (L) & $49.5(15.7)$ & $42.8(13.1)$ & $36.5(11.1)^{\dagger}$ \\
\hline Peak VE (\%MVV) & $78.1(18.5)$ & $97.1(16.5)^{\dagger}$ & $107.9(25.7)^{\dagger}$ \\
\hline Peak HR (bpm) & $132.8(23.6)$ & $127.8(21.4)$ & $132.0(19.5)$ \\
\hline Peak HR (\%predicted) & $84.9(13.6)$ & $82.3(12.5)$ & $84.0(12.6)$ \\
\hline
\end{tabular}

Results are presented as mean (standard deviation); BMI=body mass index; FFM=fat free mass; FEV1=forced expiratory volume in the first second; $L=l i t e r ; \mathrm{kg}=\mathrm{kilogram} ; \mathrm{kg} / \mathrm{m}^{2}=\mathrm{kilogram}$ per squared meters; $\mathrm{VO}_{2}=$ oxygen uptake; $\mathrm{mL}=$ milliliter; $\mathrm{min}=$ minute; $\mathrm{VE}=$ ventilation; $\mathrm{MVV}=$ maximum voluntary ventilation; $\mathrm{HR}=\mathrm{heart}$ rate; bpm=beats per minute; $\uparrow \mathrm{p} \leq 0.05$ versus GOLD II; * $\mathrm{p} \leq 0.05$ versus GOLDIII; ** 1 kilogram $=2.2046$ pounds

Table E4. Results stratified for MRC dyspnea grade

\begin{tabular}{|c|c|c|c|c|}
\hline & $\operatorname{MRC} 2(n=25)$ & $\operatorname{MRC} 3(n=27)$ & $\operatorname{MRC} 4(n=21)$ & $\operatorname{MRC} 5(n=24)$ \\
\hline Men (\%) & 72.0 & $40.7^{+}$ & $76.2^{*}$ & 54.2 \\
\hline Age (years) & $62.9(8.3)$ & $63.8(7.9)$ & $64.0(11.3)$ & $65.6(8.3)$ \\
\hline $\mathrm{BMI}\left(\mathrm{kg} / \mathrm{m}^{2}\right)^{* *}$ & $23.5(4.8)$ & $24.6(4.9)$ & $24.0(4.6)$ & $26.8(5.5)^{\dagger}$ \\
\hline FFM (kg) & $46.9(9.3)$ & $44.4(9.5)$ & $45.9(8.5)$ & $46.4(10.1)$ \\
\hline FEV1 (\% predicted) & $50.6(13.3)$ & $51.4(14.8)$ & $42.5(15.2)^{+*}$ & $43.5(14.5)^{+*}$ \\
\hline GOLD II / III / IV (\%) & $48 / 40 / 12$ & $55 / 30 / 15$ & $33 / 43 / 24$ & $25 / 58 / 17$ \\
\hline Peak $\mathrm{VO}_{2}(\mathrm{~mL} / \mathrm{min})$ & $1261(421)$ & $1154(352)$ & $1088(396)$ & $987(305)^{\dagger}$ \\
\hline Peak $\mathrm{VO}_{2}$ (\%predicted) & $66.5(22.6)$ & $75.4(24.0)$ & $57.0(24.0)^{*}$ & $71.8(30.9)$ \\
\hline Peak VO $2(\mathrm{~mL} / \mathrm{min} / \mathrm{kg})$ & $18.7(3.2)$ & $16.8(3.9)$ & $15.8(5.3)^{\dagger}$ & $13.9(3.8)^{+*}$ \\
\hline Peak VE (L) & $50.3(13.1)$ & $44.0(14.4)$ & $45.8(16.3)$ & $38.3(12.9) \dagger$ \\
\hline Peak VE (\%MVV) & $90.1(18.1)$ & $86.0(25.9)$ & $94.9(23.5)$ & $92.9(19.5)$ \\
\hline Peak HR (bpm) & $135.1(22.8)$ & $133.3(23.0)$ & $130.0(23.5)$ & $123.5(17.7)$ \\
\hline Peak HR (\%predicted) & $85.9(11.3)$ & $85.4(15.2)$ & $83.3(14.0)$ & $79.9(10.3)$ \\
\hline
\end{tabular}

Results are presented as mean (standard deviation); BMI=body mass index; FFM=fat free mass; FEV1=forced expiratory volume in the first second; $L=l i t e r ; \mathrm{kg}=\mathrm{kilogram} ; \mathrm{kg} / \mathrm{m}^{2}=\mathrm{kilogram}$ per squared meters; $\mathrm{VO}_{2}=\mathrm{oxygen}$ uptake; $\mathrm{mL}=$ milliliter; $\mathrm{min}=$ minute; $\mathrm{VE}=$ ventilation; $\mathrm{MVV}=$ maximum voluntary ventilation; $\mathrm{HR}=\mathrm{heart}$ rate; bpm=beats per minute; † $p \leq 0.05$ versus MRC $2 ;^{*} p \leq 0.05$ versus MRC $3 ;+p \leq 0.05$ versus MRC 4 ; ** 1 kilogram $=2.2046$ pounds 
Table E5. Results stratified for BODE Index

\begin{tabular}{|c|c|c|c|}
\hline & $\begin{array}{l}\text { BODE } \leq 2 \\
(n=31)\end{array}$ & $\begin{array}{l}\text { BODE } 3-4-5 \\
(n=49)\end{array}$ & $\begin{array}{l}\text { BODE } \geq 6 \\
(n=17)\end{array}$ \\
\hline Men (\%) & 55 & 63 & 59 \\
\hline Age (years) & $63.8(8.0)$ & $64.7(9.7)$ & $62.6(8.2)$ \\
\hline $\mathrm{BMI}\left(\mathrm{kg} / \mathrm{m}^{2}\right)^{* *}$ & $24.6(4.7)$ & $25.5(5.1)$ & $23.4(5.6)$ \\
\hline FFM (kg) & $46.2(8.7)$ & $46.5(9.7)$ & $43.6(9.3)$ \\
\hline FEV1 (\% predicted) & $59.0(10.5)$ & $44.7(13.7)^{\dagger}$ & $33.6(8.0)^{+*}$ \\
\hline Peak $\mathrm{VO}_{2}(\mathrm{~mL} / \mathrm{min})$ & 1235 (331) & 1149 (361) & $861(223)^{+*}$ \\
\hline Peak $\mathrm{VO}_{2}$ (\%predicted) & $72.7(24.8)$ & $71.2(27.5)$ & $51.7(17.2)^{+*}$ \\
\hline Peak $\mathrm{VO}_{2}(\mathrm{~mL} / \mathrm{min} / \mathrm{kg})$ & $17.7(3.9)$ & $16.5(4.5)$ & $13.5(3.7)^{+*}$ \\
\hline Peak VE (L) & $50.2(13.7)$ & $45.6(16.8)$ & $34.7(9.1)^{+*}$ \\
\hline Peak VE (\%MVV) & $80.1(20.2)$ & $100.3(35.6)^{\dagger}$ & $98.5(20.1)^{\dagger}$ \\
\hline Peak HR (bpm) & $133.1(25.8)$ & $128.5(20.0)$ & $131.7(20.6)$ \\
\hline Peak HR (\%predicted) & $85.0(14.9)$ & $82.9(11.5)$ & $83.8(13.3)$ \\
\hline
\end{tabular}

Results are presented as mean (standard deviation); BMI=body mass index; FFM=fat free mass; FEV1=forced expiratory volume in the first second; $\mathrm{L}=$ liter; $\mathrm{kg}=\mathrm{kilogram} ; \mathrm{kg} / \mathrm{m}^{2}=\mathrm{kilogram}$ per squared meters; $\mathrm{VO}_{2}=\mathrm{oxygen}$ uptake; $\mathrm{mL}=$ milliliter; $\mathrm{min}=$ minute; $\mathrm{VE}=$ ventilation; $\mathrm{MVV}=$ maximum voluntary ventilation; $\mathrm{HR}=$ heart rate; bpm=beats per minute; $+p \leq 0.05$ versus BODE score of $\leq 2$ points; * $p \leq 0.05$ versus BODE score of $3-4-5$ points

** 1 kilogram $=2.2046$ pounds

Table E6. Results stratified for co-morbidities

\begin{tabular}{|c|c|c|}
\hline & $\mathrm{CCMI}=1$ & $\mathrm{CCMI}>1$ \\
\hline Men (\%) & 54 & 66 \\
\hline Age (years) & $63.6(9.2)$ & $64.3(8.2)$ \\
\hline $\mathrm{BMI}\left(\mathrm{kg} / \mathrm{m}^{2}\right)^{*}$ & $24.1(4.6)$ & $25.6(5.5)$ \\
\hline FFM $(\mathrm{kg})^{*}$ & $45.5(8.8)$ & $46.4(9.1)$ \\
\hline FEV1 (\% predicted) & $45.8(15.0)$ & $48.9(14.8)$ \\
\hline Peak $\mathrm{VO}_{2}(\mathrm{~mL} / \mathrm{min})$ & $1141(340)$ & 1105 (355) \\
\hline Peak VO ${ }_{2}$ (\%predicted) & $69.9(27.7)$ & $65.6(23.5)$ \\
\hline Peak $\mathrm{VO}_{2}(\mathrm{~mL} / \mathrm{min} / \mathrm{kg})^{*}$ & $16.2(4.4)$ & $15.3(4.3)$ \\
\hline Peak VE (L) & $45.6(15.7)$ & $44.5(15.0)$ \\
\hline Peak VE (\%MVV) & $94.3(36.8)$ & $92.2(19.9)$ \\
\hline Peak HR (bpm) & $131.7(19.2)$ & $129.4(25.5)$ \\
\hline Peak HR (\%predicted) & $83.1(11.0)$ & $84.1(15.1)$ \\
\hline
\end{tabular}

Results are presented as mean (standard deviation); CCMI=Charlson co-morbidity index; BMI=body mass index; FFM=fat free mass; FEV1=forced expiratory volume in the first second; $L=l i t e r ; \mathrm{kg}=\mathrm{kilogram}$; $\mathrm{kg} / \mathrm{m}^{2}=$ kilogram per squared meters; $\mathrm{VO}_{2}=$ oxygen uptake; $\mathrm{mL}=$ milliliter; min=minute; VE=ventilation; $M V V=$ maximum voluntary ventilation; $H R=$ heart rate; bpm=beats per minute; ${ }^{*} 1$ kilogram $=2.2046$ pounds 


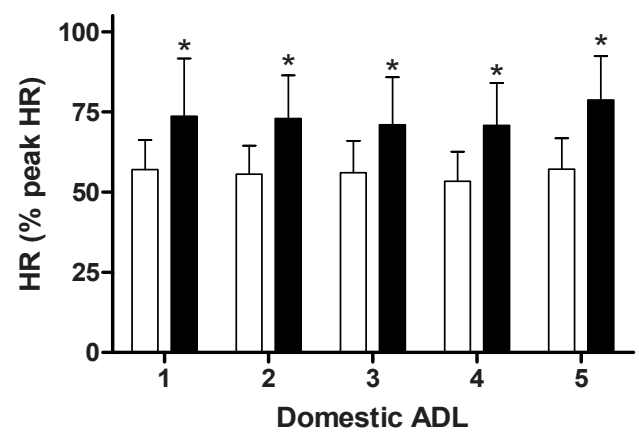

Figure E1. Task-related heart rate as a percentage of their peak during simple domestic activities of daily life in patients with COPD (black) and healthy elderly subjects (white).

$* p<0.001$ COPD versus healthy subjects

a

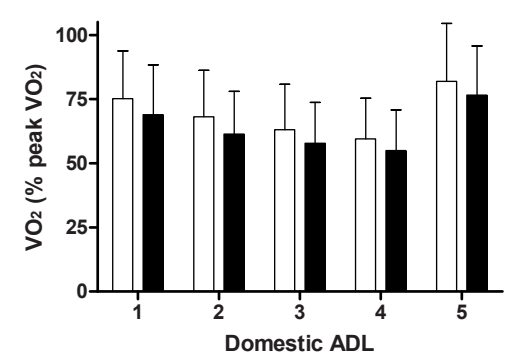

C

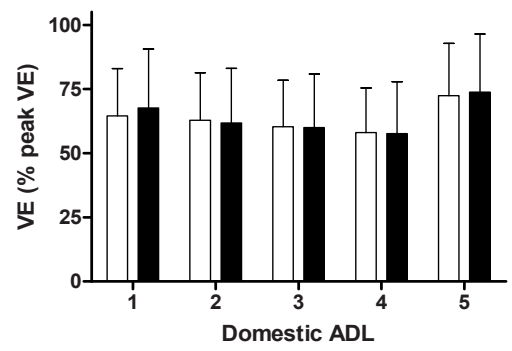

e

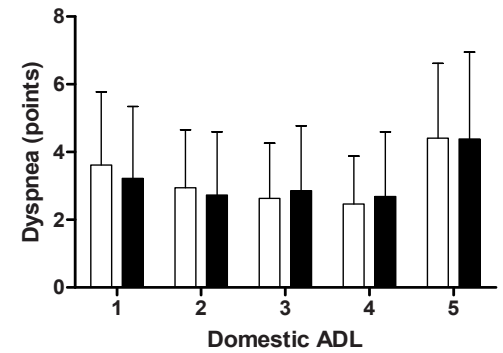

b

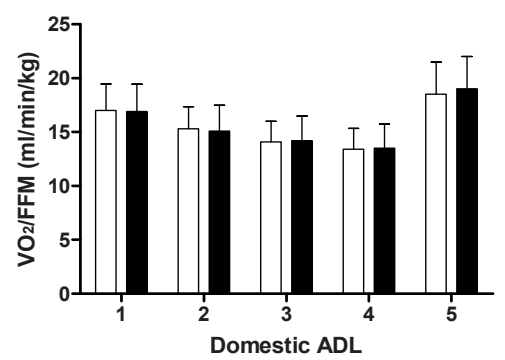

$d$

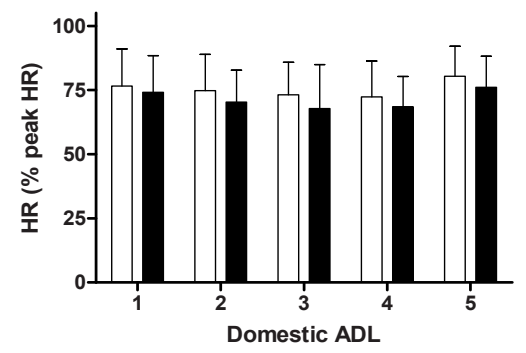

f

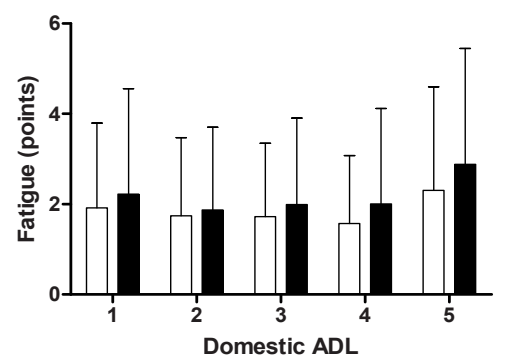

Figure E2. Results of male (black) and female (white) patients with COPD after performance of 5 simple domestic activities of daily life.

a) Task-related oxygen uptake (\% peak $V_{2}$ ); b) Task-related oxygen uptake per kg FFM; c) Task-related ventilation (\% peak VE); d) Task-related heart rate (\% peak HR); e) Borg dyspnea scores (points); f) Borg fatigue scores (points) 
a

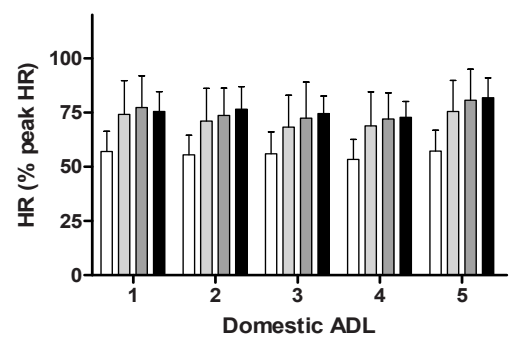

C

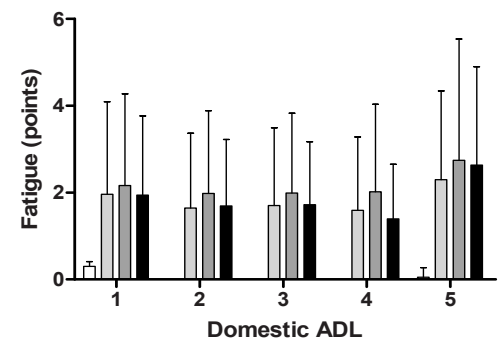

b

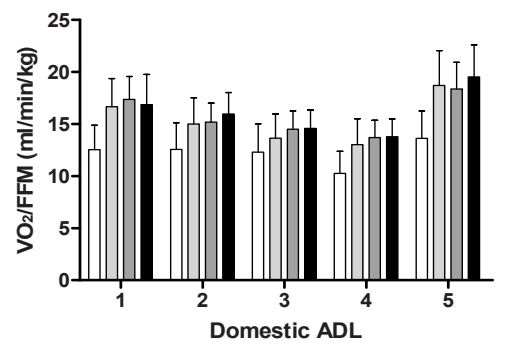

Figure E3. Results after performance of simple domestic activities of daily life in patients with COPD after stratification for GOLD stages.

a) Task-related heart rate (\% peak HR); all GOLD stages had a significantly higher task-related heart rate compared to the healthy controls $(p<0.05)$. There were no significant differences between GOLD stages; $b$ ) Task-related oxygen uptake per kg FFM; all GOLD stages had a significantly higher task-related oxygen uptake per kg FFM compared to healthy controls $(p<0.05)$. There were no significant differences between GOLD stages.; c) Borg fatigue scores (points); all GOLD stages had significantly higher Borg fatigue scores compared to the healthy controls $(p<0.05)$. There were no significant differences between GOLD stages. 
a

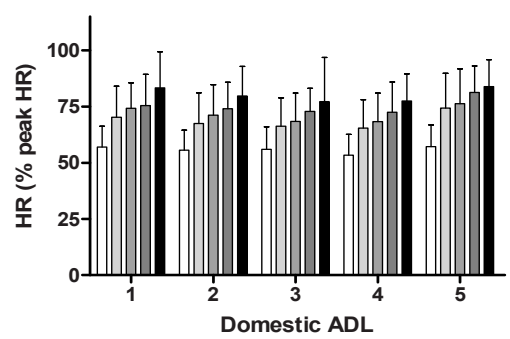

C

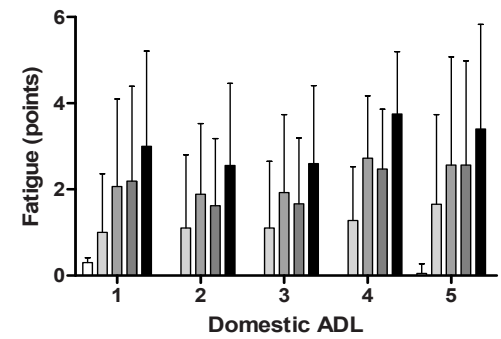

b
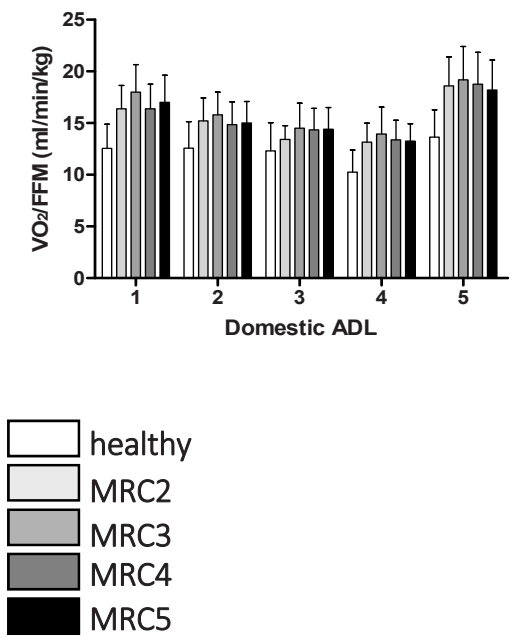

Figure E4. Results after performance of simple domestic activities of daily life in patients with COPD after stratification for MRC dyspnea grades.

a) Task-related heart rate (\% peak HR); all MRC grades had a significantly higher task-related heart rate compared to the healthy controls $(p<0.05)$. MRC grade 5 was significantly higher compared to MRC grades 2 and 3 for all ADLs ( $p<0.05)$; b) Task-related oxygen uptake per kg FFM; all MRC grades had a significantly higher task-related oxygen uptake per kg FFM compared to healthy controls $(p<0.05)$. There were no significant differences between MRC grades; c) Borg fatigue scores (points); all MRC grades had significantly higher Borg fatigue scores compared to the healthy controls $(p<0.05)$. MRC grade 5 was significantly higher compared to MRC grade 2 for all ADLs ( $p<0.05)$. 
a

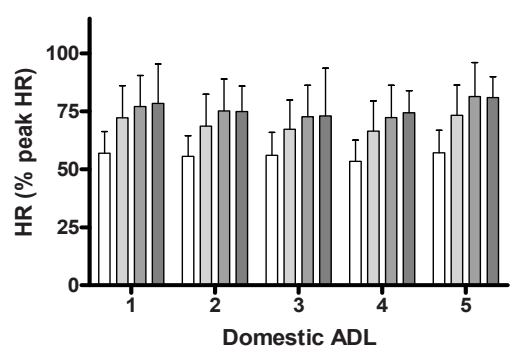

C

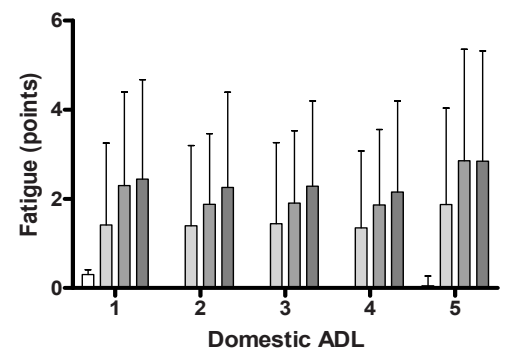

b

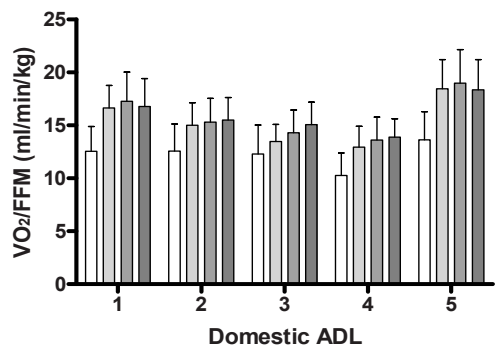

Figure E5. Results after performance of simple domestic activities of daily life in patients with COPD after stratification for BODE Index.

a) Task-related heart rate (\% peak HR); all BODE scores had a significantly higher task-related heart rate compared to the healthy controls $(p<0.05)$. BODE scores of $\geq 6$ points were significantly higher compared to BODE scores of $\leq 2$ points for all ADLs $(p<0.05)$. BODE scores of 3,4 and 5 points were significantly higher compared to BODE scores of $\leq 2$ points for ADLs 1, 2 and 5 ( $p<0.05$ ).; b) Task-related oxygen uptake per $\mathrm{kg}$ FFM; all BODE scores had a significantly higher task-related oxygen uptake per kg FFM compared to healthy controls $(p<0.05)$. There were no significant differences between BODE scores; $c$ ) Borg fatigue scores (points); all BODE scores had significantly higher Borg fatigue scores compared to the healthy controls $(p<0.05)$. BODE scores of 3,4 and 5 points and $\geq 6$ points were significantly higher compared to BODE scores of $\leq 2$ points for all $\operatorname{ADLs}(p<0.05)$. 
a

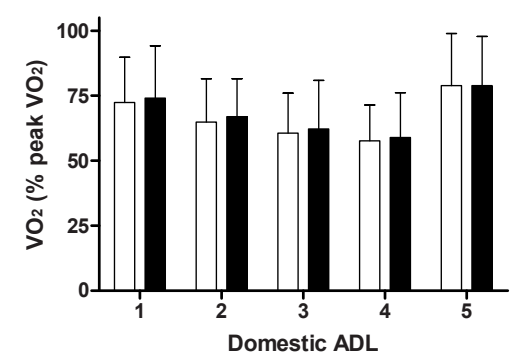

C

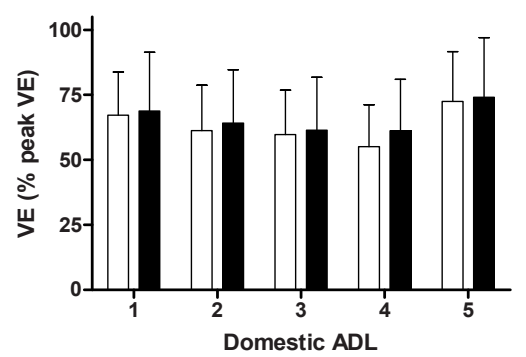

e

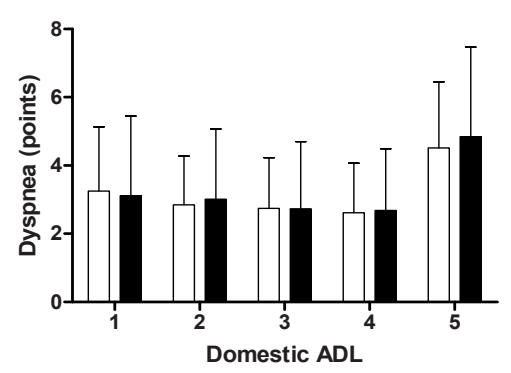

b

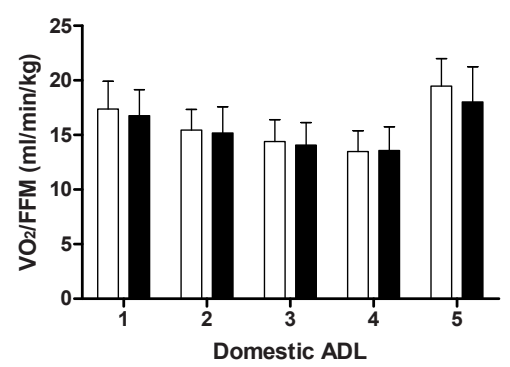

d

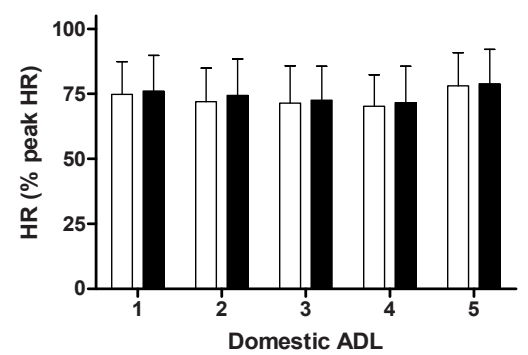

f

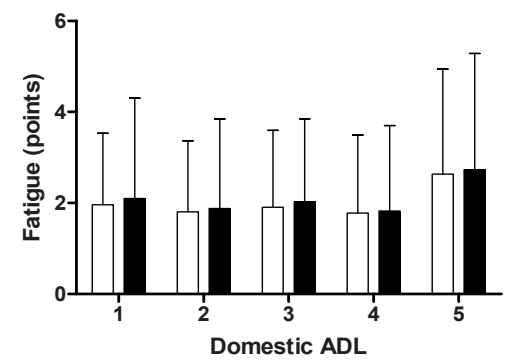

Figure E6. Results of COPD patients with (black) and without (white) other co-morbidities after performance of 5 simple domestic activities of daily life.;

a) Task-related oxygen uptake (\% peak $\left.\mathrm{VO}_{2}\right)$; b) Task-related oxygen uptake per kg FFM; c) Task-related ventilation (\% peak VE); d) Task-related heart rate (\% peak HR); e) Borg dyspnea scores (points); f) Borg fatigue scores (points) 
Chapter 3

Effects of body mass index on task-related oxygen uptake and dyspnea during activities of daily life in COPD

Anouk W. Vaes, Frits M.E. Franssen, Kenneth Meijer, Martijn W. J. Cuijpers, Emiel F.M. Wouters, Erica P.A. Rutten, Martijn A. Spruit 


\section{ABSTRACT}

Background Patients with COPD use a higher proportion of their peak aerobic capacity during the performance of domestic activities of daily life (ADLs) compared to healthy peers, accompanied by a higher degree of task-related symptoms. To date, the influence of body mass index (BMI) on the task-related metabolic demands remains unknown in patients with COPD. Therefore, the aim of our study was to determine the effects of $\mathrm{BMI}$ on metabolic load during the performance of 5 consecutive domestic ADLs in patients with COPD.

Methodology Ninety-four COPD patients and 20 healthy peers performed 5 consecutive, self-paced domestic ADLs: putting on socks, shoes and vest; folding 8 towels; putting away groceries; washing up 4 dishes, cups and saucers; and sweeping the floor for 4 min. Task-related oxygen uptake and ventilation were assessed using a mobile oxycon, while Borg scores were used to assess task-related dyspnea and fatigue.

Principal Findings 1. Relative task-related oxygen uptake after the performance of domestic ADLs was increased in patients with COPD compared to healthy elderly, whereas absolute oxygen uptake is similar between groups; 2 . Relative oxygen uptake and oxygen uptake per kilogram fat-free mass were comparable between BMI groups; and 3. Borg symptom scores for dyspnea and fatigue were comparable between BMI groups.

Conclusion Patients with COPD in different BMI groups perform self-paced domestic ADLs at the same relative metabolic load, accompanied by comparable Borg symptom scores for dyspnea and fatigue. 


\section{INTRODUCTION}

Chronic obstructive pulmonary disease (COPD) is not only characterized by pathological changes of the respiratory system, but has also significant systemic consequences like involuntary weight loss and skeletal muscle dysfunction $(1,2)$. These systemic changes adversely affect patients exercise performance, quality of life and prognosis (2).

Involuntary weight loss and muscle wasting have traditionally been an active field of interest in patients with COPD, but overweight and obesity are increasingly common (1, 3). An overweight or obese body mass index (BMI, $\left.\mathrm{kg} / \mathrm{m}^{2}\right)$ is strongly associated with a decreased compliance of the respiratory system, a restrictive lung function, increased airway resistance, and increased work of breathing (1). This can result in a worsening of dyspnea, increased physical limitations and decreased quality of life (1). On the other hand, being overweight or obese has been associated with less osteoporosis (4) and a decreased mortality among patients with severe COPD; a phenomenon commonly referred to as the 'obesity paradox' $(1,2)$.

Functional exercise performance and physical activity levels have been shown to be reduced in patients with COPD compared to healthy subjects, even in the earliest stage of the disease (3,5-9). Moreover, overweight and obese COPD patients have a significantly shorter six minute walk distance compared to normal and low BMI patients (10, 11). However, walk-work (the product of six minute walk distance in meters and body weight in kilogram) is similar between obese and non-obese COPD patients (10). This suggests that the reduced functional exercise performance reflects, at least in part, the increased work burden of overweight and obesity. Indeed, obesity has been associated with reduced physical activity levels in patients with COPD, irrespective of the degree of lung function impairment (12).

Patients with COPD use a higher proportion of their peak aerobic capacity during the performance of simple domestic ADLs compared to healthy peers, accompanied by a higher degree of task-related dyspnea and fatigue (7, 13-16). These studies did not study the possible effects of BMI on task-related oxygen uptake and symptoms in patients with COPD. Therefore, the influence of BMI on the task-related metabolic demands remains unknown in patients with COPD. Nevertheless, earlier was already shown that oxygen uptake and the ventilatory response are dependent on the corporal size. So, it seems reasonable to hypothesize that patients with low or normal BMI have a lower task-related oxygen uptake and ventilation during domestic activities in daily life compared to overweight and obese COPD patients. This is probably accompanied by lower Borg symptom scores, due to lower metabolic and ventilatory requirements during weight-bearing activities of daily life $(10,11)$. So, the aim of our study was to deter- 
mine the effects of $\mathrm{BMI}$ on metabolic load during the performance of 5 consecutive domestic activities of daily life in patients with COPD.

\section{METHODS}

One hundred COPD patients and 25 healthy peers volunteered to participate in the present study, which was approved by the institutional review board of the Maastricht University Medical Centre (MEC08-3-032). Patients were recruited at CIRO+ in Horn (the Netherlands) before the start of a comprehensive pulmonary rehabilitation program(17) and had not participated in clinical studies before (7). Healthy volunteers were recruited through posters and among healthy subjects who had participated in previous trials. At enrolment, written informed consent was obtained from potential participants and study eligibility was determined.

Patients were clinically stable (no exacerbation in past 4 weeks) and were on various (non-) pulmonary drug therapies (Table S1 of online supplement). None of the healthy subjects used physician-prescribed drugs. Exclusion criteria were the use of long-term oxygen therapy, neuromuscular co-morbidities, a cardiac pacemaker and/or an implantable cardioverter defibrillator and the disability to perform the domestic ADLs. All tests were in accordance with the World Medical Association declaration of Helsinki.

\section{Clinical phenotyping}

General demographics, post-bronchodilator pulmonary function, dyspnea, body composition and peak aerobic capacity were assessed as described previously $(14,18)$. Coexisting morbidities were scored using the Charlson Comorbidity Index and the Charlson Age Comorbidity Index, as described before $(7,19,20)$. The scores were based on patients' self-reported co-morbidities and data from medical records.

\section{Domestic ADLS}

Participants performed 5 domestic ADLs in the kitchen of the Dept. of Occupational Therapy at $\mathrm{CIRO}+$ as described before (7): putting on 2 socks (sitting in chair), 2 shoes (sitting in chair) and a vest (standing, ADL1); folding 8 towels (standing, ADL2); putting away groceries (e.g., 6 cans of beans of 400 grams each) in a cupboard (standing and walking, ADL3); washing up 4 dishes, 4 cups and 4 saucers (standing, ADL4); and sweeping the floor for 4 minutes (standing and walking, ADL5). These ADLs have all been identified as problematic valued life activities in patients with $\operatorname{COPD}(9,21)$. Participants were asked to perform ADLs at their own pace; and all ADLs were performed consecutively and, unlike to our previous study (7), without four minute rest intervals between ADLs. 
Online breath-by-breath calculations of oxygen uptake and ventilation were recorded using a mobile oxycon (Oxycon Mobile, CareFusion, San Diego, CA, USA) which provides reliable measurements of oxygen uptake and ventilation. A mobile oxycon has been used before in patients with moderate to very severe COPD and in patients with chronic heart failure without adverse events (7, 15, 22-24).

Heart rate was monitored using a Polar belt. Moreover, all participants were asked to score the degree of dyspnea and fatigue at the beginning ADL1 and at the end of all ADLs using a modified Borg symptom score ranging from 0 (no symptoms) to 10 points (worst symptoms). For unknown reasons a download of the data failed in 6 patients and 5 healthy subjects. Therefore, the final group comprised 94 COPD patients and 20 healthy subjects.

A priori, relative task-related oxygen uptake during ADLs (ie, task-related oxygen uptake expressed as a proportion of the pre-determined peak aerobic capacity) was chosen as the primary outcome. Task-related oxygen uptake $(\mathrm{mL} / \mathrm{min})$ per kilogram fat-free mass (FFM, using whole-body dual-energy x-ray absorptiometry (DEXA, GE Medical Systems Lunar Prodigy, Madison, USA)), task-related ventilation (expressed as a proportion of pre-determined peak ventilation), time to accomplish the first four ADLs (ADL5 was always set at $4 \mathrm{~min}$ ), and Borg symptom scores for dyspnea and fatigue at the end of each ADL were chosen as secondary outcomes.

\section{Statistics}

Data are presented as mean and standard deviation, unless noted otherwise. Student's t-test was used to determine differences between patients with COPD and healthy subjects. Patients were divided according to BMI: low BMI: $<21 \mathrm{~kg} / \mathrm{m}^{2}$; normal BMI: 21 $\mathrm{kg} / \mathrm{m}^{2}$ to $25 \mathrm{~kg} / \mathrm{m}^{2}$; overweight BMI: 25 to $30 \mathrm{~kg} / \mathrm{m}^{2}$; or obese BMI: $>30 \mathrm{~kg} / \mathrm{m}^{2}$. Differences between BMI groups were compared using analysis of variance and Bonferroni post hoc comparisons. Chi squared (with Cramer's V measure for strength of association) was used to assess the differences in gender distribution between groups. A priori, the level of significance was set at $\leq 0.05$. Data were analyzed with SPSS, version 19.0. 
Table 1. Characteristics

\begin{tabular}{|c|c|c|}
\hline & $\begin{array}{l}\text { Healthy subjects } \\
(n=20)\end{array}$ & $\begin{array}{l}\text { COPD patients } \\
(n=94)\end{array}$ \\
\hline Men (\%) & 60 & 61 \\
\hline Age (years) & $62.1(5.6)$ & $60.4(9.3)$ \\
\hline FEV1 (L) & $3.34(0.61)$ & $1.42(0.57)^{\dagger}$ \\
\hline FEV1 (\% predicted) & $119.4(24.2)$ & $51.2(19.1)^{\dagger}$ \\
\hline FEV1/FVC (\%) & $76.8(4.6)$ & $42.5(13.0)^{\dagger}$ \\
\hline TLCO (\%) & - & $56.7(19.8)$ \\
\hline $\mathrm{PaO}_{2}(\mathrm{kPa})^{*}$ & - & $9.75(1.24)$ \\
\hline $\mathrm{PaCO}_{2}(\mathrm{kPa})$ & - & $5.20(0.66)$ \\
\hline $\mathrm{SaO}_{2}(\%)$ & - & $95.2(2.1)$ \\
\hline GOLD stage I/II/III/IV (n) & - & $5 / 36 / 37 / 16$ \\
\hline MRC grade $1 / 2 / 3 / 4 / 5(n)$ & - & $7 / 28 / 35 / 12 / 12$ \\
\hline BODE score (points) & - & $2.88(1.89)$ \\
\hline Body weight $(\mathrm{kg}) * *$ & $79.2(12.3)$ & $69.8(17.3)^{\dagger}$ \\
\hline Height (cm) & $171.1(7.7)$ & $168.4(9.7)$ \\
\hline Body mass index $\left(\mathrm{kg} / \mathrm{m}^{2}\right)$ & $27.0(3.0)$ & $24.5(5.1)^{\dagger}$ \\
\hline FFM (kg) & $55.6(9.9)$ & $45.5(9.1)^{\dagger}$ \\
\hline FFMI $\left(\mathrm{kg} / \mathrm{m}^{2}\right)$ & $18.9(2.3)$ & $16.0(2.3)^{\dagger}$ \\
\hline Women <15 kg/m²(\%) & 25.0 & 62.2 \\
\hline Men <16 kg/m² (\%) & 0.0 & 45.5 \\
\hline Charlson CMI (points) & 0.0 & $2.0(1.4)^{\dagger}$ \\
\hline Charlson CMI 2 (points) & $1.7(0.7)$ & $3.7(2.0)^{\dagger}$ \\
\hline$\geq 1$ co-morbidities (\%) & 0.0 & $56.1^{+}$ \\
\hline Peak $\mathrm{VO}_{2}(\mathrm{~mL} / \mathrm{min})$ & $2155(770)$ & $1202(360)^{\dagger}$ \\
\hline Peak VO $2(\mathrm{~mL} / \mathrm{min} / \mathrm{kg} \mathrm{BW})$ & $27.5(10.2)$ & $17.5(4.4)^{\dagger}$ \\
\hline Peak VO ${ }_{2}(\mathrm{~mL} / \mathrm{min} / \mathrm{kg} F \mathrm{FM})$ & $38.8(12.2)$ & $26.4(6.0)+$ \\
\hline Peak VE (L) & $87.3(28.2)$ & $47.4(14.6)^{\dagger}$ \\
\hline Peak VE (\% MVV) & $65.4(17.1)$ & $89.8(26.1)^{\dagger}$ \\
\hline Peak HR (bpm) & $154(18.9)$ & $132(20.0)+$ \\
\hline Peak HR (\% max HR) & $97.5(10.7)$ & $83.0(11.5)^{\dagger}$ \\
\hline Borg dyspnoea (points) & $5.5(2.2)$ & $6.6(2.1)^{\dagger}$ \\
\hline Borg fatigue (points) & $5.7(2.2)$ & $5.9(2.2)$ \\
\hline
\end{tabular}

Results are presented as mean (standard deviation). $F E V_{1}=$ forced expiratory volume in the first second; $\mathrm{L}=$ liter; $\mathrm{FVC}=$ forced vital capacity; $\mathrm{kg}=\mathrm{kilogram}$; $\mathrm{kg} / \mathrm{m}^{2}=\mathrm{kilogram}$ per squared meters; Charlson $\mathrm{CMI}=\mathrm{Charlson}$ co-morbidity index (19); Charlson CMI 2=Charlson age comorbidity index (20); 6MWD=six-minute walking distance; $\mathrm{VO}_{2}=$ oxygen uptake; $\mathrm{mL}=$ milliliter; $\mathrm{min}=$ minute; $\mathrm{BW}=$ body weight; $\mathrm{FFM}=$ fat free mass; $V E=$ minute ventilation; $\mathrm{MVV}=$ maximum voluntary ventilation; $\mathrm{HR}=$ heart rate; bpm=beats per minute. ${ }^{*} 1 \mathrm{kPa}=7.5 \mathrm{~mm}$ Hg; ${ }^{* *} 1$ kilogram $=2.2046$ pounds; $\dagger p \leq 0.05$ vs. healthy subjects 


\section{RESULTS}

\section{Characteristics}

Subject characteristics are listed in table 1 . On average, patients had mild to very severe COPD, a normal BMI and a poor exercise capacity. Patients had a significantly lower BMI and FFM compared to healthy subjects. Moreover, patients had higher scores on the (age-adjusted) Charlson Comorbidity Index. Most common co-morbidities were cardiovascular diseases. Furthermore, 19.6\% of the COPD patients had a history of orthopedic problems. Present comorbidities had no significant effect on exercise tolerance.

Patients with COPD had a significantly lower peak aerobic capacity $(\mathrm{mL} / \mathrm{min})$, peak heart rate (beats/min), and peak ventilation $(\mathrm{L})$ than healthy subjects. Peak Borg dyspnea scores of patients were significantly higher than those of healthy subjects, whereas peak Borg fatigue scores were comparable between groups (Table 1).

Characteristics of the patients with COPD per BMI group are listed in table 2. Results showed no significant differences in lung function between BMI groups; while, obviously, there were significant differences in body composition. Peak aerobic capacity $(\mathrm{mL} / \mathrm{min})$ was significantly lower in low BMI patients compared to those with an overweight and obese BMI. Peak ventilation, peak heart rate, and peak Borg symptom scores were comparable between BMI groups (Table 2).

\section{Domestic ADLs}

Patients with COPD versus healthy subjects

Basal values before performance of ADL-protocol as well as absolute task-related oxygen uptake $(\mathrm{mL} / \mathrm{min})$ at the end of the 5 ADLs were similar between COPD patients and healthy peers (Figure 1a). Consequently, patients performed the domestic ADLs at a significantly higher proportion of their peak aerobic capacity compared to healthy subjects: mean difference (95\%Cl) ADL1: 21.1 (14.6-27.6)\%; ADL2: 26.2 (19.2-33.2)\%; ADL3: 28.5 (21.8-35.3)\%; ADL4: 30.4 (24.1-36.8)\% and ADL5: 32.4 (24.0-40.7)\%; all $p<0.001$ (Figure 1b). See online supplement for details.

COPD patients stratified by body mass index

All patients were able to complete ADL1 to ADL4 without stops, with no significant differences in time to complete the domestic tasks between BMI groups (figure S2 of the online supplement). Thirty patients with COPD needed 20 to $145 \mathrm{~s}$ rest before they were able to start ADL5, while seven patients were not able to complete ADL5 due to exertional dyspnea. No differences were found between BMI groups. Moreover, there 
are no significant difference in task-related metabolic load between patients who did rest before start of ADL 5 and patients who did not.

Table 2 Baseline characteristics by BMI categories

\begin{tabular}{|c|c|c|c|c|}
\hline & $\begin{array}{l}<21 \mathrm{~kg} / \mathrm{m}^{2} \\
(\mathrm{n}=24)\end{array}$ & $\begin{array}{l}21-25 \mathrm{~kg} / \mathrm{m}^{2}( \\
\mathrm{n}=31)\end{array}$ & $\begin{array}{l}25-30 \mathrm{~kg} / \mathrm{m}^{2} \\
(\mathrm{n}=26)\end{array}$ & $\begin{array}{l}>30 \mathrm{~kg} / \mathrm{m}^{2} \\
(n=13)\end{array}$ \\
\hline Men (\%) & 50 & 45 & $77^{*}+$ & $85^{*}+$ \\
\hline Age (years) & $57.2(7.8)$ & $59.5(9.1)$ & $66.3(8.7)^{\dagger+}$ & $56.8(8.8) \#$ \\
\hline FEV1 (L) & $1.25(0.61)$ & $1.37(0.52)$ & $1.54(0.64)$ & $1.59(0.44)$ \\
\hline FEV1 (\% predicted) & 44.8 (19.9) & $51.7(18.3)$ & $56.9(20.1)$ & $50.5(15.1)$ \\
\hline FEV1/FVC (\%) & $39.2(14.7)$ & $41.0(11.1)$ & $44.3(13.4)$ & $48.5(12.0)$ \\
\hline TLCO (\%) & $53.3(18.6)$ & $54.4(19.3)$ & $57.3(20.4)$ & $61.1(19.0)$ \\
\hline $\mathrm{PaO}_{2}(\mathrm{kPa}) *$ & $9.79(1.41)$ & $9.65(1.05)$ & $9.77(1.17)$ & $9.85(1.56)$ \\
\hline $\mathrm{PaCO}_{2}(\mathrm{kPa})$ & $5.33(0.92)$ & $5.14(0.56)$ & $5.11(0.53)$ & $5.34(0.62)$ \\
\hline $\mathrm{SaO}_{2}(\%)$ & $94.7(3.2)$ & $95.4(1.6)$ & $95.4(1.5)$ & $95.3(1.8)$ \\
\hline GOLD stage I/II/III/IV (n) & $1 / 6 / 6 / 11$ & $1 / 14 / 13 / 3$ & $2 / 11 / 11 / 2$ & $1 / 5 / 6 / 1$ \\
\hline MRC grade $1 / 2 / 3 / 4 / 5(n)$ & $3 / 5 / 9 / 4 / 3$ & $2 / 10 / 11 / 5 / 3$ & $1 / 9 / 10 / 3 / 3$ & $1 / 4 / 6 / 1 / 1$ \\
\hline BODE score (points) & $4.2(2.0)$ & $2.4(1.4)^{\dagger}$ & $2.4(2.0)^{\dagger}$ & $2.5(1.5)^{\dagger}$ \\
\hline Body weight $(\mathrm{kg})^{* *}$ & $52.6(7.9)$ & $64.9(7.7)^{\dagger}$ & $76.7(11.0)^{\dagger+}$ & $99.7(7.8)^{\dagger+\#}$ \\
\hline Height $(\mathrm{cm})$ & $167.0(9.2)$ & $167.7(9.7)$ & $168.5(10.5)$ & $172.4(8.6)$ \\
\hline Body mass index $\left(\mathrm{kg} / \mathrm{m}^{2}\right)$ & $18.8(1.7)$ & $23.0(1.0)^{\dagger}$ & $26.9(1.4)^{\dagger+}$ & $33.7(3.6)^{\dagger+\#}$ \\
\hline FFM (kg) & $39.0(5.4)$ & $42.9(5.7)$ & $48.5(8.8)++$ & $59.3(6.7)^{\dagger+\#}$ \\
\hline FFMI $\left(\mathrm{kg} / \mathrm{m}^{2}\right)$ & $14.0(1.2)$ & $15.2(1.3)^{\dagger}$ & $17.0(1.6)^{\dagger+}$ & $20.0(1.5)^{\dagger+\#}$ \\
\hline Women <15kg/m² (\%) & 75.0 & 76.5 & 16.7 & 0.0 \\
\hline Men $<16$ kg $/ \mathrm{m}^{2}(\%)$ & 91.7 & 71.4 & 20.0 & 0.0 \\
\hline Charlson CMI (points) & $1.7(0.9)$ & $1.9(1.1)$ & $2.5(1.8)$ & $2.1(1.9)$ \\
\hline Charlson CMI 2 (points) & $3.0(1.5)$ & $3.4(1.8)$ & $4.8(2.2)^{\dagger}$ & $3.4(2.6)$ \\
\hline$\geq 1$ co-morbidities (\%) & 57.6 & 55.6 & 56.7 & 53 \\
\hline 6MWD (m) & $487(111)$ & $500(96)$ & $483(114)$ & 485 (108) \\
\hline Peak $\mathrm{VO}_{2}(\mathrm{~mL} / \mathrm{min})$ & $1009(306)$ & $1172(330)$ & $1290(343) \dagger$ & $1458(374)^{\dagger}$ \\
\hline Peak VO $\mathrm{V}_{2}(\mathrm{~mL} / \mathrm{min} / \mathrm{kg} \mathrm{BW})$ & $19.2(4.9)$ & $18.0(4.3)$ & $16.8(3.6)$ & $14.6(3.7) \dagger$ \\
\hline Peak $\mathrm{VO}_{2}(\mathrm{~mL} / \mathrm{min} / \mathrm{kg}$ FFM) & $25.7(6.1)$ & $27.3(6.5)$ & $26.7(5.2)$ & $24.7(6.1)$ \\
\hline Peak VE (L) & $42.6(11.2)$ & $45.7(15.6)$ & $50.6(15.3)$ & $53.8(14.1)$ \\
\hline Peak VE (\% MVV) & $96.9(31.3)$ & $83.5(17.5)$ & $91.5(29.0)$ & $88.0(25.4)$ \\
\hline Peak HR (bpm) & $130(17.8)$ & $137(19.8)$ & $130(19.4)$ & $131(25.5)$ \\
\hline Peak HR (\% max HR) & $80.1(10.8)$ & $85.2(10.3)$ & $84.7(12.5)$ & $79.8(12.6)$ \\
\hline Borg dyspnoea (points) & $6.5(2.5)$ & $7.2(2.0)$ & $6.2(1.7)$ & $6.2(2.4)$ \\
\hline Borg fatigue (points) & $5.6(2.5)$ & $6.4(2.6)$ & $5.6(1.6)$ & $5.6(2.0)$ \\
\hline
\end{tabular}

Results are presented as mean (standard deviation). $\mathrm{FEV}_{1}=$ forced expiratory volume in the first second; $\mathrm{L}=$ liter; $\mathrm{FVC}=$ forced vital capacity; $\mathrm{kg}=$ kilogram; $\mathrm{kg} / \mathrm{m}^{2}=$ =kilogram per squared meters; Charlson $\mathrm{CMI}=$ Charlson co-morbidity index (19); Charlson CMI 2=Charlson age comorbidity index (20); 6MWD=six-minute walking distance; $\mathrm{VO}_{2}=$ oxygen uptake; $\mathrm{mL}=$ milliliter; $\mathrm{min}=$ minute; $\mathrm{BW}=$ body weight; $\mathrm{FFM=fat} \mathrm{free} \mathrm{mass;} V E=$ minute ventilation; $\mathrm{MVV}=$ maximum voluntary ventilation; $\mathrm{HR}=$ heart rate; bpm=beats per minute. $* 1 \mathrm{kPa}=7.5 \mathrm{~mm}$ $\mathrm{Hg}$; ** 1 kilogram $=2.2046$ pounds; $\dagger p<0.05$ vs. $<21 \mathrm{~kg} / \mathrm{m}^{2}+\mathrm{p}<0.05$ vs. $21-25 \mathrm{~kg} / \mathrm{m}^{2} \# \mathrm{p}<0.05$ vs. $25-30 \mathrm{~kg} / \mathrm{m}^{2}$ 


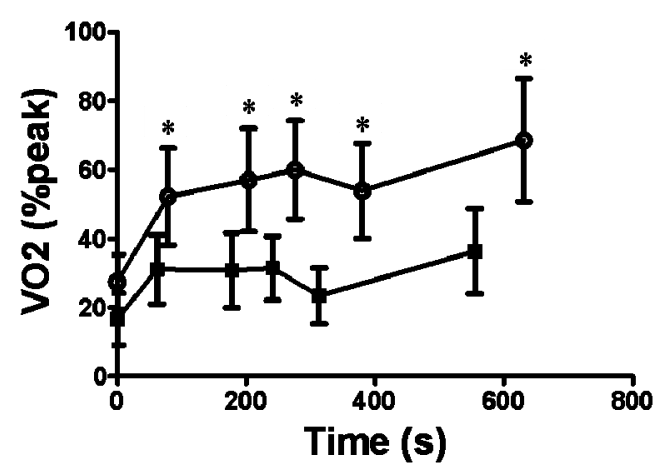

b

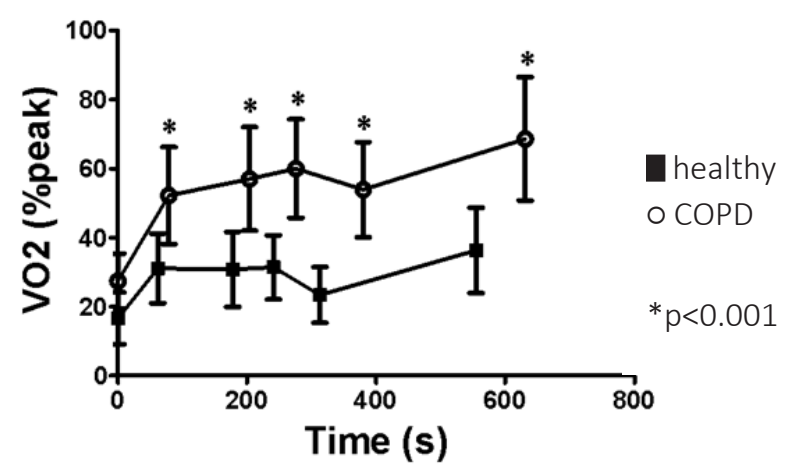

Figure 1. Task-related oxygen uptake in patients with COPD and healthy controls

a) Absolute task-related oxygen uptake ( $\mathrm{mL} / \mathrm{min})$; b) Relative task-related oxygen uptake (\%peakVO $\mathrm{F}_{2}$ )

Task-related oxygen uptake expressed as a percentage of peak aerobic capacity was comparable between BMI groups at rest and after performance of all ADLs (Figure 2a). Moreover, oxygen uptake per kilogram FFM was also comparable between BMI groups for all ADLs (Figure 2b).

Relative task-related ventilation (ventilation expressed as a proportion of the predetermined peak ventilation) was comparable between BMI groups at rest and after performance for all ADLs (Figure 3a).

Although Borg scores for dyspnea appeared lower in low BMI patients compared to obese COPD patients, these differences were non-significant (Figure 4a). Moreover, relative Borg dyspnea scores (expressed as percentage of peak Borg scores during CPET) were comparable between BMI groups (Figure 4b). Borg scores for fatigue (absolute and relative) were also comparable between BMI groups (Figure $4 \mathrm{c}$ and $4 \mathrm{~d}$ ). 
a

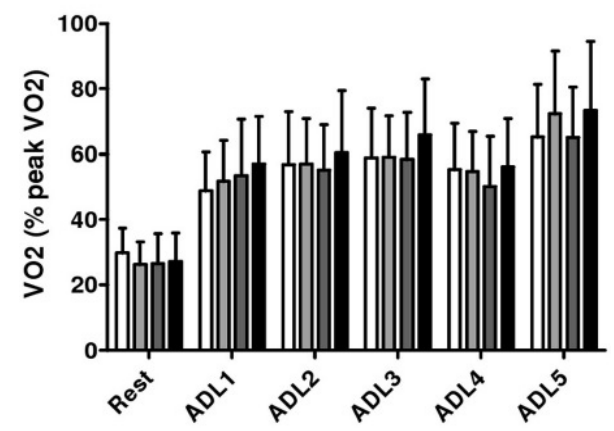

b

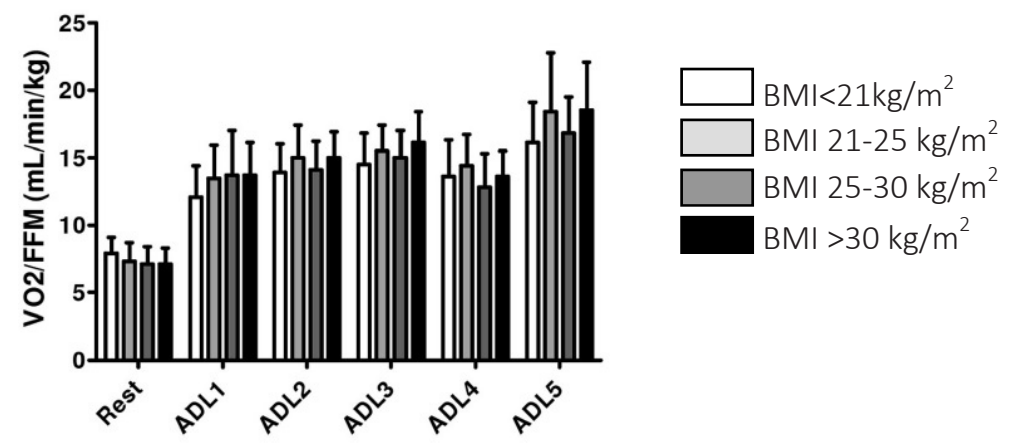

Figure 2. Task-related oxygen uptake in patients with COPD

a) Relative task-related oxygen uptake $\left(\%\right.$ peakVO $\mathrm{O}_{2}$ ); b) Task-related oxygen uptake per kilogram FFM $(\mathrm{mL} / \mathrm{min} / \mathrm{kg}$ FFM)

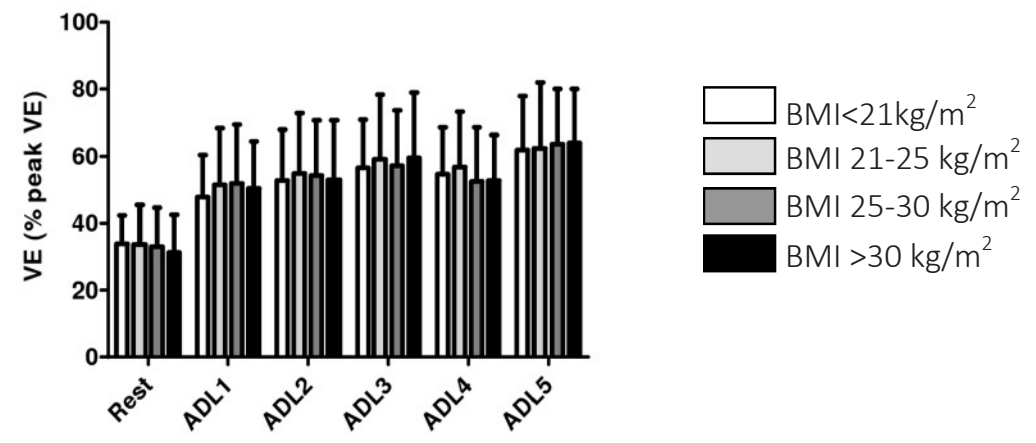

Figure 3. Task-related ventilation in patients with COPD (\%peakVE) 


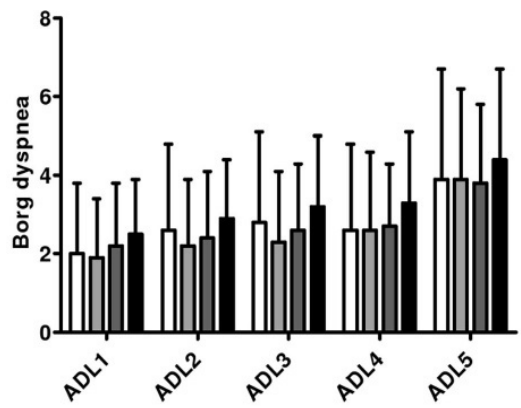

C

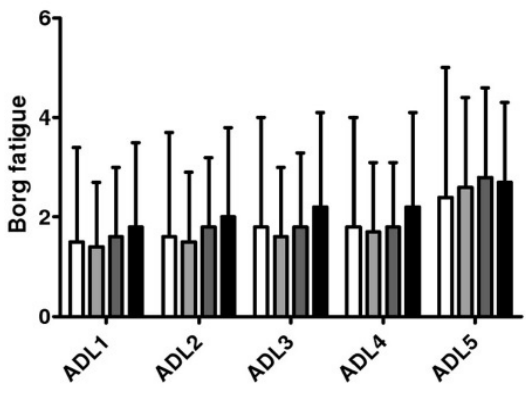

b

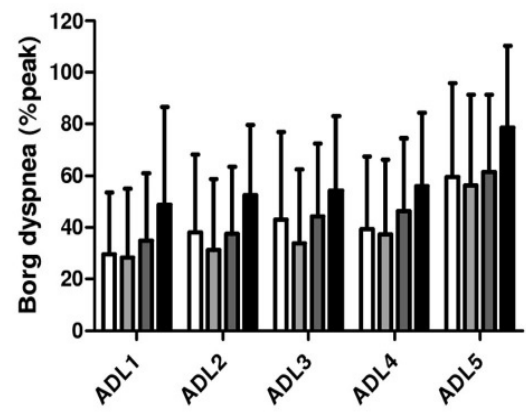

d

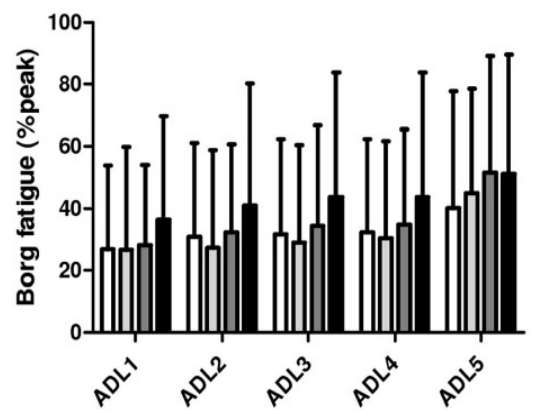

Figure 4. Borg symptom scores after performance of domestic ADLs

a) absolute Borg dyspnea scores; b) relative Borg dyspnea scores (\%peak); c) absolute Borg fatigue scores; d) relative Borg fatigue scores (\%peak)

\section{DISCUSSION}

Our results demonstrate differences in relative task-related oxygen uptake after the performance of five consecutive domestic ADLs between patients with COPD and healthy peers, whereas absolute oxygen uptake is similar between groups. Moreover, the present study is the first to demonstrate that relative oxygen uptake, oxygen uptake per kilogram FFM and relative ventilation during the performance of domestic ADLS were comparable between COPD patients with a low, normal, overweight or obese BMI. Moreover, Borg symptom scores for dyspnea and fatigue were comparable between BMI groups.

Previously was already reported that relative task-related oxygen uptake after the performance of domestic ADLs was increased in patients with COPD compared to healthy elderly $(7,13,15,16)$. Our results show similar results between patients with COPD and healthy subjects during five consecutive ADLs. This may explain why patients with COPD experience more limitations in their daily life (9). 
An increased BMI is associated with an increased work of breathing, increased breathing resistive load and worse exertional dyspnea (1). On the other hand, obesity is associated with decreased resting and dynamic lung volumes $(25,26)$, which would positively affect exercise performance and perceived dyspnea. Indeed, overweight and obese patients with COPD did not experience greater dyspnea and exercise limitation during cycle ergometry compared to normal weight patients with comparable degree of airflow limitation $(10,27)$. We also found no significant differences in dyspnea after performance of domestic ADLs between obese and non-obese COPD patients (Figure 4).

Previous studies showed that underweight COPD patients, particularly those with an abnormal low FFM, have an impaired peripheral muscle function and a poor exercise capacity (28). Therefore, underweight patients may experience more limitations during the performance of domestic ADLs compared to normal weight COPD patients. In the presents study, underweight COPD patients had a significantly lower absolute oxygen uptake and ventilation during the performance of domestic ADLs compared to overweight or obese patients. This may indicate that obese and overweight patients experience more functional impairments in their daily life, probably caused by increases in the energetic cost of moving heavier limbs during activities and increased work of breathing $(1,25,29,30)$. However, differences in task-related oxygen uptake and ventilation between BMI groups disappeared after correction for body weight or fat-free mass. These findings are corroborated by an a posteriori analysis of a previous study in which taskrelated oxygen uptake was assessed during five separate ADLs in 97 patients with COPD (7) (see online supplement for details).

Patients with COPD use a higher proportion of their peak aerobic capacity and peak ventilation to perform domestic ADLs as compared to healthy subjects, accompanied by higher task-related Borg dyspnea scores (7, 13, 15, 16). Moreover, task-related dynamic hyperinflation will contribute to a worsening of the task-related dyspnea in patients with COPD (22), Because of the reduced static and dynamic hyperinflation in overweight and obese COPD patients it was conceivable that these patients would experience less dyspnea during the performance of ADL compared to normal and underweight COPD patients. However, in the present study non-significant differences in task-related dyspnea were found after stratification for BMI (figure 4). This indicates that the burden of obesity restricts patients with COPD during the performance of ADL and offsets the potential beneficial influence of lower resting lung volumes.

Several methodological limitations need to be addressed. Due to the portable metabolic system we were not able to measure patients with long-term oxygen therapy, who may even experience more problematic ADLs compared to those without long-term oxygen therapy (31). Moreover, we did not measure dynamic hyperinflation. Nevertheless, 
dynamic hyperinflation generally occurs during the performance of ADLs in patients with $\operatorname{COPD}(22,32)$.

Fifty-six percent of the COPD patients reported $\geq 1$ co-morbidities, which may have influenced the performance of ADLs. However, proportion of patients with comorbidities was comparable between BMI groups and we did not found differences in task-related oxygen uptake, ventilation and dyspnea between COPD patients with and without co-morbidities (see online supplement for details). This strengthens the validity of the current findings.

Stratification for BMI resulted in an unequal distribution over BMI groups. Indeed, the number of obese COPD patients seems rather low. However, the percentage of obese COPD patients in our study is comparable with the prevalence of obesity in a large primary care population of patients with $\operatorname{COPD}(33)$. Moreover, the BMI groups were not comparable at baseline. However, earlier was already shown that there are no genderor age-related differences in the metabolic demands during the performance of domestic ADLs (7). Furthermore, there are no significant differences in age between patients with an obese, normal and low BMI. Therefore, the highest absolute task-related oxygen uptake and ventilation in the obese COPD group can not be explained by agerelated differences.

In our study we focused on BMI, but we did not have information on fat distribution. It would be interesting to investigate whether central versus peripheral obesity exert similar influence on the physiological response during performance of domestic ADLs.

Finally, the current findings need to be interpreted in the light of the number of comparisons that were made in the present study (34). Nonetheless, multiple findings in the same direction, rather than a single statistically significant result, suggest that these are not due to chance alone.

To conclude, despite the additional mechanical load of obesity, relative task-related oxygen uptake and ventilation, oxygen uptake per kilogram FFM and Borg symptom scores for dyspnea and fatigue were comparable between patients with low, normal, overweight and obese BMI. Therefore, patients in different BMI groups experience similar functional limitations in the performance of domestic ADLs. 


\section{REFERENCES}

1. Franssen FM, O'Donnell DE, Goossens GH, Blaak EE, Schols AM. Obesity and the lung: 5. Obesity and COPD. Thorax. 2008;63(12):1110-7.

2. Schols AM, Slangen J, Volovics L, Wouters EF. Weight loss is a reversible factor in the prognosis of chronic obstructive pulmonary disease. Am J Respir Crit Care Med. 1998;157(6 Pt 1):1791-7.

3. Monteiro F, Camillo CA, Vitorasso R, Sant'anna T, Hernandes NA, Probst VS, et al. Obesity and Physical Activity in the Daily Life of Patients with COPD. Lung. 2012;190(4):403-10.

4. Graat-Verboom L, Wouters EF, Smeenk FW, van den Borne BE, Lunde R, Spruit MA. Current status of research on osteoporosis in COPD: a systematic review. Eur Respir J. 2009;34(1):209-18.

5. Spruit MA, Watkins ML, Edwards LD, Vestbo J, Calverley PM, Pinto-Plata V, et al. Determinants of poor 6min walking distance in patients with COPD: the ECLIPSE cohort. Respir Med. 2010;104(6):849-57.

6. Pitta F, Troosters T, Spruit MA, Probst VS, Decramer M, Gosselink R. Characteristics of physical activities in daily life in chronic obstructive pulmonary disease. Am J Respir Crit Care Med. 2005;171(9):972-7.

7. Vaes AW, Wouters EF, Franssen FM, Uszko-Lencer NH, Stakenborg KH, Westra M, et al. Task-Related Oxygen Uptake During Domestic Activities of Daily Life in Patients With COPD and Healthy Elderly Subjects. Chest. 2011;140(4):970-9.

8. Watz H, Waschki B, Meyer T, Magnussen H. Physical activity in patients with COPD. Eur Respir J. 2009;33(2):262-72.

9. Annegarn J, Meijer K, Passos VL, Stute K, Wiechert J, Savelberg HH, et al. Problematic Activities of Daily Life are Weakly Associated With Clinical Characteristics in COPD. J Am Med Dir Assoc. 2012;13(3):28490.

10. Bautista J, Ehsan M, Normandin E, Zuwallack R, Lahiri B. Physiologic responses during the six minute walk test in obese and non-obese COPD patients. Respir Med. 2011;105(8):1189-94.

11. Sava F, Laviolette L, Bernard S, Breton MJ, Bourbeau J, Maltais F. The impact of obesity on walking and cycling performance and response to pulmonary rehabilitation in COPD. BMC Pulm Med. 2010;10:55.

12. Watz H, Waschki B, Kirsten A, Muller KC, Kretschmar G, Meyer T, et al. The metabolic syndrome in patients with chronic bronchitis and COPD: frequency and associated consequences for systemic inflammation and physical inactivity. Chest. 2009;136(4):1039-46.

13. Jeng C, Chang W, Wai PM, Chou CL. Comparison of oxygen consumption in performing daily activities between patients with chronic obstructive pulmonary disease and a healthy population. Heart Lung. 2003;32(2):121-30.

14. Spruit MA, Pennings HJ, Janssen PP, Does JD, Scroyen S, Akkermans MA, et al. Extra-pulmonary features in COPD patients entering rehabilitation after stratification for MRC dyspnea grade. Respir Med. 2007;101(12):2454-63.

15. Lahaije A, van Helvoort H, Dekhuijzen P, Heijdra Y. Physiologic limitations during daily life activities in COPD patients. Respir Med. 2010;104(8):1152-9.

16. Velloso M, Stella SG, Cendon S, Silva AC, Jardim JR. Metabolic and ventilatory parameters of four activities of daily living accomplished with arms in COPD patients. Chest. 2003;123(4):1047-53.

17. Spruit MA, Vanderhoven-Augustin I, Janssen PP, Wouters EF. Integration of pulmonary rehabilitation in COPD. Lancet. 2008;371(9606):12-3.

18. Spruit MA, Franssen FM, Rutten EP, Wagers SS, Wouters EF. Age-graded reductions in quadriceps muscle strength and peak aerobic capacity in COPD. Revista brasileira de fisioterapia (Sao Carlos (Sao Paulo, Brazil)). 2012;16(2):148-56.

19. Charlson ME, Pompei $P$, Ales KL, MacKenzie CR. A new method of classifying prognostic comorbidity in longitudinal studies: development and validation. J Chronic Dis. 1987;40(5):373-83.

20. Charlson M, Szatrowski TP, Peterson J, Gold J. Validation of a combined comorbidity index. J Clin Epidemiol. 1994;47(11):1245-51. 
21. Katz P, Chen H, Omachi TA, Gregorich SE, Julian L, Cisternas M, et al. The Role of Physical Inactivity in Increasing Disability Among Older Adults With Obstructive Airway Disease. J Cardiopulm Rehabil Prev. 2011;31(3):193-7.

22. Hannink JD, van Helvoort HA, Dekhuijzen PN, Heijdra YF. Dynamic hyperinflation during daily activities: does COPD global initiative for chronic obstructive lung disease stage matter? Chest. 2010;137(5):111621.

23. Spruit MA, Wouters EF, Eterman RM, Meijer K, Wagers SS, Stakenborg KH, et al. Task-related oxygen uptake and symptoms during activities of daily life in CHF patients and healthy subjects. Eur J Appl Physiol. 2011;111(8):1679-86.

24. Sillen MJ, Janssen PP, Akkermans MA, Wouters EF, Spruit MA. The metabolic response during resistance training and neuromuscular electrical stimulation (NMES) in patients with COPD, a pilot study. Respir Med. 2008;102(5):786-9.

25. Ofir D, Laveneziana P, Webb KA, O'Donnell DE. Ventilatory and perceptual responses to cycle exercise in obese women. J Appl Physiol. 2007;102(6):2217-26.

26. Ora J, Laveneziana P, Wadell K, Preston M, Webb KA, O’Donnell DE. Effect of obesity on respiratory mechanics during rest and exercise in COPD. J Appl Physiol. 2011;111(1):10-9.

27. Laviolette L, Sava F, O'Donnell DE, Webb KA, Hamilton AL, Kesten S, et al. Effect of obesity on constant workrate exercise in hyperinflated men with COPD. BMC Pulm Med. 2010;10:33.

28. Baarends EM, Schols AM, Mostert R, Wouters EF. Peak exercise response in relation to tissue depletion in patients with chronic obstructive pulmonary disease. Eur Respir J. 1997;10(12):2807-13.

29. Cecere LM, Littman AJ, Slatore CG, Udris EM, Bryson CL, Boyko EJ, et al. Obesity and COPD: Associated Symptoms, Health-related Quality of Life, and Medication Use. COPD. 2011;8(4):275-84

30. Guenette JA, Jensen D, O'Donnell DE. Respiratory function and the obesity paradox. Curr Opin Clin Nutr Metab Care. 2010;13(6):618-24.

31. Sandland CJ, Morgan MD, Singh SJ. Patterns of domestic activity and ambulatory oxygen usage in COPD. Chest. 2008;134(4):753-60.

32. O'Donnell DE, Revill SM, Webb KA. Dynamic hyperinflation and exercise intolerance in chronic obstructive pulmonary disease. Am J Respir Crit Care Med. 2001;164(5):770-7.

33. Steuten LM, Creutzberg EC, Vrijhoef HJ, Wouters EF. COPD as a multicomponent disease: inventory of dyspnoea, underweight, obesity and fat free mass depletion in primary care. Prim Care Respir J. 2006;15(2):84-91.

34. Perneger TV. What's wrong with Bonferroni adjustments. BMJ. 1998;316(7139):1236-8. 


\section{ONLINE SUPPLEMENT}

\section{METHODS}

The COPD patients who volunteered to participate in the present study were clinically stable (no exacerbation in past 4 weeks) and were on various (non-) pulmonary drug therapies (Table S1).

\section{RESULTS}

Domestic ADLs

Patients with COPD versus healthy elderly subjects

Duration of $A D L$-protocol

All subjects were able to complete ADL1 to ADL4 without stops during the performance of each ADL. COPD patients needed significantly more time to complete ADLs 1,3 , and 4 compared to healthy subjects ( $79 \pm 25$ vs. $63 \pm 13 s$; $72 \pm 19$ vs. $63 \pm 16 s$; and $104 \pm 31$ vs. $72 \pm 20$ s; all $p<0.001$ ). Time to complete ADL2 was comparable: $115 \pm 21$ vs. $125 \pm 28$ s.

Thirty COPD patients needed 20 to 145 s rest before they were able to start ADL5, and seven of them could not complete ADL5 due to exertional dyspnea.

Task-related oxygen uptake

Task-related oxygen uptake $(\mathrm{mL} / \mathrm{min})$ at the end of the 5 ADLs was similar between COPD patients and healthy subjects (Figure 1a). Consequently, patients performed the domestic ADLs at a significantly higher proportion of their peak aerobic capacity compared to the healthy subjects (Figure 1b). Moreover, COPD patients had a significantly higher task-related oxygen uptake per kilogram FFM compared to the healthy subjects (Figure S1a).

\section{Task-related ventilation}

Patients with COPD performed the domestic ADLs at a higher absolute ventilation (mean difference $(95 \% \mathrm{Cl})$ with healthy subjects for ADL1: 4.5 (1.7-7.2)L; ADL2: 6.0 (3.28.8)L; ADL3: 6.2 (3.3-9.1)L; ADL4: 7.5 (4.9-10.1)L; and ADL5: 8.2 (4.4-12.0)L; all $p<0.001$; Figure S1b). Moreover, patients had a significantly higher relative task-related ventilation compared to healthy elderly controls (mean difference $(95 \% \mathrm{Cl})$ for ADL1: 28.4 
(21.4-35.4)\%; ADL2: 31.6 (24.1-39.1)\%; ADL3: 33.5 (25.5-41.4)\%; ADL4: 33.5 (26.440.6)\%; and ADL5: 39.7 (30.0-49.4)\%; all p<0.001; Figure S1c).

Borg symptom scores

Patients with COPD reported significantly higher Borg symptom scores for dyspnea and fatigue and the end of each ADL compared to the healthy controls (Figure S1d and S1e).

COPD patients stratified by body mass index

Duration of ADL-protocol

All patients were able to complete ADL1 to ADL4 without stops, with no significant differences in time to complete the domestic tasks between BMI groups (Figure S2).

Thirty patients with COPD needed 20 to 145 s rest before they were able to start ADL5, while seven patients were not able to complete ADL5 due to exertional dyspnea. No differences were found between BMI groups.

BMI-related differences in data previous study (7)

Analysis on data of our previous study showed that absolute oxygen uptake and absolute ventilation after the performance of domestic ADLs is significantly lower in underweight COPD patients compared to overweight or obese COPD patients (7) (Figure S3a and S3b). Relative task-related oxygen uptake and ventilation were comparable between BMI groups (Figure S3c and S3d). 
Table S1. Pulmonary and non-pulmonary drugs

\begin{tabular}{|c|c|c|}
\hline & Name of drug & $\%$ of 94 COPD patients \\
\hline \multirow[t]{12}{*}{ Pulmonary drugs } & Short-acting beta2-agonists & 23.4 \\
\hline & Short-acting anticholinergics & 7.4 \\
\hline & Short-acting combinations & 27.7 \\
\hline & Long-acting beta2-agonists & 19.1 \\
\hline & Long-acting anticholinergics & 70.2 \\
\hline & Inhaled corticosteroids & 13.8 \\
\hline & Combination ICS and LABA & 74.5 \\
\hline & Theophylline & 16.0 \\
\hline & Fluimucil & 34.0 \\
\hline & Prednisone (maintenance) & 13.8 \\
\hline & Antibiotics & 5.3 \\
\hline & Singulair & 3.2 \\
\hline \multirow[t]{8}{*}{ Other drugs } & Antihypertensive agents & 27.7 \\
\hline & Diuretics & 17.0 \\
\hline & Anticoagulants & 23.4 \\
\hline & Cholesterol & 19.1 \\
\hline & Sedative/sleep medication & 23.4 \\
\hline & Stomach & 26.6 \\
\hline & Analgesic & 17.0 \\
\hline & Osteoporosis & 8.5 \\
\hline
\end{tabular}


a

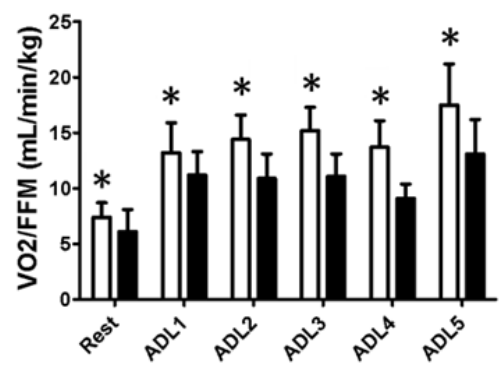

c

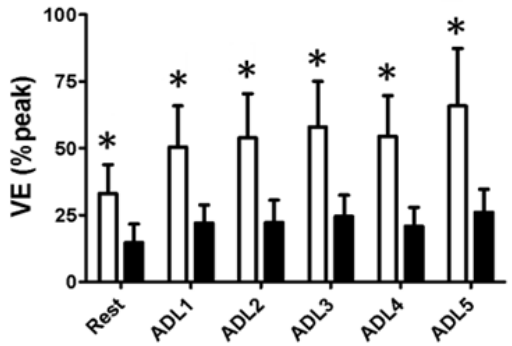

b

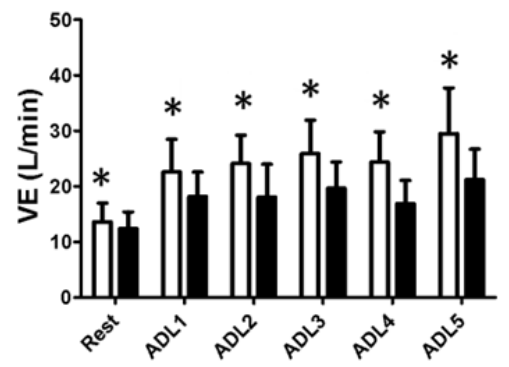

d

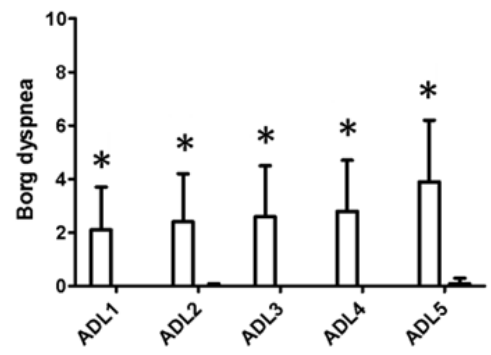

e

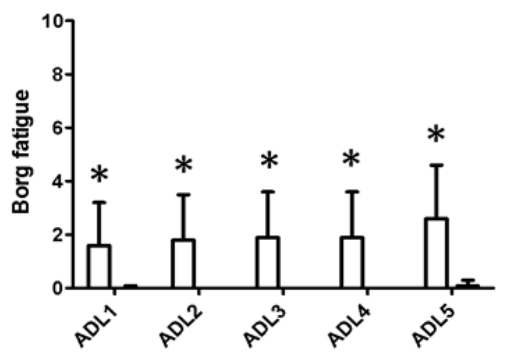

Figure S1. Results of patients with COPD (white) and healthy elderly subjects (black) after performance of 5 simple domestic activities of daily life

a) Task-related oxygen uptake per kilogram FFM (mL/min/kg FFM); b) Absolute task-related ventilation (L/min); c) Relative task-related ventilation (\%peakVE); d) Borg dyspnea scores (points); e) Borg fatigue scores (points)

${ }^{*} p<0.001$ COPD versus healthy elderly subjects 

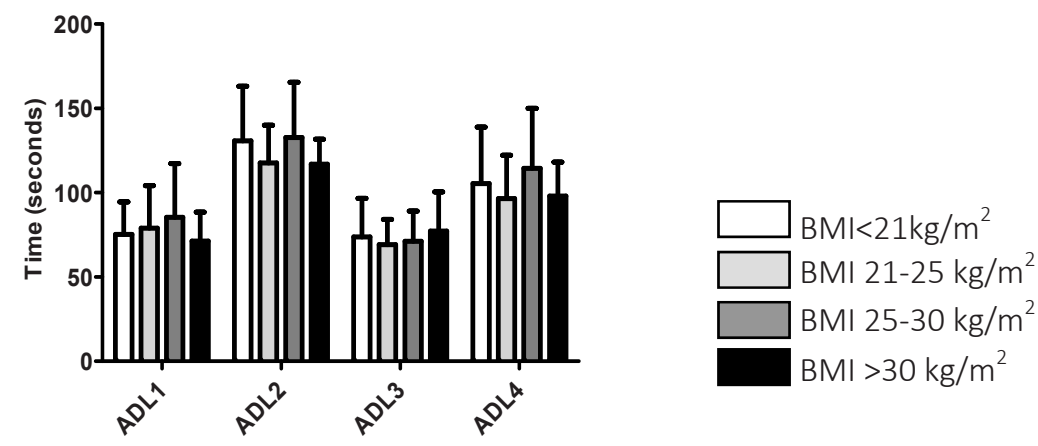

Figure S2. Time to accomplish ADLs

a

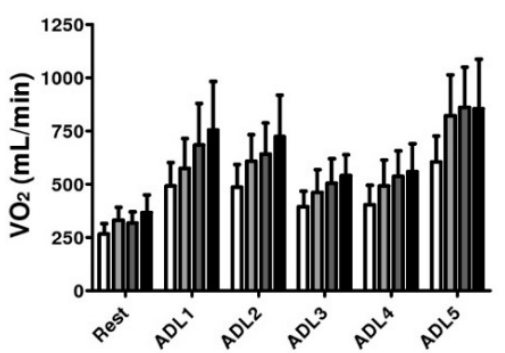

C
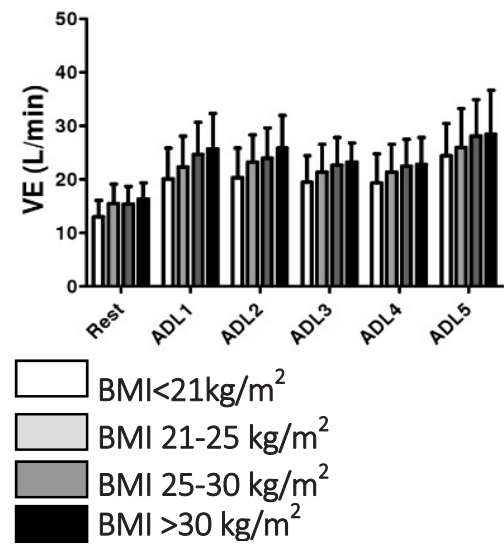

$\mathrm{BMI}<21 \mathrm{~kg} / \mathrm{m}^{2}$

BMI $21-25 \mathrm{~kg} / \mathrm{m}^{2}$

BMI $25-30 \mathrm{~kg} / \mathrm{m}^{2}$

$\mathrm{BMI}>30 \mathrm{~kg} / \mathrm{m}^{2}$ b

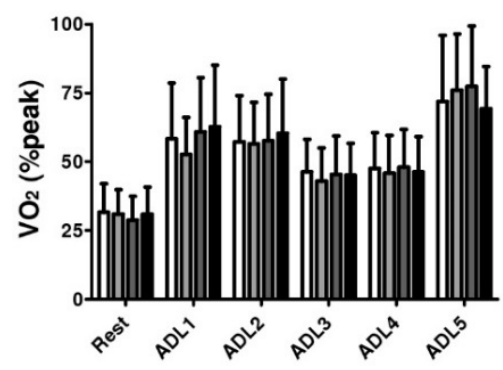

d

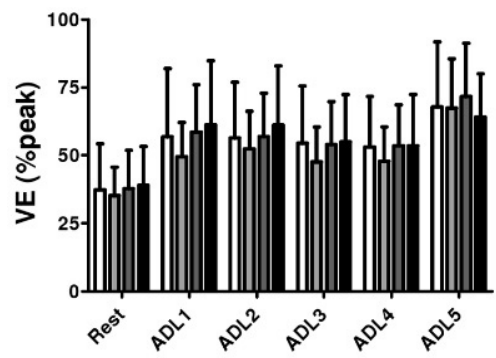

Figure S3. Results after performance of simple domestic activities of daily life in patients with COPD after stratification for BMI

a) Absolute task-related oxygen uptake ( $\mathrm{mL} / \mathrm{min}) ; \mathrm{BMI}>30 \mathrm{~kg} / \mathrm{m}^{2}$ was significantly higher compared to $\mathrm{BMI}<21$ $\mathrm{kg} / \mathrm{m}^{2}$ at rest and after all ADLs $(p<0.01)$ and compared to BMI $21-25 \mathrm{~kg} / \mathrm{m}^{2}$ for ADL 1 and 2 ( $\left.p<0.05\right)$. BMI 25$30 \mathrm{~kg} / \mathrm{m}^{2}$ was significantly higher compared to $\mathrm{BMl}<21 \mathrm{~kg} / \mathrm{m}^{2}$ at rest and after all ADLs ( $<<0.01$ ). BMI 21-25 $\mathrm{kg} / \mathrm{m}^{2}$ was significantly higher compared to $B M \mathrm{~K}<21 \mathrm{~kg} / \mathrm{m}^{2}$ at rest and after ADLs 2 and 5 ( $p<0.05$ ); b) Relative task-related oxygen uptake (\%peakVO 2$)$; c) Absolute task-related ventilation (L/min). BMl>30 kg/m² was significantly higher compared to $B M l<21 \mathrm{~kg} / \mathrm{m}^{2}$ at rest and after all $A D L s(p<0.05)$; d) Relative task-related ventilation (\%peakVE) 
Chapter 4

The effects of a 'new' walking aid on exercise performance in patients with COPD:

A randomized cross-over trial

Anouk W. Vaes, Janneke Annegarn, Kenneth Meijer, Martijn W. J. Cuijpers, Frits M.E. Franssen, Jozé Wiechert, Emiel F.M. Wouters, Martijn A. Spruit 


\section{ABSTRACT}

Background Generally, the use of a rollator improves mobility in patients with COPD. Nevertheless, not all patients benefit from its use and many patients feel embarrassed about its use. Therefore, other walking aids are worthwhile to consider. We compared the direct effects of a 'new' ambulation aid (a modern draisine) to a rollator on sixminute walk distance (6MWD) in COPD.

Methods 21 patients with COPD performed two 6-minute walk tests (6MWTs) during pre-rehabilitation assessment (best 6MWD: $369 \pm 88 \mathrm{~m}$ ). Additionally, two extra 6MWTs were performed on two consecutive days in random order: $1 \mathrm{x}$ with rollator and $1 \mathrm{x}$ with modern draisine. Walking pattern $(n=21)$ was determined using an accelerometer and metabolic requirements $(n=10)$ were assessed using a mobile oxycon.

Results Walking with the modern draisine resulted in a higher 6MWD compared to the

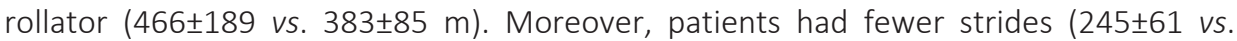
$300 \pm 49)$ and a greater stride length $(1.89 \pm 0.73$ vs. $1.27 \pm 0.14 \mathrm{~m})$ using the modern draisine compared to the rollator (all: $\mathrm{p} \leq 0.001$ ). Oxygen uptake, ventilation, heart rate, oxygen saturation and Borg symptom scores were comparable between both walking aids. Ten percent of the patients felt embarrassed using the modern draisine compared to $19 \%$ for rollator; while a significantly smaller proportion of patients would use the modern draisine in daily life.

Conclusion The mean difference in 6MWD between modern draisine and rollator seems clinically relevant, with the same metabolic requirements and symptom Borg scores. Therefore, this 'new' ambulation aid could be a good alternative for the rollator to improve functional exercise performance in patients with COPD. 


\section{INTRODUCTION}

Patients with chronic obstructive pulmonary disease (COPD) regularly experience walking as a problematic activity in everyday life(1). Indeed, patients walk less and at a lower intensity in daily life compared to their healthy peers(2). Moreover, patients with COPD have a severely reduced functional exercise capacity as assessed by the six-minute walk test (6MWT)(3-5), which contributes to a higher exacerbation-related hospitalization risk, a reduced quality of life and a worse prognosis(6).

Ambulation aids (i.e. rollators (Figure $1 \mathrm{~A})$ ) can contribute to independent living and safe mobility, although strength and metabolic demands can be excessive(7). The use of a rollator generally results in clinically relevant improvements in 6MWD of 22 to $46 \mathrm{~m}$ compared to an unaided 6MWD, particularly in sedentary COPD patients (8-11). This is at least in part due to an increase in maximal voluntary ventilation (MVV) of about $10 \%$ while using a rollator compared to no ambulation aid(10). Indeed, by bracing their arms on the rollator, patients with COPD can adopt the "forward-lean" position, which may improve diaphragm function and, therefore increase ventilatory capacity(12). This may also explain why rollator use is effective to relieve exercise-induced dyspnea in COPD patients with advanced disease $(13,14)$.

On average, a rollator is beneficial for patients with $\operatorname{COPD}(15)$. Yet, not all patients benefit from its use $(8,10,16)$. Moreover, $48 \%$ of the COPD patients using a rollator feels embarrassed about its use in daily life(17). Therefore, other ambulation aids may be worthwhile to consider in patients with COPD. Unfortunately, effects of unwheeled Zimmer frames on 6MWD are insignificant in elderly patients with $\operatorname{COPD}(16)$.

In 1817, Karl Drais invented the 'Laufmaschine', the earliest form of a bicycle, yet without pedals, later also called the velocipede or draisine(18). The modern version of the draisine (Figure 1B) may also improve 6MWD in COPD. Indeed, by holding the handlebars it will increase the MVV and in turn the 6MWD, similar to a rollator(10). Moreover, by sitting on the seat of the modern draisine the load on the deconditioned muscles of ambulation will be reduced(19). In turn, this may result in a significantly lower cost of transport (e.g., milliliters per minute $(\mathrm{mL} / \mathrm{min})$ of oxygen uptake per meter), allowing patients with COPD to achieve a higher 6MWD with similar effort.

To date, the direct effects of this 'new' ambulation aid on 6MWD remains unknown in patients with COPD. Prospectively, we sought to determine whether the modern draisine had similar direct effects on 6MWD as a rollator in patients with COPD. Moreover, we aimed to assess walking pattern, exercise-induced symptoms, metabolic requirements using both ambulation aids, and patient satisfaction. 


\section{METHODS}

\section{Design}

The study followed a prospective randomized cross-over design. Patients were eligible to participate when they were diagnosed with COPD, had a 6MWD $\leq 500 \mathrm{~m}$ (see below for details) and had no acute COPD exacerbation in the past four weeks. Patients suffering of musculoskeletal, cardiovascular or neurological disorder were excluded. All subjects gave written informed consent to participate in a study that was approved by the medical ethical committee of the Maastricht University Medical Centre (MEC 08-3-069). The current project has been registered on www.trialregister.nl (NTR1542) before enrolment of the first volunteering participant.

\section{Study protocol}

Patients were recruited by AWV and $\mathrm{MWJC}$ at $\mathrm{CIRO}+(20)$. During routine prerehabilitation assessment, pulmonary function and body composition were determined as described before(3). A symptom-limited cardiopulmonary exercise test (CPET) on a cycle ergometer (Ergoline 200P, Ergoline GmbH, Bitz, Germany) was used to determine peak aerobic capacity and was performed according to international guidelines(21). In addition, functional exercise performance was determined using the 6MWT as described by the latest ATS guidelines,(22) including a practice walk(23). Only patients with a $6 \mathrm{MWD}$ of $\leq 500 \mathrm{~m}$ were eligible to participate in the current study, as those patients are expected to benefit most from the use of ambulation aids(15).

Eligible patients were asked to perform two additional 6MWTs in a triangular walking course of 125 meters on two consecutive weekdays. Patients were randomly assigned, using sealed envelopes (made by MAS), to do a 6MWT with rollator on day one (Figure $1 \mathrm{~A})$ followed by a 6MWT with the modern draisine on day two (Figure 1B) or vice versa. See online supplement for specifications and settings of both ambulation aids.

All patients were familiarized with both ambulation aids through verbal instructions in combination with a practice session of ten minutes by MWJC. The familiarization procedure was set up in close collaboration with an experienced occupational therapist (JW). MWJC supervised all additional aided 6MWTs, which were also performed in accordance with ATS guidelines(22). At the end of the 6MWTs patients were asked to complete a questionnaire about the preference, confidence and safety of the ambulation aid. See online supplement for details. 
a

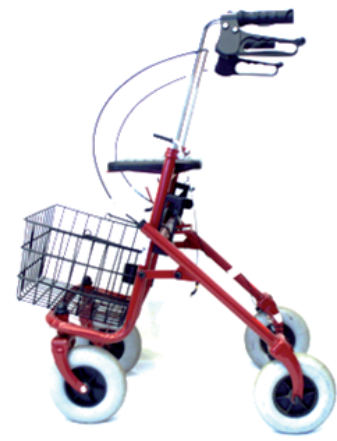

Rollator b

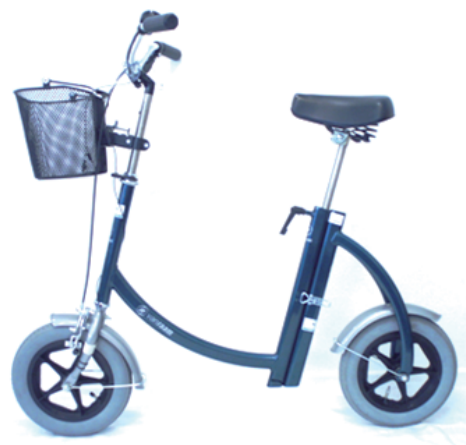

Modern draisine

Figure 1. Walking aids

\section{Outcomes}

Primary outcome was the difference in 6MWD (in meters, $\mathrm{m}$ ) between modern draisine and rollator. In addition, several explanatory outcomes were assessed: the number of assessor-initiated stops (based on an exercise induced oxygen saturation <80\%); transcutaneous oxygen saturation; heart rate; Borg symptom scores for dyspnea and fatigue(24) before and after each 6MWT and after 2 minutes of recovery; metabolic requirements during each $6 \mathrm{MWT}$; amount of strides; stride length; root mean square of the acceleration in mediolateral direction; walk ratio; and patient's preference and confidence of the ambulation aid. Please see online supplement for details.

\section{Statistics}

Data are presented as mean and standard deviation, unless noted otherwise. Pairedsamples t-test was used to assess differences between use of rollator and modern draisine. A priori, the level of significance was set at $\leq 0.05$. No adjustment was made to the statistical significance level for multiple comparisons. All data were analyzed with SPSS 17.0.

\section{RESULTS}

One-hundred fifteen of the 158 subjects that were screened between January 2009 and January 2011 were ineligible to participate due to various reasons (see Figure 2 for details). In addition, 15 eligible subjects declined participation because of disinterest, dyspnea or fatigue. Characteristics of these patients were not significantly different from those enrolled in this study. Of the remaining 28 eligible COPD patients seven 
were excluded (one before the performance of the two aided 6MWTs and 6 after the performance of the first aided 6MWT), because of the onset of symptoms of an acute COPD exacerbation $(n=4)$, orthopedic problems $(n=2)$ or malfunctioning of the measurement system that collected the gait pattern information $(n=1)$. Finally, 21 patients with COPD completed both aided 6MWTs.

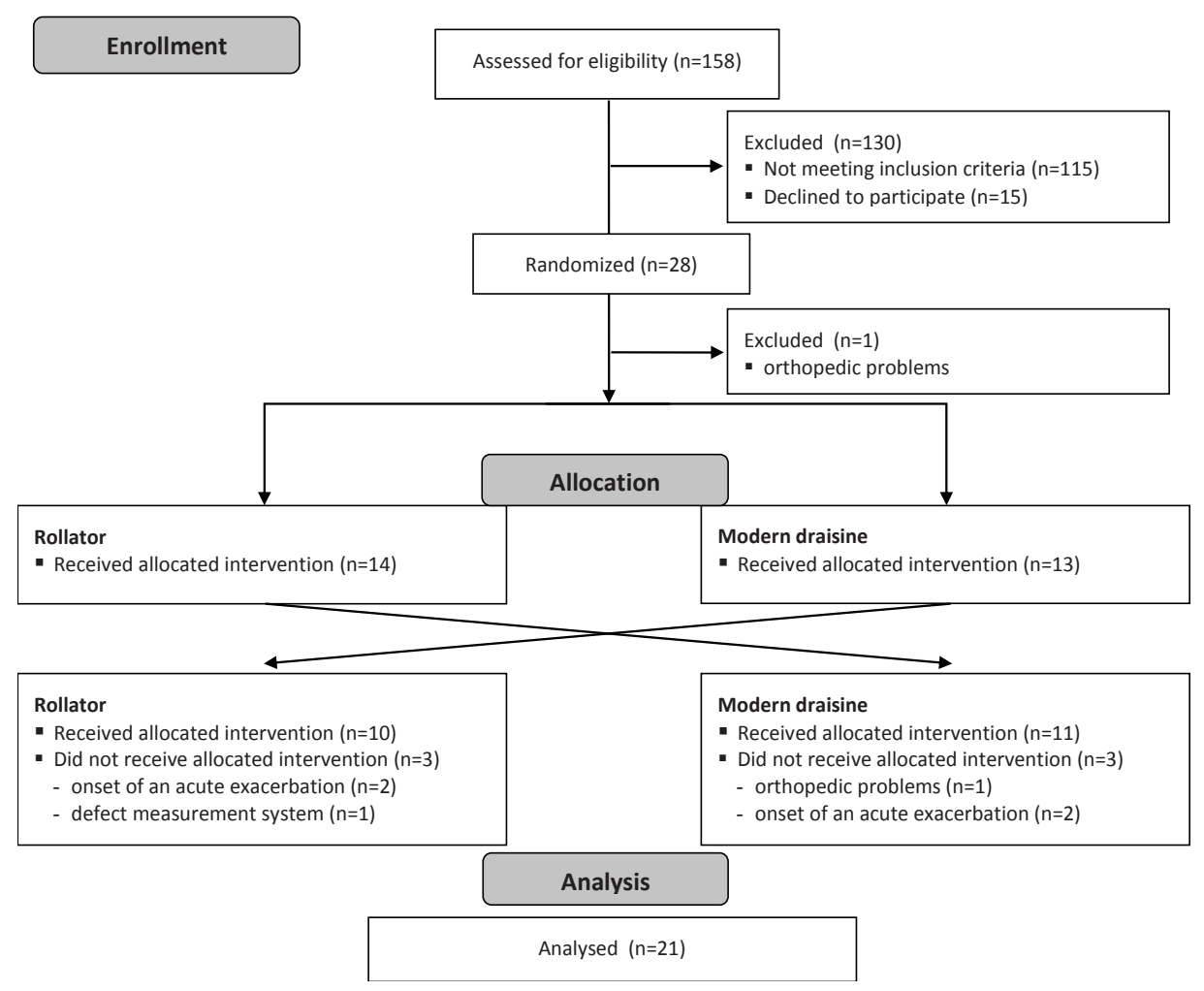

Figure 2. Disposition of patients

\section{Patient characteristics}

On average, patients had moderate to very severe COPD, a normal body mass index and a normal fat-free mass index (Table 1). Best 6MWD during routine pre-rehabilitation assessment was $369 \pm 88 \mathrm{~m}$. Eight patients (38\%) used a rollator during routine prerehabilitation 6MWTs, while 11 patients (52\%) used long-term oxygen therapy. Therefore, data of metabolic requirements were available in 10 patients with COPD. Patients receiving long-term oxygen therapy transported their oxygen in the basket of the rollator or the modern draisine. 
Table 1. Baseline characteristics $(n=21)$

\begin{tabular}{|c|c|}
\hline Characteristics & Value \\
\hline \multicolumn{2}{|l|}{ Demographics } \\
\hline Men (\%) & 52.4 \\
\hline Age (years) & $64.2(10.1)$ \\
\hline \multicolumn{2}{|l|}{ Pulmonary function } \\
\hline FEV1 (L) & $1.1(0.3)$ \\
\hline FEV1 (\% predicted) & $42.0(15.0)$ \\
\hline FEV1/FVC (\%) & $37.3(10.2)$ \\
\hline GOLD stage I/II/III/IV (n) & $0 / 3 / 9 / 9$ \\
\hline MRC grade $1 / 2 / 3 / 4 / 5(n)$ & $1 / 2 / 6 / 5 / 7$ \\
\hline \multicolumn{2}{|l|}{ Body composition } \\
\hline Body weight $(\mathrm{kg})^{*}$ & $66.0(19.0)$ \\
\hline Body mass index $\left(\mathrm{kg} / \mathrm{m}^{2}\right)$ & $23.5(5.3)$ \\
\hline $\mathrm{FFM}(\mathrm{kg})$ & $45.7(9.9)$ \\
\hline FFMI $\left(\mathrm{kg} / \mathrm{m}^{2}\right)$ & $16.3(2.2)$ \\
\hline 6MWD (m) & $369(88.0)$ \\
\hline Borg dyspnea (points) & $5.4(2.2)$ \\
\hline Borg fatigue (points) & $4.4(2.3)$ \\
\hline \multicolumn{2}{|c|}{ Cardiopulmonary exercise test } \\
\hline Peak $\mathrm{VO}_{2}(\mathrm{~mL} / \mathrm{min})$ & $902(284)$ \\
\hline Peak VO $\mathrm{O}_{2}(\mathrm{~mL} / \mathrm{min} / \mathrm{kg} \mathrm{BW})$ & $13.9(4.4)$ \\
\hline Peak VE (L) & $37.9(8.8)$ \\
\hline Peak VE (\% MVV) & $88.7(17.9)$ \\
\hline Peak HR (bpm) & $122.2(22.3)$ \\
\hline Peak HR (\% max HR) & $79.9(17.5)$ \\
\hline Borg dyspnea (points) & $7.1(1.8)$ \\
\hline Borg fatigue (points) & $5.9(2.4)$ \\
\hline
\end{tabular}

Results are presented as mean (standard deviation). $\mathrm{FEV}_{1}=$ forced expiratory volume in the first second; $\mathrm{L}=$ liter; $\mathrm{FVC}=$ forced vital capacity; $\mathrm{kg}=\mathrm{kilogram} ; \mathrm{kg} / \mathrm{m}^{2}=$ kilogram per squared meters; $\mathrm{VO}_{2}=$ oxygen uptake; $\mathrm{mL}=$ milliliter; $\mathrm{min}=$ minute; $\mathrm{BW}=$ body weight; $\mathrm{FFM=fat} \mathrm{free} \mathrm{mass;} \mathrm{VE}=$ =ventilation; $\mathrm{MVV}=$ maximum voluntary ventilation; $\mathrm{HR}=$ heart rate; $\mathrm{bpm}=$ beats per minute.

* 1 kilogram $=2.2046$ pounds

\section{Effects of ambulation aids on 6MWD}

On average, 6MWT with the modern draisine resulted in a significantly higher 6MWD compared to 6MWT with the rollator ( $466 \pm 189$ vs. $383 \pm 85 \mathrm{~m}, \mathrm{p}=0.011$; Table 2), with no significant differences between patients who already used a rollator before and those who walked unaided (Figure 3). 
Table 2. Effects of the ambulation aids $(n=21)$

\begin{tabular}{|c|c|c|c|}
\hline & Rollator & Modern draisine & $\mathrm{p}$ value \\
\hline $6 \mathrm{MWD}(\mathrm{m})$ & $382.8(84.7)$ & $465.9(188.5)$ & 0.011 \\
\hline Strides (n) & $300.3(49.1)$ & $245.3(60.9)$ & 0.001 \\
\hline Stride length (m) & $1.27(0.14)$ & $1.89(0.73)$ & 0.001 \\
\hline Stride frequency (strides/s) & $0.88(0.11)$ & $0.76(0.14)$ & 0.001 \\
\hline Number of stops (n) & $0.50(0.68)$ & $0.62(0.86)$ & 0.186 \\
\hline Total duration of stops (s) & $20.5(29.9)$ & $25.9(35.0)$ & 0.297 \\
\hline Walk ratio $\left(\mathrm{m} /\left(\right.\right.$ steps $\left.^{-1} \mathrm{~s}^{-1}\right)$ & $1.46(0.22)$ & $2.36(1.04)$ & 0.001 \\
\hline Acceleration RMS & $0.19(0.07)$ & $0.10(0.03)$ & 0.001 \\
\hline Borg dyspnea before (points) & $2.0(1.5)$ & $1.7(1.2)$ & 0.351 \\
\hline Borg dyspnea after (points) & $4.9(1.8)$ & $5.1(1.3)$ & 0.620 \\
\hline Borg dyspnea 2 minutes after (points) & $3.0(1.2)$ & $3.3(1.5)$ & 0.377 \\
\hline Borg fatigue before (points) & $1.9(1.8)$ & $1.4(1.4)$ & 0.154 \\
\hline Borg fatigue after (points) & $3.6(2.4)$ & $3.9(2.3)$ & 0.543 \\
\hline Borg fatigue 2 minutes after (points) & $2.7(2.0)$ & $2.4(1.7)$ & 0.342 \\
\hline $\mathrm{spO}_{2}$ before $(\%)$ & $93.4(2.0)$ & $93.4(2.2)$ & 1.000 \\
\hline $\mathrm{spO}_{2}$-drop (\%) & $-8.0(4.0)$ & $-8.1(5.2)$ & 0.950 \\
\hline $\mathrm{spO}_{2} 2$ minutes after (\%) & $94.2(2.1)$ & $94.1(1.8)$ & 0.729 \\
\hline
\end{tabular}

Results are presented as mean (standard deviation). 6MWD=six minute walking distance; $m=m e t e r ; s=s e c o n d ;$ RMS=root mean square

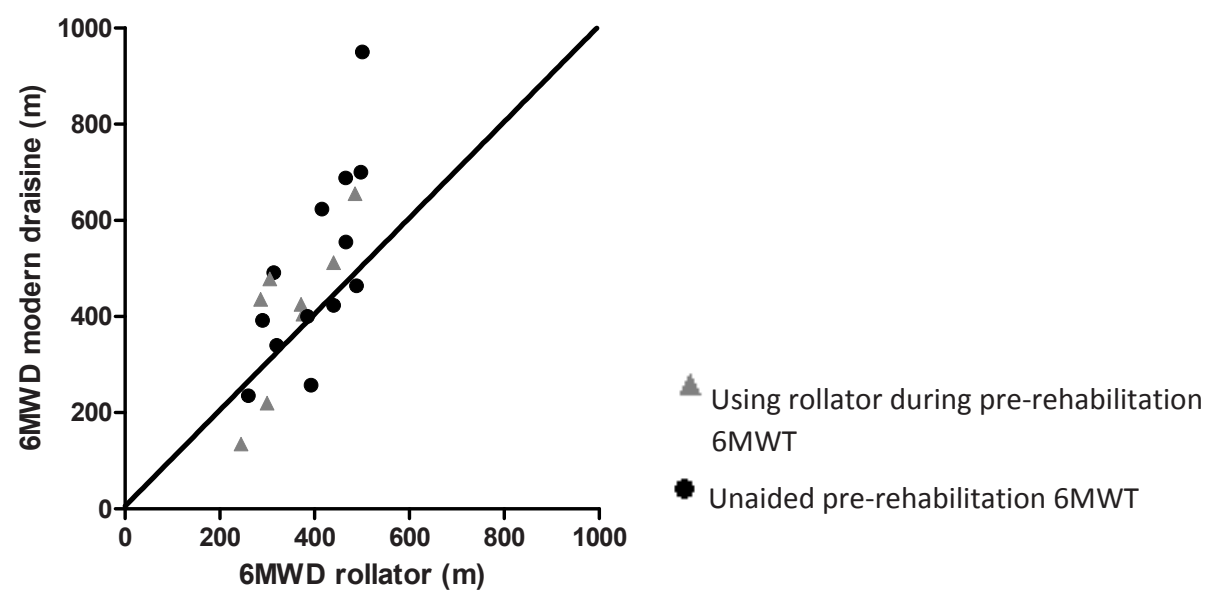

Figure 3. 6MWD in patients with COPD using rollator vs. modern draisine $6 M W D=6-$ minute walking distance in meters 
COPD patients who did not use a rollator at baseline had a baseline 6MWD of $384 \pm 90$ $\mathrm{m}$. Use of a rollator resulted in a significantly higher 6MWD compared to baseline $(402 \pm 83 \mathrm{~m} ; \mathrm{p}=0.040)$. Moreover, using the modern draisine resulted in a mean 6MWD of $501 \pm 200 \mathrm{~m}$, which is significantly higher compared to baseline 6MWD $(p=0.024)$ and also compared to rollator-aided 6MWD ( $p=0.038)$.

\section{Effects of ambulation aids on exercise-induced symptoms}

No significant differences were found between 6MWT with rollator or modern draisine in Borg symptom scores for dyspnea and fatigue at start of 6MWT, at the end of 6MWT and after 2 minutes recovery (Table 2). Moreover, number and duration of patientinitiated stops was comparable between both ambulation aids (Table 2). The main reason for patient-related stops was dyspnea. Other reasons were fatigue and/or pain in shoulders/arms, foot, os sacrum or lower back. There were no assessor-initiated stops.

\section{Effects of ambulation aids on 6MWD walking pattern}

The use of the modern draisine resulted in significantly fewer strides compared to the rollator ( $245 \pm 61$ vs. $300 \pm 49 ; p=0.001$ ). Consequently, patients had a significantly lower stride frequency and a greater stride length with the modern draisine compared to the rollator ( $p=0.001$, Table 2 ). Moreover, the walk ratio was significantly higher and the root mean square in mediolateral direction was significantly lower while using the modern draisine compared to the rollator $(p=0.001)$.

\section{Effects of ambulation aids on metabolic requirements}

Oxygen uptake, ventilation, heart rate and oxygen saturation before and directly after the 6MWT were comparable between ambulation devices, as well as after two minutes recovery (Table 3). Because of the higher walking distance, use of the modern draisine resulted in a significantly lower cost of transport (oxygen uptake per meter) compared to use of the rollator $(0.10(0.03)$ vs. $0.14(0.03) \mathrm{mL} / \mathrm{min} / \mathrm{m} ; \mathrm{p}<0.05)$. 
Table 3. Metabolic requirements during the 6MWTs $(n=10)$

\begin{tabular}{|c|c|c|c|}
\hline & Rollator & Modern draisine & $p$ value \\
\hline $\mathrm{VO}_{2}$ before $(\mathrm{mL} / \mathrm{min})$ & $304.7(41.2)$ & 314.5 (32.0) & 0.308 \\
\hline $\mathrm{VO}_{2}$ before $\left(\% \mathrm{VO}_{2} \max \right)$ & $30.3(9.0)$ & $31.4(9.7)$ & 0.241 \\
\hline $\mathrm{VO}_{2}$ at the end of $6 \mathrm{MWT}(\mathrm{mL} / \mathrm{min})$ & $946.4(159.5)$ & $888.9(173.8)$ & 0.600 \\
\hline $\mathrm{VO}_{2}$ at the end of $6 \mathrm{MWT}\left(\% \mathrm{VO}_{2} \max \right)$ & $93.6(26.9)$ & $90.8(22.7)$ & 0.444 \\
\hline $\mathrm{VO}_{2} 2$ minutes after $(\mathrm{mL} / \mathrm{min})$ & $437.7(88.1)$ & $458.1(135.0)$ & 0.546 \\
\hline $\mathrm{VO}_{2} 2$ minutes after $\left(\% \mathrm{VO}_{2} \max \right)$ & $43.8(16.0)$ & $48.4(19.5)$ & 0.302 \\
\hline VE before (L/min) & $14.8(2.9)$ & $14.2(2.5)$ & 0.325 \\
\hline VE before (\%VE-max) & $38.4(14.9)$ & $37.0(13.9)$ & 0.311 \\
\hline VE at the end of $6 \mathrm{MWT}(\mathrm{L} / \mathrm{min})$ & $34.8(6.4)$ & $35.3(8.2)$ & 0.739 \\
\hline VE at the end of 6MWT (\%VE-max) & $89.4(24.1)$ & $89.6(22.8)$ & 0.951 \\
\hline VE 2 minutes after (L/min) & $20.3(4.6)$ & $21.0(7.3)$ & 0.591 \\
\hline VE 2 minutes after (\%VE-max) & $53.1(21.9)$ & $55.1(26.6)$ & 0.521 \\
\hline HR before (bpm) & $84.6(10.6)$ & $85.7(12.2)$ & 0.459 \\
\hline HR before (\%HR-max) & $70.2(12.2)$ & $71.1(12.6)$ & 0.472 \\
\hline HR at the end of 6MWT (bpm) & $107.5(12.2)$ & $110.4(14.3)$ & 0.341 \\
\hline HR at the end of 6MWT (\%HR-max) & $90.1(10.8)$ & $92.1(12.2)$ & 0.290 \\
\hline HR 2 minutes after (bpm) & $90.1(12.9)$ & $97.8(9.9)$ & 0.128 \\
\hline HR 2 minutes after (\%HR-max) & $75.5(12.8)$ & $81.8(11.2)$ & 0.109 \\
\hline
\end{tabular}

Results are presented as mean (standard deviation).

$\mathrm{VO}_{2}=$ oxygen uptake; $\mathrm{mL}=$ milliliter; $\mathrm{min}=$ minute; $\mathrm{VE}=$ ventilation; $\mathrm{L}=$ liter; $\mathrm{HR}=$ heart rate; $\mathrm{bpm}=$ beats per minute

\section{Level of acceptance with use of ambulation aids}

Sixty-two percent of the COPD patients had never used a rollator before in daily life or during $6 \mathrm{MWT}$, but $81 \%$ liked the rollator and $76 \%$ would use it in daily life. Nineteen percent of the COPD patients felt embarrassed using the rollator (Table 4).

None of the patients had ever used the modern draisine. Although only ten percent of the subjects felt embarrassed using modern draisine, significantly fewer patients (38\%) would like to use the new ambulation aid in their daily life compared to a rollator $(p<0.05)$. Furthermore, significantly more patients believed to walk further than an unaided 6MWT while using rollator compared to the modern draisine $(p<0.01)$.

COPD patients gave significantly higher scores for stability and solidity of the rollator compared to the modern draisine $(p<0.05)$. Moreover, the feeling of falling was significantly lower while using the rollator $(p<0.05)$. No significant differences were found in scores for safety and confidence between rollator and modern draisine. 
Table 4. Data from questionnaire

\begin{tabular}{|c|c|c|}
\hline & Rollator $(n=21)$ & Modern draisine $(n=21)$ \\
\hline Used before in daily life? & 8 & $0^{+}$ \\
\hline Used before during 6MWT? & 8 & $\mathrm{O}^{+}$ \\
\hline Did you like the ambulation aid? & 17 & 13 \\
\hline If not, why not? & $\begin{array}{l}\text { Pain in arms (2) } \\
\text { Emotionally uncomfortable (1) } \\
\text { Can easily do without (1) }\end{array}$ & $\begin{array}{l}\text { Balance problems ( } 4 \text { ) } \\
\text { Problems with placing oxygen tank } \\
\text { (1) } \\
\text { Too heavy (1) } \\
\text { Problems with seat (1) } \\
\text { No reason (1) }\end{array}$ \\
\hline $\begin{array}{l}\text { Could you walk further with the } \\
\text { ambulation aid compared to an unaided } \\
\text { 6MWT? }\end{array}$ & 20 & $13+$ \\
\hline If you walk further, why? & $\begin{array}{l}\text { Less dyspnoea (6) } \\
\text { Safer (2) } \\
\text { More stable ( } 7 \text { ) } \\
\text { Less dyspnoea \& more stable ( } 2 \text { ) } \\
\text { Less leg fatigue (1) } \\
\text { No reason (2) }\end{array}$ & $\begin{array}{l}\text { Less dyspnoea ( } 6 \text { ) } \\
\text { More stable ( } 2 \text { ) } \\
\text { Less dyspnoea \& more stable ( } 2 \text { ) } \\
\text { Less exhausting ( } 2 \text { ) } \\
\text { Faster (1) }\end{array}$ \\
\hline $\begin{array}{l}\text { Were you ashamed using the } \\
\text { ambulation aid? }\end{array}$ & 4 & 2 \\
\hline If you were ashamed, why? & $\begin{array}{l}\text { Too young ( } 3 \text { ) } \\
\text { Illness is visible (1) }\end{array}$ & $\begin{array}{l}\text { Acceptance ambulation aid (1) } \\
\text { Other aids are more convenient (1) }\end{array}$ \\
\hline Would you use it in daily life? & 16 & $8+$ \\
\hline I felt safe while using the aid* & $83.5(21.8)$ & $75.8(19.6)$ \\
\hline I felt like I could fall while using the aid* & $13.1(24.7)$ & $36.6(33.1)^{\dagger}$ \\
\hline I felt stable while using the aid\# & $88.9(18.2)$ & $63.4(27.9) \dagger$ \\
\hline I think this is a solid ambulation aid* & $93.7(8.7)$ & $68.8(32.8)^{\dagger}$ \\
\hline $\begin{array}{l}\text { I had confidence in the aid during the } \\
6 \mathrm{MWT}^{*}\end{array}$ & $89.6(15.1)$ & $73.4(33.9)$ \\
\hline
\end{tabular}

Numbers indicates positive answers; *VAS-score $(\mathrm{mm}) ; \uparrow p<0.05$ vs. rollator

\section{DISCUSSION}

The present study has three important findings. First, ambulation aids generally improve functional exercise performance in patients with COPD. Second, the use of the modern draisine may result in clinically relevant improvements in 6MWD in patients with COPD as compared to a rollator aided 6MWT, while the metabolic requirements and exercise-related symptoms are comparable. Third, clear differences in gait pattern were observed between the modern draisine aided 6MWT and the rollator aided 
$6 \mathrm{MWT}$, resulting in a lower cost of transport for the modern draisine compared to the rollator. This partially explains the difference in 6MWD.

Previous studies have already shown that the use of a rollator during 6MWT is associated with a significant improvement in walking distance of 22 to $46 \mathrm{~m}(8-10,25)$. This study is the first to compare the effects of a rollator on 6MWD with those of a 'new' walking aid in patients with COPD. The mean difference in 6MWD between the modern draisine and the rollator clearly exceeded the upper limit of the 95\% confidence interval (61 $\mathrm{m}$ ) of the updated minimal clinically important difference of 6MWD as proposed by Holland et al(11). Indeed, occupational therapists may want to consider the use of the modern draisine to augment the mean improvement in 6MWD of $50 \mathrm{~m}$ following exercise-based pulmonary rehabilitation(20).

None of the COPD patients had used the modern draisine before. Therefore, all patients had a practice walk of ten minutes with each ambulation aid. This may be too short for proper familiarizing. Some patients reported to have problems with their balance during the extra 6MWTs. Indeed, six subjects walked 17 to $135 \mathrm{~m}$ less with the modern draisine compared to the rollator aided 6MWT (Figure 3). Then again, one patient had pain in the os sacrum due to an accidental fall one day before the draisine aided 6MWT, which made sitting on the seat of the draisine painful; and another patient bumped her foot to the bike resulting in pain during the 6MWT. Because the rollator and the modern draisine were adapted to the size of the patients (see online supplement), balance problems were not caused by incorrect adjustment of the ambulation aids. However, a rollator is a stable ambulation aid, while the modern draisine needs active support of the user to remain stable and to avoid falling. Therefore, a 6MWT with the modern draisine could result in a feeling of lower safety in terms of balance and falling. This may improve when patients are able to practice more frequent or for a longer period (more than ten minutes).

Previously, Probst and colleagues investigated the direct effects of the use of a rollator on metabolic requirements in patients with COPD. They found an average oxygen uptake of $1.0 \mathrm{~L} / \mathrm{min}$ and a ventilation of $34 \mathrm{~L} / \mathrm{min}$ in patients during a rollator aided 6MWT(10). This is very consistent with our results. Indeed, walking with rollator resulted in a mean oxygen uptake of $0.9 \mathrm{~L} / \mathrm{min}$ and a mean ventilation of $34.8 \mathrm{~L} / \mathrm{min}$ compared to a mean oxygen uptake of $0.9 \mathrm{~L} / \mathrm{min}$ and a mean ventilation of $35.3 \mathrm{~L} / \mathrm{min}$ when walking with the modern draisine. Differences in overall metabolic requirements between the two ambulation aids were not significant. However, while using the modern draisine patients with COPD walked on average $83 \mathrm{~m}$ further with the same oxygen uptake, ventilation, and heart rate compared to walking with a rollator (Table 2 and 3 ). Therefore, the use of the modern draisine resulted in a greater walking distance with 
the same energy use and metabolic demands in patients with COPD, which could be considered as an improvement in walking economy.

One of the main advantages of the modern draisine is the possibility to sit on the seat of the modern draisine, resulting in a lower load for the muscles of ambulation. This could at least partially explain why patients with COPD are able to walk further with the same metabolic demands. Furthermore, the modern draisine is foldable and lightweight (modern draisine: $9.0 \mathrm{~kg}$ compared to rollator: $12.4 \mathrm{~kg}$ ), which makes it easy for everyday use. Similar to the rollator, the modern draisine has a basket, which gives patients with long-term oxygen therapy the ability to transport their oxygen. The major disadvantage of the modern draisine compared to a rollator is the higher cost, which is fivefold the cost of a rollator.

In the present study, patients with COPD had a higher velocity while walking with modern draisine compared to walking with rollator. Several studies have shown that ratio between stride length and stride frequency is constant over a large range of walking speeds during normal walking in healthy subjects $(26,27)$. However, we found a significant higher walk ratio in patients while using the modern draisine. This altered pattern indicates that COPD patients using the modern draisine walked with a greater stride length relative to stride frequency, probably caused by the natural tendency to slightly roll between steps while using the modern draisine. Moreover, accelerations in mediolateral direction were significantly lower using the modern draisine compared to using a rollator, which indicates a walking pattern with smaller lateral displacement. This is inconsistent with findings of Menz and colleagues who previously reported that accelerations in mediolateral direction appear to increase as walking speed increases(28). However, patients with COPD were able to sit on the seat of the modern draisine, probably resulting in a more fixed center of gravity and a reduced lateral displacement. Therefore, the 'new' ambulation aid could result in a more effective walking pattern in patients with COPD, compared to walking with the rollator.

Hill et al. showed that the use of a rollator seems well-tolerated in everyday life of patients with COPD(17). COPD patients mostly use their rollator for outdoor activities, like walking, shopping or recreational pursuits $(17,25)$. Even though a rollator appears to be beneficial for patients with COPD, $48 \%$ of the COPD patients using a rollator feel embarrassed about its use in daily life(17). In our study only 19\% of the COPD patients felt embarrassed using the rollator, because of 'a visual indication of disability and aging', compared to only $10 \%$ using the modern draisine. Still, only $38 \%$ of the patients would use the new ambulation aid in their daily life. Whether patients' satisfaction with their walking aid may improve after they have used it for a longer period(29) remains unknown. 
Several methodological limitations need to be addressed. For obvious reasons, it was not possible to blind patients or outcome assessor to the interventions. Furthermore, due to the portable metabolic system we were not able to measure patients with longterm oxygen therapy. Therefore, data from oxygen uptake, ventilation and heart rate during the 6MWTs were only available in ten patients with COPD.

Previously, unaided 6MWD cut offs of 300 to $400 \mathrm{~m}$ have been suggested to identify patients with COPD who may benefit from a rollator $(8,10)$. Nevertheless, the current trial is the first to study the effects of the draisine in patients with COPD. Therefore, we decided to set a baseline 6MWD of $500 \mathrm{~m}$ as upper limit for inclusion. In fact, seven of nine patients with a baseline 6MWD $>400 \mathrm{~m}$ walked further with the draisine compared to the rollator (Figure 3).

In this study, the 6MWTs were conducted indoors on a flat surface. Indeed, it can be questioned if the modern draisine can be used indoors. Earlier studies showed that a rollator is often used for outside activities $(17,25)$. Moreover, patients with COPD frequently reported outdoor walking as a problematic activity of daily life(30). Therefore, future studies are needed to compare the effects of modern draisine with the rollator during outdoor walking, using a self-paced walking test(31). Because of the larger wheel size the benefits of the modern draisine may even better emerge when used outdoors. This may also show that patients are able to walk at similar speed but for a longer period while using a modern draisine.

The use of walking aids can result in clinically relevant increases in 6MWD in patients with COPD (Table 2), which may improve their everyday mobility. Then again, the observed increase in 6MWD due to the use of ambulation aids can only be considered as an increase in functional exercise performance; it cannot be considered as a real improvement in functional exercise capacity (e.g., as seen for example after pulmonary rehabilitation) (32).

The proportion of patients with feelings of embarrassment about the use of ambulation aids was rather low (Table 4). This may be due to the fact that the tests were performed in a clinical context. Numbers most probably increase when the tested walking aids are used in daily life(17). The questionnaire used to assess patients' satisfaction was not validated. Future trials should consider to use the Quebec User Evaluation of Satisfaction with Assistive Technology(33).

Finally, the current findings need to be interpreted in the light of the number of comparisons that were made in the present study. Nonetheless, multiple findings in the same direction, rather than a single statistically significant result, suggest that these are not due to chance alone. Moreover, 'Bonferroni adjustments are at best, unnecessary and, at worst, deleterious to sound statistical inference'(34).

Because of the improvement in walking economy, the modern draisine may also be considered to facilitate early mobilization during and following exacerbation-related hospital admissions. Indeed, a combination of early walking with ambulation aids and short-term exercise therapy have been shown to result in positive outcomes in patients 
with COPD and may complement outcomes achieved through early pulmonary rehabilitation programs and reduce hospitalization(35). This warrants further investigation.

In conclusion, the present study shows that the use of the modern draisine can improve functional exercise performance in patients with COPD. Therefore, this new ambulation aid may be a good alternative for rollator in patients with COPD. Nevertheless, the choice of ambulation aid should be based upon an exercise field test and the degree of acceptance by the patient with COPD. 


\section{RERERENCES}

1. Annegarn J, Meijer K, Passos VL, Stute K, Wiechert J, Savelberg HH, et al. Problematic activities of daily life are weakly associated with clinical characteristics in COPD. J Am Med Dir Assoc. 2012;13(3):284-90.

2. Pitta F, Troosters T, Spruit MA, Probst VS, Decramer M, Gosselink R. Characteristics of physical activities in daily life in chronic obstructive pulmonary disease. Am J Respir Crit Care Med. 2005;171(9):972-7.

3. Spruit MA, Pennings HJ, Janssen PP, Does JD, Scroyen S, Akkermans MA, et al. Extra-pulmonary features in COPD patients entering rehabilitation after stratification for MRC dyspnea grade. Respir Med. 2007;101(12):2454-63.

4. Troosters T, Gosselink R, Decramer M. Six minute walking distance in healthy elderly subjects. Eur Respir J. 1999;14(2):270-4.

5. Spruit MA, Watkins ML, Edwards LD, Vestbo J, Calverley PM, Pinto-Plata V, et al. Determinants of poor 6min walking distance in patients with COPD: the ECLIPSE cohort. Respir Med. 2010;104(6):849-57.

6. Spruit MA, Polkey MI, Celli B, Edwards LD, Watkins ML, Pinto-Plata V, et al. Predicting outcomes from 6minute walk distance in chronic obstructive pulmonary disease. J Am Med Dir Assoc. 2012;13(3):291-7.

7. Bateni H, Maki BE. Assistive devices for balance and mobility: benefits, demands, and adverse consequences. Arch Phys Med Rehabil. 2005;86(1):134-45.

8. Solway S, Brooks D, Lau L, Goldstein R. The short-term effect of a rollator on functional exercise capacity among individuals with severe COPD. Chest. 2002;122(1):56-65.

9. Gupta R, Goldstein R, Brooks D. The acute effects of a rollator in individuals with COPD. J Cardiopulm Rehabil. 2006;26(2):107-11.

10. Probst VS, Troosters T, Coosemans I, Spruit MA, Pitta Fde O, Decramer M, et al. Mechanisms of improvement in exercise capacity using a rollator in patients with COPD. Chest. 2004;126(4):1102-7.

11. Holland AE, Hill CJ, Rasekaba T, Lee A, Naughton MT, McDonald CF. Updating the minimal important difference for six-minute walk distance in patients with chronic obstructive pulmonary disease. Arch Phys Med Rehabil. 2010;91(2):221-5.

12. Sharp JT, Drutz WS, Moisan T, Foster J, Machnach W. Postural relief of dyspnea in severe chronic obstructive pulmonary disease. Am Rev Respir Dis. 1980;122(2):201-11.

13. Crisafulli E, Costi S, De Blasio F, Biscione G, Americi F, Penza S, et al. Effects of a walking aid in COPD patients receiving oxygen therapy. Chest. 2007;131(4):1068-74.

14. Bausewein C, Booth S, Gysels M, Higginson I. Non-pharmacological interventions for breathlessness in advanced stages of malignant and non-malignant diseases. Cochrane Database Syst Rev. 2008(2):CD005623.

15. Spruit MA, Mercken EM, Wouters EFM, Schols AMWJ. Role of exercise testing in defining response to interventions in copd patients. European Respiratory Monograph2007. p. 208-20.

16. Roomi J, Yohannes AM, Connolly MJ. The effect of walking aids on exercise capacity and oxygenation in elderly patients with chronic obstructive pulmonary disease. Age Ageing. 1998;27(6):703-6.

17. Hill K, Goldstein R, Gartner EJ, Brooks D. Daily utility and satisfaction with rollators among persons with chronic obstructive pulmonary disease. Arch Phys Med Rehabil. 2008;89(6):1108-13.

18. Wikipedia. http://en.wikipedia.org/wiki/Draisine. [updated 9 March 2011 cited 201115 March]

19. Gosselink R, Decramer M. Peripheral skeletal muscles and exercise performance in patients with chronic obstructive pulmonary disease. Monaldi Arch Chest Dis. 1998;53(4):419-23.

20. Spruit MA, Vanderhoven-Augustin I, Janssen PP, Wouters EF. Integration of pulmonary rehabilitation in COPD. Lancet. 2008;371(9606):12-3.

21. ATS/ACCP Statement on cardiopulmonary exercise testing. Am J Respir Crit Care Med. 2003;167(2):21177.

22. ATS statement: guidelines for the six-minute walk test. Am J Respir Crit Care Med. 2002;166(1):111-7.

23. Hernandes NA, Wouters EF, Meijer K, Annegarn J, Pitta F, Spruit MA. Reproducibility of 6-minute walking test in patients with COPD. Eur Respir J. 2011;38(2):261-7.

24. Borg GA. Psychophysical bases of perceived exertion. Med Sci Sports Exerc. 1982;14(5):377-81. 
25. Gupta RB, Brooks D, Lacasse Y, Goldstein RS. Effect of rollator use on health-related quality of life in individuals with COPD. Chest. 2006;130(4):1089-95.

26. Nagasaki $H$, Itoh $H$, Hashizume $K$, Furuna $T$, Maruyama $H$, Kinugasa $T$. Walking patterns and finger rhythm of older adults. Percept Mot Skills. 1996;82(2):435-47.

27. Terrier P, Schutz Y. Variability of gait patterns during unconstrained walking assessed by satellite positioning (GPS). Eur J Appl Physiol. 2003;90(5-6):554-61.

28. Menz HB, Lord SR, Fitzpatrick RC. Acceleration patterns of the head and pelvis when walking on level and irregular surfaces. Gait Posture. 2003;18(1):35-46.

29. Brandt A, Iwarsson S, Stahl A. Satisfaction with rollators among community-living users: a follow-up study. Disabil Rehabil. 2003;25(7):343-53.

30. Vaes AW, Wouters EFM, Franssen FME, Uszko-Lencer NHMK, Stakenborg KHP, Westra M, et al. Taskrelated oxygen uptake during domestic activities of daily life in patients with COPD and healthy elderly subjects. Chest. 2011;140(4):970-9.

31. Evans RA, Hill K, Dolmage TE, Blouin M, O'Hoski S, Brooks D, et al. Properties of self-paced walking in chronic respiratory disease: a patient goal-oriented assessment. Chest. 2011;140(3):737-43.

32. Spruit MA, Wouters EF. New modalities of pulmonary rehabilitation in patients with chronic obstructive pulmonary disease. Sports Med. 2007;37(6):501-18.

33. Demers L, Weiss-Lambrou R, Ska B. The Quebec User Evaluation of Satisfaction with Assistive Technology (QUEST 2.0): an overview and recent progress. Technol Disabil 2002;14:101-5.

34. Perneger TV. What's wrong with Bonferroni adjustments. BMJ. 1998;316(7139):1236-8.

35. Yohannes AM, Connolly MJ. Early mobilization with walking aids following hospital admission with acute exacerbation of chronic obstructive pulmonary disease. Clin Rehabil. 2003;17(5):465-71. 


\section{ONLINE SUPPLEMENT}

\section{METHODS}

Design

Patients were randomly assigned to walk with a rollator during the first extra six-min walking test (6MWT) followed by a second extra 6MWT with the modern draisine or vice versa. The 6MWT was performed in accordance with the guidelines of the American Thoracic Society (ATS)(1). Indeed, the 6MWT was performed at a 125-m course, which clearly exceeds the ATS minimum of 30 meters.

Specifications and settings of the ambulation aids are described below.

Rollator (EASY GOING, A1 Topgros BV, Maastricht, The Netherlands):

- Foldable four wheel rollator

- Weight: $12.4 \mathrm{~kg}$

- Handle height: $78-96 \mathrm{~cm}$

- Width: $58 \mathrm{~cm}$

- Depth: $70 \mathrm{~cm}$

- Height seat: $60 \mathrm{~cm}$

- $\quad$ Suitable for height of $1.50-1.90 \mathrm{~m}$

The handlebars of the rollator were adjusted $2 \mathrm{~cm}$ above the lateral styloid process, and rotated $15^{\circ}$ outwards. The arm position was assumed with the elbows flexed at approximately $30^{\circ}$.

All the participants got a short explanation about the use of the rollator, and a short training session of ten minutes to get familiar with the rollator which was used during the test. During the training session subjects were instructed to walk with a straight back and relaxed shoulders. Feet had to been placed between the back wheels of the rollator. All participants used the same light weight rollator.

The modern version of the draisine: Modern draisine 'City' (Van Raam, Varsseveld, the Netherlands):

Foldable

- Weight: $9.0 \mathrm{~kg}$

- Frame height: $68-89 \mathrm{~cm}$

- Maximum height seat: $108 \mathrm{~cm}$

The height of the seat was adjusted to $6 \mathrm{~cm}$ shorter than the leg length (leg length defined as: height from trochanter major to the ground, without shoes), or until the sub- 
ject sat in a comfortable position. The handlebars were adjusted to the same height of the elbow when the arms were relaxed. All participants got a short explanation about the use of the modern draisine. To get familiar with the modern draisine, all the participants got a ten minutes training session. During the training session subjects were told to sit with a straight back on the modern draisine. They had to copy their normal walking pattern as much as possible and swing the legs alternately.

After each 6MWT, COPD patients were asked to fill out a questionnaire about acceptance, confidence, fear and embarrassment while using a ambulation aid (Appendices 1 and 2). Each questionnaire consisted of 14 questions: nine multiple-choice questions and five visual analogue scale (VAS).

\section{Outcomes}

Primary outcome was the difference in 6MWD (in meters, $\mathrm{m}$ ) between modern draisine and rollator. In addition, several explanatory outcomes were assessed: the number of patient-initiated stops (based on the symptoms, like dyspnea, fatigue or pain); the number of assessor-initiated stops (based on an exercise induced oxygen saturation $<80 \%$ ); transcutaneous oxygen saturation, heart rate and Borg symptom scores for dyspnea and fatigue(2) before and after each 6MWT and after two minutes of recovery; and patient's preference and confidence of the ambulation aid. The metabolic requirements during the two extra 6MWTs were assessed using a mobile oxycon (Oxycon Mobile, CareFusion, San Diego, CA, USA) in COPD patients without oxygen use during 6MWT(3-6), including cost of transport: $\mathrm{mL} / \mathrm{min}$ of oxygen uptake per meter walked during 6MWT.

The amount of strides, stride length (defined as the distance in meters covered between a heel strike of the right foot and a consecutive heel strike of the right foot), stride frequency (number of strides per second), and the root mean square of the acceleration in mediolateral direction (provides an indication of balance via the average magnitude of sway in mediolateral direction)(7) were determined using two tri-axial accelerometer (KXP94, Kionix inc, Ithaca New York, USA) which were placed two fingers above the lateral malleolus of the right ankle and on the lower back, respectively $(8,9)$.

The $\pm 5 \mathrm{~g}$ tri-axial accelerometers were connected with a wireless multi-channel signal acquisition system for ambulant measurements (PASAQ, Maastricht Instruments bv, Maastricht, The Netherlands) to measure the amount of steps (accelerometer on the right ankle) and displacement in lateral direction (accelerometer on the lower back). Data was collected at a sampling rate of $100 \mathrm{~Hz}$.

Raw acceleration signals in the anterior-posterior direction resulted in a clear repetitive pattern for both the rollator (figure E1A) and the new walking device (figure E1B). Each repetition marked by two successive light vertical dotted lines represents one stride (two steps). The total amount of strides was counted for each walking trial. The average 
stride length $(m)$ was then calculated by dividing the amount of strides $(n)$ by the distance walked $(\mathrm{m})$.

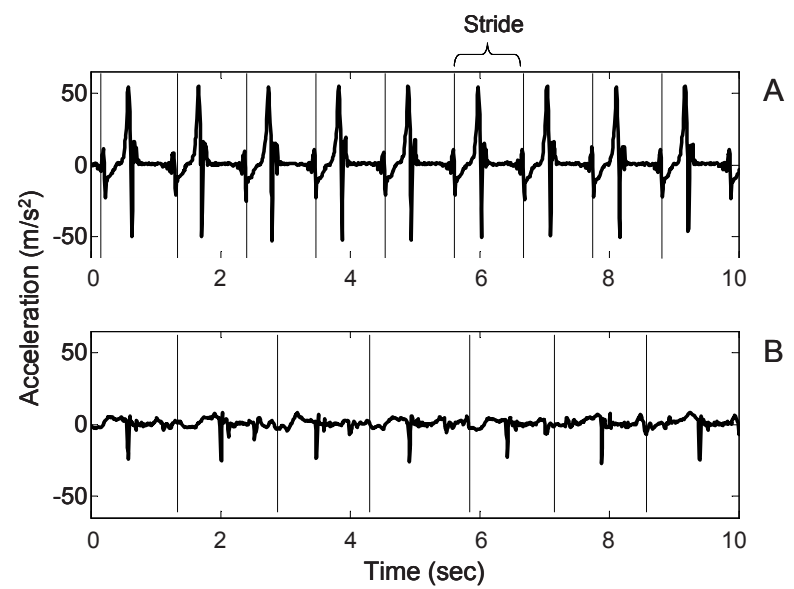

Figure E1. Strides measured over 10 seconds from a representative patient using the rollator $(A)$ and the modern draisine (B).

Walk ratio (defined as the ratio between stride length and stride frequency) can be seen as a simple index for describing temporal and spatial coordination(10) and was used to describe differences in walking pattern while using modern draisine or rollator.

The configuration used to assess walking patterns with the Kionix accelerometers was especially constructed for the purpose of this study although these single units have been used repeatedly for walking analysis. The algorithm for assessing the walking pattern from the acceleration data is a modified version of that designed by Zijlstra et al., they have been proven reproducible for walking analysis in healthy elderly and they have recently been applied successfully in a COPD population $(11,12)$.

\section{REFERENCES}

1 ATS statement: guidelines for the six-minute walk test. Am J Respir Crit Care Med 2002; 166:111-117

2 Borg GA. Psychophysical bases of perceived exertion. Med Sci Sports Exerc 1982; 14:377-381

3 Probst VS, Troosters T, Coosemans I, et al. Mechanisms of improvement in exercise capacity using a rollator in patients with COPD. Chest 2004; 126:1102-1107

4 Sillen MJ, Wouters EF, Franssen FM, et al. Oxygen Uptake, Ventilation, and Symptoms During LowFrequency Versus High-Frequency NMES in COPD: A Pilot Study. Lung 2011; 189:21-26

5 Troosters T, Vilaro J, Rabinovich R, et al. Physiological responses to the 6 -min walk test in patients with chronic obstructive pulmonary disease. Eur Respir J 2002; 20:564-569

6 Sillen MJ, Janssen PP, Akkermans MA, et al. The metabolic response during resistance training and neuromuscular electrical stimulation (NMES) in patients with COPD, a pilot study. Respir Med 2008; 102:786-789 
7 Menz HB, Lord SR, Fitzpatrick RC. Acceleration patterns of the head and pelvis when walking on level and irregular surfaces. Gait Posture 2003; 18:35-46

8 Moe-Nilssen R. A new method for evaluating motor control in gait under real-life environmental conditions. Part 1: The instrument. Clin Biomech (Bristol, Avon) 1998; 13:320-327

9 Kavanagh JJ. Lower trunk motion and speed-dependence during walking. J Neuroeng Rehabil 2009; 6:9

10 Terrier P, Schutz Y. Variability of gait patterns during unconstrained walking assessed by satellite positioning (GPS). Eur J Appl Physiol 2003; 90:554-561

11 Zijlstra W. Assessment of spatio-temporal parameters during unconstrained walking. Eur J Appl Physiol 2004; 92:39-44

12 Senden R, Grimm B, Heyligers IC, et al. Acceleration-based gait test for healthy subjects: reliability and reference data. Gait Posture 2009; 30:192-196 


\section{Appendix 1. \\ Questionnaire rollator}

1. Have you ever used a rollator before in daily life?

$\square$ Yes $\square$ No

2. Have you ever used a rollator before during a six-minute walking test?

$\square$ Yes $\square$ No

3. Did you like the rollator?

$\square$ Yes $\square$ No

4. If not, why not?

Difficult to move forward

Too heavy

$\square$ Else - Please explain:

5. Could you walk further with the rollator compared to a six-minute walking test without ambulation aid?

$\square$ Yes $\square$ No

6. If you walk further, why?

$\square$ Less dyspnea

$\square$ Safer

$\square$ More stable

$\square$ Else - Please explain:

7. Did you feel embarrassed while using the rollator?

$\square$ Yes $\square$ No

8. If you felt embarrassed, why?

9. Would you use the rollator in your daily life?

$\square$ Yes $\square$ No 
10. I felt safe while using the rollator

Strongly disagree

Totally agree

11. I felt like I could fall while using the rollator

Strongly disagree

Totally agree

12. I felt stable while using the rollator

Strongly disagree

Totally agree

13. I think the rollator is a solid ambulation aid

Strongly disagree

Totally agree

14. I had confidence in the rollator during the six-minute walking test

Strongly disagree

Totally agree 


\section{Appendix 2. \\ Questionnaire modern draisine}

1. Have you ever used the modern draisine before in daily life?

$\square$ Yes $\square$ No

2. Have you ever used the modern draisine before during a six-minute walking test?

$\square$ Yes $\square$ No

3. Did you like the modern draisine?

$\square$ Yes $\square$ No

4. If not, why not?

$\square$ Difficult to move forward

Too heavy

$\square$ Else - Please explain:

5. Could you walk further with the modern draisine compared to a six-minute walking test without ambulation aid?

$\square$ Yes $\square$ No

6. If you walk further, why?

$\square$ Less dyspnea

$\square$ Safer

$\square$ More stable

$\square$ Else - Please explain:

7. Did you feel embarrassed while using the modern draisine?

$\square$ Yes $\square$ No

8. If you felt embarrassed, why?

9. Would you use the modern draisine in your daily life ?

$\square$ Yes $\square$ No 
10. I felt safe while using the modern draisine

Strongly disagree

Totally agree

11. I felt like I could fall while using the modern draisine

Strongly disagree

Totally agree

12. I felt stable while using the modern draisine

Strongly disagree

Totally agree

13. I think the modern draisine is a solid ambulation aid

Strongly disagree Totally agree

14. I had confidence in the modern draisine during the six-minute walking test

Strongly disagree

Totally agree 

Chapter 5

Efficacy of walking aids on selfpaced outdoor walking in individuals with COPD:

A randomized cross-over trial

Anouk W. Vaes, Kenneth Meijer, Jeannet M. Delbressine, Jozé Wiechert, Paul Willems, Emiel F.M. Wouters, Frits M.E. Franssen, Martijn A. Spruit 


\section{ABSTRACT}

Background and objective Walking aids, such as a rollator or draisine, improve mobility and functional exercise performance in individuals with COPD during an indoor sixminute walk test. However, this test does not reflect everyday walking, which is the most frequently reported problematic activity of daily life in individuals with COPD. To date, efficacy of walking aids during self-paced outdoor walking remains unknown. Therefore, we aimed to determine the efficacy of a rollator and draisine on self-paced outdoor walking in individuals with COPD.

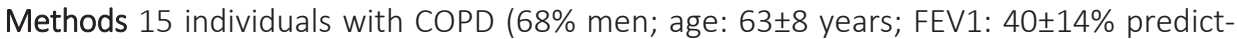
ed) performed 3 self-paced outdoor walking tests on 2 consecutive days: test 1 unaided; test 2 and 3 with rollator or draisine in random order. Participants had to walk as long as possible at their own pace. The test ended when participants needed to stop, with a maximum duration of $30 \mathrm{~min}$.

Results The use of rollator resulted in the highest walk distance and time $(p<0.05$ versus unaided and draisine). Furthermore, individuals with COPD walked significantly further and longer during an unaided test compared to a draisine aided test $(p<0.05)$. Moreover, use of the draisine resulted in a significantly higher walking speed, fewer strides, greater stride length and higher step and stride variability $(p<0.05$ versus unaided and rollator).

Conclusion To conclude, a rollator improves the self-paced outdoor walk distance and time in individuals with moderate and advanced COPD and a poor functional exercise capacity, whereas the use of a draisine had a detrimental effect compared to unaided walking. 


\section{INTRODUCTION}

Walking aids generally improve functional exercise performance in individuals with chronic obstructive pulmonary disease (COPD)(1-5). For example, the use of a rollator resulted in clinically relevant improvements in the indoor six-minute walk distance (6MWD), and reduced exercise-induced dyspnea and improved walking economy $(1,2$, 4-6). Moreover, the use of a modern draisine, a bicycle without pedals, improved the 6MWD even to a greater extent compared to a rollator aided 6-min walk test (6MWT), while the metabolic requirements and exercise-related symptoms were comparable(4).

It seems reasonable to hypothesize that self-paced outdoor walk distance, duration and speed will improve in individuals with COPD using a rollator or draisine. To date, however, the efficacy of walking aids on self-paced outdoor walking remains unknown in individuals with COPD. Indeed, the efficacy of walking aids on indoor 6MWD cannot be generalized to self-paced outdoor walking, as an indoor 6MWT does not reflect selfpaced outdoor walking(7). Then again, individuals with COPD appear to be satisfied with the self-reported effectiveness of rollator use for outdoor ambulation(8).

Therefore, we sought to determine the efficacy of a rollator and draisine on self-paced outdoor walk distance, time and speed in individuals with COPD. Moreover, we aimed to assess walk pattern, exercise-induced symptoms and user satisfaction. A priori, we hypothesized that individuals with COPD have a higher outdoor walk distance, time and speed while using the rollator compared to unaided walking. Moreover, we hypothesized that individuals with COPD have more benefit from the use of a draisine compared to unaided or rollator-aided walking, since it is related to a lower cost of transport and a more effective walking pattern(4).

\section{METHODS}

\section{Design}

This trial followed a prospective randomized cross-over design. Individuals with COPD with a $6 \mathrm{MWD} \leq 500 \mathrm{~m}$, without a COPD exacerbation in the past four weeks, and without known cardiovascular or neurological disorders and ability to walk unaided, were eligible to participate. All subjects gave written informed consent to participate in this trial, which was approved by the medical ethical committee of the Maastricht University Medical Centre (MEC 08-3-069). The project was registered on www.trialregister.nl (NTR1542) before enrolment of the first individual with COPD willing to participate. 


\section{Study protocol}

Individuals with COPD were recruited at $\mathrm{CIRO}+$, center of expertise for chronic organ failure in Horn (the Netherlands)(9). During the routine pre-rehabilitation assessment, pulmonary function, peak aerobic capacity, and body composition were determined as described before(10). In addition, functional exercise performance was determined using the 6MWT, including a practice walk(11). The best 6MWD was used for further analyses. Individuals with a 6MWD of $\leq 500 \mathrm{~m}$ were eligible to participate in the current study, as they were expected to benefit most from the use of walking aids(12).

Eligible individuals were asked to perform three self-paced outdoor walks (SPOWs) on two consecutive weekdays. Participants started with an unaided SPOW on day one. In addition, participants were randomly assigned, using sealed envelopes, to do a SPOW with rollator on day one, followed by a SPOW with the draisine on day two, or vice versa (Figure 1). Participants had a minimum of three hours rest between the unaided SPOW and the first aided SPOW on day one.

Before start of the SPOWs, all participants were familiarized with both walking aids through an outdoor practice session of fifteen minutes in combination with verbal instruction, which was developed in collaboration with an experienced occupational therapist. See online supplement for specifications and settings of both walking aids and instructions during practice session. Participants receiving long-term oxygen therapy could use the basket of the rollator or the draisine to transport their oxygen cylinder or use a portable system over their shoulder or on their waist.

\section{Self-paced outdoor walk}

The efficacy of the walking aids was determined using an SPOW. The SPOW was designed to provide more patient-meaningful information on walking ability(13). Because it is reported in absolute time, the self-paced walk can be used to evaluate whether and to what extent individuals with COPD are able to walk longer, one of the most common goals described by individuals with COPD entering pulmonary rehabilitation(14).

All SPOWs were performed on the same 250-m trail, which was divided into four sections: 1) flat surface, $78 \mathrm{~m}$; 2) some curves and a small slope up and down, $76 \mathrm{~m}$; 3) flat surface (same as section 1), $78 \mathrm{~m}$; and 4) flat surface with turning point, $18 \mathrm{~m}$. The investigators showed the outdoor walking route to all participants before performing the SPOWs, by using a wheelchair if necessary. All participants received standardized instructions to walk for as long as possible at their own pace, with a maximum duration of 30 minutes. Test ended when participants needed to stop due to intolerable dyspnea and/or leg fatigue. 
Weather conditions during SPOWs were noted. No information about wind was available. However, since the test was performed in a sheltered area, surrounded by buildings and trees, the wind should not have had a major influence on the different SPOWs.

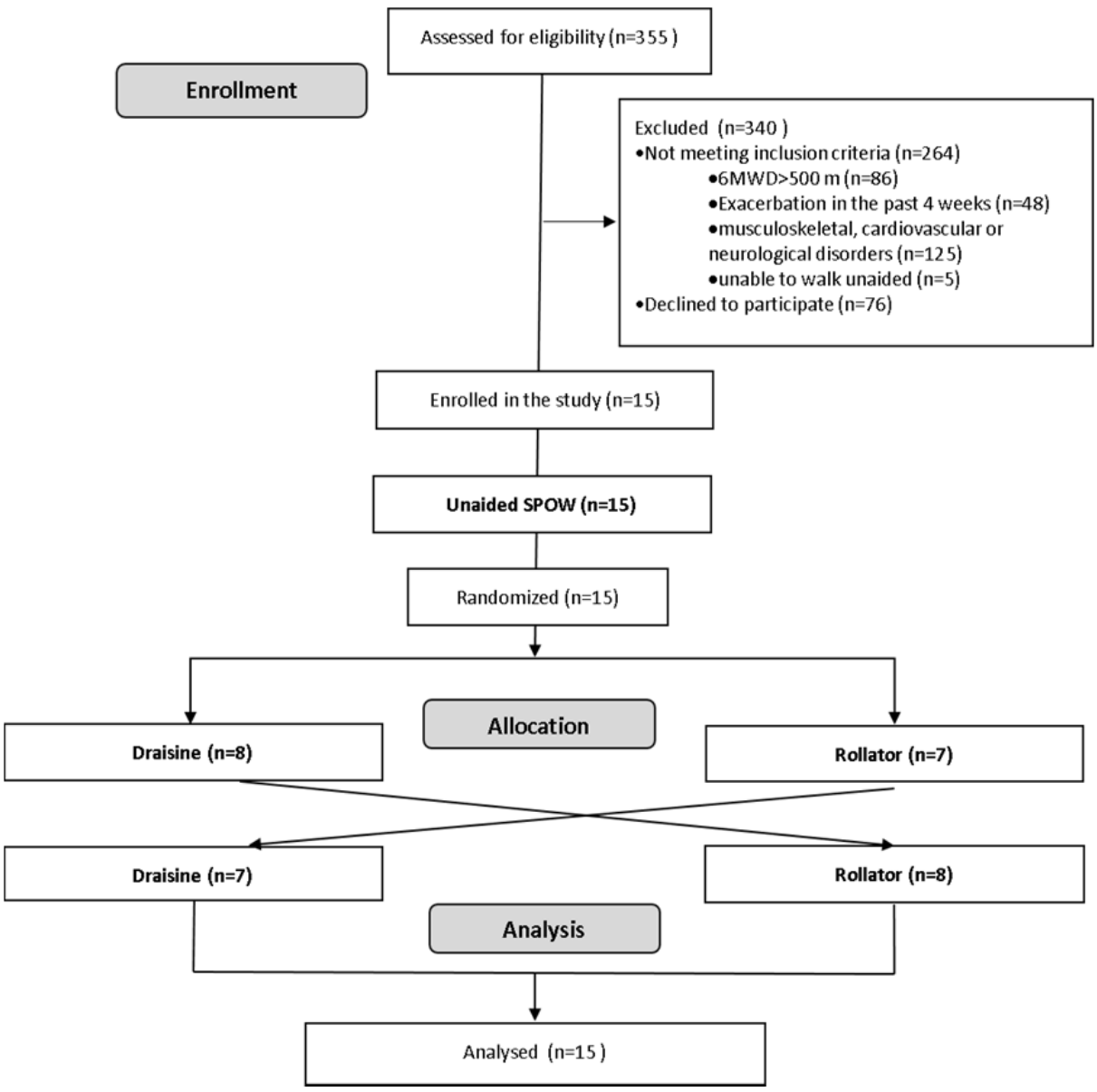

Figure 1. Disposition of participants

\section{Patient's satisfaction}

After both aided SPOWs, participants were asked to answer four questions about the use of the walking aid, and feelings of embarrassment while using the aid (See Appendix 1, online supplement)(4).

In addition, the final eight participants also filled out a questionnaire to determine the satisfaction with the walking aids (Appendix 2, online supplement). These satisfaction 
items were derived from the Dutch version of the Quebec User Evaluation of Satisfaction with Assistive Technology 2.0 (D-QUEST), which is a generic standardized instrument designed to assess satisfaction with assistive technology $(15,16)$. The QUEST has been shown to yield reliable and valid results $(15,16)$, and has been used before in COPD(8). The QUEST consists of twelve item related to device characteristics $(n=8)$ and assistive technology services $(n=4)(15)$. The items are scored using a 5 -point satisfaction scale ranging from 'not satisfied at all' to 'very satisfied', where higher scores indicate greater satisfaction. In this study, items on assistive technology services were not applicable, and, in turn, were not scored. Moreover, by using only items on device characteristics, a good indication about users' satisfaction about the walking aids was obtained.

\section{Outcomes}

Primary outcomes were difference in walk distance, time, and speed between an unaided, rollator-aided and draisine-aided SPOW. In addition, several explanatory outcomes were assessed: amount of strides, stride length, stride frequency, walk ratio and step and stride variability in mediolateral, vertical and anteroposterior direction using two tri-axial accelerometers (KXP94, Kionix inc, Ithaca New York, USA); transcutaneous oxygen saturation, heart rate, and Borg symptom scores for dyspnea and fatigue(17) before and after each SPOW; and preferences for the walking aids. Please see online supplement for additional information.

\section{Data analysis}

Matlab was used to analyze the raw acceleration data of the accelerometers. The software included algorithms to calculate the spatio-temporal aspects of gait. Onsets of support phases were determined from forward accelerations(18). During the transition from single to double support (i.e. after contra-lateral foot contact), the forward acceleration of the lower trunk changes sign from positive to negative. The peak forward acceleration preceding the change of sign coincides with the instant of foot contact, so the acceleration peak preceding a change of sign was taken as the instant of a left or right foot contact(18). Consequently, steps (period from one heel strike to next contralateral heel strike) and strides (period from one heel strike to next ipsilateral heel strike) could be identified. Trunk acceleration variability was assessed by an unbiased autocorrelation procedure $(19,20)$. Unbiased autocorrelation coefficients were obtained by correlating the overlapping parts of an acceleration time series representing a walking trial and a replication of the same time series at a phase shift equivalent to one stride $(20,21)$. The autocorrelation coefficients were used to determine regularity between steps and strides. A higher autocorrelation coefficient indicates lower gait variability (range: 0 to 1$)(20,21)$. Step and stride regularity were reported for the mediolateral axis, vertical axis and anteroposterior axis. 
Data are presented as mean and standard deviation, unless noted otherwise. ANOVA with post hoc tests was used to assess differences between use of rollator and draisine. The level of significance was set at $\leq 0.05$. No adjustment was made to the statistical significance level for multiple comparisons (22). All data were analysed with SPSS 19.0. A priori, we have calculated the minimum sample size to achieve adequate power. Based on the Lacasse et al. (23) we should include 16 participants to achieve a mean difference of 50 meter (standard deviation 35 meter) (2-sided p-value: <0.05, probability: 90\%).

\section{RESULTS}

Two hundred sixty-four of the 335 subjects screened between March 2011 and December 2012 did not meet the inclusion criteria. In addition, 76 eligible subjects declined participation because of disinterest. Characteristics of these participants were not significantly different from those enrolled in this trial. Finally, 15 individuals with COPD completed unaided, rollator-aided and draisine-aided SPOWs (Figure 1).

Weather conditions were similar during the different SPOWs (see online supplement).

\section{Patient characteristics}

On average, participants had moderate to very severe COPD, a normal body mass index and normal fat-free mass index (Table 1). The best 6MWD during routine prerehabilitation assessment was $404 \pm 6 \mathrm{~m}$. Two participants (13\%) used long-term oxygen therapy using a portable system over their shoulder or on their waist.

\section{Effects on SPOW distance, time and speed}

The use of a rollator resulted in a significantly higher mean SPOW distance $(1262 \pm 826$ $\mathrm{m})$ and time $(1123 \pm 684 \mathrm{~s})$ compared to an unaided SPOW $(985 \pm 812 \mathrm{~m}$, and $870 \pm 671 \mathrm{~s}$, respectively; $p<0.05)$ or the draisine-aided SPOW $(586 \pm 508 \mathrm{~m}$, and $468 \pm 361 \mathrm{~s}$, respectively; $\mathrm{p}<0.05$; Table 2). In addition, the unaided SPOW distance and time were significantly higher compared to a draisine-aided SPOW ( $p<0.05$; Table 2). In contrast, the mean SPOW speed was significantly higher while using the draisine compared to the unaided or rollator-aided SPOW $(1.24 \pm 0.23 \mathrm{~m} / \mathrm{s}$ vs. $1.07 \pm 0.19 \mathrm{~m} / \mathrm{s}$ and $1.09 \pm 0.14 \mathrm{~m} / \mathrm{s}$, respectively; $p<0.05$; Table 2 ). 
Table 1. Baseline characteristics $(n=15)$

\begin{tabular}{|c|c|}
\hline \multicolumn{2}{|l|}{ Demographics } \\
\hline Men (\%) & 66.7 \\
\hline Age (years) & $63.3(8.2)$ \\
\hline \multicolumn{2}{|l|}{ Pulmonary function } \\
\hline FEV1 (I) & $1.1(0.4)$ \\
\hline FEV1 (\% predicted) & $39.7(14.1)$ \\
\hline FEV1/FVC (\%) & $35.3(11.7)$ \\
\hline GOLD stage I/II/III/IV (n) & $0 / 3 / 9 / 3$ \\
\hline MMRC grade $0 / 1 / 2 / 3 / 4$ (n) & $0 / 0 / 3 / 9 / 3$ \\
\hline \multicolumn{2}{|l|}{ Body composition } \\
\hline Body weight $(\mathrm{kg})^{*}$ & $72.5(22.8)$ \\
\hline Body mass index $\left(\mathrm{kg} / \mathrm{m}^{2}\right)$ & $25.1(6.9)$ \\
\hline FFM (kg) & $49.5(12.6)$ \\
\hline FFMI $\left(\mathrm{kg} / \mathrm{m}^{2}\right)$ & $17.2(3.7)$ \\
\hline 6MWD (m) & $404(61.3)$ \\
\hline HR before (bpm) & $85.2(9.9)$ \\
\hline HR after (bpm) & $109.7(13.0)$ \\
\hline $\mathrm{spO}_{2}$ before (\%) & $94.8(2.7)$ \\
\hline $\mathrm{spO}_{2}$-drop (\%) & $5.8(4.7)$ \\
\hline Borg dyspnea (points) & $5.3(1.7)$ \\
\hline Borg fatigue (points) & $4.5(2.2)$ \\
\hline
\end{tabular}

Results are presented as mean (standard deviation). $\mathrm{FEV}_{1}=$ forced expiratory volume in the first second; I=liter; $\mathrm{FVC}=$ forced vital capacity; $\mathrm{kg}=$ kilogram; $\mathrm{m}=$ meter; $\mathrm{kg} / \mathrm{m}^{2}=$ kilogram per squared meters; $\mathrm{FFM=fat} \mathrm{free} \mathrm{mass;}$

* 1 kilogram $=2.2046$ pounds

\section{Effects on exercise-induced symptoms}

Symptom scores for dyspnea and fatigue at start of the SPOWs were comparable. Participants reported significantly higher dyspnea and fatigue scores immediately after the draisine-aided SPOW compared to an unaided or rollator-aided SPOW. The differences in fatigue scores were still significant two minutes after the SPOWs (Table 2). In addition, fatigue scores directly after the rollator-aided SPOW were significantly lower compared to the unaided SPOW (Table 2).

No significant differences were found in heart rate and saturation after the unaided, rollator-aided and draisine-aided SPOW (Table 2). 
Table 2. Outcomes of the self-paced outdoor walks

\begin{tabular}{llll}
\hline & $\begin{array}{l}\text { Unaided } \\
(\mathrm{n}=15)\end{array}$ & $\begin{array}{l}\text { Rollator } \\
(\mathrm{n}=15)\end{array}$ & $\begin{array}{l}\text { Modern draisine } \\
(\mathrm{n}=15)\end{array}$ \\
\hline Walk distance $(\mathrm{m})$ & $985.2(812.4)$ & $1261.6(825.8)^{*}$ & $586.2(508.1)^{*+}$ \\
Walk time (s) & $870.1(671.1)$ & $1123.3(683.5)^{*}$ & $468.3(360.9)^{*+}$ \\
Walk speed (m/s) & $1.07(0.19)$ & $1.09(0.14)$ & $1.24(0.23)^{*+}$ \\
Section 1 & $1.12(0.17)$ & $1.11(0.14)$ & $1.28(0.25)^{* \dagger}$ \\
Section 2 & $1.17(0.12)$ & $1.15(0.14)$ & $1.37(0.27)^{*+}$ \\
Section 3 & $1.11(0.09)$ & $1.10(0.12)$ & $1.34(0.24)^{*+}$ \\
Section 4 & $1.00(0.13)$ & $0.92(0.18)$ & $0.95(0.19)$ \\
Borg dyspnea before (points) & $1.8(1.3)$ & $1.2(0.9)$ & $1.4(1.0)$ \\
Borg dyspnea after (points) & $5.1(1.7)$ & $4.5(1.6)$ & $5.4(2.1)^{\dagger}$ \\
Borg dyspnea 2 minutes after (points) & $3.0(1.6)$ & $2.6(1.2)$ & $3.0(1.6)$ \\
Borg fatigue before (points) & $1.2(1.0)$ & $1.1(0.8)$ & $1.1(0.9)$ \\
Borg fatigue after (points) & $3.9(2.5)$ & $2.9(2.1)^{*}$ & $4.8(2.6)^{*+}$ \\
Borg fatigue 2 minutes after (points) & $2.3(1.5)$ & $1.9(1.0)$ & $3.0(1.7)^{\dagger}$ \\
HR before (bpm) & $79.1(10.6)$ & $79.8(9.1)$ & $78.1(8.7)$ \\
HR after (bpm) & $103.7(11.9)$ & $103.5(15.9)$ & $104.1(11.8)$ \\
spO 2 before (\%) & $95.3(2.8)$ & $95.0(2.8)$ & $95.2(2.5)$ \\
spO ${ }_{2}$-drop (\%) & $4.1(3.8)$ & $5.5(4.3)$ & $4.7(5.4)$ \\
\hline
\end{tabular}

Results are presented as mean (standard deviation). 6MWD=six minute walk distance; $m=$ meter; $s=s e c o n d ;$ $\mathrm{HR}=$ heart rate; $\mathrm{bpm}=$ beats per minute; $\mathrm{spO}_{2}=$ Saturation of Peripheral Oxygen;

$* p<0.05$ vs. unaided; $+p<0.05$ vs. rollator

\section{Effects on SPOW gait variables}

The use of the draisine resulted in significantly fewer strides compared to the unaided and rollator-aided SPOW (301 \pm 234 versus $743 \pm 582$ and $781 \pm 656$, respectively; $p<0.05$, Table 3). Consequently, participants had a significantly greater stride length $(p<0.01$ versus rollator and unaided; Table 3$)$ and lower stride frequency $(p<0.05$ versus unaided; Table 3). Moreover, the walk ratio was significantly higher while using the draisine compared to the rollator-aided and unaided SPOW. In addition, step and stride regularity in vertical, anteroposterior and mediolateral direction were significantly lower during the draisine-aided SPOW compared to the rollator-aided and unaided SPOW. No significant differences in gait variables were found between unaided and rollator-aided walking. 
Table 3. Gait variables of the self-paced outdoor walks

\begin{tabular}{llll}
\hline & $\begin{array}{l}\text { Unaided } \\
(\mathrm{n}=15)\end{array}$ & $\begin{array}{l}\text { Rollator } \\
(\mathrm{n}=15)\end{array}$ & $\begin{array}{l}\text { Modern draisine } \\
(\mathrm{n}=15)\end{array}$ \\
\hline Strides $(\mathrm{n})$ & $743(582)$ & $781(656)$ & $301(234)^{*+}$ \\
Stride length $(\mathrm{m})$ & $1.30(0.10)$ & $1.34(0.10)$ & $1.67(0.41)^{*+}$ \\
Stride frequency (strides/s) & $0.84(0.11)$ & $0.86(0.15)$ & $0.76(0.11)^{*+}$ \\
Walk ratio (m/(steps·s $\left.{ }^{-1}\right)$ & $1.57(0.26)$ & $1.59(0.27)$ & $2.29(0.90)^{*+}$ \\
Step regularity V-Trunk & $0.75(0.09)$ & $0.73(0.11)$ & $0.24(0.07)^{*+}$ \\
Step regularity AP-Trunk & $0.63(0.12)$ & $0.69(0.10)$ & $0.18(0.07)^{* \dagger}$ \\
Step regularity ML-Trunk & $0.41(0.23)$ & $0.29(0.30)$ & $0.17(0.10)^{* \dagger}$ \\
Stride regularity V-Trunk & $0.77(0.11)$ & $0.72(0.12)$ & $0.22(0.06)^{* \dagger}$ \\
Stride regularity AP-Trunk & $0.68(0.11)$ & $0.66(0.10)$ & $0.17(0.07)^{* \dagger}$ \\
Stride regularity ML-Trunk & $0.60(0.11)$ & $0.54(0.16)$ & $0.14(0.11)^{* \dagger}$ \\
\hline
\end{tabular}

Results are presented as mean (standard deviation). $\mathrm{m}=$ meter; $\mathrm{s}=$ second; $\mathrm{V}=$ vertical axis; $\mathrm{AP}=$ anteroposterior axis; $\mathrm{ML}=$ mediolateral axis

$* p<0.05$ vs. unaided; $+p<0.05$ vs. rollator

\section{Patient's preferences}

Twelve individuals with COPD had never used a rollator before in daily life or during a 6MWT compared to fifteen who had never used the draisine (Table 4). Thirteen participants reported to like the rollator. However, only five participants would use it in daily life, of which three were already using a rollator. The proportion of individuals with COPD who liked the draisine was significantly lower $(p<0.05)$. Although only two of the participants felt embarrassed using the draisine, fewer would like to use the draisine in their daily life compared to a rollator (Table 4).

The rollator scored significantly higher in terms of comfort, safety and security $(p<0.05$; Table 3). Lower satisfaction scores for the draisine were caused by problems with the seat, steering problems and/or balance problems. No significant differences were found in satisfaction for dimension, weight, ease in adjusting, ease of use, and effectiveness between the walking aids (Table 4). Though, overall satisfaction for the rollator was significantly higher compared to the draisine ( $p<0.05$; Table 4). 
Table 4. Data from questionnaire

\begin{tabular}{|c|c|c|}
\hline & Rollator & Draisine \\
\hline \multicolumn{3}{|l|}{$\begin{array}{l}\text { Use of walking aid and feelings of } \\
\text { embarrassment }(n=20) \text { : }\end{array}$} \\
\hline Used before in daily life?* & 3 & $0+$ \\
\hline Used before during 6MWT?* & 2 & 0 \\
\hline Did you like the walking aid?* & 13 & $6+$ \\
\hline $\begin{array}{l}\text { Were you ashamed using the walking } \\
\text { aid?* }\end{array}$ & 5 & 2 \\
\hline If you were ashamed, why?* & $\begin{array}{l}\text { Too young ( } 2 \text { ) } \\
\text { Illness is visible ( } 3 \text { ) }\end{array}$ & $\begin{array}{l}\text { Afraid for public use (1) } \\
\text { No reason (1) }\end{array}$ \\
\hline Would you use it in daily life?* & 5 & 3 \\
\hline If not, why not? & $\begin{array}{l}\text { Too heavy (1) } \\
\text { Embarrassed (2) } \\
\text { Can easily do without (1) } \\
\text { Too few benefits (1) } \\
\text { Arm swing not possible (1) } \\
\text { Pain in arms (1) }\end{array}$ & $\begin{array}{l}\text { Difficult to move forward (2) } \\
\text { Much heavier than walking/ Too heavy (6) } \\
\text { Steering problems (1) } \\
\text { Balance problems (1) } \\
\text { Wheels are too small (1) } \\
\text { Increase dyspnea (1) } \\
\text { Embarrassed (1) } \\
\text { Preference for rollator (1) }\end{array}$ \\
\hline \multicolumn{3}{|l|}{$\begin{array}{l}\text { Satisfaction walking aid (D-QUEST) } \\
(n=10) \text { : }\end{array}$} \\
\hline $\begin{array}{l}\text { Satisfaction dimensions (size, height, } \\
\text { length, width)?** }\end{array}$ & $3.8(3-4)$ & $3.5(2-5)$ \\
\hline Satisfaction weight?** & $3.2(1-5)$ & $3.7(3-5)$ \\
\hline Satisfaction ease in adjusting?** & $3.7(3-4)$ & $3.5(3-4)$ \\
\hline Satisfaction safety and security?** & $3.8(3-5)$ & $3.0(1-4)^{\dagger}$ \\
\hline Satisfaction ease of use?** & $3.5(1-5)$ & $3.0(1-4)$ \\
\hline Satisfaction comfort?** & $4.0(3-5)$ & $3.3(1-5)^{+}$ \\
\hline Satisfaction effectiveness?** & $3.8(3-5)$ & $3.7(2-5)$ \\
\hline Overall satisfaction?** & $3.9(2-5)$ & $2.3(1-4)^{\dagger}$ \\
\hline
\end{tabular}

* Numbers indicates positive answers

** scored using a 5-point satisfaction scale ranging from (1) 'not satisfied at all' to (5) 'very satisfied' $+p<0.05$ vs. rollator

\section{DISCUSSION}

The present study is the first to investigate the efficacy of walking aids during a selfpaced outdoor walk in individuals with moderate to very severe COPD. Results show that the use of a rollator improves the SPOW distance and time compared to an unaided SPOW. In addition, the use of a draisine had a detrimental effect on the distance and time compared to the unaided SPOW. 
The efficacy of walking aids during an indoor 6MWT has been studied frequently and has shown to be associated with a significant and clinically relevant improvement in $\operatorname{GMWD}(1-3,24,25)$. However, this may not reflect everyday walking, which is the most frequently reported problematic activity of daily life in $\operatorname{COPD(26).~In~addition,~patients~}$ with COPD reported to use their walking aids mostly during outdoor activities $(8,24)$.

This study showed that individuals with COPD also have substantial benefit from a rollator during outdoor walking. Indeed, while using the rollator, individuals with COPD walked on average $276 \mathrm{~m}$ further compared to an unaided SPOW (Table 2). The use of a draisine resulted in a lower SPOW distance and time compared to the unaided SPOW. This is in great contrast with earlier findings from our group, where we found an increased indoor 6MWD using a draisine compared a rollator-aided 6MWD.(4) This may due to the fact that the 6MWD trial was performed indoors on a triangular, flat, enclosed corridor with a hard surface(4), while the SPOW was performed on a $250 \mathrm{~m}$ course, including straight parts of $78 \mathrm{~m}$. Even though participants were instructed to walk at their own pace during each SPOW, the SPOW speed was significantly higher during the use of the draisine compared to the rollator-aided and unaided SPOW. Indeed, mean SPOW speed during the use of a draisine $(1.24 \mathrm{~m} / \mathrm{s})$ was probably too high for the participants as the mean indoor 6MWD speed was $1.13 \mathrm{~m} / \mathrm{s}$. This hypothesis is supported by the significantly lower distance and duration during the draisine-aided SPOW and the significantly higher exercise-induced dyspnea and fatigue scores.

Several studies have shown that the walk ratio (ratio between stride length and stride frequency) is constant over a large range of walking speeds during normal walking in healthy subjects $(27,28)$. Our results show a significant higher walk ratio in individuals with COPD while using the draisine, indicating an altered walking pattern. Indeed, the higher walk ratio could be explained by the significantly longer strides. Although individuals with COPD were instructed to have continuous ground contact, they had the tendency to slightly roll between steps while using the draisine. This alteration in walking pattern could be caused by feelings of uncertainty and imbalance while using the draisine (Table 4). Indeed, an increased walk ratio was shown previously to maintain stability during walking under challenging conditions(29).

Step and stride variability during the SPOWs were higher compared to indoor walking(19). Moreover, the use of the draisine resulted in a significantly higher step and stride variability compared to unaided or rollator-aided walking. Earlier it was shown that this increased variability is used as an active control strategy to compensate for balance disturbance(20), indicating a more imbalanced walking pattern during the draisine-aided SPOW.

In this trial a SPOW was used to determine the efficacy of walking aids during outdoor use. This test is not designed to replace field exercise tests, but can be used to acquire more patient-meaningful information(13). Indeed, the SPOW time is a direct and imme- 
diately understandable measure of a commonly goal stated by individuals with COPD entering pulmonary rehabilitation: to walk for longer. Furthermore, this test may be more representative for real-life walking in individuals with COPD, since participants are able to choose their own walking speed. This chosen walking speed is a good indicator for functional status, since a lower walking speed is related to a decline in functional performance and higher mortality in individuals with $\operatorname{COPD}(30,31)$. Moreover, this test can provide meaningful information on walking ability and normal walking pattern in individuals with COPD, which may be important, since walking stability in individuals with COPD cannot only be attributed to changes in walking speed(19). In addition, this information can be helpful for a clinician to determine the choice of a walking aid for individuals with COPD.

Several methodological limitations need to be addressed. For obvious reasons, it was not possible to blind participants or outcome assessor to the walking aids.

The outdoor practice session of fifteen minutes may be too short for proper familiarizing, especially for the draisine, which has never been used by $95 \%$ of the individuals with COPD. Indeed, some patients reported to have problems with their balance and feelings of lower safety (Table 4). Since the rollator and the draisine were adapted to the size of the participants, these balance problems were not caused by incorrect adjustment, but are likely related to the active support needed to remain stable and the alteration in walking pattern. This may improve when patients are able to practice more frequent or for a longer period.

Because of the design of the study, with no randomization of the unaided SPOW, a carry-over effect might be present. In addition, the study protocol did not include a practice SPOW, and the SPOWs were performed on two consecutive days. Since it is possible that a second SPOW is associated with a learning effect, the outcomes of this study may be overestimated. However, earlier was shown that the improvement of a second SPOW was relatively small and the day to day variability is similar to that reported for other frequently used outcome measures for pulmonary rehabilitation(13). Moreover, additional analyses showed no significant effect differences in order of walking aid use during SPOWs.

We only included individuals with a baseline 6MWD $\leq 500 \mathrm{~m}$, since it is expected that they would benefit the most from the use of walking aids(1). However, since data on the use of a draisine and on the outdoor use of walking aids is limited, individuals with a $6 \mathrm{MWD}>500 \mathrm{~m}$ might also benefit from the outdoor use of a walking aid. Furthermore, we only included rollator naïve individuals, and our study was slightly underpowered. However, data from 5 rollator users show similar results, which strengthens the conclusions of our study.

The number of patients eligible and/or willing to participate in the study is rather low, which may limit the generalisation of the results. However, we think it is reasonable to exclude patients who were not clinically stable and patients with neurological, musculo- 
skeletal and/or cardiovascular problems, making it unable to complete a 6MWT without problems or complaints. Moreover, we only included patients with a 6MWD of $\leq 500 \mathrm{~m}$, since it is known that patients with a lower 6MWD benefit most of the use of walking aids $(1,12)$. In addition, clinical characteristics of eligible patients who declined to participate were not significantly different in terms of demographics, pulmonary function, body composition and 6MWD from those enrolled in the study. Therefore, it can be assumed that these are no reasons for non-participation.

It would have been interesting to measure metabolic requirement and dynamic lung hyperinflation. However, data on the validity of a mobile oxycon under different outdoor conditions are limited. Moreover, when using a portable metabolic system, we would not be able to measure patients with long-term oxygen therapy, who would probably benefit the most from the use of a walking aid $(1,2)$.

To conclude, a rollator improves SPOW distance and time in individuals with moderate and advanced COPD and a poor functional exercise capacity, whereas the use of a draisine had even a detrimental effect compared to unaided walking. However, the needs and daily use should be considered for selection of a walking aid for individuals with COPD. 


\section{REFERENCES}

1. Solway S, Brooks D, Lau L, Goldstein R. The short-term effect of a rollator on functional exercise capacity among individuals with severe COPD. Chest. 2002;122(1):56-65.

2. Probst VS, Troosters T, Coosemans I, Spruit MA, Pitta Fde O, Decramer M, et al. Mechanisms of improvement in exercise capacity using a rollator in patients with COPD. Chest. 2004;126(4):1102-7.

3. Gupta R, Goldstein R, Brooks D. The acute effects of a rollator in individuals with COPD. J Cardiopulm Rehabil. 2006;26(2):107-11.

4. Vaes AW, Annegarn J, Meijer K, Cuijpers MW, Franssen FM, Wiechert J, et al. The effects of a "new" walking aid on exercise performance in patients with COPD: a randomized crossover trial. Chest. 2012;141(5):1224-32.

5. Crisafulli E, Costi S, De Blasio F, Biscione G, Americi F, Penza S, et al. Effects of a walking aid in COPD patients receiving oxygen therapy. Chest. 2007;131(4):1068-74.

6. Hill K, Dolmage TE, Woon LJ, Brooks D, Goldstein RS. Rollator use does not consistently change the metabolic cost of walking in people with chronic obstructive pulmonary disease. Arch Phys Med Rehabil. 2012;93(6):1077-80.

7. Pitta F, Troosters T, Spruit MA, Probst VS, Decramer M, Gosselink R. Characteristics of physical activities in daily life in chronic obstructive pulmonary disease. Am J Respir Crit Care Med. 2005;171(9):972-7.

8. Hill K, Goldstein R, Gartner EJ, Brooks D. Daily utility and satisfaction with rollators among persons with chronic obstructive pulmonary disease. Arch Phys Med Rehabil. 2008;89(6):1108-13.

9. Spruit MA, Vanderhoven-Augustin I, Janssen PP, Wouters EF. Integration of pulmonary rehabilitation in COPD. Lancet. 2008;371(9606):12-3.

10. Spruit MA, Pennings HJ, Janssen PP, Does JD, Scroyen S, Akkermans MA, et al. Extra-pulmonary features in COPD patients entering rehabilitation after stratification for MRC dyspnea grade. Respir Med. 2007;101(12):2454-63.

11. Hernandes NA, Wouters EF, Meijer K, Annegarn J, Pitta F, Spruit MA. Reproducibility of 6-minute walking test in patients with COPD. Eur Respir J. 2011;38(2):261-7.

12. Spruit MA, Mercken EM, Wouters EFM, Schols AMWJ. Role of exercise testing in defining response to interventions in copd patients. European Respiratory Monograph2007. p. 208-20.

13. Evans RA, Hill K, Dolmage TE, Blouin M, O'Hoski S, Brooks D, et al. Properties of self-paced walking in chronic respiratory disease: a patient goal-oriented assessment. Chest. 2011;140(3):737-43.

14. Spruit MA, Singh SJ, Garvey C, Zuwallack R, Nici L, Rochester C, et al. An official american thoracic society/european respiratory society statement: key concepts and advances in pulmonary rehabilitation. Am J Respir Crit Care Med. 2013;188(8):e13-64.

15. Demers L, Weiss-Lambrou R, Ska B. The Quebec User Evaluation of Satisfaction with Assistive Technology (QUEST 2.0): an overview and recent progress. Technol Disabil 2002;14:101-5.

16. Wessels RD, De Witte LP. Reliability and validity of the Dutch version of QUEST 2.0 with users of various types of assistive devices. Disabil Rehabil. 2003;25(6):267-72.

17. Borg GA. Psychophysical bases of perceived exertion. Med Sci Sports Exerc. 1982;14(5):377-81.

18. Zijlstra W. Assessment of spatio-temporal parameters during unconstrained walking. Eur J Appl Physiol. 2004;92(1-2):39-44.

19. Annegarn J, Spruit MA, Savelberg HH, Willems PJ, van de Bool C, Schols AM, et al. Differences in walking pattern during 6-min walk test between patients with COPD and healthy subjects. PLoS ONE. 2012;7(5):e37329.

20. Moe-Nilssen R, Helbostad JL. Interstride trunk acceleration variability but not step width variability can differentiate between fit and frail older adults. Gait Posture. 2005;21(2):164-70.

21. Moe-Nilssen R, Helbostad JL. Estimation of gait cycle characteristics by trunk accelerometry. J Biomech. 2004;37(1):121-6.

22. Perneger TV. What's wrong with Bonferroni adjustments. BMJ. 1998;316(7139):1236-8. 
23. Lacasse Y, Goldstein R, Lasserson TJ, Martin S. Pulmonary rehabilitation for chronic obstructive pulmonary disease. Cochrane Database Syst Rev. 2006(4):CD003793.

24. Gupta RB, Brooks D, Lacasse Y, Goldstein RS. Effect of rollator use on health-related quality of life in individuals with COPD. Chest. 2006;130(4):1089-95.

25. Holland AE, Hill CJ, Rasekaba T, Lee A, Naughton MT, McDonald CF. Updating the minimal important difference for six-minute walk distance in patients with chronic obstructive pulmonary disease. Arch Phys Med Rehabil. 2010;91(2):221-5.

26. Annegarn J, Meijer K, Passos VL, Stute K, Wiechert J, Savelberg HH, et al. Problematic activities of daily life are weakly associated with clinical characteristics in COPD. J Am Med Dir Assoc. 2012;13(3):284-90.

27. Nagasaki $H$, Itoh $H$, Hashizume $K$, Furuna $T$, Maruyama $H$, Kinugasa T. Walking patterns and finger rhythm of older adults. Percept Mot Skills. 1996;82(2):435-47.

28. Terrier P, Schutz Y. Variability of gait patterns during unconstrained walking assessed by satellite positioning (GPS). Eur J Appl Physiol. 2003;90(5-6):554-61.

29. Menz HB, Lord SR, Fitzpatrick RC. Acceleration patterns of the head and pelvis when walking on level and irregular surfaces. Gait Posture. 2003;18(1):35-46.

30. Spruit MA, Polkey MI, Celli B, Edwards LD, Watkins ML, Pinto-Plata V, et al. Predicting outcomes from 6minute walk distance in chronic obstructive pulmonary disease. J Am Med Dir Assoc. 2012;13(3):291-7.

31. Cooper R, Kuh D, Hardy R. Objectively measured physical capability levels and mortality: systematic review and meta-analysis. BMJ. 2010;341:c4467. 


\title{
ONLINE SUPPLEMENT
}

\section{METHODS}

\author{
Specifications, settings and instructions
}

Rollator (EASY GOING, A1 Topgros BV, Maastricht, The Netherlands):

- Foldable four wheel rollator

- Weight: $12.4 \mathrm{~kg}$

- Handle height: $78-96 \mathrm{~cm}$

- Width: $58 \mathrm{~cm}$

- Depth: $70 \mathrm{~cm}$

- Height seat: $60 \mathrm{~cm}$

- Suitable for height of $1.50-1.90 \mathrm{~m}$

The handlebars of the rollator were adjusted $2 \mathrm{~cm}$ above the lateral styloid process, and rotated $15^{\circ}$ outwards. The arm position was assumed with the elbows flexed at approximately $30^{\circ}$.

All the participants got a short explanation about the use of the rollator, and a short outdoor training session of fifteen minutes to get familiar with the rollator used during the test. During the training session subjects were instructed to walk with a straight back and relaxed shoulders. Feet had to been placed between the back wheels of the rollator. All participants used the same light weight rollator.

The modern version of the draisine: Modern draisine 'City' (Van Raam, Varsseveld, the Netherlands):

- Foldable

- Weight: $9.0 \mathrm{~kg}$

- Frame height: $68-89 \mathrm{~cm}$

- Maximum height seat: $108 \mathrm{~cm}$

The height of the seat was adjusted to $6 \mathrm{~cm}$ shorter than the leg length (leg length defined as: height from trochanter major to the ground, without shoes), or until the subject sat in a comfortable position. The handlebars were adjusted to the same height of the elbow when the arms were relaxed. All participants got a short explanation about the use of the modern draisine. To get familiar with the modern draisine, all the participants got a fifteen minutes outdoor training session. During the training session subjects were told to sit with a straight back on the modern draisine. They had to copy their normal walking pattern as much as possible, with continuous ground contact by one of the feet and alternately swing of the legs. 


\section{Outcomes}

Primary outcomes were the difference in walk distance (in meters, $\mathrm{m}$ ), time (in seconds, $\mathrm{s})$, and speed (kilometers per hour, $\mathrm{m} / \mathrm{s}$ ) between an unaided, rollator-aided and draisine-aided SPOW. In addition, several explanatory outcomes were assessed: amount of strides, stride length (defined as the distance in meters covered between a heel strike of the right foot and a consecutive heel strike of the right foot), stride frequency (number of strides per second), walk ratio (ratio between stride length and stride frequency) and step and stride variability mediolateral, vertical and anteroposterior direction using two tri-axial accelerometers using two tri-axial accelerometers (KXP94, Kionix inc, Ithaca New York, USA), which were placed two fingers above the lateral malleolus of the right ankle and on the lower back, respectively $(1,2)$; transcutaneous oxygen saturation, heart rate and Borg symptom scores for dyspnea and fatigue(3) before and after each SPOW, and after two minutes of recovery; and preferences for the walking aids.

The $\pm 5 \mathrm{~g}$ tri-axial accelerometers were connected with a wireless multi-channel signal acquisition system for ambulant measurements (PASAQ, Maastricht Instruments bv, Maastricht, The Netherlands). Data were collected at a sampling rate of $100 \mathrm{~Hz}$. The configuration used to assess walking patterns with the Kionix accelerometers have been used repeatedly for walking analysis. The algorithm for assessing the walking pattern from the acceleration data is a modified version of that designed by Zijlstra et al., they have been proven reproducible for walking analysis in healthy elderly and they have recently been applied successfully in a COPD population $(4,5)$.

\section{RESULTS}

\section{Weather conditions}

All SPOWs were performed in dry weather conditions. Temperature, humidity and barometric pressure were comparable between SPOWs (Table S1).

Table S1. Weather conditions during SPOWs

\begin{tabular}{llll}
\hline & Unaided & Rollator & Draisine \\
\hline Temperature $\left({ }^{\circ} \mathrm{C}\right)$ & $16.7(6.5)$ & $17.0(5.7)$ & $16.8(5.1)$ \\
Humidity (\%) & $63.7(13.7)$ & $64.3(11.8)$ & $66.0(14.4)$ \\
Barometric pressure (hPa) & $1016.9(7.9)$ & $1015.2(8.0)$ & $1016.7(6.3)$ \\
\hline
\end{tabular}

${ }^{\circ} \mathrm{C}=$ degree Celsius; $\mathrm{hPa}=$ hectopascal 


\section{References}

1. Moe-Nilssen R. A new method for evaluating motor control in gait under real-life environmental conditions. Part 1: The instrument. Clin Biomech (Bristol, Avon). 1998;13(4-5):320-7.

2. Kavanagh JJ. Lower trunk motion and speed-dependence during walking. J Neuroeng Rehabil. 2009;6:9.

3. Borg GA. Psychophysical bases of perceived exertion. Med Sci Sports Exerc. 1982;14(5):377-81.

4. Zijlstra W. Assessment of spatio-temporal parameters during unconstrained walking. Eur J Appl Physiol. 2004;92(1-2):39-44.

5. Senden R, Grimm B, Heyligers IC, Savelberg HH, Meijer K. Acceleration-based gait test for healthy subjects: reliability and reference data. Gait Posture. 2009;30(2):192-6. 

Chapter 6

\section{Changes in physical activity and all-cause mortality in chronic obstructive pulmonary disease}

Anouk W. Vaes, Judith Garcia-Aymerich, Jacob L. Marott, Marta Benet, Miriam T.J. Groenen, Peter Schnohr, Frits M.E. Franssen, Jørgen Vestbo, Emiel F.M. Wouters, Peter Lange, Martijn A. Spruit 


\section{ABSTRACT}

Background: Little is known about changes in physical activity in subjects with COPD and its impact on mortality. Therefore, we aimed to study changes in physical activity in subjects with and without COPD and their impact on mortality risk.

Methods: Subjects of the Copenhagen City Heart Study with $\geq$ two consecutive examinations were selected. Each examination included a self-administered questionnaire and clinical examination.

Findings: 1,270 COPD subjects ( $\mathrm{FEV}_{1}: 67 \pm 18 \%$ pred) and 8,734 subjects without COPD ( $\mathrm{FEV}_{1}: 91 \pm 15 \%$ pred) were included. COPD subjects with moderate or high baseline physical activity who reported low physical activity level at follow up had the highest hazards to die (HR 1.73 and 2.35, respectively; both $p<0.001)$, whereas in COPD subjects with low baseline physical activity, no differences were found in survival between unchanged or increased physical activity at follow up. In addition, subjects without COPD with low physical activity at follow up had the highest hazard to die, irrespective of baseline physical activity level ( $p \leq 0.05)$.

Conclusion: A decline to low physical activity at follow up was associated with an increased mortality risk in subjects with and without COPD. These observational data suggest that it is important to assess and encourage physical activity already in the earliest stages of COPD in order to maintain an as high as possible physical activity level as this is associated with a better prognosis. 


\section{BACKGROUND}

Subjects with chronic obstructive pulmonary disease (COPD) have lower levels of regular physical activity compared to subjects without COPD, even in mild to moderate COPD(1). Many subjects with COPD are not able to meet the recommended minimal amount of daily regular physical activity(2-4). This may differ between geographic areas, cultural backgrounds and/or methods used to assess daily physical activity(5).

Lower levels of physical activity have been associated with accelerated lung function decline,(6) exercise intolerance(1), lower-limb muscle weakness(1), lower muscle mass(7), and hospitalizations(8, 9). In addition, subjects with COPD with very low levels of regular physical activity have the worst prognosis. This has been shown in a population-based study using self-reported levels of physical activity(8), as well as in clinical samples of subjects with COPD using objectified levels of physical activity(10).

In most COPD studies, physical activity has been assessed at only one point of time(6, 8, 10-13). Subjects with COPD, however, may change their physical activity behavior over time. Only few studies have focused on long-term changes in regular physical activity in subjects with COPD, showing a decline in physical activity in 19 to $26 \%$ of the subjects(14-16). However, a common limitation to all previous studies is a lack of comparison between the physical activity changes in subjects with COPD with physical activity changes in subjects without COPD. Therefore, it is not possible to establish whether the observed changes are due to COPD progression or aging.

A decline in regular physical activity may affect clinical characteristics in subjects with COPD. Esteban and colleagues showed that a decline in self-reported regular physical activity at 5 year follow up was associated with a decline in disease-specific health status in subjects with $\operatorname{COPD}(14)$. Moreover, a study in the general population found that maintaining or adopting a moderate or high level of physical activity was associated with lower risk of death(17). Whether and to what extent changes in regular physical activity affect survival of subjects with COPD remains unknown. Nevertheless, it seems reasonable to hypothesize that a decline over time in regular physical activity may affect risk for all-cause mortality in subjects with COPD.

Therefore we sought 1) to compare the longitudinal changes in the level of selfreported regular physical activity between subjects with and without COPD; 2) to identify baseline determinants of changes in physical activity in subjects with and without COPD; and 3) to identify the association between the changes in the level of selfreported regular physical activity and all-cause mortality in subjects with and without COPD. 


\section{METHODS}

\section{Study design and population}

All subjects participated in the Copenhagen City Heart Study (CCHS)(18). A sample of the general population aged 20 years or older was selected at random and invited to participate. 14,223 subjects attended the first CCHS examination in 1976-78. In 198183, 1991-94, and 2001-03, participants were re-examined, and new 20-49 year old subjects were invited in an attempt to have a study population with representatives from all age groups. The institutional review board and Danish regional ethics committees approved the research protocol. All participants gave written informed consent(18).

Subjects with at least two consecutive examinations were analyzed. COPD was defined on the ratio forced expiratory volume in one second $\left(\mathrm{FEV}_{1}\right)$ and forced vital capacity (FVC) $\leq 70 \%(8)$. The date of participation in the examination when COPD was first diagnosed was considered as baseline examination.

After excluding subjects with missing data (lung function and/or physical activity at baseline and/or follow up), and/or with an inconsistent diagnosis of COPD, a total of 10,004 subjects were analyzed ( $n=1,270$ subjects with COPD; $n=8,734$ subjects without COPD). A total of 5,408 subjects had 1 follow-up examination, 2,537 subjects had 2 follow-up examinations, and 2,059 subjects had 3 follow-up examinations. This resulted in 16,659 data points with repeated examinations ( $n=1,733$ in subjects with COPD; $n=14,926$ in subjects without COPD (Figure 1). Median time between the baseline examination and follow-up examination was 9.0 years (interquartile range (IQR): 5.0, 11.0).

Mortality data were available in 1,166 subjects with COPD and 7,143 subjects without COPD. Follow-up started at the last evaluation for each subject, and had a median duration of 17.1 years (interquartile range (IQR): 9.3, 24.2). Then, there was no artificial nomortality-risk initial period.

\section{Measurements}

\section{Physical activity}

Physical activity was measured at each examination using a valid and reliable questionnaire(19-21). Physical activity was classified into 'low', 'moderate' or 'high', as described earlier(17, 20). Please see online supplement for all details. 


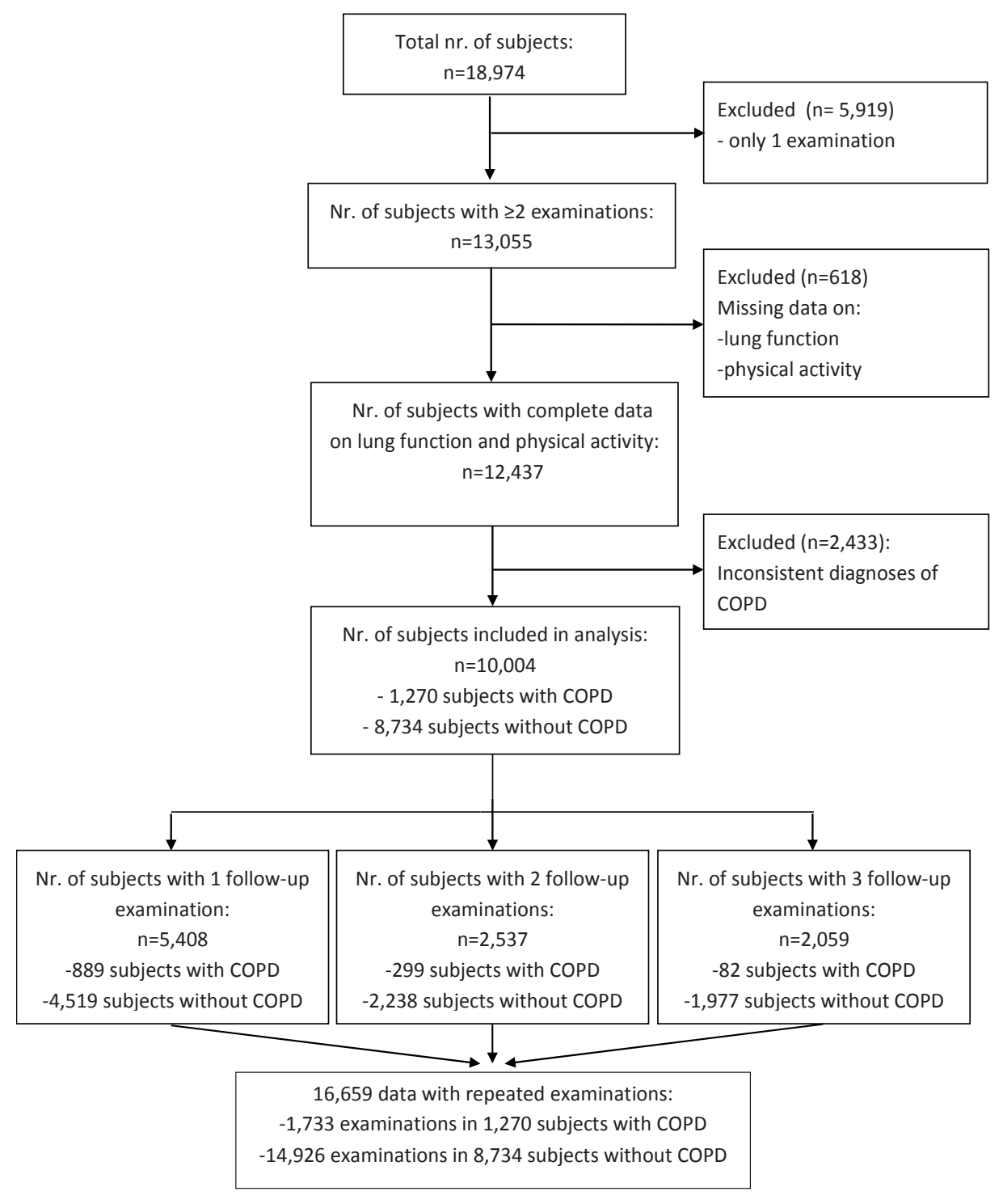

Figure 1. Flow Chart 


\section{Lung function}

Spirometry was used to assess lung function. At each examination three sets of values were obtained, and at least two measurements differing by less than $5 \%$ had to be produced. The highest values of $\mathrm{FEV}_{1}$ and FVC were used for further analyses. Please see online supplement for details.

\section{Other variables}

Each examination included a self-administered questionnaire and clinical examination. The questionnaire included questions regarding socioeconomic factors (sex, age, education, marital status, and cohabitation), current smoking, self-reported comorbidities (cardiac comorbidities, diabetes, and current symptoms of chest pain and/or leg pain).

\section{Statistics}

Differences between subjects with and without COPD were compared using two-tailed t-tests and chi squared tests, as appropriate. Changes in physical activity level from baseline to follow-up examination were stratified according to baseline physical activity level (e.g., low, moderate or high). Differences between physical activity levels and changes in physical activity level were compared using analysis of variance (ANOVA) and Bonferroni post hoc comparisons or chi squared analysis. Generalized estimating equations (GEEs) with exchangeable correlation structure, adjusted for gender and age, were used to identify determinants of longitudinal changes in physical activity level in subjects with and without COPD. Models were stratified according to baseline physical activity level. The outcome variable had the following categories: decrease in physical activity level, no change in physical activity level, or increase in physical activity level. No change in physical activity level was used as reference category. Possible predictor variables, including sociodemographic data (marital status, cohabitation, and years of education), clinical data (lung function, and body mass index (BMI)), self-reported comorbidities and smoking history, with a significant association and the interaction of each variable with time were subsequently modeled as possible explanatory variables. Results are presented as odds ratios (OR) and 95\% confidence intervals (CI).

Cox proportional hazards regression was used to determine the potential effect of longitudinal changes in physical activity as a predictor of survival. The models were stratified according to baseline physical activity level and to COPD status (subjects with or without COPD). The exposure variable had the following categories: decrease in physical activity level, no change in physical activity level and increase in physical activity level. No change in physical activity level was considered as reference category. Variables considered as potential confounders were tested, and were maintained in the final multivariate models if they modified the hazard ratio estimate for any of the remaining covariates ( $\geq 10 \%$ change in beta coefficients). We tested proportionality assumptions and goodness of fit of the models using both the graphical check based on the log- 
minus-log curves and Schoenfeld residuals. Both methods revealed no violation of the proportional hazard assumption.

All analyses were carried out using SPSS 21.0. A priori, a two-sided level of significance was set at $p \leq 0.05$.

\section{RESULTS}

\section{Characteristics at baseline}

Table 1 shows the baseline characteristics of 1,270 subjects with COPD and 8,734 subjects without COPD. Significant differences were found in sociodemographic and clinical data, presence of self-reported symptoms and comorbidities, and smoking status (Table 1). The baseline characteristics stratified by CCHS examination are included in the online supplement (Table E1).

\section{Baseline physical activity}

The proportion of subjects with COPD with a low physical activity level was significantly higher compared to the proportion of subjects without COPD (Table 1). Subjects with COPD with a low physical activity level had a significantly worse lung function, shorter education, a higher proportion of current smokers, and more smoking years compared to subjects with COPD with a moderate or high baseline physical activity level. Furthermore, significant differences were found for gender and marital status (Table 2). Similar results were found in the subjects without COPD. In addition, age, BMI and the presence of self-reported symptoms and comorbidities were significantly different between subjects without COPD with a low, moderate or high baseline physical activity level (Table 2). Differences between subjects with COPD with and without self-reported comorbidities are available in the online supplement, showing that subjects with comorbidities were older, had a higher BMI and more smoking years. 
Table 1. Population characteristics at first examination

\begin{tabular}{|c|c|c|c|c|}
\hline & & $\begin{array}{l}\text { Subjects with COPD } \\
\qquad(n=1270)\end{array}$ & $\begin{array}{l}\text { Subjects without COPD } \\
\qquad(n=8734)\end{array}$ & p-value \\
\hline \multicolumn{5}{|l|}{ Sociodemographic data } \\
\hline Sex, male & $\%$ & 57.9 & 42.4 & $<0.001$ \\
\hline Age, years & $\mathrm{m}(\mathrm{SD})$ & $56.2(9.5)$ & $48.5(12.6)$ & $<0.001$ \\
\hline Marital status & & & & 0.040 \\
\hline Married/cohabiting & $\%$ & 68.4 & 65.9 & \\
\hline Other & $\%$ & 31.6 & 34.1 & \\
\hline Cohabitation & & & & 0.030 \\
\hline Alone & $\%$ & 32.8 & 30.2 & \\
\hline With others & $\%$ & 67.2 & 69.8 & \\
\hline Education, years at school & $\mathrm{m}(\mathrm{SD})$ & $8.4(1.9)$ & $9.0(2.2)$ & $<0.001$ \\
\hline \multicolumn{5}{|l|}{ Clinical data } \\
\hline $\mathrm{BMI}, \mathrm{kg} / \mathrm{m}^{2}$ & $\mathrm{~m}(\mathrm{SD})$ & $24.6(3.7)$ & $25.1(4.0)$ & 0.001 \\
\hline$<20 \mathrm{~kg} / \mathrm{m}^{2}$ & $\%$ & 9.2 & 6.6 & 0.002 \\
\hline $20-25 \mathrm{~kg} / \mathrm{m}^{2}$ & $\%$ & 49.3 & 49.0 & \\
\hline$>25 \mathrm{~kg} / \mathrm{m}^{2}$ & $\%$ & 41.5 & 44.3 & \\
\hline FEV1, L & $\mathrm{m}(\mathrm{SD})$ & $2.1(0.8)$ & $2.9(0.9)$ & $<0.001$ \\
\hline FEV1, \%pred & $\mathrm{m}(\mathrm{SD})$ & $67.0(18.2)$ & $90.9(15.4)$ & $<0.001$ \\
\hline FEV1/FVC, \% & $\mathrm{m}(\mathrm{SD})$ & $63.0(6.9)$ & $83.4(6.8)$ & $<0.001$ \\
\hline GOLD stage, I/II/III/IV & $\%$ & $24.3 / 57.4 / 15.9 / 2.4$ & -- & \\
\hline \multicolumn{5}{|c|}{ Self-reported symptoms and comorbidities } \\
\hline Diabetes & $\%$ & 0.6 & 2.4 & $<0.001$ \\
\hline Cardiac comorbidities & $\%$ & 32.4 & 26.5 & $<0.001$ \\
\hline Chest pain & $\%$ & 38.1 & 33.5 & 0.001 \\
\hline Leg pain while walking & $\%$ & 11.9 & 10.1 & 0.046 \\
\hline \multicolumn{5}{|l|}{ Smoking } \\
\hline Current smoking & $\%$ & 79.1 & 54.8 & $<0.001$ \\
\hline Never smoked & $\%$ & 5.8 & 26.3 & $<0.001$ \\
\hline Ex-smoker & $\%$ & 15.1 & 18.9 & $<0.001$ \\
\hline Smoking years & $\mathrm{m}(\mathrm{SD})$ & $34.5(11.5)$ & $24.6(12.8)$ & $<0.001$ \\
\hline \multicolumn{5}{|l|}{ Physical activity } \\
\hline $\begin{array}{l}\text { Self-reported baseline physical } \\
\text { activity level }\end{array}$ & & & & $<0.001$ \\
\hline Low & $\%$ & 19.5 & 14.6 & \\
\hline Moderate & $\%$ & 51.5 & 53.8 & \\
\hline High & $\%$ & 29.0 & 31.7 & \\
\hline
\end{tabular}

First examination may be different for each subject (CCHS examination 1, 2 or 3)

$\mathrm{BMI}=$ Body mass index; FEV1=Forced expiratory volume in one second; FVC=Forced vital capacity 


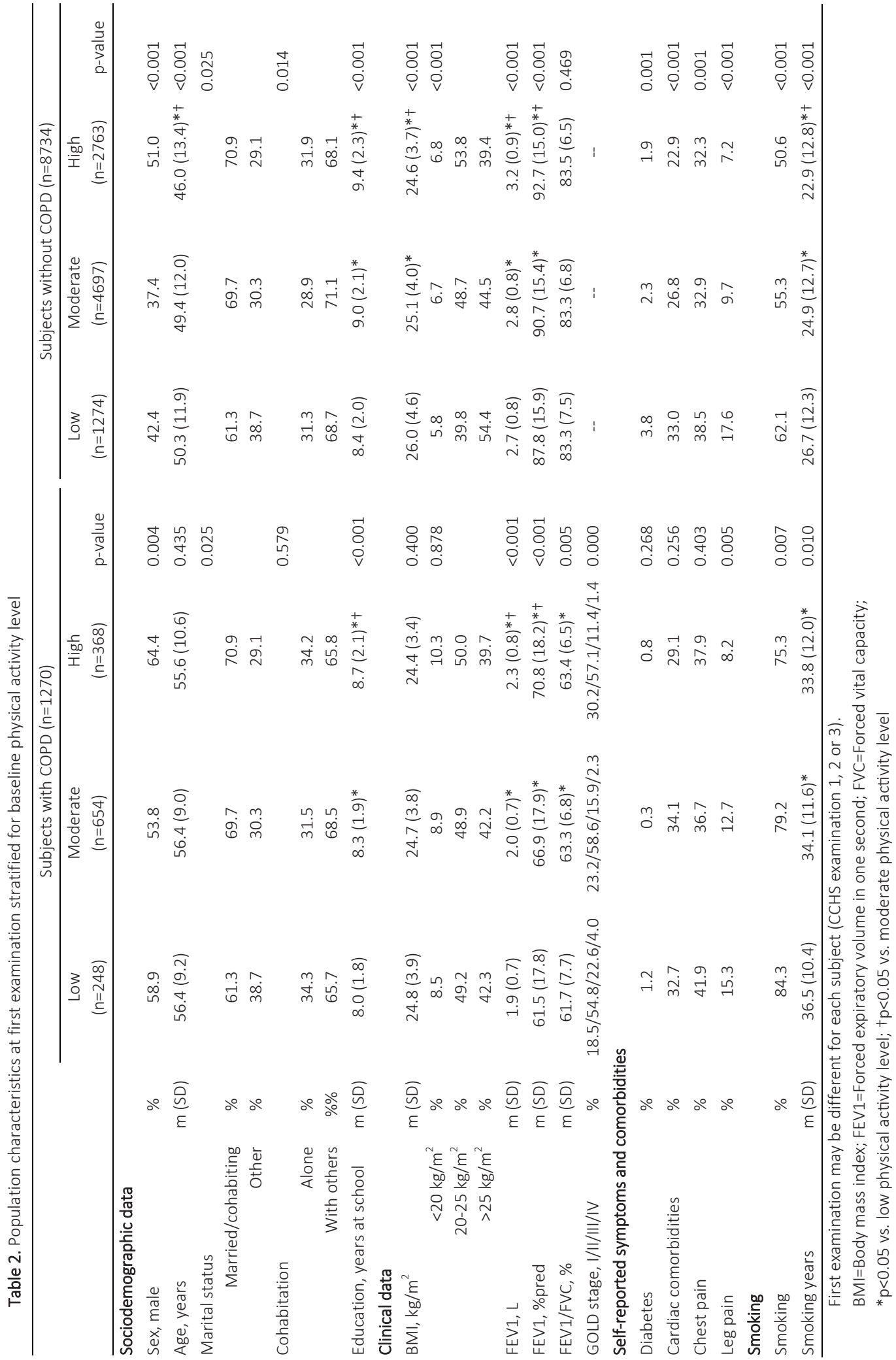


The proportion of the subjects with COPD with a low baseline physical activity who remained physically low active at follow-up was significantly higher compared to the proportion of subjects without COPD (42.6 versus $31.9 \%, p<0.001$; Figure 2 ). Furthermore, the proportion of subjects with COPD with a moderate baseline physical activity level who changed their physical activity level at follow-up was significantly different compared to the proportion of subjects without COPD (decrease in physical activity: $14.9 \%$ versus $11.4 \%, p=0.003$; increase in physical activity: $26.4 \%$ versus $27.8 \%$, $\mathrm{p}=0.045$; Figure 2). Finally, the proportion of subjects with COPD with a high physical activity level at baseline who reported a decline in physical activity at follow up was significantly higher compared to the subjects without COPD (52.6\% versus $46.7 \%$; $p=0.010$; Figure 2). All differences remained significant after correction for differences in age and gender $(p<0.05)$. Differences in baseline characteristics of groups of physical activity change in subjects with and without COPD are shown in tables E4/E5 of online supplement.

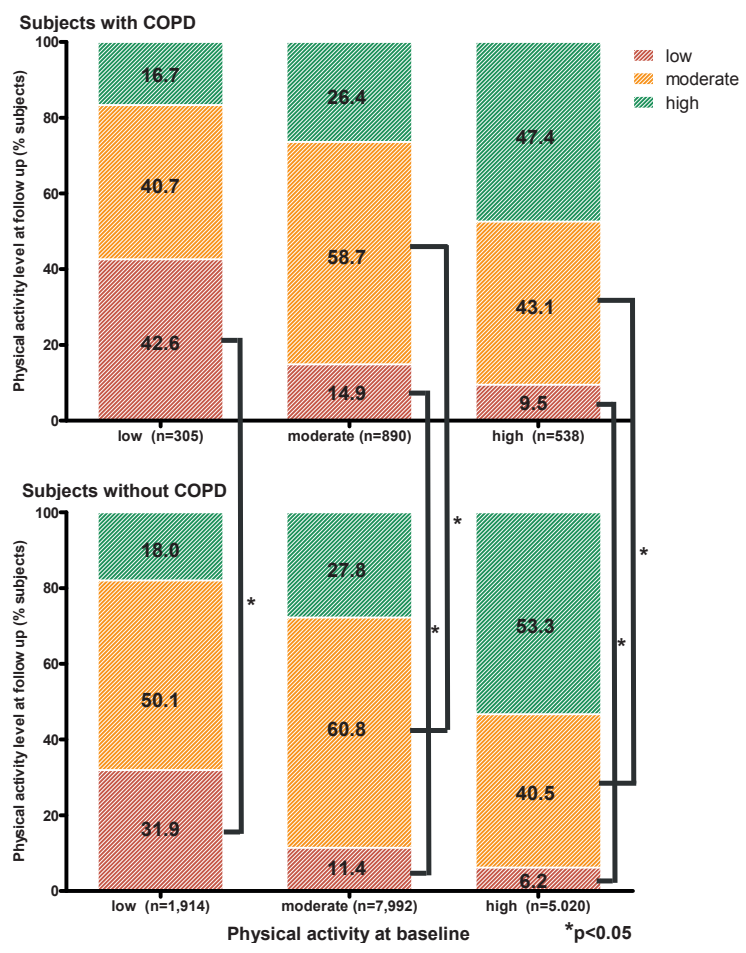

Figure 2. Longitudinal changes in physical activity in subjects with COPD (1,733 data points) and subjects without COPD (14,926 data points) 
In subjects with COPD, a higher baseline FEV ${ }_{1}$ was associated with a lower risk of decrease in physical activity level (OR: 0.507 and 0.553 for subjects with a moderate or high baseline physical activity, respectively; $p<0.001$ for both; Table 3 and Table E6 online supplement). Moreover, age (inversely), male sex, not smoking and cohabiting were associated with an increase in physical activity in subjects with COPD with a moderate baseline physical activity, and more smoking years was associated with a decrease in physical activity level in subjects with a high baseline physical activity level (Table 3). In subjects without COPD, low baseline $\mathrm{FEV}_{1}$, active smoking, female sex, high age, short education, presence of comorbidities, being unmarried and overweight or obese were associated with a decrease in physical activity level (Table 3 and Table E7 online supplement). In addition, active smoking, male sex, being married and years of education were associated with an increase in physical activity level (Table 3).

\section{Longitudinal changes in physical activity and all-cause mortality}

During a median follow up of 17.1 years (IQR: 9.3, 24.2), 5,392 subjects died (64.9\%). The highest proportion of non-survivors was found among subjects with COPD ( $n=944$; 81.0\%). In the subjects with COPD and a low physical activity at baseline, no significant differences were found in crude and adjusted hazards to die between subjects who remained low physically active at follow up and subjects who reported an increase in physical activity (Table 4; Figure 3a). Subjects with COPD and baseline moderate to high physical activity who reported a low physical activity level at follow up had the highest crude and adjusted hazards to die (crude HR: 1.64 and adjusted HR 1.73 for subjects with moderate baseline physical activity; and crude HR: 3.31 and adjusted HR: 2.35 for subjects with high baseline physical activity, both $p<0.001$; Table 4; Figures $3 b / 3 c$ ). In addition, subjects without COPD with a low physical activity at follow up had the highest hazard to die, irrespective of baseline physical activity level $(p<0.05$; Table 4; Figures $3 d / 3 e / 3 f)$. 
Table 3. Odds ratios for determinants of longitudinal changes in physical activity in subjects with and without COPD*

\begin{tabular}{|c|c|c|c|c|}
\hline & Low baseline PA & Moderate & baseline PA & High baseline PA \\
\hline & $\begin{array}{l}\text { Increase } \\
(95 \% \mathrm{Cl})\end{array}$ & $\begin{array}{c}\text { Decrease } \\
(95 \% \mathrm{Cl})\end{array}$ & $\begin{array}{l}\text { Increase } \\
(95 \% \mathrm{Cl})\end{array}$ & $\begin{array}{c}\text { Decrease } \\
(95 \% \mathrm{Cl})\end{array}$ \\
\hline Subjects with COPD & & & & \\
\hline FEV1 (L) & $1.672(1.127-2.477)$ & $0.507(0.346-0.741)$ & . & $0.553(0.400-0.765)$ \\
\hline Age (years) & . & . & $0.980(0.963-0.998)$ & . \\
\hline Sex [female] & . & . & $0.602(0.428-0.848)$ & . \\
\hline Sex [male] & . & . & 1.0 & . \\
\hline Smoking [yes] & . & . & $0.536(0.355-0.811)$ & . \\
\hline Smoking [no] & . & . & 1.0 & . \\
\hline Cohabitation [with others] & . & . & $1.456(1.006-2.109)$ & . \\
\hline Cohabitation [alone] & . & . & 1.0 & . \\
\hline Smoking (years) & . & . & . & $1.020(1.001-1.041)$ \\
\hline Subjects without COPD & & & & \\
\hline FEV1 (L) & . & $0.811(0.690-0.953)$ & . & $0.817(0.720-0.927)$ \\
\hline Age (years) & . & . & . & $1.008(1.001-1.015)$ \\
\hline Sex [female] & . & $1.441(1.150-1.806)$ & $0.614(0.542-0.694)$ & . \\
\hline Sex [male] & $\cdot$ & 1.0 & 1.0 & $\cdot$ \\
\hline Smoking [yes] & 1.319 (1.077-1.616) & 1.340 (1.096-1.639) & 0.891 (0.780-0.999) & 1.381 (1.189-1.605) \\
\hline Smoking [no] & 1.0 & 1.0 & 1.0 & 1.0 \\
\hline Marital status & & & & \\
\hline [married/cohabiting] & $1.064(1.009-1.123)$ & . & . & $0.847(0.731-0.981)$ \\
\hline Marital status [other] & . & . & . & 1.0 \\
\hline Education (years) & . & $0.883(0.841-0.928)$ & $1.039(1.006-1.073)$ & 0.951 (0.918-0.986) \\
\hline Comorbidities [yes] & . & $1.530(1.281-1.828)$ & . & 1.161 (1.009-1.336) \\
\hline Comorbidities [no] & . & 1.0 & . & 1.0 \\
\hline BMI [>25 kg/m2] & . & . & . & $1.218(1.047-1.416)$ \\
\hline BMI [20-25 kg/m2] & . & . & . & 1.0 \\
\hline
\end{tabular}

*adjusted for age and gender

The complete models are included in the online supplement (Table E4 and E5). 
Table 4. Crude and adjusted associations between longitudinal changes in physical activity and all-cause mortality in subjects with and without COPD

\begin{tabular}{|c|c|c|c|c|c|}
\hline $\begin{array}{l}\text { Physical activity leve } \\
\text { at baseline }\end{array}$ & $\begin{array}{l}\text { Physical activity } \\
\text { level at follow-up }\end{array}$ & $\begin{array}{l}\text { Crude HR } \\
(95 \% \mathrm{Cl})\end{array}$ & $p$-value & $\begin{array}{l}\text { Adjusted HR } \\
(95 \% \mathrm{Cl})^{*}\end{array}$ & p-value \\
\hline \multicolumn{6}{|l|}{ Subjects with COPD } \\
\hline \multirow[t]{3}{*}{ Low $(n=235)$} & Low $(n=95)$ & 1 & & 1 & \\
\hline & Moderate (n=99) & $0.798(0.590-1.079)$ & 0.142 & $0.835(0.605-1.151)$ & 0.270 \\
\hline & High $(n=41)$ & $0.853(0.567-1.262)$ & 0.425 & $1.012(0.669-1.531)$ & 0.953 \\
\hline \multirow{3}{*}{ Moderate $(n=602)$} & $\operatorname{Low}(n=84)$ & $1.644(1.271-2.126)$ & $<0.001$ & $1.729(1.335-2.239)$ & $<0.001$ \\
\hline & Moderate $(n=351)$ & 1 & & 1 & \\
\hline & High ( $n=167)$ & $1.183(0.962-1.455)$ & 0.112 & $1.174(0.952-1.447)$ & 0.134 \\
\hline \multirow[t]{3}{*}{ High $(n=329)$} & Low $(n=34)$ & $3.307(2.202-4.966)$ & $<0.001$ & $2.351(1.516-3.646)$ & $<0.001$ \\
\hline & Moderate $(n=148)$ & 1.253 (0.957-1.639) & 0.101 & $1.048(0.790-1.390)$ & 0.746 \\
\hline & High $(n=147)$ & 1 & & 1 & \\
\hline \multicolumn{6}{|l|}{ Subjects without COPD } \\
\hline \multirow[t]{3}{*}{ Low $(n=1116)$} & Low $(n=390)$ & 1 & & 1 & \\
\hline & Moderate $(n=512)$ & $0.745(0.636-0.874)$ & $<0.001$ & $0.707(0.592-0.844)$ & $<0.001$ \\
\hline & High $(n=214)$ & $0.777(0.637-0.949)$ & 0.013 & $0.747(0.599-0.931)$ & 0.009 \\
\hline \multirow{3}{*}{ Moderate $(n=4007)$} & Low $(n=520)$ & 1.518 (1.355-1.700) & $<0.001$ & $1.224(1.091-1.373)$ & 0.001 \\
\hline & Moderate $(n=2342)$ & 1 & & 1 & \\
\hline & High $(n=520)$ & $1.120(1.024-1.225)$ & 0.013 & $0.961(0.878-1.053)$ & 0.727 \\
\hline \multirow[t]{3}{*}{ High (n=2020) } & Low $(n=148)$ & 1.642 (1.302-2.070) & $<0.001$ & $1.256(1.000-1.590)$ & 0.050 \\
\hline & Moderate $(n=742)$ & $1.071(0.932-1.230)$ & 0.331 & 1.007 (0.876-1.159) & 0.919 \\
\hline & High $(n=1130)$ & 1 & & 1 & \\
\hline
\end{tabular}

*Multivariate model adjusted for gender, age and confounders of the association between physical activity and all-cause mortality, including self-reported comorbidities, smoking, smoking years, education, FEV 1 , and BMI. The complete models with all covariates are included in the online supplement (Table E8 and E9). 
a

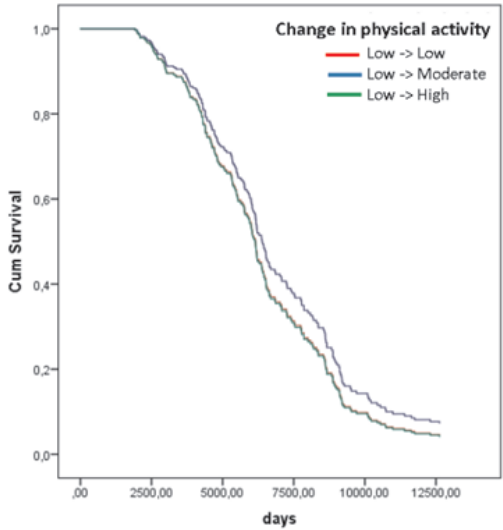

b

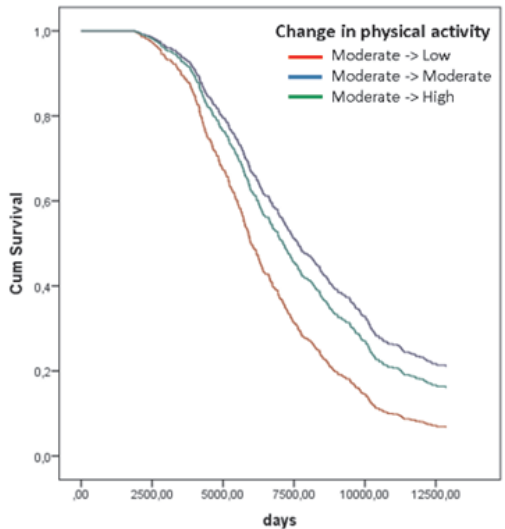

C

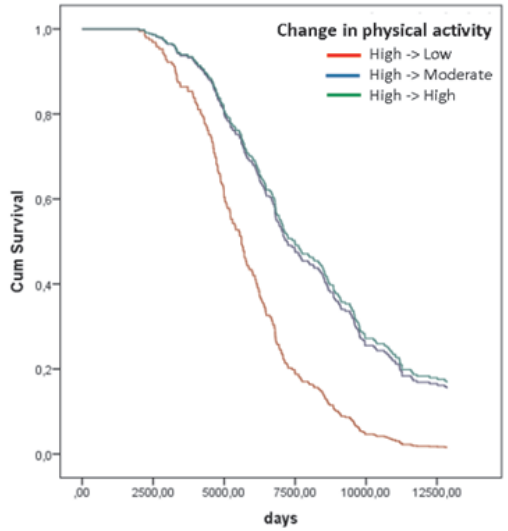

d

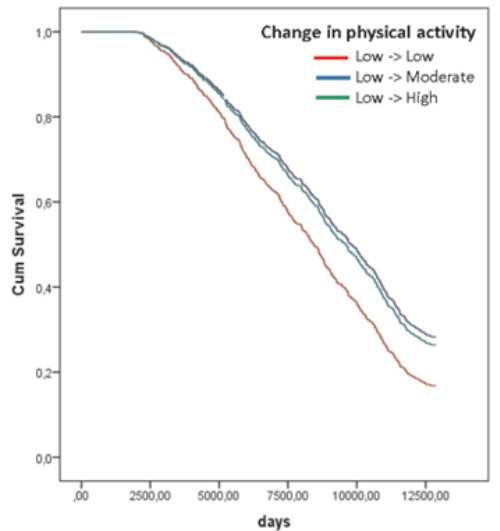

e

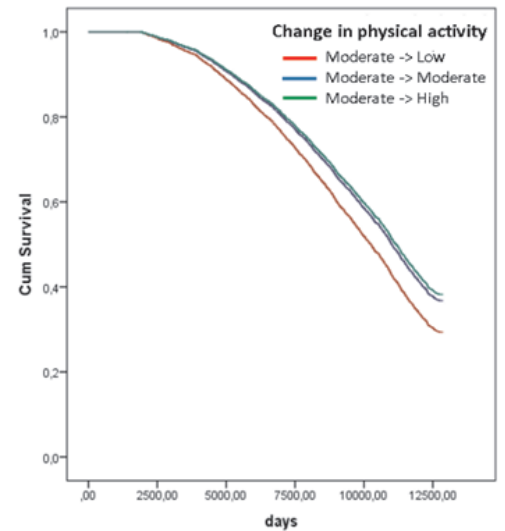

f

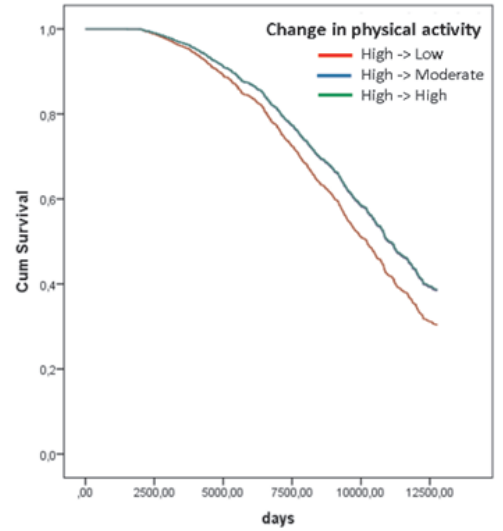

Figure 3. Survival curves according to longitudinal changes in physical activity

a) Subjects with COPD with a low physical activity level at baseline; b) Subjects with COPD with a moderate physical activity level at baseline; c) Subjects with COPD with a high physical activity level at baseline; d) Subjects without COPD with a low physical activity level at baseline; e) Subjects without COPD with a moderate physical activity level at baseline; f) Subjects without COPD with a high physical activity level at baseline 


\section{DISCUSSION}

The present study has three major findings: 1) a decline in self-reported regular physical activity is significantly more common in subjects with COPD compared to subjects without COPD; 2) baseline determinants of longitudinal changes in self-reported physical activity are different between subjects with and without COPD; and 3) a decline in physical activity at follow up was associated with an increased all-cause mortality risk in subjects with and without COPD. Thus, it seems that whereas an increase in physical activity was associated with reduced mortality in subjects without COPD, this was not so in subjects with COPD who increased their activity level from low to either moderate or high.

The proportion of subjects with COPD with a low physical activity level was significantly higher compared to subjects without COPD, indicating a more inactive lifestyle in subjects with COPD. This finding is consistent with earlier studies(3, 11, 22-24). The proportions of subjects with COPD with a high physical activity level (29\%) may be somewhat surprising compared to subjects without COPD (31.7\%). Then again, the CCHS cohort is a sample of the general population. This may explain at least in part that the proportion of COPD patients with high baseline physical activity level is comparable with the proportion of subjects without COPD who report a high baseline physical activity level. Indeed, COPD patients with GOLD I and II were highly prevalent.

In addition, the proportion of subjects with COPD with a decline in physical activity was higher compared to the proportion of subjects without COPD, irrespective of physical activity level at baseline (Tables 3/4). This finding is novel as previous studies on the long-term changes in physical activity did not include a non-COPD control group(14-16).

From cross-sectional studies it is well known that physical activity is associated with clinical, sociodemographic and behavioral factors(1, 5, 11, 14, 22, 23, 25, 26). However, data on determinants of longitudinal changes in regular physical activity are limited. The current results indicate that determinants of longitudinal changes in self-reported physical activity differ between subjects with and without COPD. Changes in physical activity in subjects without COPD are determined by a large variety of factors, including clinical data, sociodemographic data and the presence of comorbidities, whereas in subjects with COPD the variables with the highest likelihood for changes in physical activity are sex, the degree of airflow obstruction and smoking status. This may indicate that subjects with COPD are mainly limited by the consequences of COPD and that other variables have a limited additional impact on changes in physical activity. Then again, possible confounders, such as diet and objectified comorbidities, were not assessed, which may also partly explain the greater decline in physical activity in subjects with COPD. Determination of clinical and demographic correlates of physical activity may be im- 
portant for identifying subjects that are at risk for developing an inactive lifestyle, but also for designing a specific and adequate physical activity program for these subjects.

Previously, Garcia-Aymerich and colleagues using the present population showed that subjects with COPD and a very low to low baseline physical activity level had a higher mortality risk than subjects with COPD and a moderate to high physical activity level(8). Changes in physical activity behavior, however, were not taken into account. Our analyses are the first to show an association between long-term changes in regular physical activity and all-cause mortality in subjects with COPD. A decline to a low physical activity level was associated with the highest all-cause mortality risk in subjects with and without COPD. Moreover, it seems that being moderate physically active may already have important beneficial consequences in subjects with and without COPD. However, in subjects with COPD with a low physical activity level at baseline, no beneficial effect of an increased physical activity at follow up was seen. This suggests that once subjects with COPD become physically low active, the high mortality risk cannot be reversed by increasing activity levels. So, in subjects with COPD it is of clinical importance to remain moderate to high physically active.

Given the association between reduced physical activity and important health-related outcomes $(8,10,25)$ and the findings of this study, an adequate physical activity level should be encouraged already in subjects with mild COPD. Structured exercise programs seem to be beneficial in increasing physical activity; however, results are not uniform and long-term data are lacking(27). Since it is important that subjects with COPD integrate physical activity in their daily life, education and counseling should be an important component of programs targeting physical activity. Indeed, it has previously been shown that activity monitor-based counseling has a beneficial effect on physical activity and health-related outcomes in patients with chronic diseases(28). Stimulating physical activity and prevention of a sedentary lifestyle, already in the earliest stages of COPD, may not only result in less adverse health-related consequences and a reduction in health care utilization and costs(8), but also in better survival.

The results of our study may be affected by several limitations. The inclusion of subjects with at least two consecutive examinations may have caused a certain degree of selection bias, since we will have selected the healthiest subjects for analyses. Furthermore, the assessment of physical activity by a questionnaire may represent a subjective level of physical activity. However, previously was shown that self-reported measures are fairly accurate of changes in physical activity in large epidemiological studies(29) and it is probably the only way to collect repeated data in such a large sample sizes during decades. Moreover, the large sample size in this study compensates any degree of nondifferential misclassification of subjects(30). Finally, the questionnaire used in the CCHS to assess physical activity fulfills the criteria of a patient-reported outcome (PRO) questionnaire(19). Questions and answer options could easily be interpreted and completed 
by the participants; subjects' physical activity behavior was measured, without interpretation from anyone else; and this questionnaire was able to detect clinically relevant changes in physical activity (Figure 3). As such, it provides important results to subjects with COPD and their healthcare providers in order to make proper, patient-centered treatment decisions, including lifestyle modifications(31).

The used sample is regarded as representative for the Danish population. It might be argued whether our results can be generalized to other populations, for example those who cycle less. With regard to the possibility of residual confounding factors, our results have been adjusted for all available risk factors. It is plausible that other factors not included in the CCHS data (e.g. diet, objectified comorbidities), may also contribute to changes in physical activity. In addition, we did not adjust for changes in $\mathrm{FEV}_{1}$ and BMI, since we believe that these are mediators rather than confounders. Nevertheless, additional analyses showed that the small non-significant changes in FEV1 and BMI over time do not contribute significantly to the final multivariate model as presented in Table 4 and Table E8/9 of the online supplement.

Although a longitudinal study design can limit the effect of reverse causality, it might still be present. However, a previous paper showed that earlier reported associations from the CCHS were not due to time-dependent confounding(32).

To conclude, our results show that subjects with COPD not only reported a lower physical activity levels compared to subjects without COPD, but are also more likely to decrease their level of physical activity over time. Moreover, subjects with a decline to a low physical activity level at follow up had a higher all-cause mortality risk than subjects who remained or increased regular physical activity compared to baseline. However, the beneficial effect of increasing physical activity did not apply to subjects with COPD who were physically inactive at baseline. Therefore, these observational data suggest that it is important to assess and encourage regular physical activity already in the earliest stages of COPD in order to maintain an as high as possible physical activity level as this is associated with a better prognosis. 


\section{REFERENCES}

1. Waschki B, Spruit MA, Watz H, Albert PS, Shrikrishna D, Groenen M, et al. Physical activity monitoring in COPD: compliance and associations with clinical characteristics in a multicenter study. Respir Med. 2012;106(4):522-30.

2. Nelson ME, Rejeski WJ, Blair SN, Duncan PW, Judge JO, King AC, et al. Physical activity and public health in older adults: recommendation from the American College of Sports Medicine and the American Heart Association. Med Sci Sports Exerc. 2007;39(8):1435-45.

3. Hernandes NA, Teixeira Dde C, Probst VS, Brunetto AF, Ramos EM, Pitta F. Profile of the level of physical activity in the daily lives of patients with COPD in Brazil. Jornal brasileiro de pneumologia : publicacao oficial da Sociedade Brasileira de Pneumologia e Tisilogia. 2009;35(10):949-56.

4. Pitta F, Troosters T, Probst VS, Lucas S, Decramer M, Gosselink R. Potential consequences for stable chronic obstructive pulmonary disease patients who do not get the recommended minimum daily amount of physical activity. Jornal brasileiro de pneumologia : publicacao oficial da Sociedade Brasileira de Pneumologia e Tisilogia. 2006;32(4):301-8.

5. Donaire-Gonzalez D, Gimeno-Santos E, Balcells E, Rodriguez DA, Farrero E, de Batlle J, et al. Physical activity in COPD patients: patterns and bouts. Eur Respir J. 2013;42(4):993-1002.

6. Garcia-Aymerich J, Lange P, Benet M, Schnohr P, Anto JM. Regular physical activity modifies smokingrelated lung function decline and reduces risk of chronic obstructive pulmonary disease: a populationbased cohort study. Am J Respir Crit Care Med. 2007;175(5):458-63.

7. Shrikrishna D, Patel M, Tanner RJ, Seymour JM, Connolly BA, Puthucheary ZA, et al. Quadriceps wasting and physical inactivity in patients with COPD. Eur Respir J. 2012;40(5):1115-22.

8. Garcia-Aymerich J, Lange P, Benet M, Schnohr P, Anto JM. Regular physical activity reduces hospital admission and mortality in chronic obstructive pulmonary disease: a population based cohort study. Thorax. 2006;61(9):772-8.

9. Pitta F, Troosters T, Probst VS, Spruit MA, Decramer M, Gosselink R. Physical activity and hospitalization for exacerbation of COPD. Chest. 2006;129(3):536-44.

10. Waschki B, Kirsten A, Holz O, Muller KC, Meyer T, Watz H, et al. Physical activity is the strongest predictor of all-cause mortality in patients with COPD: a prospective cohort study. Chest. 2011;140(2):331-42.

11. Pitta F, Troosters T, Spruit MA, Probst VS, Decramer M, Gosselink R. Characteristics of physical activities in daily life in chronic obstructive pulmonary disease. Am J Respir Crit Care Med. 2005;171(9):972-7.

12. Gosker HR, Lencer NH, Franssen FM, van der Vusse GJ, Wouters EF, Schols AM. Striking similarities in systemic factors contributing to decreased exercise capacity in patients with severe chronic heart failure or COPD. Chest. 2003;123(5):1416-24.

13. Serres I, Gautier V, Varray A, Prefaut C. Impaired skeletal muscle endurance related to physical inactivity and altered lung function in COPD patients. Chest. 1998;113(4):900-5.

14. Esteban C, Quintana JM, Aburto M, Moraza J, Egurrola M, Perez-Izquierdo J, et al. Impact of changes in physical activity on health-related quality of life among patients with COPD. Eur Respir J. 2010;36(2):292-300.

15. Agarwal V, Tetenta S, Bautista J, ZuWallack R, Lahiri B. Longitudinal changes in directly measured physical activity in patients with chronic obstructive pulmonary disease: the trajectory of change. J Cardiopulm Rehabil Prev. 2012;32(5):292-5.

16. Waschki B, Schaper M, Sack AL, Holz O, Kirsten A, Meyer T, et al. Decrease of physical activity in patients with COPD in the course of the disease. European Respiratory Society Annual Congress 2012 Abstract 3019.

17. Schnohr $\mathrm{P}$, Scharling $\mathrm{H}$, Jensen JS. Changes in leisure-time physical activity and risk of death: an observational study of 7,000 men and women. Am J Epidemiol. 2003;158(7):639-44.

18. Schnohr P, Jensen G, Lange P, Scharling H, Appleyard M. The Copenhagen City heart study. Eur Heart J. 2001;3:(suppl H)(H):H1-H83. 
19. Saltin B, Grimby G. Physiological analysis of middle-aged and old former athletes. Comparison with still active athletes of the same ages. Circulation. 1968;38(6):1104-15.

20. Schnohr P. Physical activity in leisure time: impact on mortality. Risks and benefits. Danish medical bulletin. 2009;56(1):40-71.

21. Aires N, Selmer R, Thelle D. The validity of self-reported leisure time physical activity, and its relationship to serum cholesterol, blood pressure and body mass index. A population based study of 332,182 men and women aged 40-42 years. European journal of epidemiology. 2003;18(6):479-85.

22. Watz H, Waschki B, Meyer T, Magnussen H. Physical activity in patients with COPD. Eur Respir J. 2009;33(2):262-72.

23. Troosters T, Sciurba F, Battaglia S, Langer D, Valluri SR, Martino L, et al. Physical inactivity in patients with COPD, a controlled multi-center pilot-study. Respir Med. 2010;104(7):1005-11.

24. Vorrink SN, Kort HS, Troosters T, Lammers JW. Level of daily physical activity in individuals with COPD compared with healthy controls. Respir Res. 2011;12:33.

25. Garcia-Aymerich J, Serra I, Gomez FP, Farrero E, Balcells E, Rodriguez DA, et al. Physical activity and clinical and functional status in COPD. Chest. 2009;136(1):62-70.

26. Bauman AE, Reis RS, Sallis JF, Wells JC, Loos RJ, Martin BW. Correlates of physical activity: why are some people physically active and others not? Lancet. 2012;380(9838):258-71.

27. Cindy Ng LW, Mackney J, Jenkins S, Hill K. Does exercise training change physical activity in people with COPD? A systematic review and meta-analysis. Chron Respir Dis. 2012;9(1):17-26.

28. Vaes AW, Cheung A, Atakhorrami M, Groenen MT, Amft O, Franssen FM, et al. Effect of 'activity monitor-based' counseling on physical activity and health-related outcomes in patients with chronic diseases: A systematic review and meta-analysis. Ann Med. 2013;45(5-6):397-412.

29. Shephard RJ. Limits to the measurement of habitual physical activity by questionnaires. Br J Sports Med. 2003;37(3):197-206; discussion

30. Szklo M, Nieto J. Epidemiology beyond the basics. Gaithersburg: Aspen publisher, Inc; 2000.

31. Frei A, Williams K, Vetsch A, Dobbels F, Jacobs L, Rudell K, et al. A comprehensive systematic review of the development process of 104 patient-reported outcomes (PROs) for physical activity in chronically ill and elderly people. Health Qual Life Outcomes. 2011;9(1):116.

32. Garcia-Aymerich J, Lange P, Serra I, Schnohr P, Anto JM. Time-dependent confounding in the study of the effects of regular physical activity in chronic obstructive pulmonary disease: an application of the marginal structural model. Ann Epidemiol. 2008;18(10):775-83. 


\section{ONLINE SUPPLEMENT}

\section{METHODS}

\section{Measurements}

\section{Physical activity}

Physical activity was measured at each examination using a questionnaire originally developed by Saltin and Grimby(1, 2), which has shown good validity and reliability (2, 3). Physical activity was classified into three categories, as described earlier(2, 4): (1) low: engaging in light regular physical activity, such as walking or biking for less than 2 hours per week; (2) moderate: engaging in light physical activity for 2-4 hours per week; and (3) high: engaging in light regular physical activity for more than 4 hours per week, or in more vigorous physical activity, such as brisk walking, fast biking, heavy gardening, or sports that cause perspiration or exhaustion for more than 2 hours per week. This questionnaire has been shown to discriminate between sedentary persons and their more active counterparts with respect to maximal oxygen uptake and has been widely used to describe the effects of physical activity on health outcomes in similar types of populations(5).

\section{Lung function}

Spirometry was performed using an electronic spirometer (Monaghan N403; Monaghan Littleton, CO, USA) at the first (1976-78) and second CCHS examinations (1981-83), and with a dry wedge spirometer (Vitalograph, Maidenhead, UK) at the third (1991-94) and fourth CCHS examination (2001-03). At each examination three sets of values were obtained, and at least two measurements differing by less than $5 \%$ had to be produced. The highest values of $\mathrm{FEV}_{1}$ and $\mathrm{FVC}$ were used for further analyses.

\section{RESULTS}

\section{Characteristics}

Baseline characteristics of 1,270 subjects with COPD and 8,734 subjects without COPD stratified for CCHS examination are listed in Table E1. 
Characteristics of subjects with COPD with self-reported cardiac comorbidities and/or diabetes and subjects with COPD without comorbidities are listed in Table E2. Characteristics are comparable, except for age, BMI and smoking years $(p<0.05)$.

Subjects with COPD without comorbidities in the lowest physical activity category had a significantly worse lung function, less year of education, more symptoms, a higher proportion of current smokers and more smoking years compared to patients with a moderate or high physical activity level (Table E3). Results in subjects with COPD with comorbidities show significant differences in gender, lung function and smoking years between subjects with a low physical activity level and subjects with a moderate or high physical activity level (Table E3).

\section{Longitudinal changes in physical activity}

\section{Low baseline physical activity}

Subjects with COPD who reported an increase in physical activity at follow up, had a significantly better baseline $\mathrm{FEV}_{1}$ and $\mathrm{FEV}_{1} / \mathrm{FVC}$ ratio compared to subjects with COPD who remained physically low active. Moreover, proportion of subjects with COPD and symptoms of chest pain was significantly lower (Table 3). Subjects without COPD who reported moderate to high physical activity at follow up also had a better FEV $\mathrm{F}_{1}$ compared to their peers who remained physically low active (Table 4). In addition, they had more years of education, less symptoms of leg pain, and higher proportion of cohabiting (Table 4).

\section{Moderate baseline physical activity}

The proportion of subjects with COPD with a moderate physical activity at baseline who changed their physical activity level at follow up was significantly different compared to the proportion of subjects without COPD (decrease in physical activity: $14.9 \%$ versus $11.4 \%, p<0.05$; increase in physical activity: $26.4 \%$ versus $27.8 \%, p<0.05$ ). These differences remained significant after correction for differences in age and gender $(p<0.05)$.

Subjects with COPD who reported an increase in physical activity at follow up were significantly younger, had a better baseline $\mathrm{FEV}_{1}$ and $\mathrm{FEV}_{1} / \mathrm{FVC}$ ratio and less smoking years compared to subjects with COPD who reported a moderate or low physical activity at follow up. Moreover, proportion of male subjects and subjects cohabiting or married was significantly higher, while proportion of subjects with symptoms of chest pain and/or leg pain, subjects who are divorced or living alone, and current smokers was significantly lower. Presence of self-reported diabetes was significantly lower in subjects who reported a high physical activity at follow up compared to subjects who reported a decrease in physical activity, although proportions are very low (Table 3). 
Subjects with COPD who reported a decrease in physical activity at follow-up had a significantly worse $\mathrm{FEV}_{1}$ and a higher proportion of divorced subjects compared to subjects who remained moderately physically active. In addition, presence of self-reported diabetes, symptoms of chest pain and leg pain and the proportion of divorced subjects was significantly higher (Table 3).

Subjects without COPD who reported an increase in physical activity at follow up were significantly younger and had a higher $\mathrm{FEV}_{1}$ compared to subjects without COPD who remained or decreased their physical activity. Moreover, proportion male subjects and proportion of subjects cohabiting or married was significantly higher, while proportion of subjects with symptoms of leg pain and chest pain and current smokers was lower. In addition, they had more years of education and a lower BMI (Table 4).

Subjects without COPD with a decrease in physical activity level at follow up had a significantly worse $\mathrm{FEV}_{1}$, a higher BMI, less years of education, more self-reported cardiac comorbidities, and more smoking years compared to subjects who remained moderately physical active. Furthermore, proportion of male subjects and symptoms of chest pain and leg pain was lower, while proportion of subjects living alone was higher (Table 4).

\section{High baseline physical activity}

The proportion of subjects with COPD with a high physical activity level at baseline who reported a decline in physical activity at follow up was significantly higher compared to the subjects without COPD (52.6\% versus $46.7 \%$; $<0.01)$. This difference remained significant after correction for differences in age and gender $(p<0.05)$.

Subjects with COPD who reported a decrease in physical activity at follow up were significantly older, had a worse $\mathrm{FEV}_{1}$, less years of education, more cardiac comorbidities, and more smoking years compared to subjects with COPD who remained physically high active. Moreover, proportion of male was lower and proportion of subjects with symptoms of leg pain was higher (Table 3).

Similar to the subjects with COPD, subjects without COPD who reported a moderate or low physical activity at follow-up were significantly older, had a worse FEV $\mathrm{V}_{1}$, less years of education, more self-reported cardiac comorbidities, and more smoking years. In addition, proportion of male was lower and proportion of subjects with symptoms of leg pain and current smokers was higher (Table 4). 


\section{REFERENCES}

1. Saltin B, Grimby G. Physiological analysis of middle-aged and old former athletes. Comparison with still active athletes of the same ages. Circulation. 1968;38(6):1104-15.

2. Schnohr P. Physical activity in leisure time: impact on mortality. Risks and benefits. Danish medical bulletin. 2009;56(1):40-71.

3. Aires N, Selmer R, Thelle D. The validity of self-reported leisure time physical activity, and its relationship to serum cholesterol, blood pressure and body mass index. A population based study of 332,182 men and women aged 40-42 years. European journal of epidemiology. 2003;18(6):479-85.

4. Schnohr P, Scharling $H$, Jensen JS. Changes in leisure-time physical activity and risk of death: an observational study of 7,000 men and women. Am J Epidemiol. 2003;158(7):639-44.

5. Petersen CB, Gronbaek M, Helge JW, Thygesen LC, Schnohr P, Tolstrup JS. Changes in physical activity in leisure time and the risk of myocardial infarction, ischemic heart disease, and all-cause mortality. Eur J Epidemiol. 2012;27(2):91-9. 


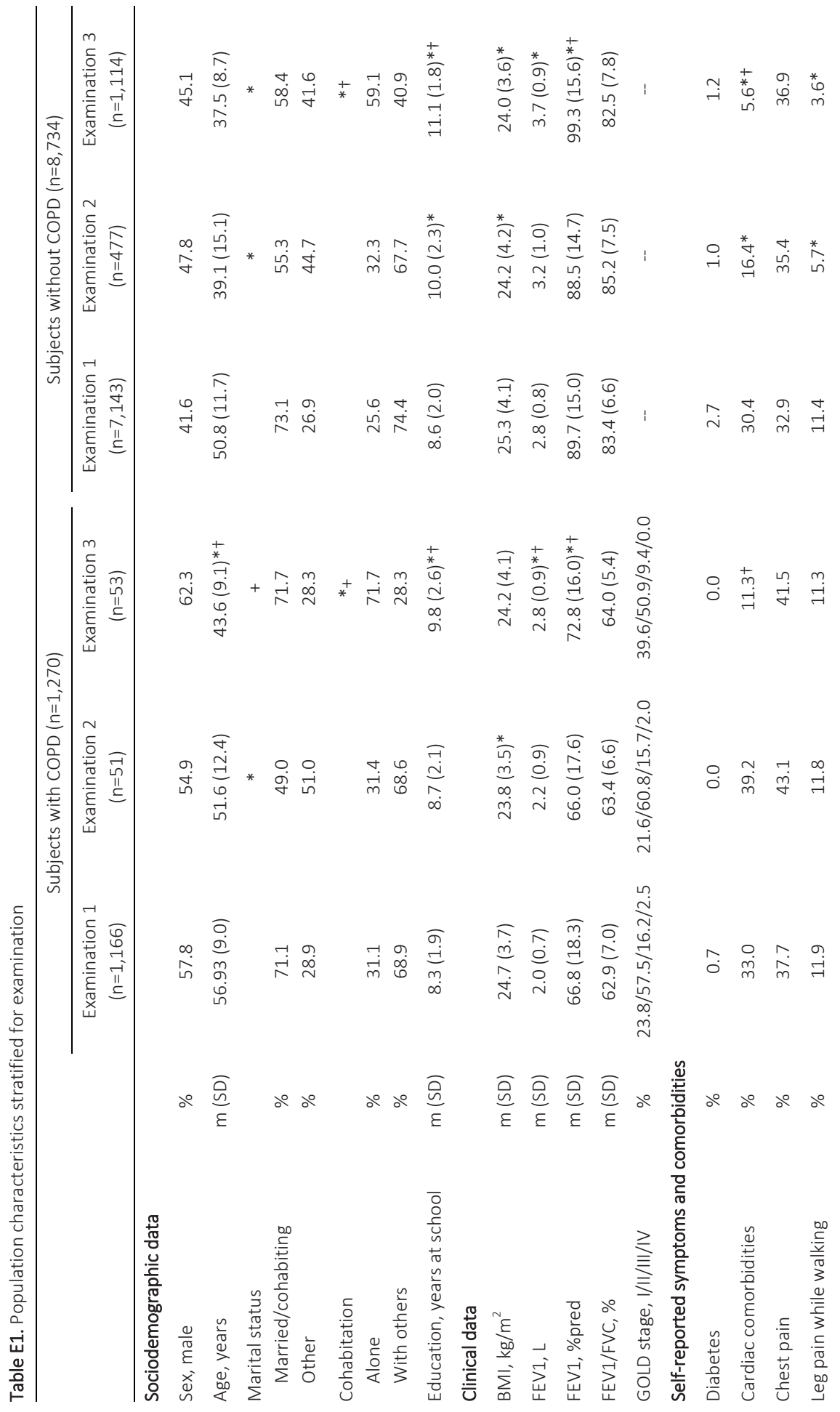




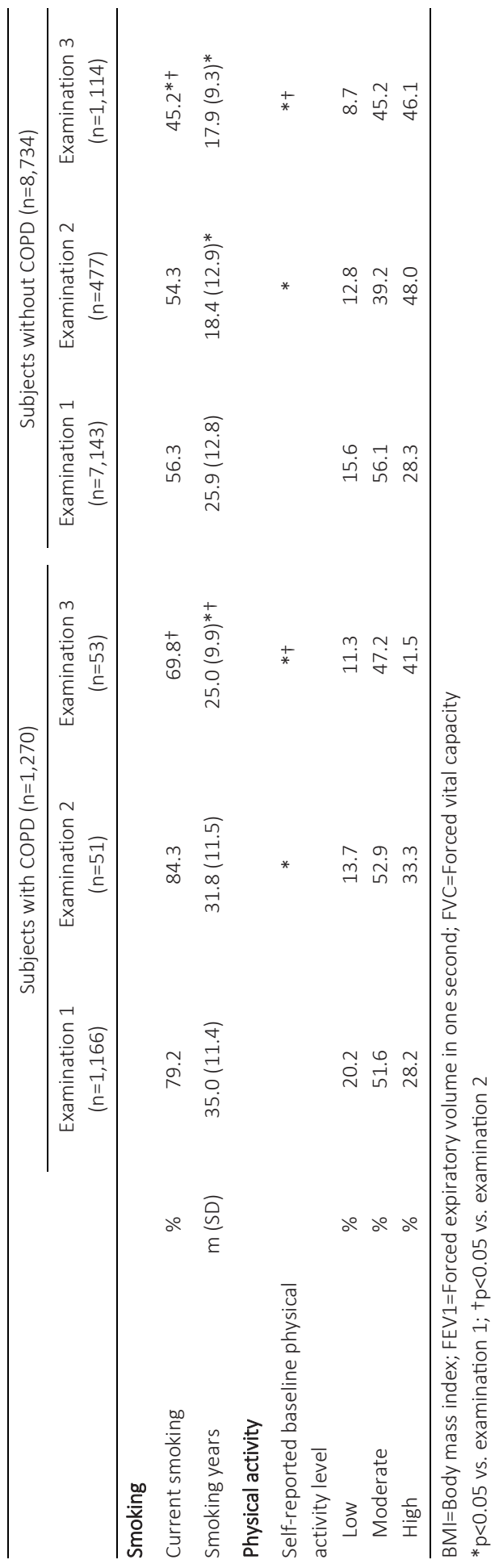


Table E2. Population characteristics at first examination in subjects with COPD with and without comorbidities

\begin{tabular}{|c|c|c|c|c|}
\hline & & $\begin{array}{l}\text { Subjects with COPD } \\
\text { without comorbidities } \\
\qquad(n=854)\end{array}$ & $\begin{array}{l}\text { Subjects with COPD } \\
\text { with comorbidities } \\
\qquad(n=416)\end{array}$ & $\mathrm{p}$-value \\
\hline \multicolumn{5}{|l|}{ Sociodemographic data } \\
\hline Sex, male & $\%$ & 57.1 & 59.4 & 0.450 \\
\hline Age, years & $\mathrm{m}(\mathrm{SD})$ & $55.0(9.7)$ & $58.7(8.7)$ & $<0.001$ \\
\hline Marital status & & & & 0.151 \\
\hline Married/cohabiting & $\%$ & 69.8 & 70.9 & \\
\hline Other & $\%$ & 30.2 & 29.1 & \\
\hline Cohabitation & & & & 0.128 \\
\hline Alone & $\%$ & 33.1 & 32.2 & \\
\hline With others & $\%$ & 66.9 & 67.8 & \\
\hline Education, years at school & $\mathrm{m}(\mathrm{SD})$ & $8.4(2.0)$ & $8.2(1.9)$ & 0.067 \\
\hline \multicolumn{5}{|l|}{ Clinical data } \\
\hline $\mathrm{BMI}, \mathrm{kg} / \mathrm{m}^{2}$ & $\mathrm{~m}(\mathrm{SD})$ & $24.4(3.7)$ & $25.1(3.8)$ & 0.001 \\
\hline FEV1, L & $\mathrm{m}(\mathrm{SD})$ & $2.1(0.8)$ & $2.0(0.7)$ & 0.103 \\
\hline FEV1, \%pred & $\mathrm{m}(\mathrm{SD})$ & $67.4(18.3)$ & $66.2(18.1)$ & 0.278 \\
\hline FEV1/FVC, \% & $\mathrm{m}(\mathrm{SD})$ & $62.8(7.0)$ & $63.3(6.8)$ & 0.216 \\
\hline GOLD stage, I/II/III/IV & $\%$ & $24.9 / 57.5 / 15.3 / 2.2$ & $23.1 / 57.2$ / $17.1 / 2.6$ & 0.768 \\
\hline \multicolumn{5}{|l|}{ Self-reported symptoms } \\
\hline Chest pain & $\%$ & 36.3 & 41.7 & 0.065 \\
\hline Leg pain while walking & $\%$ & 10.8 & 14.2 & 0.079 \\
\hline \multicolumn{5}{|l|}{ Smoking } \\
\hline Current smoking & $\%$ & 80.1 & 76.9 & 0.193 \\
\hline Smoking years & $\mathrm{m}(\mathrm{SD})$ & $33.6(11.5)$ & $36.3(11.4)$ & $<0.001$ \\
\hline \multicolumn{5}{|l|}{ Physical activity } \\
\hline $\begin{array}{l}\text { Self-reported baseline } \\
\text { physical activity level }\end{array}$ & & & & 0.254 \\
\hline Low & $\%$ & 19.2 & 20.2 & \\
\hline Moderate & $\%$ & 50.4 & 53.8 & \\
\hline High & $\%$ & 30.4 & 26.0 & \\
\hline
\end{tabular}

BMI=Body mass index; FEV1=Forced expiratory volume in one second; FVC=Forced vital capacity 


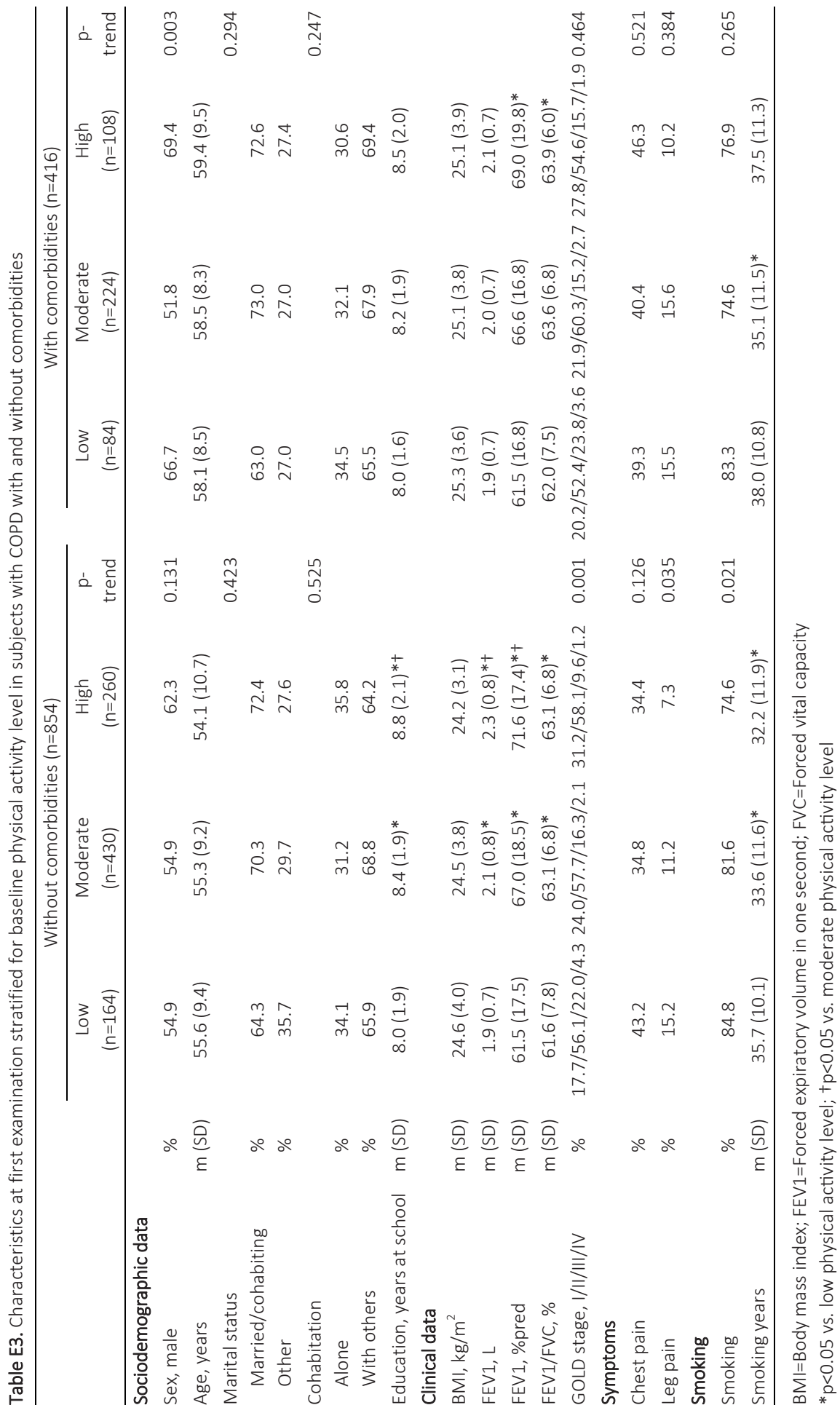




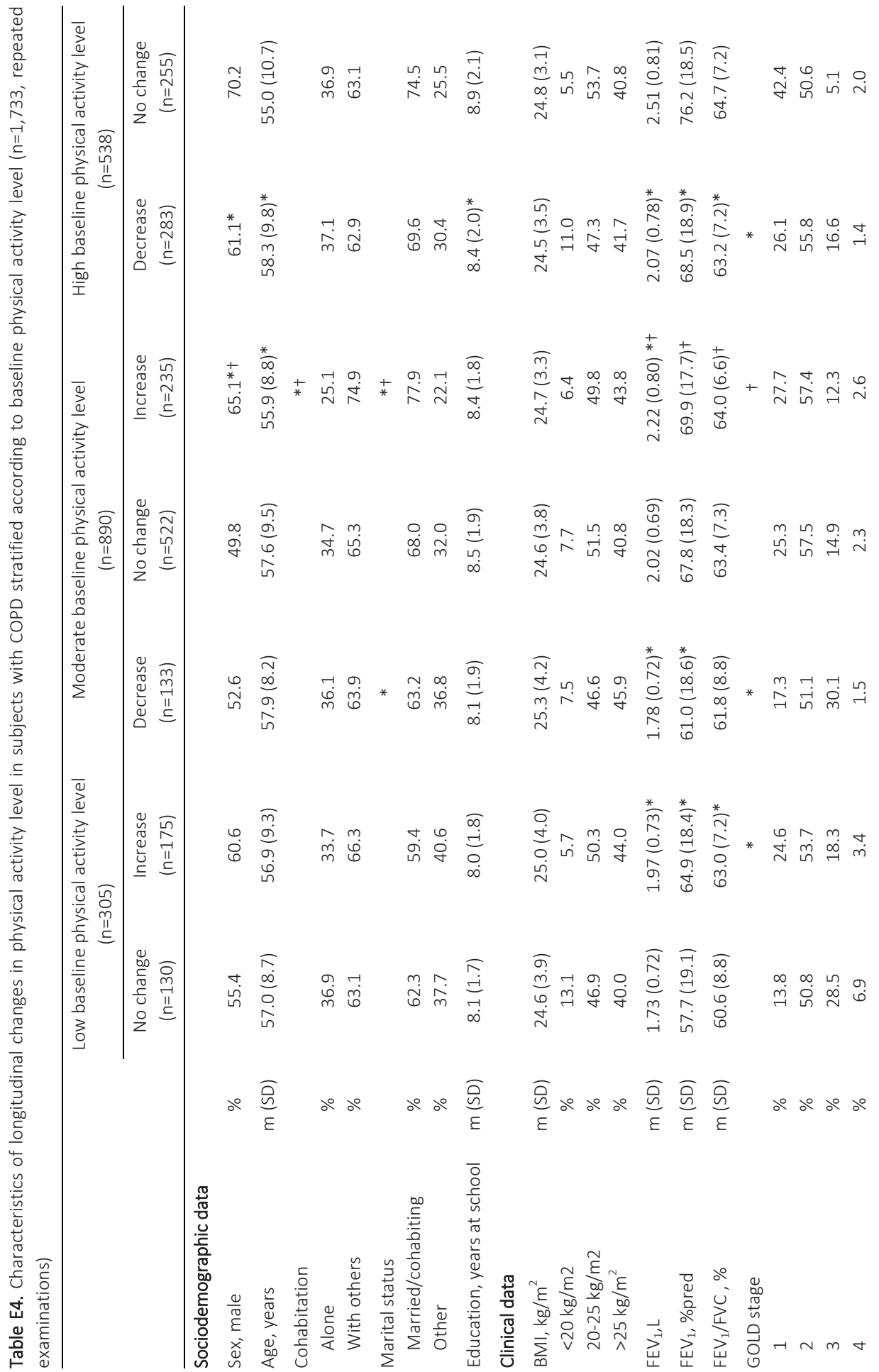




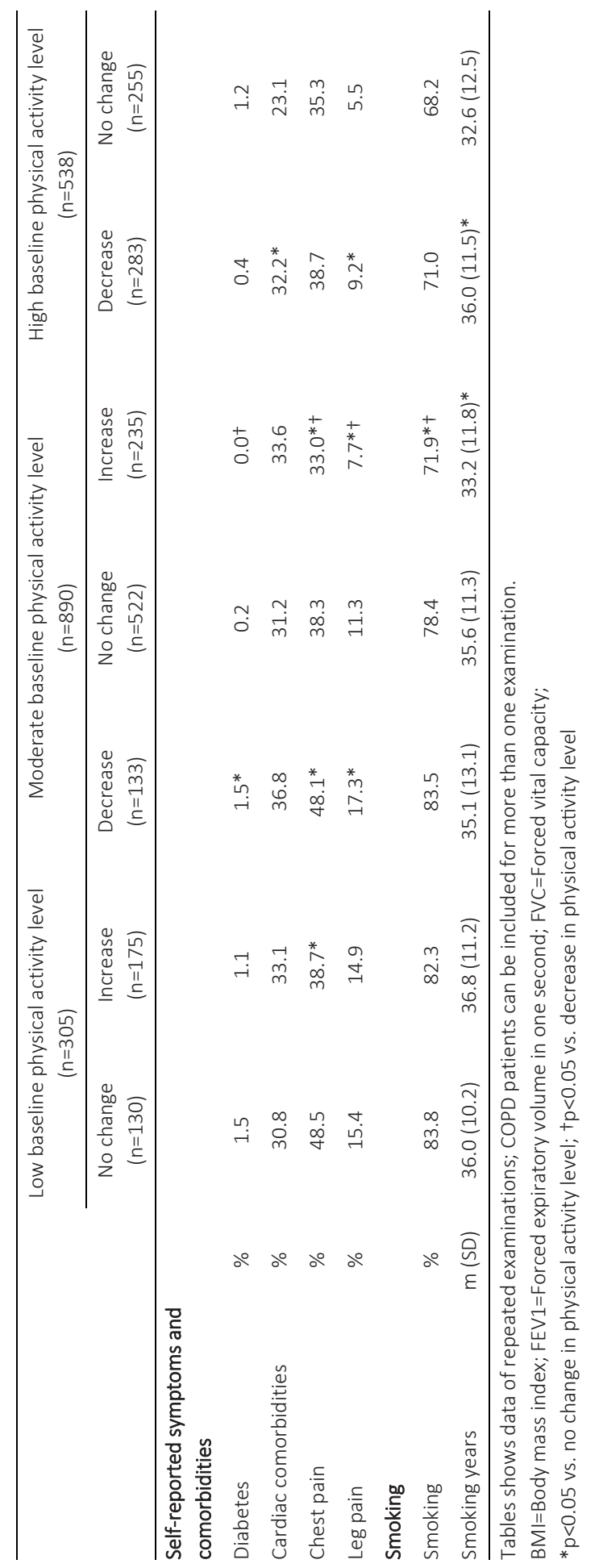




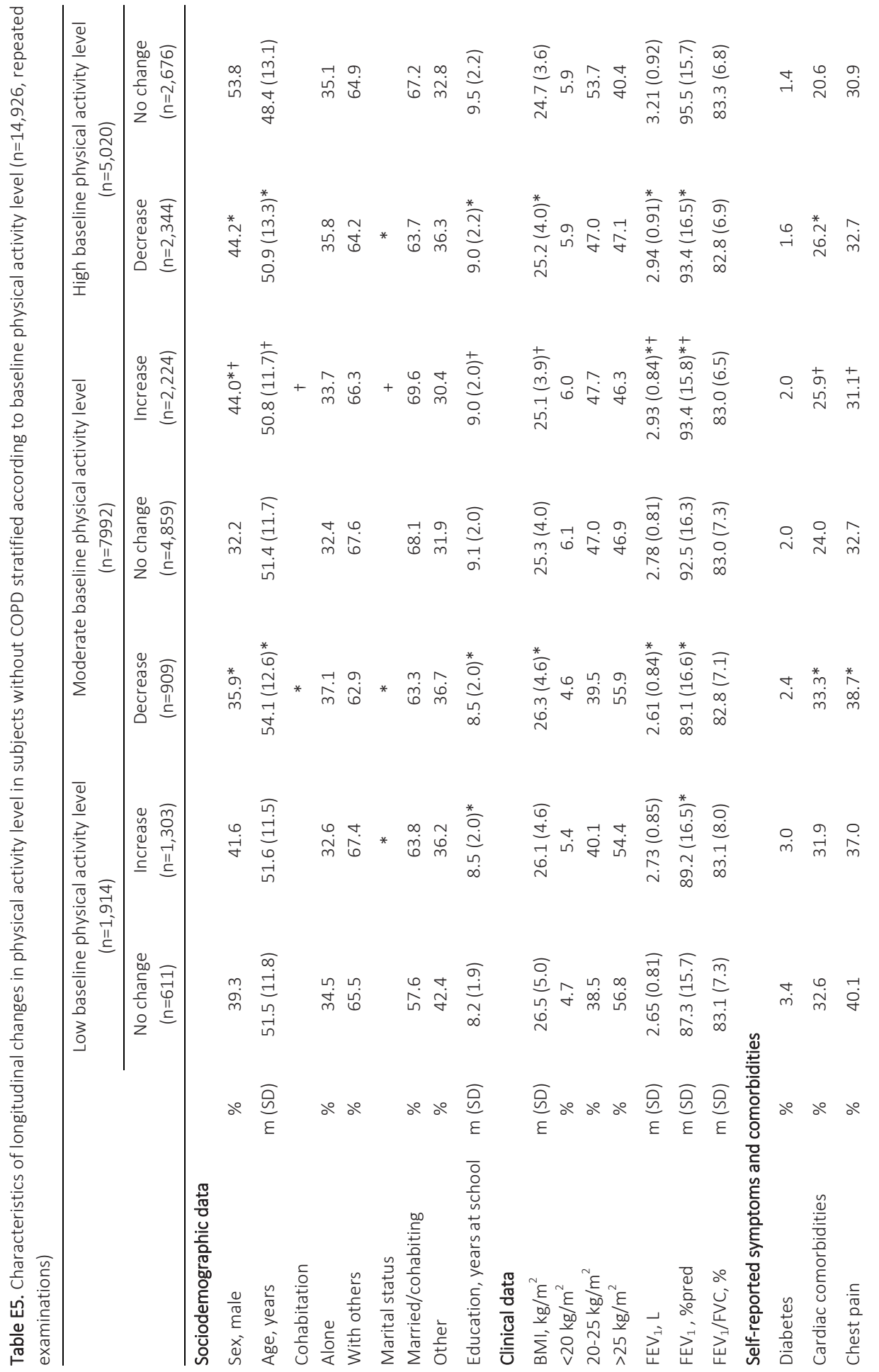




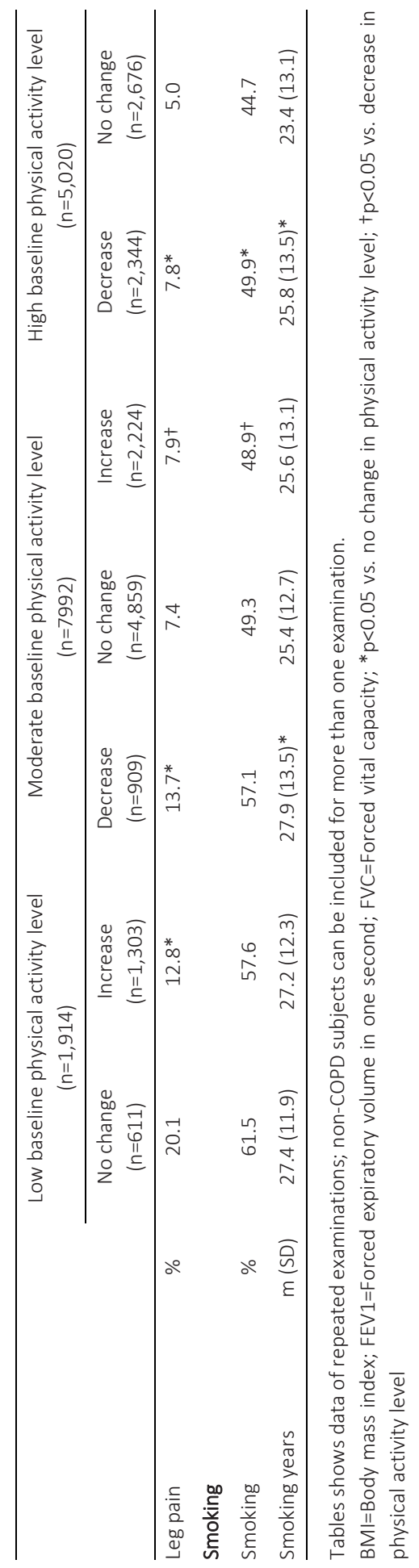


Table E6. Determinants of longitudinal changes in physical activity in subjects with COPD

\begin{tabular}{|c|c|c|c|c|}
\hline $\begin{array}{l}\text { Baseline physical } \\
\text { activity level }\end{array}$ & & B & p-value (Wald) & $\operatorname{Exp}(B)$ \\
\hline \multirow{6}{*}{$\begin{array}{l}\text { Low } \\
(n=305)\end{array}$} & Increase PA (n=175) & & & \\
\hline & vs. no change $(n=130)$ & & & \\
\hline & Age (years) & $0.028(0.015)$ & 0.055 & 1.028 \\
\hline & Sex [female] & $0.227(0.257)$ & 0.377 & 1.255 \\
\hline & Sex [male] & 0 & . & . \\
\hline & FEV1 (L) & $0.514(0.201)$ & 0.011 & 1.672 \\
\hline \multirow{6}{*}{$\begin{array}{l}\text { Moderate } \\
(n=655)\end{array}$} & Decrease $(n=133)$ & & & \\
\hline & vs. no change ( $n=522)$ & & & \\
\hline & Age (years) & $-0.015(0.012)$ & 0.200 & 0.985 \\
\hline & Sex [female] & $-0.391(0.208)$ & 0.060 & 0.676 \\
\hline & Sex [male] & 0 & . & . \\
\hline & FEV1 (L) & $-0.680(0.194)$ & 0.000 & 0.507 \\
\hline \multirow{9}{*}{$\begin{array}{l}\text { Moderate } \\
(n=757)\end{array}$} & Increase $(n=235)$ & & & \\
\hline & vs. no change ( $n=522)$ & & & \\
\hline & Age (years) & $-0.020(0.009)$ & 0.032 & 0.980 \\
\hline & Sex [female] & $-0.507(0.175)$ & 0.004 & 0.602 \\
\hline & Sex [male] & 0 & . & . \\
\hline & Smoking [yes] & $-0.623(0.211)$ & 0.003 & 0.536 \\
\hline & Smoking [no] & 0 & $\cdot$ & $\cdot$ \\
\hline & Cohabitation [with others] & $0.376(0.189)$ & 0.046 & 1.456 \\
\hline & Cohabitation [alone] & 0 & . & . \\
\hline \multirow{7}{*}{$\begin{array}{l}\text { High } \\
(n=538)\end{array}$} & Decrease PA (n=283) & & & \\
\hline & vs. no change $(n=255)$ & & & \\
\hline & Age (years) & $-0.002(0.012)$ & 0.854 & 0.998 \\
\hline & Sex [female] & $0.043(0.241)$ & 0.859 & 1.044 \\
\hline & Sex [male] & 0 & . & . \\
\hline & FEV1 (L) & $-0.592(0.166)$ & 0.000 & 0.553 \\
\hline & Smoking years & $0.020(0.010)$ & 0.046 & 1.020 \\
\hline
\end{tabular}


Table E7. Determinants of longitudinal changes in physical activity in patients without COPD

\begin{tabular}{|c|c|c|c|c|}
\hline $\begin{array}{l}\text { Baseline physical } \\
\text { activity level }\end{array}$ & & B & p-value (Wald) & $\operatorname{Exp}(B)$ \\
\hline \multirow{8}{*}{$\begin{array}{l}\text { Low } \\
(n=1,914)\end{array}$} & Increase PA $(n=1,303)$ & & & \\
\hline & vs. no change $(n=611)$ & & & \\
\hline & Age (years) & $0.007(0.005)$ & 0.154 & 1.007 \\
\hline & Sex [female] & $-0.047(0.105)$ & 0.653 & 0.954 \\
\hline & Sex [male] & 0 & . & \\
\hline & Marital status [married/cohabiting] & $0.277(0.104)$ & 0.008 & 1.319 \\
\hline & Marital status [other] & 0 & . & \\
\hline & Education (years) & 0.062 & 0.023 & 1.064 \\
\hline \multirow{11}{*}{$\begin{array}{l}\text { Moderate } \\
(n=5,768)\end{array}$} & Decrease $(n=909)$ & & & \\
\hline & vs. no change $(n=4,859)$ & & & \\
\hline & Age (years) & $0.008(0.005)$ & 0.086 & 1.008 \\
\hline & Sex [female] & $0.365(0.115)$ & 0.002 & 1.441 \\
\hline & Sex [male] & 0 & . & . \\
\hline & FEV1 (L) & $-0.210(0.082)$ & 0.011 & 0.811 \\
\hline & Smoking [yes] & $0.293(0.103)$ & 0.004 & 1.340 \\
\hline & Smoking [no] & 0 & . & . \\
\hline & Comorbidities [yes] & $0.425(0.091)$ & $<0.001$ & 1.530 \\
\hline & Comorbidities [no] & 0 & . & . \\
\hline & Educationn (years) & $-0.124(0.025)$ & $<0.001$ & 0.883 \\
\hline \multirow{8}{*}{$\begin{array}{l}\text { Moderate } \\
(n=7,083)\end{array}$} & Increase $(n=2,224)$ & & & \\
\hline & vs. no change $(n=4,859)$ & & & \\
\hline & Age (years) & $-0.003(0.003)$ & 0.355 & 0.997 \\
\hline & Sex [female] & $-0.488(0.063)$ & 0.000 & 0.614 \\
\hline & Sex [male] & 0 & . & . \\
\hline & Smoking [yes] & $-0.115(0.068)$ & 0.047 & 0.891 \\
\hline & Smoking [no] & 0 & . & . \\
\hline & Education (years) & $0.038(0.016)$ & 0.019 & 1.039 \\
\hline \multirow{16}{*}{$\begin{array}{l}\text { High } \\
(n=5,020)\end{array}$} & Decrease PA $(n=2,344)$ & & & \\
\hline & vs. no change $(n=2,676)$ & & & \\
\hline & Age (years) & $0.008(0.004)$ & 0.041 & 1.008 \\
\hline & Sex [female] & $0.159(0.097)$ & 0.100 & 1.172 \\
\hline & Sex [male] & 0 & . & . \\
\hline & FEV1 (L) & $-0.202(0.064)$ & 0.002 & 0.817 \\
\hline & Smoking [yes] & $0.323(0.077)$ & $<0.001$ & 1.381 \\
\hline & Smoking [no] & 0 & . & . \\
\hline & BMI [<20 kg/m2] & $-0.025(0.167)$ & 0.882 & 0.975 \\
\hline & BMI [20-25 kg/m2] & $-0.197(0.077)$ & 0.011 & 0.821 \\
\hline & BMI [>25 kg/m2] & 0 & . & . \\
\hline & Comorbidities [yes] & $0.149(0.072)$ & 0.037 & 1.161 \\
\hline & Comorbidities [no] & 0 & . & . \\
\hline & Marital status [married/cohabiting] & $-0.166(0.075)$ & 0.027 & 0.847 \\
\hline & Marital status [other] & 0 & . & . \\
\hline & Education (years) & $-0.050(0.018$ & 0.006 & 0.951 \\
\hline
\end{tabular}




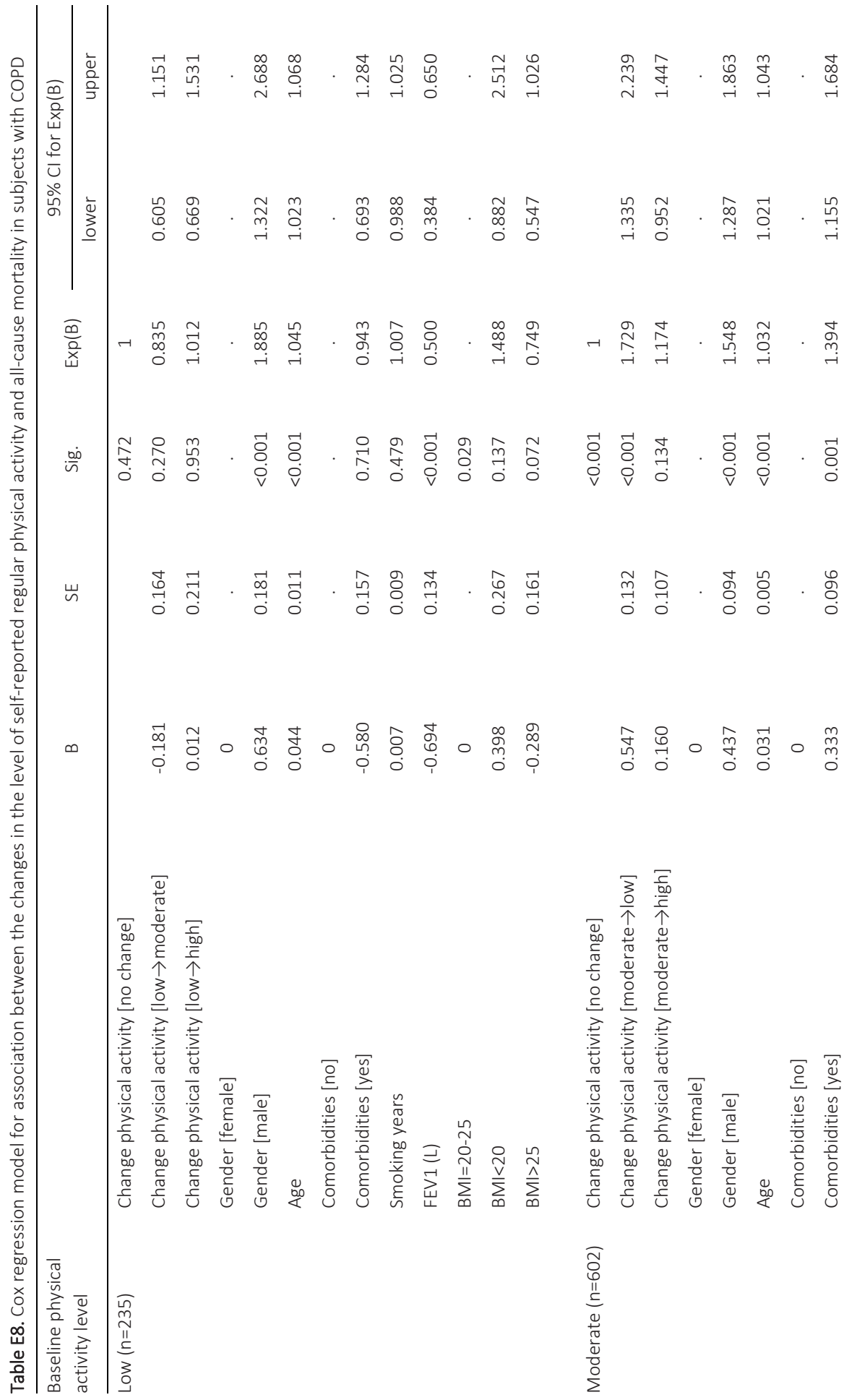




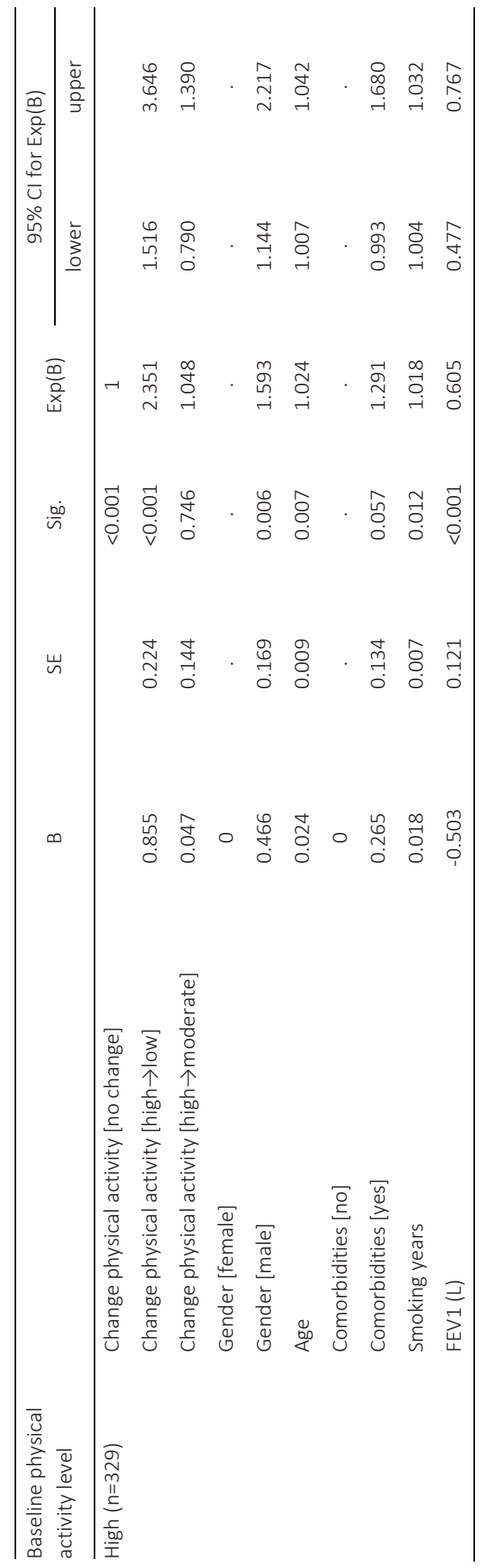




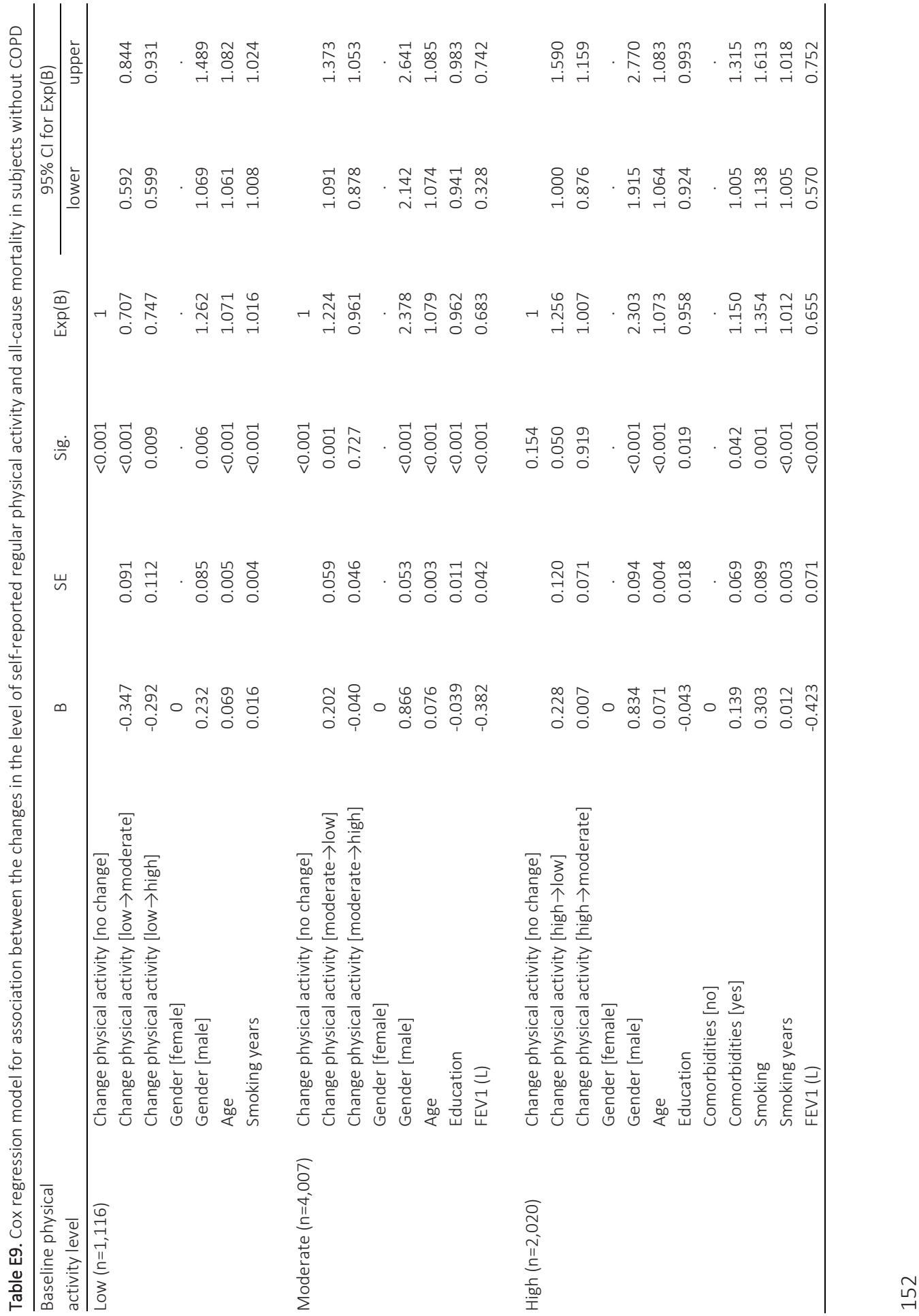


Chapter 7

Effect of 'activity monitor-based' counseling on physical activity and health-related outcomes in patients with chronic diseases:

A systematic review and meta-analysis

Anouk W. Vaes, Amy Cheung, Maryam Atakhorrami, Miriam T.J. Groenen, Oliver Amft, Frits M.E. Franssen, Emiel F.M. Wouters, Martijn A. Spruit 


\section{ABSTRACT}

Aim This review evaluated the effects of activity monitor-based counseling on physical activity (PA) and generic and disease-specific health-related outcomes in adults with diabetes mellitus type II (DMII), chronic obstructive pulmonary disease (COPD) or chronic heart failure (CHF).

Methods Four electronic databases were searched for randomized controlled trials using activity monitor-based counseling versus control intervention or usual care in adults with DMII, COPD or CHF. Pooled effect sizes were calculated using a random effects model.

Results 24 articles were included, 21 DMII studies and 3 COPD studies. No CHF studies were identified. Pooled analysis showed that activity monitor-based counseling resulted in a significant higher improvement in PA compared to control intervention or usual care in DMII. Furthermore, these interventions had a beneficial effect on hemoglobin A1c ( HbA1c), systolic blood pressure and body mass index (BMI) $(p<0.05)$, whereas no differences were found on diastolic blood pressure and health-related quality of life. Meta-analysis of COPD studies was not possible due to lack of available data.

Conclusion Activity monitor-based counseling had a beneficial effect on PA, HbA1c, systolic blood pressure and BMI in patients with DMII. Data in patients with COPD and $\mathrm{CHF}$ are limited or non-existing, respectively. 


\section{INTRODUCTION}

Regular physical activity has a positive impact on the onset and progression of prevalent chronic diseases, such as cardiovascular disease, obesity, diabetes mellitus type II (DMII), stroke, chronic obstructive pulmonary disease (COPD), chronic heart failure (CHF) and some forms of cancer (1-3). This indicates the importance of promoting physical activity in the general population by organizations, such as the American College of Sports Medicine (ACSM) and the American Heart Association (AHA)(4). Despite substantial health benefits from regular physical activity, many older adults do not meet the ACSM/AHA physical activity recommendations (5), and the level of physical activity seriously declines with increasing age $(5,6)$. Having a chronic disease most probably accelerates this decline in physical activity, as patients with DMII, COPD or CHF are markedly physically inactive compared to healthy peers (7-10).

Physical inactivity in older adults, particularly in elderly with a chronic disease, results in a significant economic burden, accounting for up to $3 \%$ of the direct healthcare costs in developed countries $(11,12)$. Moreover, sedentary patients with DMII, COPD or CHF have a higher risk of disease-related hospitalization and mortality (1, 13-15). Therefore, there is a need for low-cost, easily accessible and side-effect free programs to promote physical activity in older adults with a chronic disease.

Nowadays, activity monitors are increasingly popular to promote physical activity (16, 17). They can be categorized in simple and inexpensive pedometers, which basically quantify steps, to technologically advanced accelerometers, which assess the amount and intensity of physical activity in daily life (18). Activity monitors can be worn without major inconvenience, are compatible with most daily activities and are easy to use (18). Moreover, feedback from the activity monitors can be used to increase physical activity (17). Therefore, physical activity monitors can be a very useful tool to promote physical activity.

A previous review has already shown that physical activity counseling is associated with a significant increase in self-reported daily physical activity levels (16). However, selfreported physical activity measurements may not provide valuable data, since they lack precision and may be influenced by social desirability bias (18). Other reviews showed that interventions of physical activity counseling combined with an activity monitor have a beneficial effect on daily physical activity levels in adults and subjects living with disability and/or chronic disease $(17,19)$. To date, little is known about the effects of activity monitor-based counseling on objectively measured physical activity and generic health-related outcomes in chronic diseases, such as hospitalization and survival rates; and on disease-specific health-related outcomes, such as hemoglobin A1c (HbA1c), body mass index (BMI), systemic blood pressure and quality of life $(1,13,14,20-24)$. 
Therefore, the aim of this study was to systematically evaluate the effect of activity monitor-based counseling on physical activity levels in adults with a highly prevalent chronic disease, such as DMII, COPD or CHF. Additionally, we sought to determine the effect of these interventions on generic and disease-specific health-related outcomes.

\section{METHODS}

This systematic review followed the Preferred Reporting Items for Systematic Reviews and Meta-Analyses (PRISMA) guidelines (25).

\section{Eligibility criteria}

Included studies met the following criteria:

- Participants: patients with DMII, COPD or CHF.

- Intervention: (randomized) controlled trials using an activity monitor-based counseling intervention versus a control intervention or usual care.

- Primary outcome: objectified physical activity.

- Secondary outcomes: generic and/or disease-specific health-related outcomes.

\section{Data Sources and Searches}

A computerized literature search was performed in Medline/PubMed, Web of Knowledge (WOK), Embase and BIOSIS in August 2012. The following key words were used to identify relevant trials: (activit? OR "energy expenditure" OR step* OR walk?) AND ("chronic obstructive pulmonary disease" OR copd OR "chronic lung disease" OR emphysema OR "chronic bronchitis " OR "chronic heart failure" or chf OR "congestive heart failure" OR "chronic heart disease" OR "chronic disease*" OR diabet?) AND (acceleromet? OR pedomet? OR "activity monitor?" OR “step count?" OR actigraph?).

In total, 667 articles were retrieved. In addition 2 potentially relevant articles were found by checking reference lists of included trials (Figure 1).

\section{Study Selection}

Titles and abstracts were screened against inclusion criteria by two authors (AWV and $\mathrm{AC}$ ) and potentially eligible articles were retrieved. All articles were independently selected for inclusion by two reviewers (AWV and AC). Disagreements could be resolved by consulting a third reviewer (MA). Non-English language articles, review articles, editorials, qualitative studies and congress abstracts were excluded. 


\section{Data Extraction and Assessment of Methodological Quality}

A predesigned data abstraction form was used to obtain data on study design and relevant results. For each study, authors, journal, years of publication, studied disease, patient characteristics (gender, age, and disease severity), intervention, outcome parameters and results were recorded. Authors of included studies were contacted via (multiple) e-mail(s) and telephone call(s) to request additional data when applicable. The methodological quality of the included trials was scored independently using the Physiotherapy Evidence-Based Database (PEDro) Scale (26). This scale is based largely on the Delphi List and expert consensus. It consists of 11 items to score the internal validity and statistics. Items scored a 'yes' if the criterion was clearly satisfied, and all 'yes' were summed. A k coefficient was used to measure the level of interobserver agreement. Previously, trials with a PEDro score of $\geq 6$ points were classified as "highquality trials"; trials with a PEDro score $\leq 5$ points were classified as "low-quality trials" (26).

\section{Statistical Analysis}

Meta-analytic techniques were conducted using a random effects model in RevMan 5. Pooled effect estimates were calculated using a random effects model for physical activity and health-related outcomes. All trials reporting these outcomes were included in the model. If a study included more than one intervention group, each comparison with the control group was entered in the meta-analysis.

For each analysis, the $\mathrm{I}^{2}$ statistic was calculated to estimate the proportion of observed variance in effects across studies. Values of $25 \%, 50 \%$, and $75 \%$ were used as boundary limits for low, moderate, or high heterogeneity, respectively (27). The presence of publication bias was checked by a funnel plot for change in physical activity level.

\section{RESULTS}

\section{Study and participant characteristics}

Twenty-four articles fulfilled the review criteria (Figure 1). Twenty-one studies included subjects with DMII and three studies included subjects with COPD. The selection included no trials that studied patients with CHF. Funnel plot did not display asymmetry, which indicates that there is no indication for publication bias (Figure 2). PEDro scores ranged from 4 to 9 points (median: 7 points, Table 1). Three studies were classified as "low-quality trials" (28-30). Failure to conceal allocation and blinding of the patients, 
therapists and/or outcome assessors were the most prevalent methodological shortcomings.

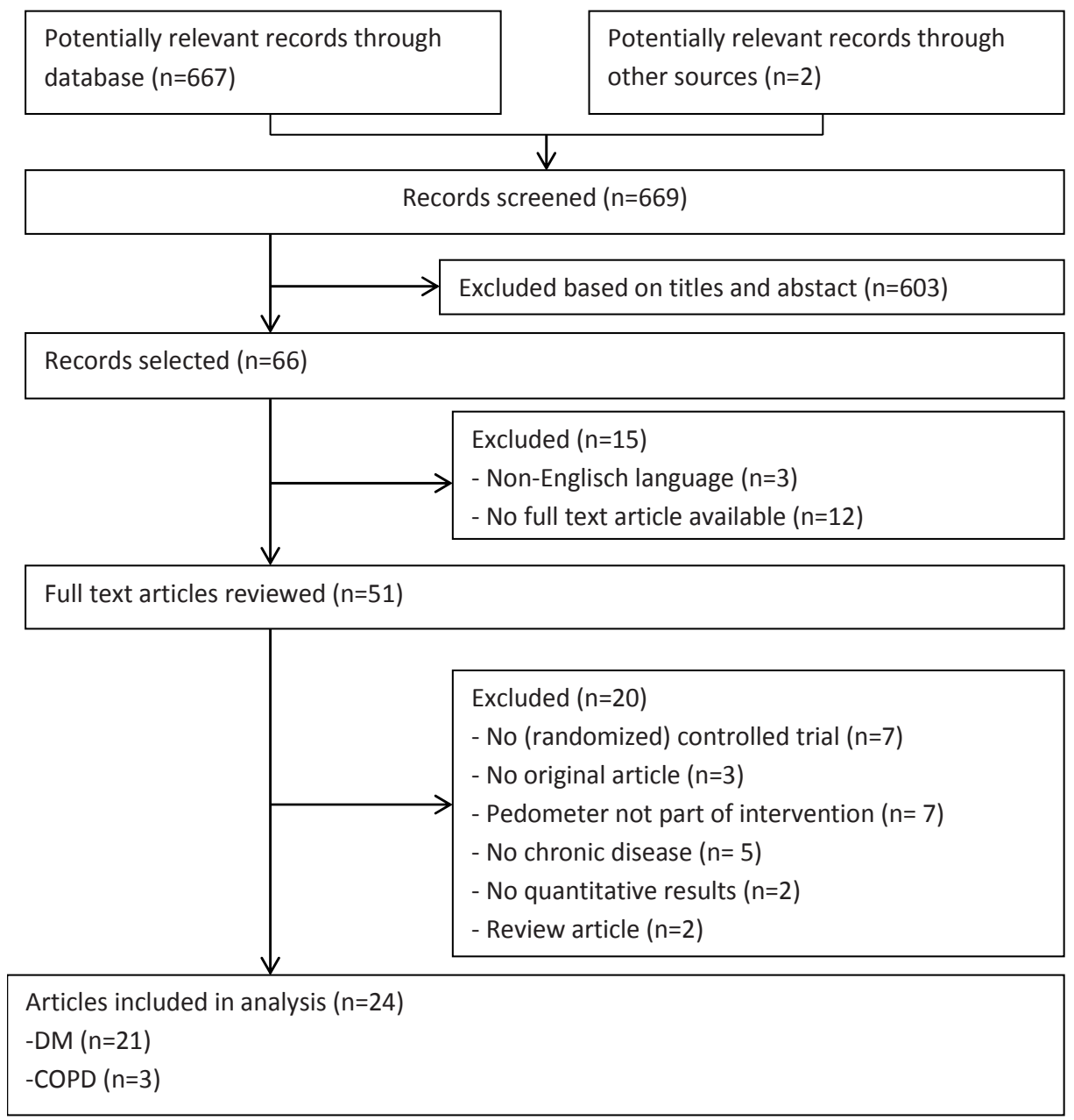

FIGURE 1. Study flow diagram

A total of 2,908 participants were evaluated: 2,763 patients with DMII and 145 patients with COPD (Tables 2 and 3). About half of the patients (48.1\%) were male. Reported mean age ranged from 47.0 to 70.9 years in patients with DMII, and 61.2 to 65.7 years in patients with COPD. However, in some studies data on patient characteristics were missing or incomplete (Table 2 and 3) (28, 29, 31-35).

Drop out ranged from 0 to $38 \%$ (Table 2 and 3 ). 


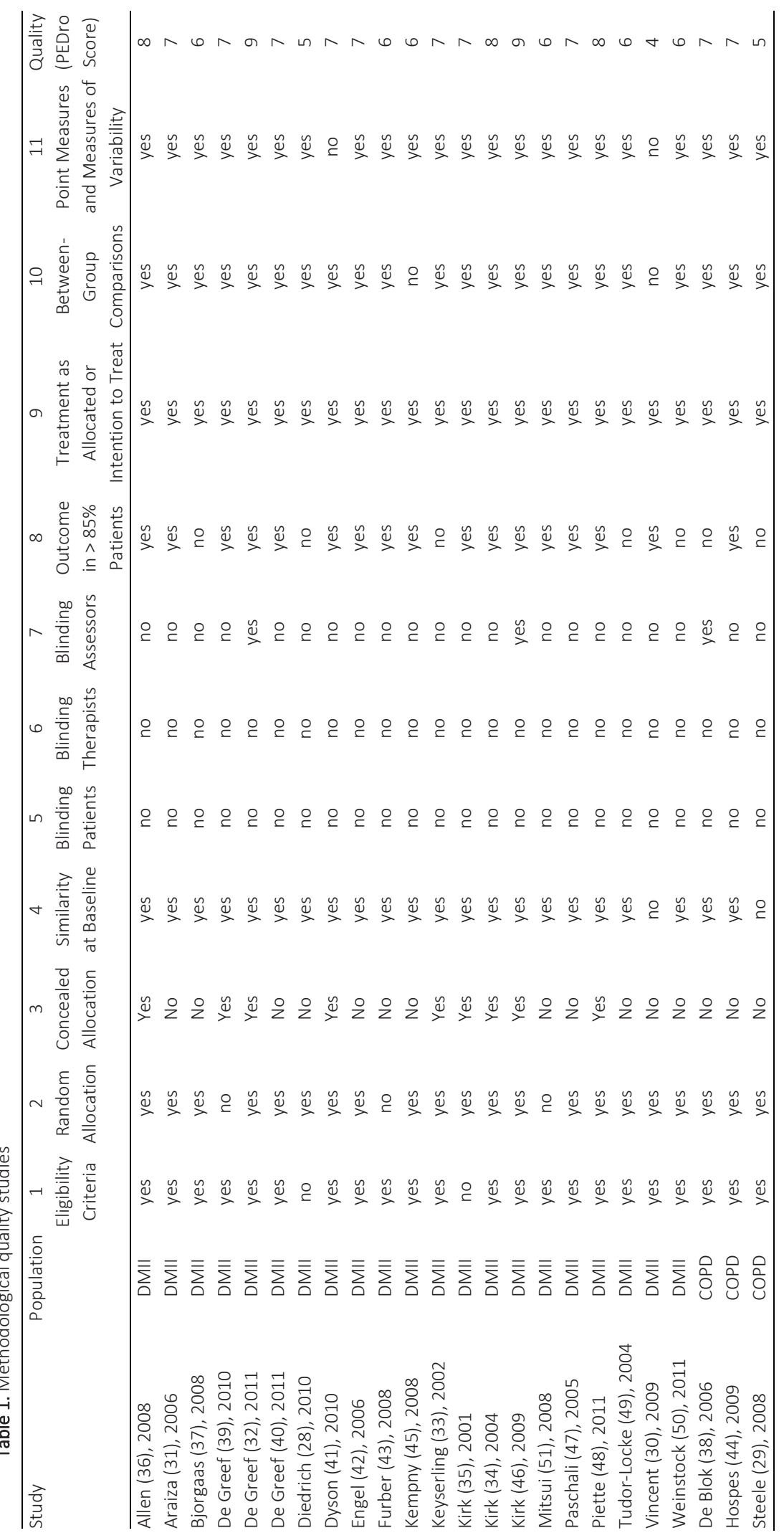




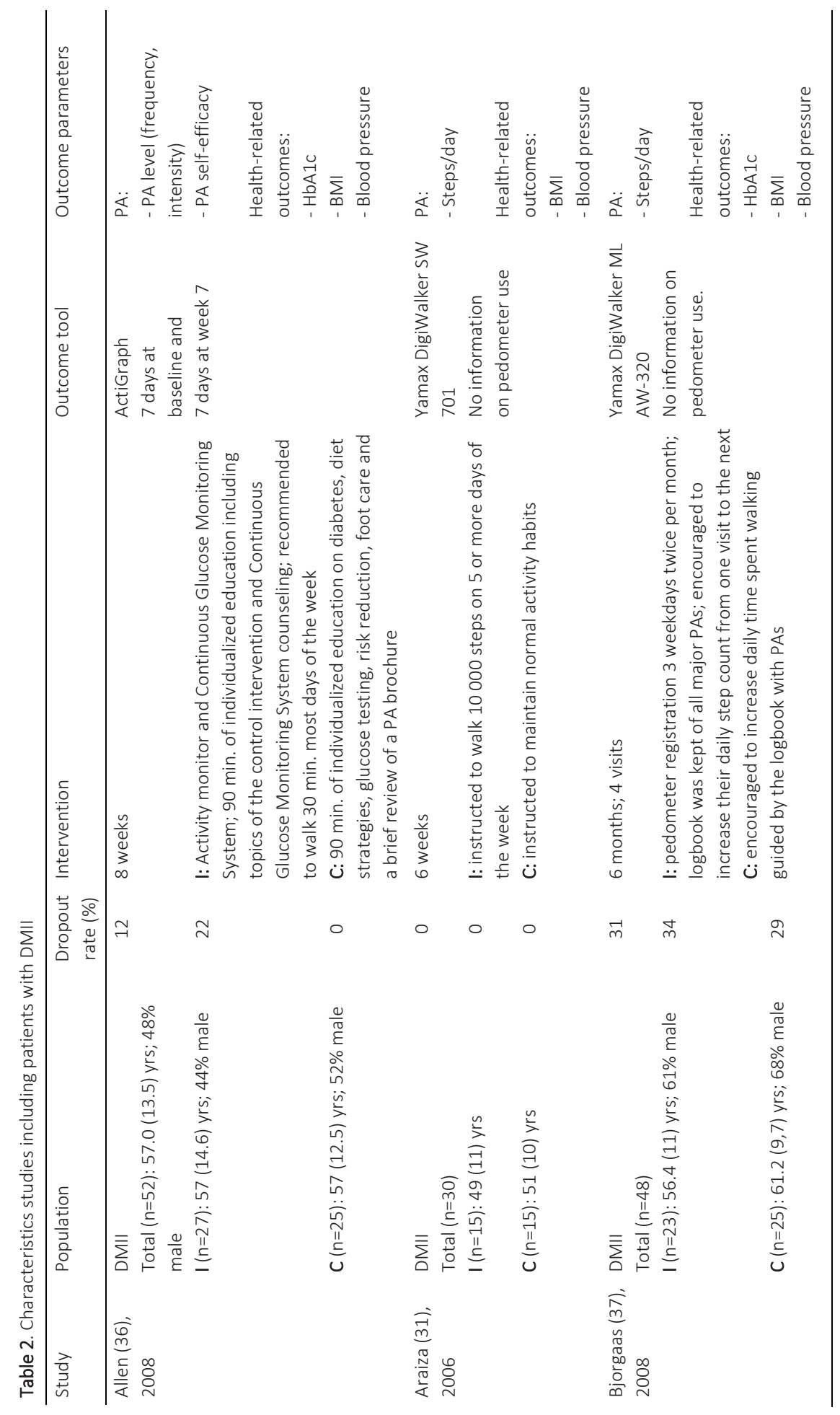




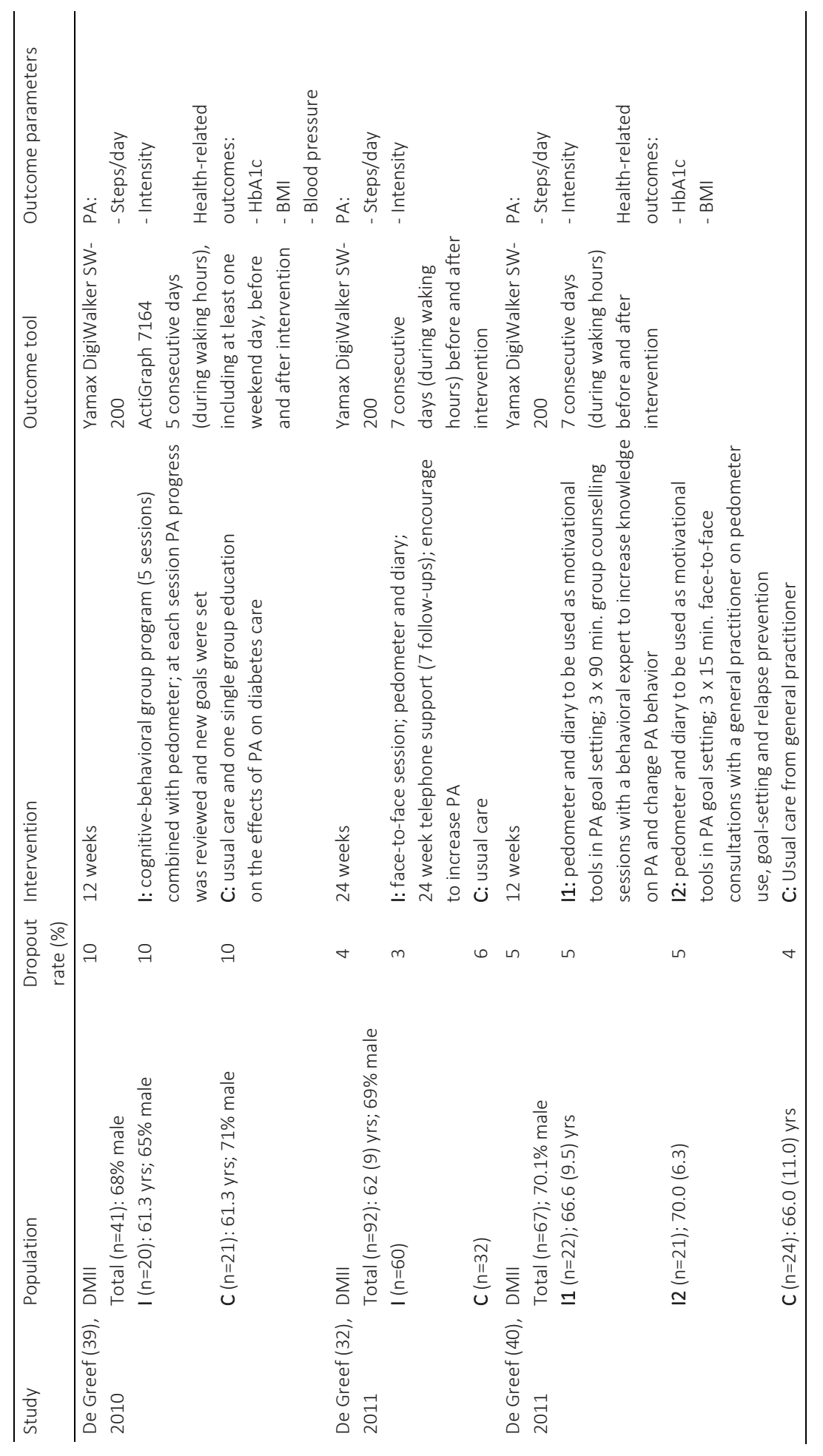




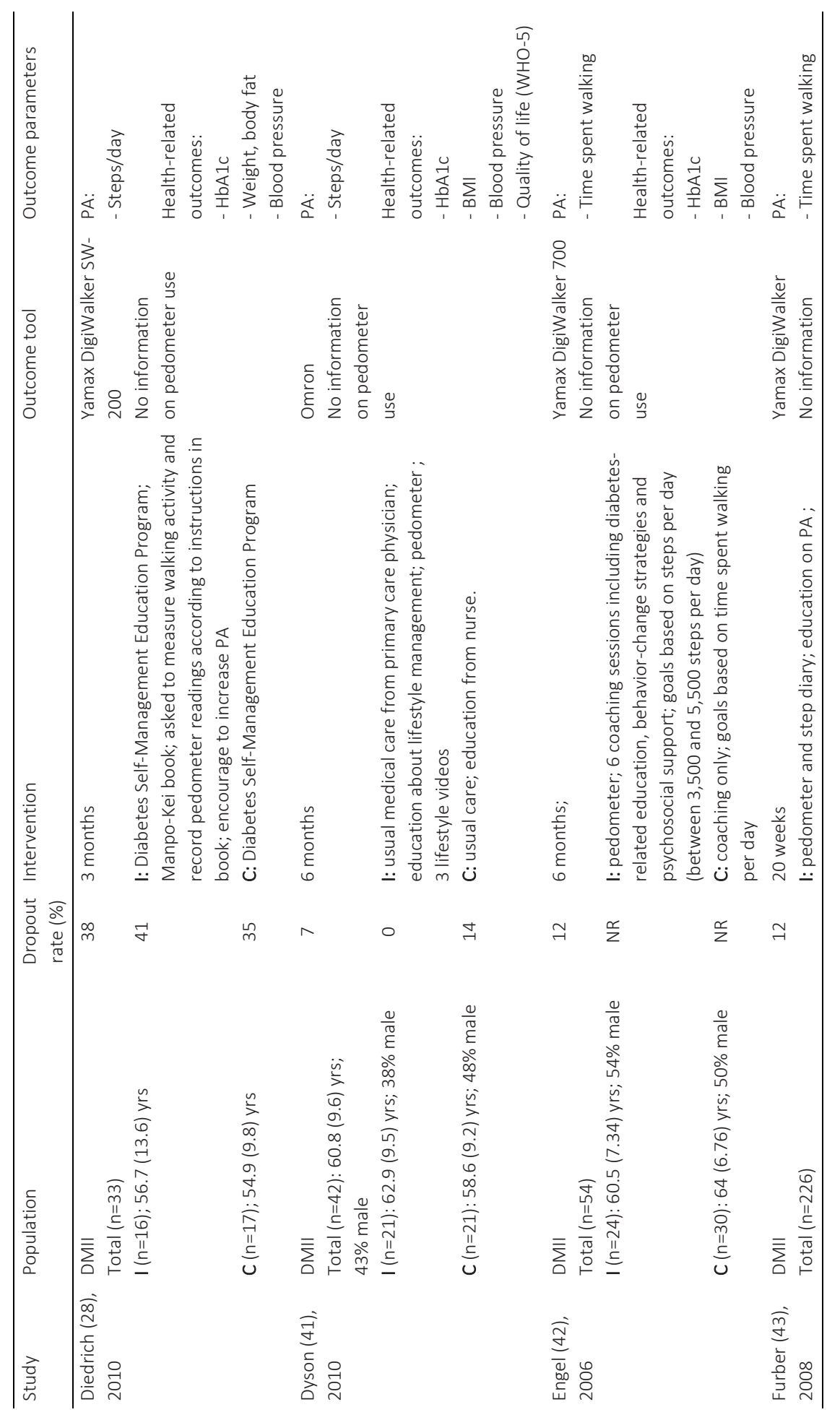




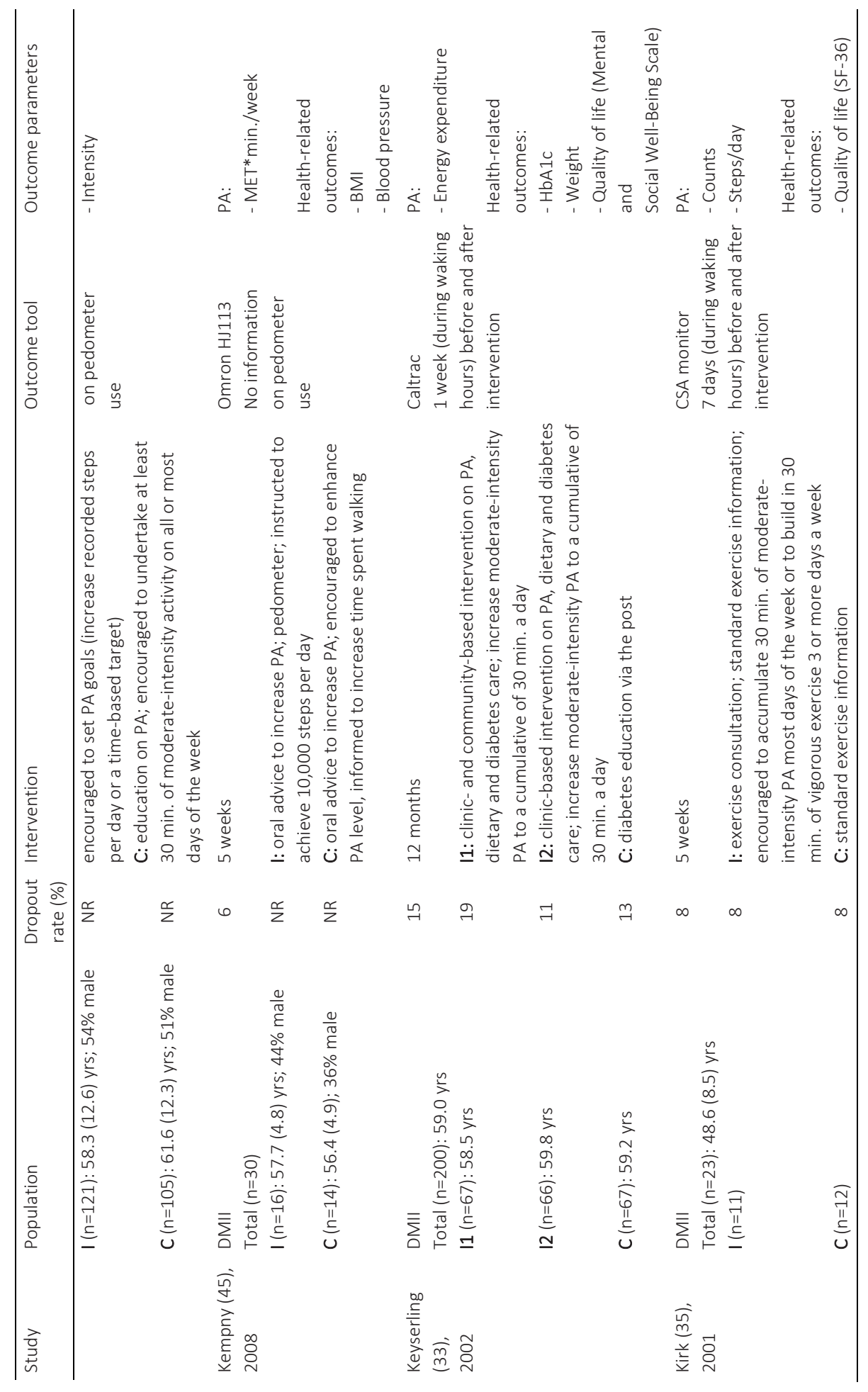




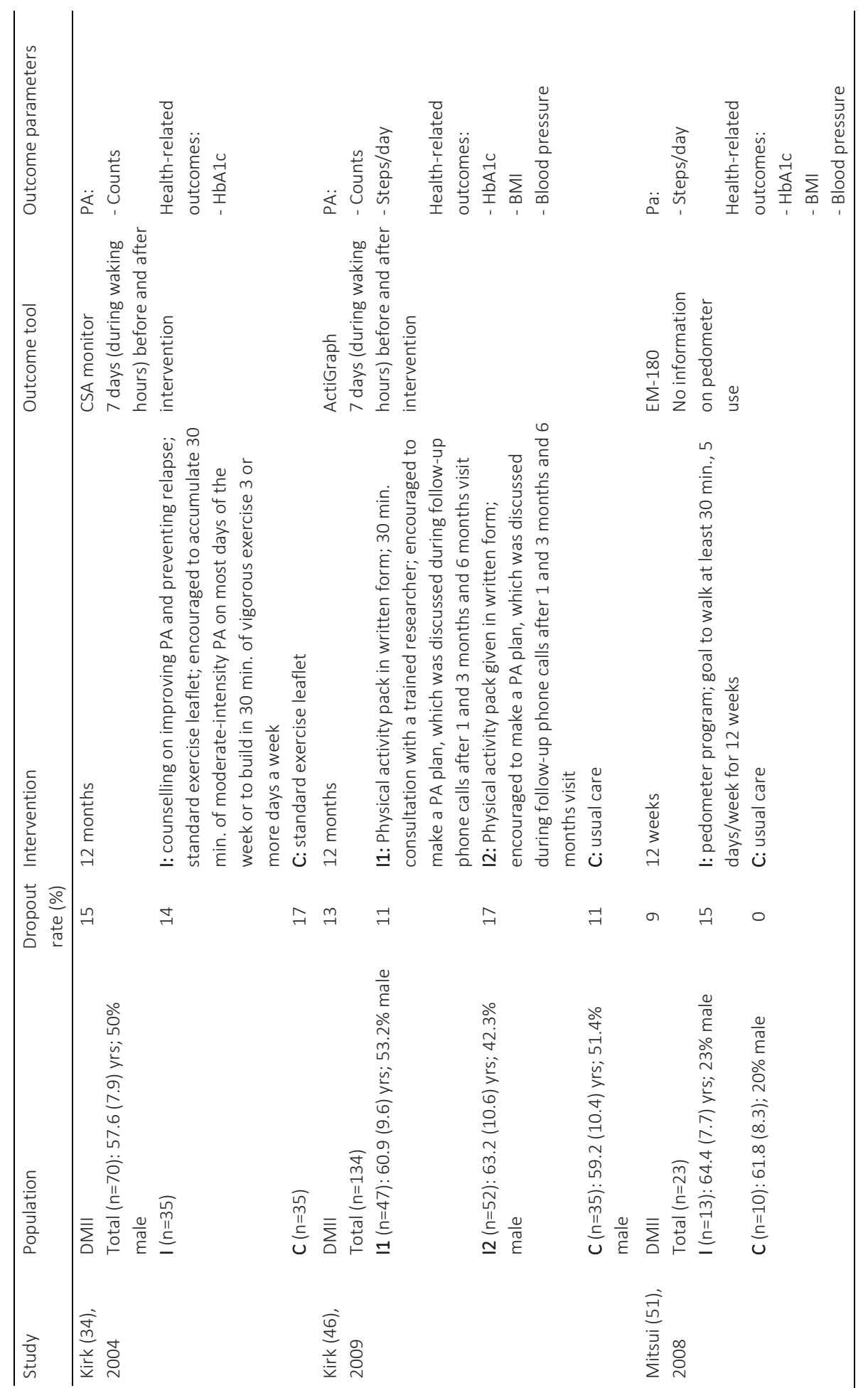




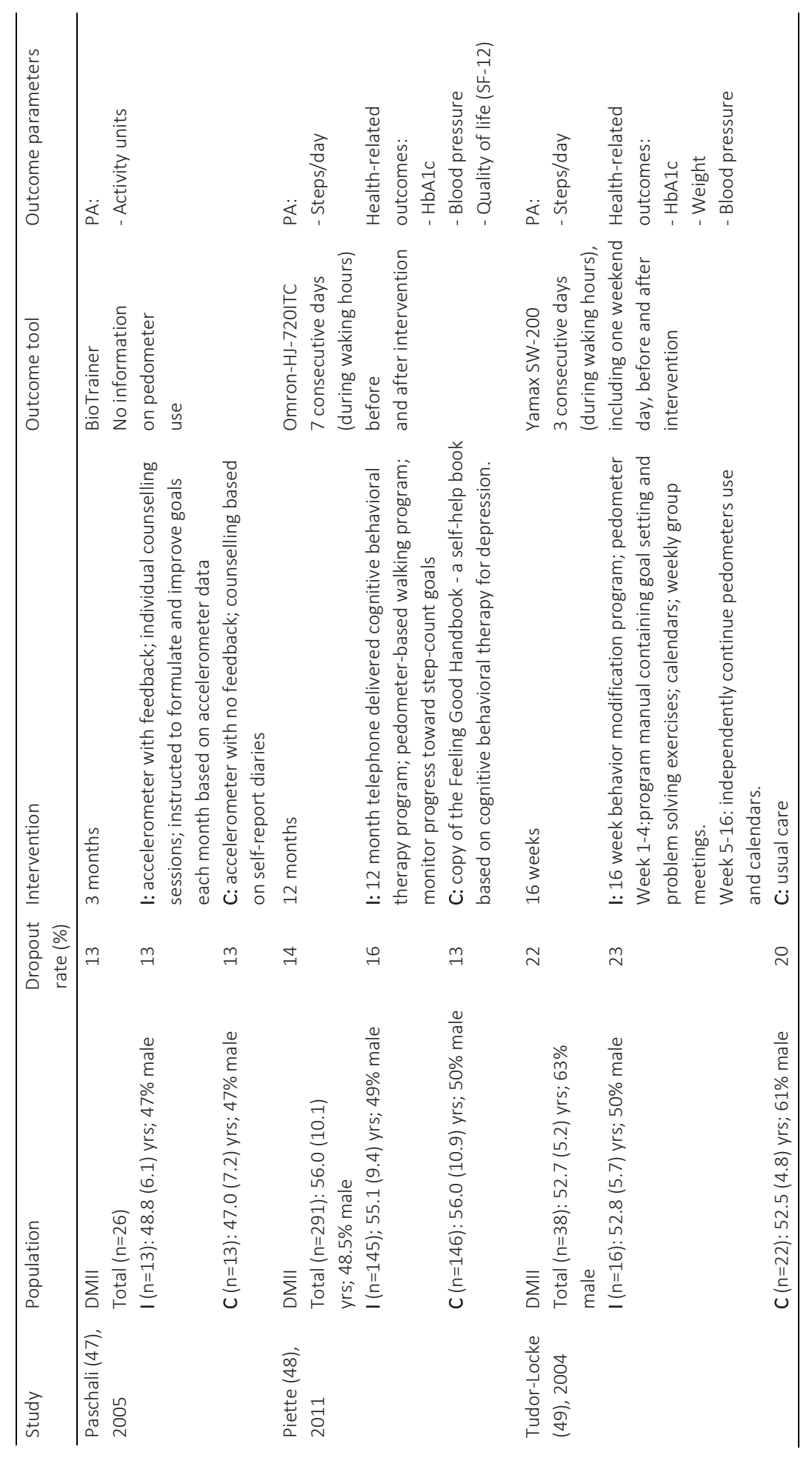




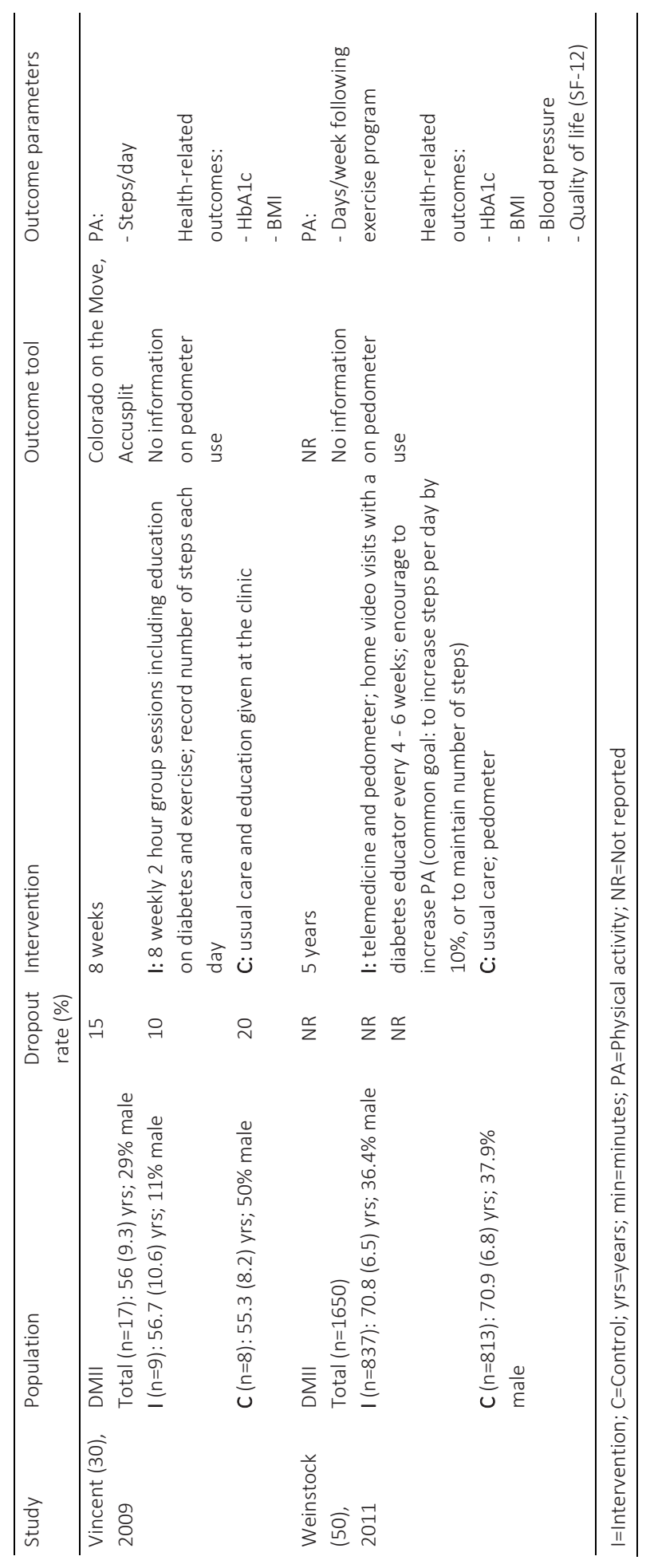




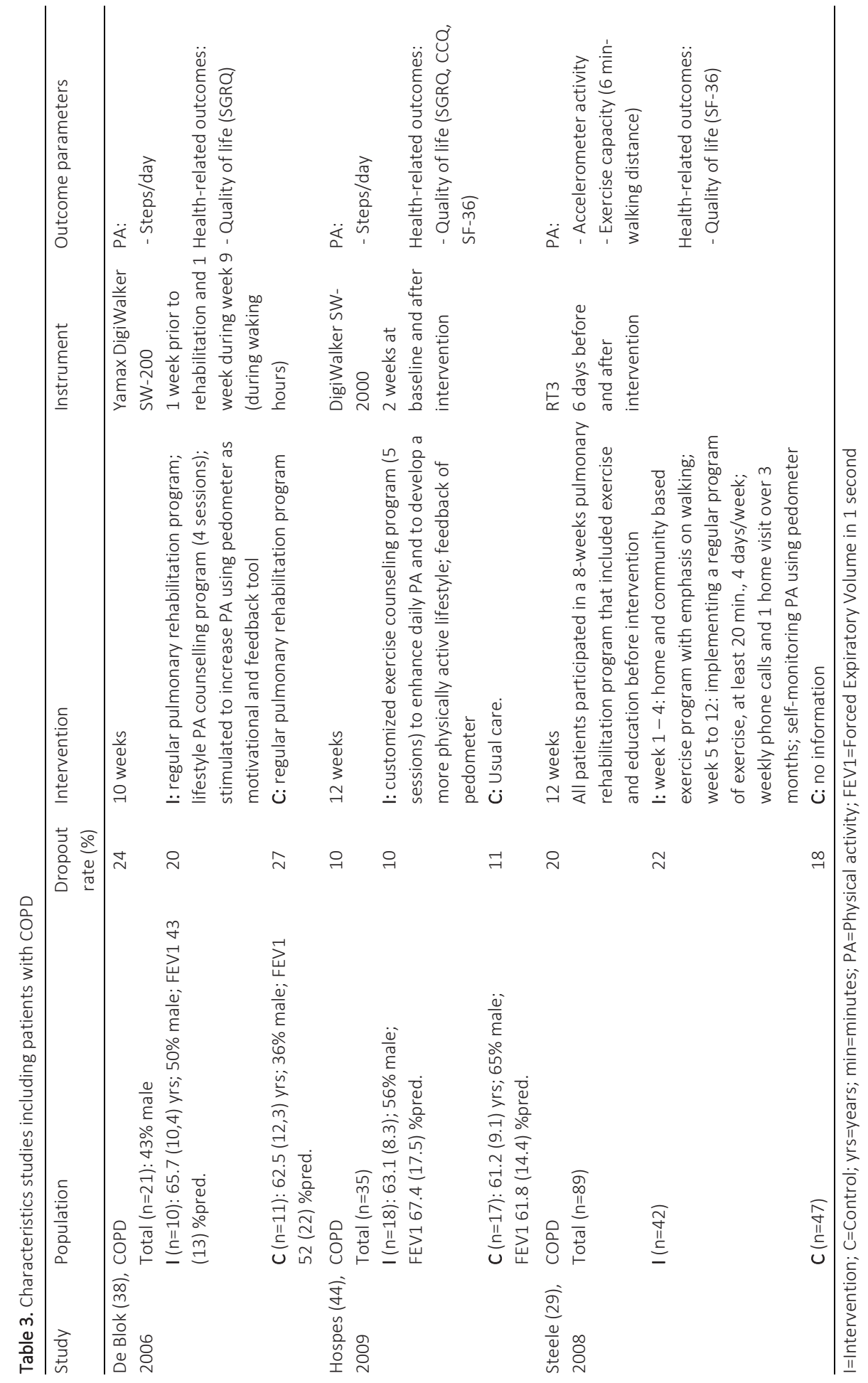




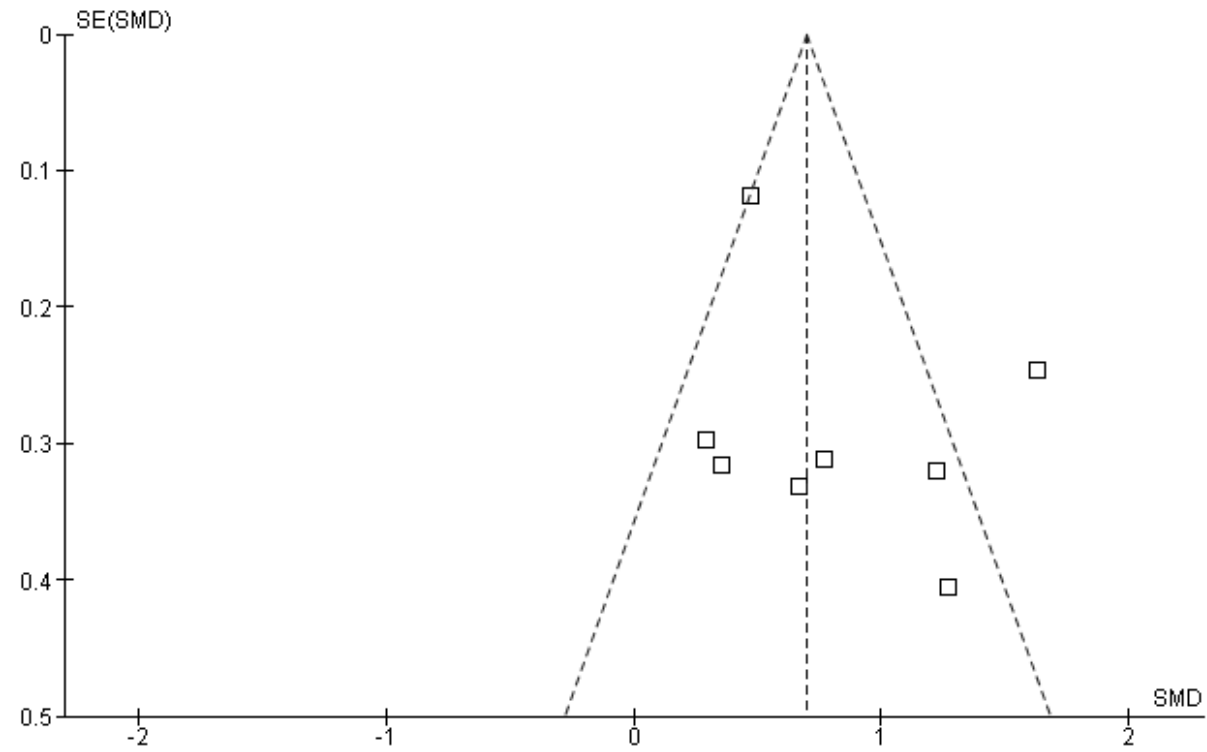

Figure 2. Funnel plot comparing interventions reporting steps/day as physical activity outcome

\section{Intervention characteristics}

Different types of interventions were used to evaluate the effect of activity monitorbased counseling on physical activity levels (Table 2 and 3). Mean duration of the interventions was 30.3 weeks (range: 5 to 260 weeks). In most interventions, physical activity counseling was delivered in one or more face-to-face sessions (29, 30, 32-50). These sessions were given by a nurse, physical therapist, (clinical) psychologist and/or general practitioner. Supplementary advice or counseling was delivered by telephone (32-34, $36,48)$, videoconference $(50)$, video $(41)$, or in written form $(28,46)$. All studies used an activity monitor device to provide feedback to patients.

In sixteen studies, intervention was compared with usual care combined with one or more sessions of advice or information on physical activity (28-30, 33-37, 39, 41-43, 4548). In eight studies, control subjects received only usual care (no intervention) (31, 32, $38,40,44,49-51)$.

\section{Diabetes mellitus type II}

\section{Effects on physical activity}

Physical activity level at baseline and post-intervention was measured using different activity monitors (Table 2). In all studies, physical activity counseling sessions were based on data acquired from the activity monitors. The most reported outcome param- 
eter on physical activity was number of steps per day (13 studies), but several other parameters were used, such as time spent walking $(42,43)$, activity counts $(34,35,46$, $47)$, activity intensity (36), frequency $(36)$ and/or energy expenditure $(33,45)$.

A pooled analysis to study the effect of activity monitor-based counseling on changes in steps per day included seven studies, all using a pedometer to determine step counts. Four studies were excluded because steps per day were only available in the intervention group $(28,30,37,51)$ and in two studies absolute changes in steps per day were not available, even after contacting the corresponding authors $(46,50)$.

Analysis showed that activity monitor-based interventions in combination with counseling resulted in a significant higher amount of steps per day in patients with DMII compared to a usual care control group (steps per day: $+2,042 ; 95 \%$ confidence interval $1,067$ to 3,$017 ; p<0.001$; Figure $3 a)$. Heterogeneity was moderate $\left(I^{2}=73 \%\right)$, which can be caused by differences in included patients (age, gender distribution) and interventions (methods, duration).

Studies excluded from the meta-analysis showed contrary results. In several studies, in which steps per day was only measured in the intervention group, a significant improvement in steps per day was found after an activity monitor-based intervention in patients with DMII $(28,30,51)$, only one study showed no improvement (37). Another study, in which absolute changes in steps per day were not available from the corresponding author, found no significant differences in change in steps per day between an activity monitor-based intervention and usual care (46). In one study, data on steps per day were not presented (50).

Studies using activity counts (34, 36), time spent walking (43), total physical activity (43, 50) and energy expenditure (33) as parameter to measure intervention effects on physical activity all reported significant positive benefits. Only the study of Engel and colleagues found no differences between subjects following an activity monitor-based intervention and a control group (42).

Effects on generic health-related outcomes

None of the studies used hospitalization or mortality rate as primary outcomes. 
Figure 3. Effects of activity monitor-based counseling on physical activity and generic and disease-specific health-related outcomes in adults with DMII.

a) Effects of activity monitor-based interventions versus control on physical activity (steps/day) in patients with DMII; b) Effects of activity monitor-based interventions versus control on HbA1c in patients with DMII; c) Effects of activity monitor-based interventions versus control on BMI in patients with DMII; d) Effects of activity monitor-based interventions versus control on systolic blood pressure in patients with DMII; e) Effects of activity monitor-based interventions versus control on diastolic blood pressure in patients with DMII

a

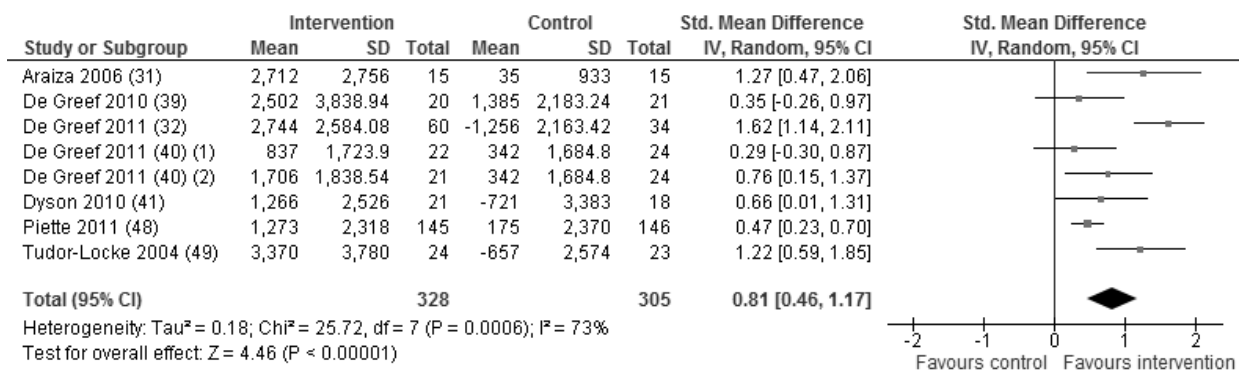

(1) Individual consultation

(2) Group counseling

b

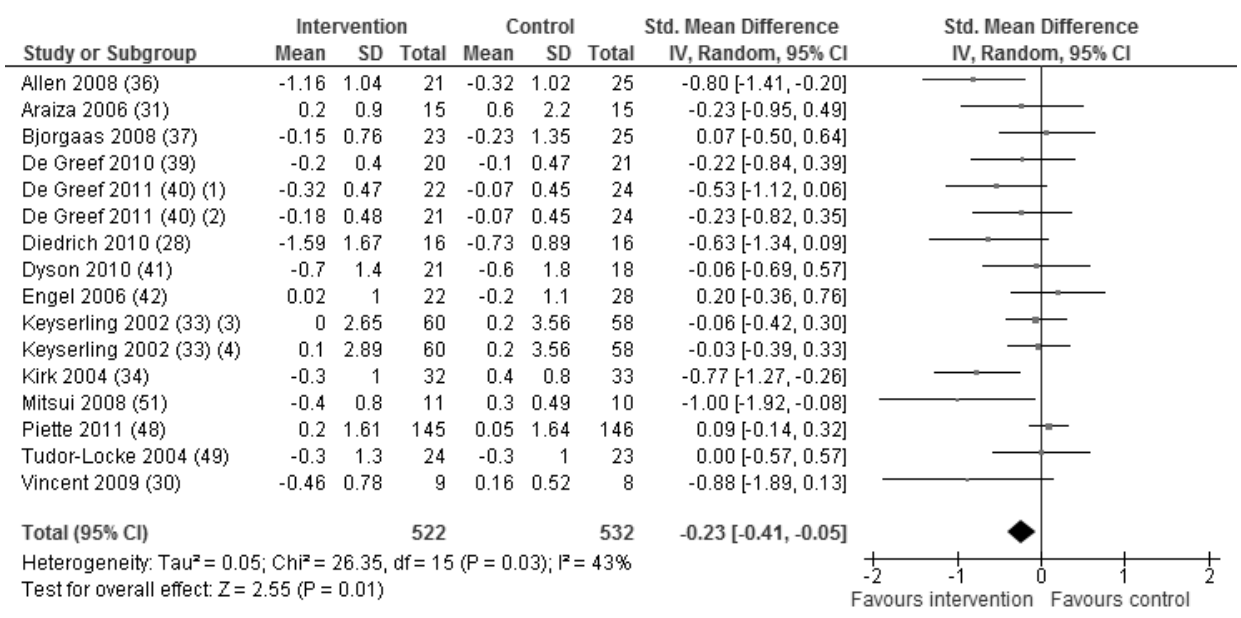

(1) Individual consultation

(2) Group counseling

(3) Clinic \& Community Intervention

(4) Clinic only Intervention 


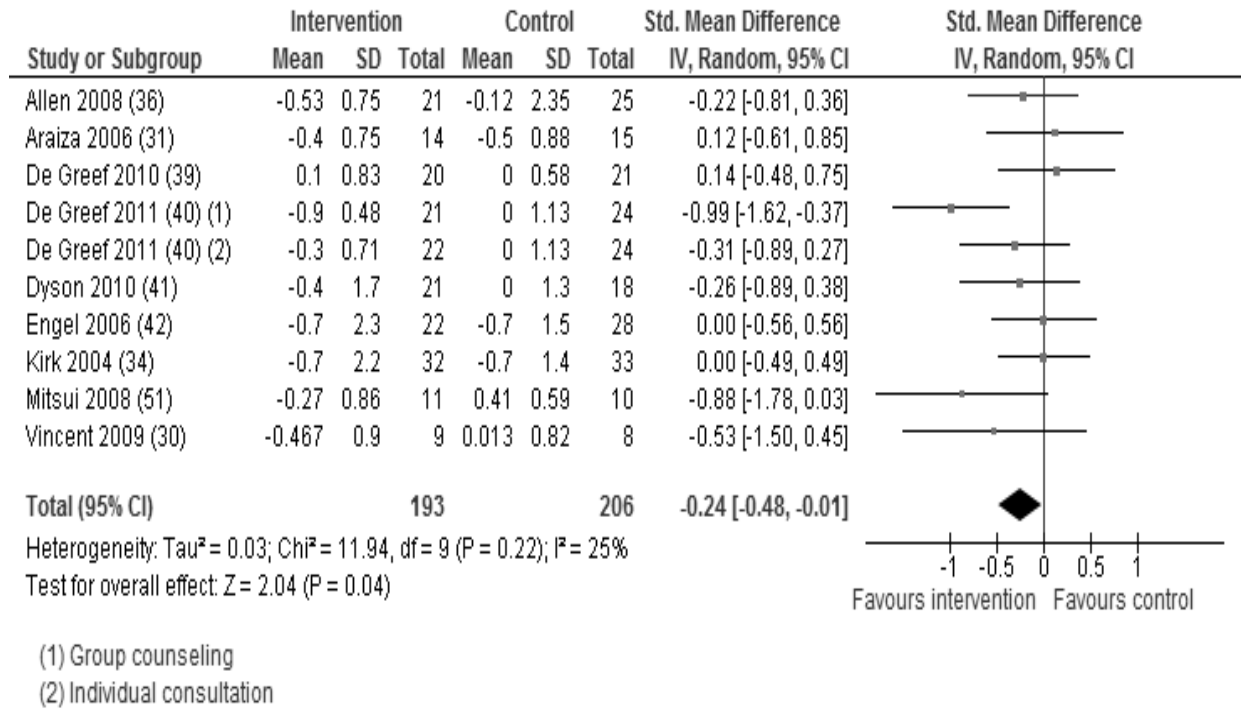

d

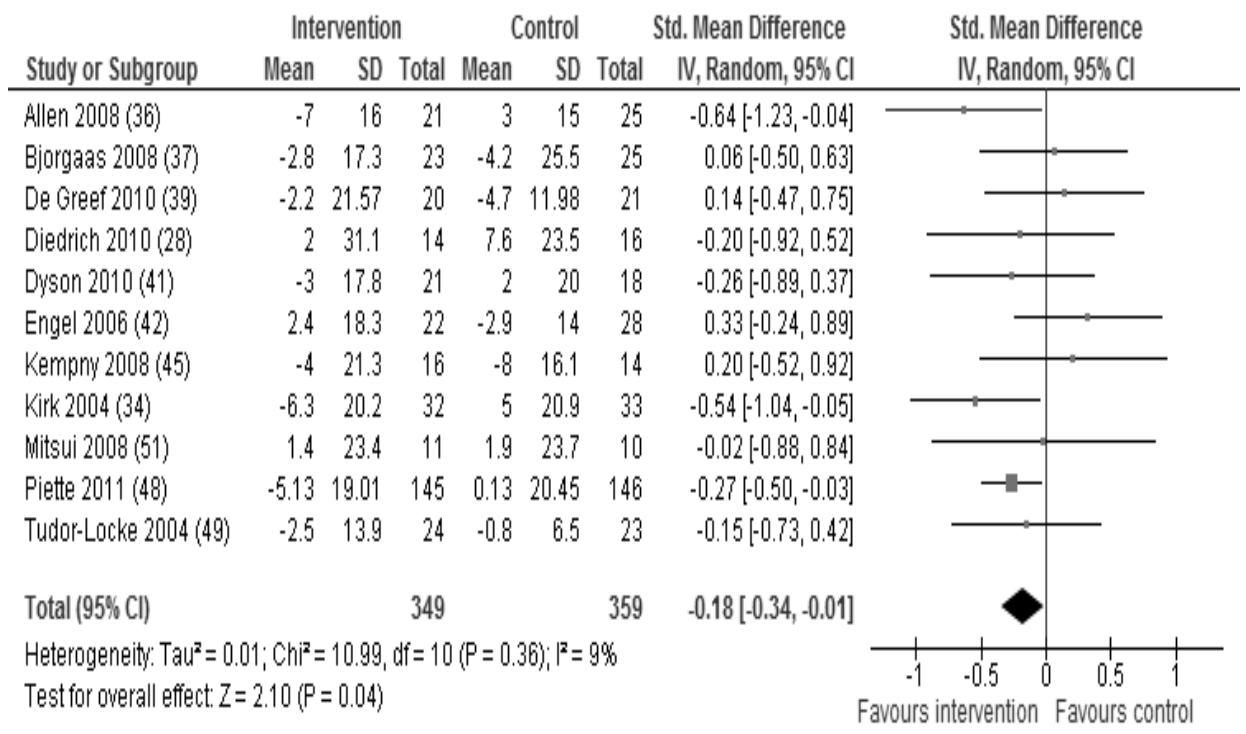




\begin{tabular}{|c|c|c|c|c|c|c|c|c|}
\hline \multirow[b]{2}{*}{ Study or Subgroup } & \multicolumn{3}{|c|}{ Intervention } & \multicolumn{2}{|c|}{ Control } & \multirow{2}{*}{\multicolumn{2}{|c|}{$\begin{array}{c}\text { Std. Mean Difference } \\
\text { Total } \quad \text { IV, Random, } 95 \% \mathrm{Cl} \\
\end{array}$}} & \multirow{2}{*}{$\begin{array}{l}\text { Std. Mean Difference } \\
\text { IV, Random, } 95 \% \mathrm{Cl} \\
\end{array}$} \\
\hline & Mean & SD & Total & Mean & SD & & & \\
\hline Allen 2008 (36) & -3 & 11 & 21 & -2 & 9 & 25 & $-0.10[-0.68,0.48]$ & \\
\hline Bjorgaas 2008 (37) & -2.9 & 14 & 23 & -7.4 & 14.8 & 25 & $0.31[-0.26,0.88]$ & \\
\hline De Greef 2010 (39) & -3.5 & 13.05 & 20 & -2.4 & 6.94 & 21 & $-0.10[-0.72,0.51]$ & \\
\hline Diedrich 2010 (28) & -2.79 & 13.24 & 14 & 3.88 & 13.73 & 16 & $-0.48[-1.21,0.25]$ & \\
\hline Dyson 2010 (41) & -2 & 12.1 & 21 & 3 & 11.7 & 18 & $-0.41[-1.05,0.23]$ & \\
\hline Engel 2006 (42) & 1.6 & 9.9 & 22 & -4.1 & 9.9 & 28 & $0.57[-0.00,1.14]$ & \\
\hline Kempny 2008 (45) & -5 & 9 & 16 & 3 & 12.4 & 14 & $-0.73[-1.47,0.02]$ & \\
\hline Kirk 2004 (34) & -4 & 9.5 & 32 & -4 & 11.8 & 33 & $0.00[-0.49,0.49]$ & \\
\hline Mitsui 2008 (51) & -2.4 & 10.8 & 11 & 2.6 & 11.4 & 10 & $-0.43[-1.30,0.44]$ & \\
\hline Piette 2011 (48) & -2.93 & 11.23 & 145 & -1.12 & 10.81 & 146 & $-0.16[-0.39,0.07]$ & -1 \\
\hline Tudor-Locke 2004 (49) & -0.4 & 7.5 & 24 & -0.8 & 6.5 & 23 & $0.06[-0.52,0.63]$ & \\
\hline Total (95\% Cl) & & & 349 & & & 359 & $-0.09[-0.28,0.10]$ & \\
\hline $\begin{array}{l}\text { Heterogeneity: Tau }{ }^{2}=0.0 \\
\text { Test for overall effect: } Z=\end{array}$ & $\begin{array}{l}2 ; \mathrm{Ch}^{2}= \\
0.96(\mathrm{P}=\end{array}$ & $\begin{array}{l}13.20,0 \\
=0.34)\end{array}$ & $d f=10$ & $(P=0$. & $21) ; 1^{2}=2$ & & & $\begin{array}{cccc}-1 & -0.5 & 0 & 0.5 \\
r s & \text { intervention } & \text { Favours }\end{array}$ \\
\hline
\end{tabular}

Effects on disease-specific health-related outcomes

Hemoglobin A1c. Sixteen studies reported intervention effects on HbA1c. Because in two studies data were not available in absolute changes and standard deviation, even after contacting authors $(46,50)$, fourteen studies could be included in the pooled analysis.

Results showed a significant higher decrease in $\mathrm{HbA1c}$ in the intervention group compared to controls (standardized mean difference -0.23 ; 95\% confidence interval -0.41 to $-0.05 ; p=0.01$; Figure $3 b)$. Although, the heterogeneity of the studies was moderate $\left(I^{2}=43 \%\right.$; Figure $\left.3 \mathrm{~b}\right)$. Results remained significant after exclusion of the study of Allen et al., in which physical activity counseling was combined with a continuous glucose monitoring system (standardized mean difference - 0.19 ; 95\% confidence interval -0.36 to $0.02 ; p=0.03)(36)$. One study excluded from the meta-analysis did not observe betweengroup differences in $\mathrm{HbA1c}(46)$.

Body mass index. Eleven articles described the effect of the intervention on BMI. Nine studies were included in the pooled analyses. The other two studies were excluded from the analysis because data were not available in absolute changes and standard deviation, even after contacting authors $(45,46)$.

Results showed a beneficial effect on decreasing BMI following an activity monitorbased intervention compared to control interventions (standardized mean difference 0.24 ; $95 \%$ confidence interval -0.48 to $-0.01 ; p=0.04$; Figure $3 c$ ). Heterogeneity of the 
included studies was low $\left(I^{2}=25 \%\right)$. Studies excluded from the meta-analysis found no significant differences between the intervention and control group $(45,46)$.

Systolic and diastolic blood pressure. Effects on systolic and diastolic blood pressure were reported in fourteen studies. In three studies absolute changes in systolic and diastolic blood pressure were not available, even after contacting authors $(31,46,50)$. Therefore, pooled analysis was performed using eleven studies (figure $3 d$ and $3 e$ ).

Pooled analysis showed a significant difference in changes in systolic blood pressure $(p=0.04$; Figure $3 d)$, but not in diastolic blood pressure ( $p=0.34$; Figure $3 e)$ between the intervention and control group. Heterogeneity of the studies was low $\left(I^{2}=9 \%\right.$ and $\left.24 \%\right)$. Two studies excluded from the meta-analysis found no significant changes in systolic or diastolic blood pressure after activity monitor-based interventions $(31,46)$.

Health-related quality of life. Health-related quality of life was examined in four studies $(33,35,41,50)$. No meta-analysis was conducted because of the use of different questionnaires (SF-36, SF-12, Mental and Social Well-Being Scale and WHO-5 Well-Being Index) or absolute changes in health-related quality of life were not presented $(41,50)$. Studies found no significant improvement in health-related quality of life in patients with DMII, or no significant between group differences $(33,35,41)$.

COPD

\section{Effects on physical activity}

Physical activity was measured using different activity monitors (Table 3). Studies used steps per day $(38,44)$ or activity counts $(29)$ as outcome parameter. A pooled analysis to study the effect of an activity monitor-based intervention on changes in steps per could not be performed, because absolute changes in steps per day were not available, even after contacting authors $(38,44)$. In studies presenting only absolute changes in steps per day, one study showed a significant difference in steps per day between an activity monitor-based intervention and usual care (44), whereas no significant difference was found in another study (38). Study using activity counts as parameter to measure intervention effects on physical activity only reported significant short-term benefits (29).

\section{Effects on generic health-related outcomes}

None of the studies used hospitalization or mortality rate as primary outcomes.

\section{Effects on disease-specific health-related outcomes}

Health-related quality of life. Health-related quality of life was examined in all studies $(29,38,44)$. No meta-analysis was conducted, because of the use of different questionnaires (St. Georges Respiratory Questionnaire (SGRQ), Clinical COPD Questionnaire 
(CCQ), Seattle Obstructive Lung Disease Questionnaire (SOLDQ), 36-Item Short-Form Health Survey (SF-36)). One study found a beneficial effect of an activity monitor-based intervention on health-related quality of life in patients with COPD compared to a control intervention (44), whereas other studies found no significant between group differences in health-related quality of life $(29,38)$.

\section{DISCUSSION}

In this review we systematically evaluated the effect of activity monitor-based interventions on physical activity levels and health-related outcomes in patients with a DMII, COPD or CHF. In general, interventions using an activity monitor in combination with counseling are associated with a significantly higher improvement in physical activity compared to a control intervention or usual care in patients with DMII. Moreover, these interventions had a beneficial effect on $\mathrm{HbA} 1 \mathrm{c}$, systolic blood pressure and $\mathrm{BMI}$ in patients with DMII. Contrary results were found on physical activity and health-related quality of life in patients with COPD, although data were limited. None of the studies used hospitalization or mortality rate as primary outcomes. Moreover, CHF trials were not available.

\section{Daily physical activity level}

Pooled analysis showed that interventions using an activity monitor in combination with counseling had a beneficial effect on physical activity, measured in steps per day, compared to a control intervention (Figure 3a). This is consistent with findings of an earlier meta-analysis, showing that the use of a pedometer is associated with a significant increase of more than 2,000 steps per day in outpatient (healthy) adults (17). Avery et al. also showed an increase in physical activity levels in patients with DMII, following behavioral interventions including exercise (24). Nevertheless, relevant articles seem to be missing in this review $(33,36,37,42,48)$.

The included studies used different types of activity monitors (Table 2 and 3). Pedometers can be used to provide direct feedback to the participants on the level of physical activity (amount of steps per day). Therefore, participants can monitor themselves and set goals for increasing their level of physical activity. In contrast, most accelerometers do not have a display and can therefore not provide direct feedback to participants. However, accelerometer data, processed by a computer, can be used for promoting physical activity by counseling sessions or by a self-monitoring approach.

It is known that simple pedometers are less sensitive to lower force accelerations, such as slow walking, than accelerometers (18). Moreover, earlier was shown that patients with a chronic disease walk less, but also with a lower speed compared to healthy adults (52), which can lead to an underestimation of steps while using a pedometer (53). Fur- 
thermore, pedometers can only give an indication about steps per day, whereas an accelerometer is able to give information about the quantity and intensity of performed activities (18).

\section{Health-related outcomes}

To date, the effects of activity monitor-based counseling on hospitalization or survival has not been studied. Then again, this systematic review showed a significantly larger decrease in $\mathrm{HbA1c}$ in the intervention group compared to a control intervention or usual care in patients with DMII (Figure 3b). This is consistent with results of earlier reviews showing a positive effect of physical activity on the reduction of $\mathrm{HbA} 1 \mathrm{c}$, which was not mediated by weight loss $(23,24,54)$. A decrease in $\mathrm{HbA} 1 \mathrm{c}$ level is an indication of better glucose control, which is associated with a reduced burden of cardiovascular disease and microvascular complications in people with DMII (55). Indeed, current guidelines recommend intensive glycemic control as an effective treatment, with a target $\mathrm{HbA} 1 \mathrm{c}$ of $7 \%$ or less (56). However, results regarding the association between $\mathrm{HbA1C}$ and cardiovascular events in DMII are contrary $(57,58)$. Therefore, it remains unknown whether and to what extent a reduction in $\mathrm{HbA1c}$ will result in long-term health benefit in patients with DMII.

Pooled analysis showed a beneficial effect on decreasing BMI following an activity monitor-based intervention compared to control interventions, although results are limited to patients with DMII (Figure 3c). These results confirm findings of earlier reviews, in which was shown that interventions promoting physical activity resulted in a significant reduction in BMI both in healthy sedentary adults and in adults with COPD, DMII, neuromuscular disease or obesity $(17,24)$. Unfortunately, data on changes in fat free mass and fat mass are limited, whereas these data provide more valuable information than changes in BMI.

The risk of additional weight gain is increased in patients with DMII as a result of a reduced level of physical activities compared to healthy peers. Earlier studies already showed that weight loss is associated with positive long-term outcomes and substantial reduction in mortality in obese patients with DMII (59).

Obesity is also associated with decreased levels of physical activity in patients with COPD (21). The currently available data do not suggest a reduction in BMI following an activity monitor-based counseling. Then again, being overweight or obese has been associated with a decreased mortality among patients with severe COPD; a phenomenon commonly referred to as the 'obesity paradox' (60).

Elevated resting blood pressure is associated with a significant increased risk for cardiovascular diseases (61). An earlier published review already showed the positive effects of physical activity on decreasing blood pressure (17), which in turn will result in a better prognosis and health benefits. Pooled analyses in the current review showed a 
beneficial effect on systolic blood pressure following an activity monitor-based intervention compared to a control intervention in patients with DMII, whereas no significant changes were found in diastolic blood pressure (Figure $3 \mathrm{~d}$ and 3e). Earlier was shown that even relatively small reductions in resting diastolic blood pressure of $2 \mathrm{mmHg}$ can reduce the cardiovascular risk by 6\% (62). Indeed, most studies showed a decrease in diastolic blood pressure of $\geq 2 \mathrm{mmHg}$ following an activity-monitor-based intervention $(34,36,37,39,41,46,48)$, which was found non-significant in some studies $(39,41,46)$ or non-different between intervention and control group $(34,37,48)$.

This systematic review found contrary results on the health-related quality of life after activity monitor-based interventions. Indeed, different questionnaires were used (SGRQ $(38,44)$, CCQ (44), SOLDQ (29), SF-36 (29, 35, 44), SF-12 (50), Mental and Social WellBeing Scale(33) and WHO-5 Well-Being Index(41)), making it difficult to compare outcomes. However, quality of life is an important measure of health, particular for older people and those suffering from a chronic disease. Indeed, earlier has been shown that patients with DMII, COPD or CHF have a reduced health-related quality of life compared to healthy peers, and it decreases with disease progression and complications (63-65). Moreover, worsening of health-related quality of life is associated with increased overall mortality (65-67) and maintaining moderate or high levels of physical activity and improvement in physical activity level are associated with a better health-related quality of life in patients with DMII, COPD or $\operatorname{CHF}(20,22,68)$.

\section{Strengths}

To the best of our knowledge, this review is the first to examine the effects of activity monitor-based counseling on objectified physical activity levels and health-related outcomes in adults with a chronic disease. Indeed, earlier reviews already studied the effectiveness of physical activity promotion in adults and subjects living with disability and/or chronic disease $(16,17,19)$, but these reviews only focused on physical activity (19), included studies with healthy subjects (17), or included studies using self-reported measures of physical activity $(16,24)$. The strength of this meta-analysis is that only trials were included that objectively measured physical activity before and after the intervention, because self-reported measures are associated with a lack of precision and sensitivity to social desirability $(18,69)$. Surprisingly, studies on the effects of activity monitor-based counseling in patients with CHF are currently lacking. Therefore, we believe we have identified a major research topic within CHF. Indeed, accelerometers are already incorporated in implanted devices for continuous activity telemonitoring in patients with CHF (70). Moreover, physical activity monitoring using an accelerometer during the first phase of cardiac rehabilitation (in-hospital) and directly after discharge from the hospital may increase physical activity levels in patients with cardiovascular disease, such as coronary artery bypass graft myocardial infarction and valve replace- 
ment (71). Therefore, it seems reasonable to assume that patients with CHF also may benefit from interventions using an accelerometer.

\section{Limitations}

Our review has several limitations. First, the included results may have been biased, because outcome assessors, therapists and/or patients were not blinded for the intervention arm. Though, blinding of patients and therapists is probably not possible in these study designs, and most probably will not affect objective measures such as $\mathrm{HbAc1}$ and blood pressure.

Secondly, this meta-analysis included trials with different intervention duration (5 weeks to 260 weeks), methods of counseling (number of sessions, individual or group, face to face or written, phone or video), activity monitors and patient characteristics (age, gender distribution). Moreover, the use of the activity monitors to measure physical activity before and after the intervention and also the use during the intervention was different in most studies, though reportings on this were often limited. Although our review demonstrated the effectiveness of activity monitor-based programs, these differences could have influenced the intervention effects. Because of the large variety in activity monitor types, intervention duration and intervention design, a sensitivity analysis was not feasible. Therefore, we were not able to demonstrate differences between different activity monitors, intervention duration and intervention designs. Furthermore, these differences in study designs resulted in low to moderate scores of heterogeneity (0\% to $73 \%)$. However, earlier was shown that about a quarter of metaanalysis have $\mathrm{I}^{2}$ values over $50 \%$ (27).

Thirdly, data on physical activity and health-related outcomes in patients with COPD and CHF were limited or non-existing. It can be assumed that activity monitor-based interventions in patients with COPD and CHF will have similar beneficial effects as in patients with DMII However, the amount and quality of the data studies are not sufficient to support this assumption, and therefore, conclusions on health-related outcomes are mainly based on studies including patients with DMII.

Fourthly, interventions using an activity monitor in combination with counseling appear to be cost-effective in the general population (72). It seems reasonable to assume that the cost-effectiveness is even higher in patients with DMII, COPD or CHF. Nevertheless, this remains currently unknown.

Finally, 24 studies were selected for this review, but not all studies could be included in the meta-analysis, because studies used different physical activity parameters or different questionnaires to measure health-related quality of life. Furthermore, some of the authors did not reply on the request for additional data $(46,50)$, or were not able to provide the requested data $(38,44)$. Therefore, the observed effect of this metaanalysis may be biased by this exclusion. 
To conclude, our review shows the effectiveness of activity monitor-based interventions to promote physical activity in patients with DMII. Moreover, these interventions resulted in significant reductions in $\mathrm{HbA1c}$, systolic blood pressure and BMI in patients with DMII compared to usual care. Data in patients with COPD and CHF are limited or non-existing, respectively. Future studies are needed to study the long-term effects of activity-monitor based counseling interventions on physical activity and generic and disease-specific outcomes, including a cost-effectiveness analysis. 


\section{REFERENCES}

1. Garcia-Aymerich J, Lange P, Benet M, Schnohr P, Anto JM. Regular physical activity reduces hospital admission and mortality in chronic obstructive pulmonary disease: a population based cohort study. Thorax. 2006;61(9):772-8.

2. Sigal RJ, Kenny GP, Wasserman DH, Castaneda-Sceppa C, White RD. Physical activity/exercise and type 2 diabetes: a consensus statement from the American Diabetes Association. Diabetes Care. 2006;29(6):1433-8.

3. Lee IM, Shiroma EJ, Lobelo F, Puska P, Blair SN, Katzmarzyk PT. Effect of physical inactivity on major noncommunicable diseases worldwide: an analysis of burden of disease and life expectancy. Lancet. 2012;380(9838):219-29.

4. Nelson ME, Rejeski WJ, Blair SN, Duncan PW, Judge JO, King AC, et al. Physical activity and public health in older adults: recommendation from the American College of Sports Medicine and the American Heart Association. Med Sci Sports Exerc. 2007;39(8):1435-45.

5. Hallal PC, Andersen LB, Bull FC, Guthold R, Haskell W, Ekelund U. Global physical activity levels: surveillance progress, pitfalls, and prospects. Lancet. 2012;380(9838):247-57.

6. Caspersen CJ, Pereira MA, Curran KM. Changes in physical activity patterns in the United States, by sex and cross-sectional age. Med Sci Sports Exerc. 2000;32(9):1601-9.

7. Resnick HE, Foster GL, Bardsley J, Ratner RE. Achievement of American Diabetes Association clinical practice recommendations among U.S. adults with diabetes, 1999-2002: the National Health and Nutrition Examination Survey. Diabetes Care. 2006;29(3):531-7.

8. Morrato EH, Hill JO, Wyatt HR, Ghushchyan V, Sullivan PW. Physical activity in U.S. adults with diabetes and at risk for developing diabetes, 2003. Diabetes Care. 2007;30(2):203-9.

9. Gosker HR, Lencer NH, Franssen FM, van der Vusse GJ, Wouters EF, Schols AM. Striking similarities in systemic factors contributing to decreased exercise capacity in patients with severe chronic heart failure or COPD. Chest. 2003;123(5):1416-24.

10. Waschki B, Spruit MA, Watz H, Albert PS, Shrikrishna D, Groenen M, et al. Physical activity monitoring in COPD: compliance and associations with clinical characteristics in a multicenter study. Respir Med. 2012;106(4):522-30.

11. Oldridge NB. Economic burden of physical inactivity: healthcare costs associated with cardiovascular disease. Eur J Cardiovasc Prev Rehabil. 2008;15(2):130-9.

12. Spruit MA, Gosselink R, Troosters T, De Paepe K, Decramer M. Resistance versus endurance training in patients with COPD and peripheral muscle weakness. Eur Respir J. 2002;19(6):1072-8.

13. Oerkild B, Frederiksen M, Hansen JF, Prescott E. Self-reported physical inactivity predicts survival after hospitalization for heart disease. Eur J Cardiovasc Prev Rehabil. 2011;18(3):475-80.

14. Wei M, Gibbons LW, Kampert JB, Nichaman MZ, Blair SN. Low cardiorespiratory fitness and physical inactivity as predictors of mortality in men with type 2 diabetes. Ann Intern Med. 2000;132(8):605-11.

15. Waschki B, Kirsten A, Holz O, Muller KC, Meyer T, Watz H, et al. Physical activity is the strongest predictor of all-cause mortality in patients with COPD: a prospective cohort study. Chest. 2011;140(2):331-42.

16. Orrow G, Kinmonth AL, Sanderson S, Sutton S. Effectiveness of physical activity promotion based in primary care: systematic review and meta-analysis of randomised controlled trials. BMJ. 2012;344:e1389.

17. Bravata DM, Smith-Spangler C, Sundaram V, Gienger AL, Lin N, Lewis R, et al. Using pedometers to increase physical activity and improve health: a systematic review. JAMA. 2007;298(19):2296-304.

18. Pitta F, Troosters T, Probst VS, Spruit MA, Decramer M, Gosselink R. Quantifying physical activity in daily life with questionnaires and motion sensors in COPD. Eur Respir J. 2006;27(5):1040-55.

19. Tudor-Locke C, Craig CL, Aoyagi Y, Bell RC, Croteau KA, De Bourdeaudhuij I, et al. How many steps/day are enough? For older adults and special populations. Int J Behav Nutr Phys Act. 2011;8:80. 
20. Esteban C, Quintana JM, Aburto M, Moraza J, Egurrola M, Perez-Izquierdo J, et al. Impact of changes in physical activity on health-related quality of life among patients with COPD. Eur Respir J. 2010;36(2):292-300.

21. Watz H, Waschki B, Kirsten A, Muller KC, Kretschmar G, Meyer T, et al. The metabolic syndrome in patients with chronic bronchitis and COPD: frequency and associated consequences for systemic inflammation and physical inactivity. Chest. 2009;136(4):1039-46.

22. Eckert K. Impact of physical activity and bodyweight on health-related quality of life in people with type 2 diabetes. Diabetes, metabolic syndrome and obesity : targets and therapy. 2012;5:303-11.

23. Umpierre D, Ribeiro PA, Kramer CK, Leitao CB, Zucatti AT, Azevedo MJ, et al. Physical activity advice only or structured exercise training and association with $\mathrm{HbA} 1 \mathrm{c}$ levels in type 2 diabetes: a systematic review and meta-analysis. JAMA : the journal of the American Medical Association. 2011;305(17):1790-9.

24. Avery L, Flynn D, van Wersch A, Sniehotta FF, Trenell MI. Changing Physical Activity Behavior in Type 2 Diabetes: A systematic review and meta-analysis of behavioral interventions. Diabetes care. 2012;35(12):2681-9.

25. Moher D, Liberati A, Tetzlaff J, Altman DG. Preferred reporting items for systematic reviews and metaanalyses: the PRISMA statement. PLoS medicine. 2009;6(7):e1000097.

26. Foley NC, Bhogal SK, Teasell RW, Bureau Y, Speechley MR. Estimates of quality and reliability with the physiotherapy evidence-based database scale to assess the methodology of randomized controlled trials of pharmacological and nonpharmacological interventions. Phys Ther. 2006;86(6):817-24.

27. Higgins JP, Thompson SG, Deeks JJ, Altman DG. Measuring inconsistency in meta-analyses. BMJ. 2003;327(7414):557-60.

28. Diedrich A, Munroe DJ, Romano M. Promoting physical activity for persons with diabetes. Diabetes Educ. 2010;36(1):132-40

29. Steele BG, Belza B, Cain KC, Coppersmith J, Lakshminarayan S, Howard J, et al. A randomized clinical trial of an activity and exercise adherence intervention in chronic pulmonary disease. Arch Phys Med Rehabil. 2008;89(3):404-12.

30. Vincent D. Culturally tailored education to promote lifestyle change in Mexican Americans with type 2 diabetes. J Am Acad Nurse Pract. 2009;21(9):520-7.

31. Araiza P, Hewes H, Gashetewa C, Vella CA, Burge MR. Efficacy of a pedometer-based physical activity program on parameters of diabetes control in type 2 diabetes mellitus. Metabolism. 2006;55(10):13827.

32. De Greef KP, Deforche BI, Ruige JB, Bouckaert JJ, Tudor-Locke CE, Kaufman JM, et al. The effects of a pedometer-based behavioral modification program with telephone support on physical activity and sedentary behavior in type 2 diabetes patients. Patient Educ Couns. 2011;84(2):275-9.

33. Keyserling TC, Samuel-Hodge CD, Ammerman AS, Ainsworth BE, Henriquez-Roldan CF, Elasy TA, et al. A randomized trial of an intervention to improve self-care behaviors of African-American women with type 2 diabetes: impact on physical activity. Diabetes Care. 2002;25(9):1576-83.

34. Kirk A, Mutrie N, Maclntyre P, Fisher M. Effects of a 12-month physical activity counselling intervention on glycaemic control and on the status of cardiovascular risk factors in people with Type 2 diabetes. Diabetologia. 2004;47(5):821-32.

35. Kirk AF, Higgins LA, Hughes AR, Fisher BM, Mutrie N, Hillis S, et al. A randomized, controlled trial to study the effect of exercise consultation on the promotion of physical activity in people with Type 2 diabetes: a pilot study. Diabet Med. 2001;18(11):877-82.

36. Allen NA, Fain JA, Braun B, Chipkin SR. Continuous glucose monitoring counseling improves physical activity behaviors of individuals with type 2 diabetes: A randomized clinical trial. Diabetes Res Clin Pract. 2008;80(3):371-9.

37. Bjorgaas MR, Vik JT, Stolen T, Lydersen S, Grill V. Regular use of pedometer does not enhance beneficial outcomes in a physical activity intervention study in type 2 diabetes mellitus. Metabolism. 2008;57(5):605-11. 
38. de Blok BM, de Greef MH, ten Hacken NH, Sprenger SR, Postema K, Wempe JB. The effects of a lifestyle physical activity counseling program with feedback of a pedometer during pulmonary rehabilitation in patients with COPD: a pilot study. Patient Educ Couns. 2006;61(1):48-55.

39. De Greef K, Deforche B, Tudor-Locke C, De Bourdeaudhuij I. A cognitive-behavioural pedometer-based group intervention on physical activity and sedentary behaviour in individuals with type 2 diabetes. Health Educ Res. 2010;25(5):724-36.

40. De Greef K, Deforche B, Tudor-Locke C, De Bourdeaudhuij I. Increasing physical activity in Belgian type 2 diabetes patients: a three-arm randomized controlled trial. Int J Behav Med. 2011;18(3):188-98.

41. Dyson PA, Beatty S, Matthews DR. An assessment of lifestyle video education for people newly diagnosed with type 2 diabetes. J Hum Nutr Diet. 2010;23(4):353-9.

42. Engel L, Lindner H. Impact of using a pedometer on time spent walking in older adults with type 2 diabetes. Diabetes Educ. 2006;32(1):98-107.

43. Furber S, Monger C, Franco L, Mayne D, Jones LA, Laws R, et al. The effectiveness of a brief intervention using a pedometer and step-recording diary in promoting physical activity in people diagnosed with type 2 diabetes or impaired glucose tolerance. Health Promot J Austr. 2008;19(3):189-95.

44. Hospes G, Bossenbroek L, Ten Hacken NH, van Hengel P, de Greef MH. Enhancement of daily physical activity increases physical fitness of outclinic COPD patients: results of an exercise counseling program. Patient Educ Couns. 2009;75(2):274-8.

45. Kempny A, Moczulski D, Kempny A. Pedometer improves doctor's advice to enhance physical activity in type 2 diabetes. Diabetologia Doswiadczalna i Klinicza. 2008;8(1):33-7.

46. Kirk A, Barnett J, Leese G, Mutrie N. A randomized trial investigating the 12-month changes in physical activity and health outcomes following a physical activity consultation delivered by a person or in written form in Type 2 diabetes: Time2Act. Diabet Med. 2009;26(3):293-301.

47. Paschali AA, Goodrick GK, Kalantzi-Azizi A, Papadatou D, Balasubramanyam A. Accelerometer feedback to promote physical activity in adults with type 2 diabetes: a pilot study. Percept Mot Skills. 2005;100(1):61-8

48. Piette JD, Richardson C, Himle J, Duffy S, Torres T, Vogel M, et al. A randomized trial of telephonic counseling plus walking for depressed diabetes patients. Med Care. 2011;49(7):641-8.

49. Tudor-Locke C, Bell RC, Myers AM, Harris SB, Ecclestone NA, Lauzon N, et al. Controlled outcome evaluation of the First Step Program: a daily physical activity intervention for individuals with type II diabetes. Int J Obes Relat Metab Disord. 2004;28(1):113-9.

50. Weinstock RS, Brooks G, Palmas W, Morin PC, Teresi JA, Eimicke JP, et al. Lessened decline in physical activity and impairment of older adults with diabetes with telemedicine and pedometer use: results from the IDEATel study. Age Ageing. 2011;40(1):98-105.

51. Mitsui T, Shimaoka K, Kobayashi T. Examining a 30-minute walking program using a pedometer in the management of type 2 diabetes. Gazzetta Medica Italiana Archivio per le Scienze Mediche. 2008;167(6):293-8.

52. Pitta F, Troosters T, Spruit MA, Probst VS, Decramer M, Gosselink R. Characteristics of physical activities in daily life in chronic obstructive pulmonary disease. Am J Respir Crit Care Med. 2005;171(9):972-7.

53. Cyarto EV, Myers AM, Tudor-Locke C. Pedometer accuracy in nursing home and community-dwelling older adults. Med Sci Sports Exerc. 2004;36(2):205-9.

54. Boule NG, Haddad E, Kenny GP, Wells GA, Sigal RJ. Effects of exercise on glycemic control and body mass in type 2 diabetes mellitus: a meta-analysis of controlled clinical trials. JAMA : the journal of the American Medical Association. 2001;286(10):1218-27.

55. Patel A, MacMahon S, Chalmers J, Neal B, Billot L, Woodward M, et al. Intensive blood glucose control and vascular outcomes in patients with type 2 diabetes. N Engl J Med. 2008;358(24):2560-72.

56. Standards of medical care in diabetes--2010. Diabetes Care. 2010;33 Suppl 1:S11-61.

57. Gerstein HC, Miller ME, Genuth S, Ismail-Beigi F, Buse JB, Goff DC, Jr., et al. Long-term effects of intensive glucose lowering on cardiovascular outcomes. N Engl J Med. 2011;364(9):818-28.

58. Duckworth W, Abraira C, Moritz T, Reda D, Emanuele N, Reaven PD, et al. Glucose control and vascular complications in veterans with type 2 diabetes. N Engl J Med. 2009;360(2):129-39. 
59. Williamson DF, Thompson TJ, Thun M, Flanders D, Pamuk E, Byers T. Intentional weight loss and mortality among overweight individuals with diabetes. Diabetes Care. 2000;23(10):1499-504.

60. Franssen FM, O'Donnell DE, Goossens GH, Blaak EE, Schols AM. Obesity and the lung: 5. Obesity and COPD. Thorax. 2008;63(12):1110-7.

61. Vasan RS, Larson MG, Leip EP, Evans JC, O’Donnell CJ, Kannel WB, et al. Impact of high-normal blood pressure on the risk of cardiovascular disease. N Engl J Med. 2001;345(18):1291-7.

62. Cook NR, Cohen J, Hebert PR, Taylor JO, Hennekens CH. Implications of small reductions in diastolic blood pressure for primary prevention. Arch Intern Med. 1995;155(7):701-9.

63. Wexler DJ, Grant RW, Wittenberg E, Bosch JL, Cagliero E, Delahanty L, et al. Correlates of health-related quality of life in type 2 diabetes. Diabetologia. 2006;49(7):1489-97.

64. Janssen DJ, Spruit MA, Leue C, Gijsen C, Hameleers H, Schols JM, et al. Symptoms of anxiety and depression in COPD patients entering pulmonary rehabilitation. Chronic respiratory disease. 2010;7(3):147-57.

65. Iqbal J, Francis L, Reid J, Murray S, Denvir M. Quality of life in patients with chronic heart failure and their carers: a 3-year follow-up study assessing hospitalization and mortality. European journal of heart failure. 2010;12(9):1002-8.

66. Kleefstra N, Landman GW, Houweling ST, Ubink-Veltmaat LJ, Logtenberg SJ, Meyboom-de Jong B, et al. Prediction of mortality in type 2 diabetes from health-related quality of life (ZODIAC-4). Diabetes care. 2008;31(5):932-3.

67. Domingo-Salvany A, Lamarca R, Ferrer M, Garcia-Aymerich J, Alonso J, Felez M, et al. Health-related quality of life and mortality in male patients with chronic obstructive pulmonary disease. American journal of respiratory and critical care medicine. 2002;166(5):680-5.

68. van Tol BA, Huijsmans RJ, Kroon DW, Schothorst M, Kwakkel G. Effects of exercise training on cardiac performance, exercise capacity and quality of life in patients with heart failure: a meta-analysis. Eur J Heart Fail. 2006;8(8):841-50.

69. Annegarn J, Spruit MA, Uszko-Lencer NH, Vanbelle S, Savelberg HH, Schols AM, et al. Objective physical activity assessment in patients with chronic organ failure: a validation study of a new single-unit activity monitor. Arch Phys Med Rehabil. 2011;92(11):1852-7 e1.

70. Shoemaker MJ, Curtis AB, Vangsnes E, Dickinson MG, Paul R. Analysis of daily activity data from implanted cardiac defibrillators: The minimum clinically important difference and relationship to mortality/life expectancy. World Journal of Cardiovascular Diseases 2012;2(3):129-35.

71. Izawa KP, Watanabe S, Hiraki K, Morio Y, Kasahara Y, Takeichi N, et al. Determination of the Effectiveness of Accelerometer Use in the Promotion of Physical Activity in Cardiac Patients: A Randomized Controlled Trial. Arch Phys Med Rehabil. 2012;93(11):1896-902.

72. De Smedt D, De Cocker K, Annemans L, De Bourdeaudhuij I, Cardon G. A cost-effectiveness study of the community-based intervention '10 000 Steps Ghent'. Public health nutrition. 2012;15(3):442-51. 
Chapter 8

Discussion

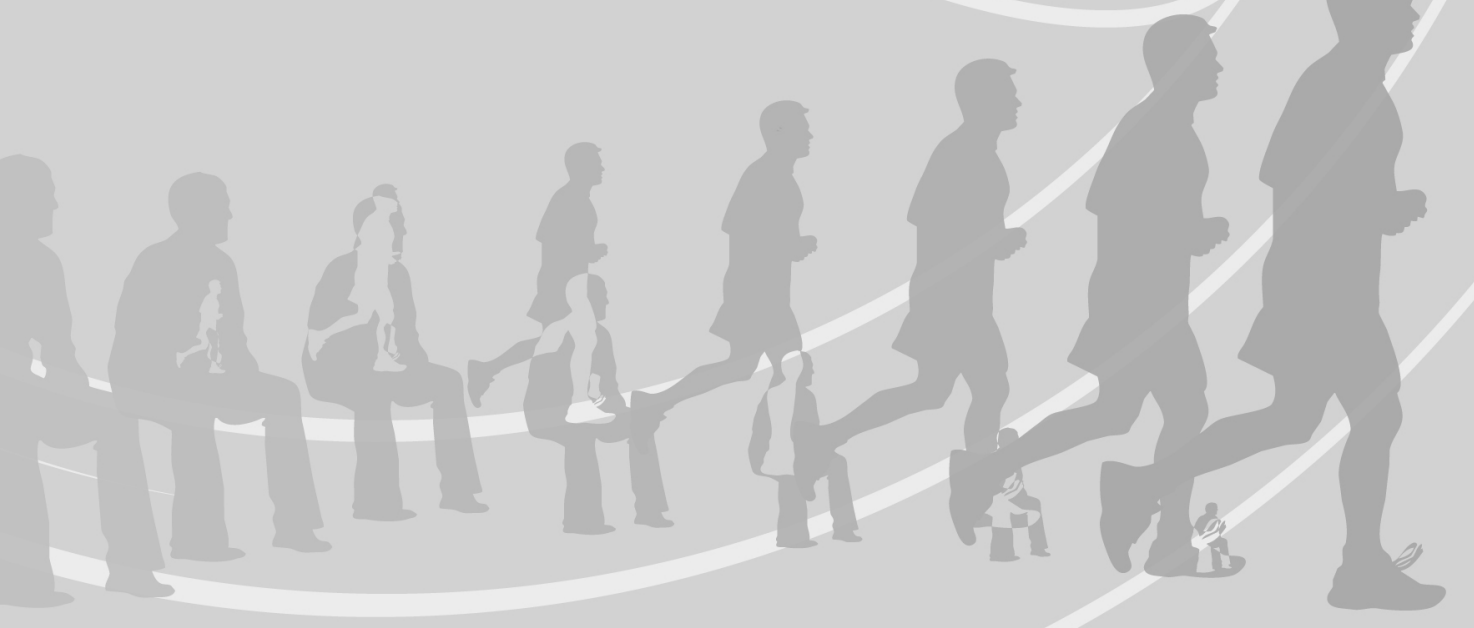


COPD is a highly prevalent disease, which negatively affects patients daily functioning (1). It is known that patients experience problems with performance of activities of daily life (2) and that physical activity levels are decreased in patients with COPD compared to healthy controls (3-6). The many health benefits of regular physical activity underline the importance of promoting regular physical activity in daily life, especially in patients with COPD (7). Since physical activity is an important modifiable risk factor, it can therefore be an important disease management target in COPD.

Although physical activity has been studied frequently in $\operatorname{COPD}(3-6,8)$, less is known about activities of daily life (ADLs). Moreover, strategies for improving physical activity are rarely studied. This thesis investigated the impact of COPD on the performance of ADLs, strategies to improve functional exercise performance, symptom burden and physical activity level and the impact of longitudinal changes in physical activity level. In this chapter, the main findings of this thesis will be discussed.

\section{Performance of activities of daily life}

The low levels of physical activity observed in people with COPD may be partly due to the difficulties they experience in the performance of ADLs. Many patients with COPD experience problems with the performance of $\operatorname{ADLs}(2,9)$, which may result in a loss of independence, social isolation and therefore a reduction in their quality of life $(10,11)$. A recent observational study showed that up to $88.8 \%$ of the COPD patients reported marked deficiency or inability to perform general domestic tasks, such as preparing a hot meal, washing clothes and cleaning (12). Patients considered themselves partially or fully dependent on help from others in the performance of one or more domestic ADLs (12). Moreover, more than $90 \%$ of the COPD patients reported an increased effort and/or fatigue causing inefficient ADL task performance. Results from the Confronting COPD International Survey also confirmed the great burden to limitations in ADL associated with COPD. One-third of the COPD patients reported breathlessness when doing light housework or while getting washed or dressed and nearly $70 \%$ were short of breath when climbing stairs (13).

To date, less attention has been given to factors underlying this high burden during the performance of ADLs in patients with COPD. In chapter 2 and 3 we showed that patients with COPD use a higher proportion of their peak aerobic capacity and peak ventilation during the performance of simple domestic ADLs compared to healthy peers. Indeed, sweeping the floor resulted in a mean task-related oxygen uptake of $84 \%$ of peak aerobic capacity, which was even $94 \%$ in patients with GOLD stage IV disease. These results are comparable with earlier findings (14). In addition, data in chapter 3 demonstrated that, despite the higher energetic cost of moving heavier limbs during activities and an increased work of breathing in obese COPD patients, relative metabolic load and symp- 
toms of dyspnea and fatigue during the performance of domestic ADLs were comparable between patients with low, normal, overweight and obese BMI. So, COPD patients in different BMI groups experience similar functional limitations in the performance of domestic ADLs. The possible impact of dynamic hyperinflation on the performance of ADLs remains unknown, as changes in lung volumes were not assessed. Though, from earlier studies, it is known that patients with COPD develop dynamic hyperinflation during ADLs (14-16), which contributes to an increased dyspnea sensation and in turn may limit patients in their performance of ADLs.

Previous studies did not find strong correlations between ADL performance and COPD characteristics, such as GOLD classification, MRC dyspnea grade, scores on St. Georges Respiratory Questionnaire, and smoking status $(2,12)$. We showed in chapter 2 that patients with COPD with GOLD stage IV disease, MRC dyspnea grade 5, or BODE score of $\geq 6$ points used the highest proportion of their peak aerobic capacity and peak ventilation, accompanied by higher task-related dyspnea scores. However, patients with GOLD stage II, MRC dyspnea grade II or BODE score $\leq 2$ points still performed domestic ADLs at a significantly higher metabolic load compared to healthy peers. This emphasizes the importance to not only focus on improving exercise tolerance, but also on improving patient's ADL performance as part of a pulmonary rehabilitation program, which should start in the earliest stages of the disease. Earlier was already shown that COPD patients substantial improved their domestic ADLs and functional independence after a pulmonary rehabilitation program(17). In addition, individually tailored occupational therapy can be beneficial in reducing the burden of ADLs by learning and applying energyconservation techniques (18). Reduced energy cost and dyspnea perception during ADL may increase performance and satisfaction scores of problematic ADLs. This however has never been studied.

Walking is reported as the most problematic ADL in patients with COPD (10). Indeed, $68 \%$ of the patients reported to have problems with the performance and satisfaction of walking (2).

It may be reasonable to assume that walking aids may be beneficial for patients with COPD. As early as 1957, it was reported that leaning on a portable walking aid when walking caused an increased ventilator capacity and a reduction in distress of breathlessness (19). However, several studies using Zimmer frames, gutter frames and rollators, indicated that not all walking aids will be beneficial for patients with COPD (20-23). The use of a wheeled walker seems to improve functional exercise capacity and symptoms in patients with COPD (21-26), especially in those with a six-minute walking distance (6MWD) of $<300 \mathrm{~m}$ and those who required an intended stop during an unaided six-minute walking test (21). Given the fact that not all patients benefit from the use of a rollator and that $48 \%$ of the COPD patients feels embarrassed about using a rollator, we aimed to determine in chapter 4 and 5 whether and to what extent the use of a new walking aid could be useful in patients with COPD. 
The draisine, a modern version of the earliest form of a bicycle without pedals, can be beneficial because of the possibility of sitting on the seat, resulting in a lower load for the muscles of ambulation. Indeed, we showed in chapter 3 that using the draisine indoors, patients walked on average $83 \mathrm{~m}$ further, which not only exceeded the earlier improvements associated with the use of a rollator (22 to $46 \mathrm{~m})(21,22,25,26)$, but also the upper limit of the $95 \%$ confidence interval of the updated minimal clinically important difference of the 6MWD $(61 \mathrm{~m})(27)$. In addition, the cost of transport was lower compared to the use of a rollator, indicated by a lower oxygen uptake per meter. However, these results cannot be generalized to outdoor walking. Indeed, the use of a draisine during a self-paced outdoor walk resulted in a significantly lower walking distance and time compared to unaided or rollator-aided walking. These contrary findings can possibly be explained by the higher walking speed while using the draisine, which resulted in higher symptom scores for dyspnea and fatigue, and therefore in a lower walking distance and time. In addition, a longer practice period may be needed for proper familiarizing, since most of the patients had never used the draisine before, and some of them reported balance problems and feelings of lower safety. This will likely improve when patient use the draisine more frequent or for a longer period. Indeed, the importance of a training session on how to use a walking aid has already been established $(28,29)$. Supervised training by a physical therapist or occupational therapist in a real-life situations may reduce possible problems handling walking aids and can help patients feel more comfortable about its use (28).

Though, our data indicate that walking aids can improve functional exercise performance not only indoors, but also during outdoor use. Clinicians should base the selection of a walking aid preferably on an exercise field test instead of an indoor 6MWT. Indeed, patients reported to use their walking aid mostly during outdoor activities (30). In addition, an exercise field test can be used to acquire more patient-meaningful information on walking ability and walking pattern (31). Moreover, patients' needs and daily use should also be taken into consideration.

\section{Longitudinal changes in physical activity}

In previous studies, physical activity has been modeled as a static risk factor (3-6, 8, 32, 33), whereas it is known that subjects change their level of physical activity over time. From earlier studies in healthy subjects it is known that remaining sedentary or adopting a sedentary lifestyle were both associated with increased mortality risk as compared with remaining physically active (34-37). The impact of longitudinal changes in physical activity on survival has never been compared between healthy subjects and patients with COPD. In chapter 6 we used data from the Copenhagen City Heart Study, one of the largest and longest running cohort studies including almost 20,000 individuals from the general Danish population. We showed that a decline in physical activity is signifi- 
cantly more common in subjects with COPD compared to healthy subjects, and that determinants of these longitudinal changes in physical activity are different in healthy subjects and patients with COPD.

Changes in healthy subjects are determined by a complex variety of factors, including clinical data, sociodemographic data and the presence of comorbidities. In contrast, in subjects with COPD the variables with the highest likelihood for changes in physical activity are sex, the degree of airflow obstruction and smoking status. Insight in these determinants may be important for identifying subjects that are at risk for developing an inactive lifestyle, but also for developing more specific and efficient programs to enhance or stimulate physical activity.

The most important finding presented in chapter 6 is that longitudinal decline to a low physical activity level was associated with an increased all-cause mortality risk. Moreover, it seems that being moderate physically active may already have important beneficial consequences in healthy subjects and patients with COPD. Though, in patients with COPD with a low physical activity level at baseline, an increase in physical activity at follow up had no beneficial outcome. These findings suggest that once patients with COPD become physically low active, the high mortality risk cannot be reversed by increasing activity levels. Therefore, it is of clinical importance that patients with COPD are encouraged to maintain an active lifestyle and cautioned about the negative consequences of prolonged inactivity already in the earliest stages of the disease.

\section{Strategies to improve physical activity}

In the past decade, physical activity has increasingly been noticed as an important outcome variable in COPD and the literature on the role of physical activity in COPD patients is growing. Exercise training and comprehensive pulmonary rehabilitation programs have shown to improve exercise capacity, peripheral muscle function, and health status in patients with COPD (38). However, this does not necessarily indicate a change in daily physical activity (39). The questions arises whether it is better to not only focus on improving physical exercise capacity but also on improving physical activity levels, since it is important that COPD patients integrate physical activity in their daily life and adopt an active lifestyle. In addition, it can be argued that current treatment programs are not tailored enough, due to a limited insight in the daily activity behavior and the heterogeneous picture of $\operatorname{COPD}(40,41)$. So, more studies are needed that explore strategies to enhance physical activity in COPD.

The development of physical activity monitors (pedometers, accelerometers) which are able to objectively measure the actual performed level of physical activity has given an important boost (42). Nowadays, these activity meters are mostly used in research 
settings. However, with the increasing popularity and ease of use, activity meters may be useful tools for stimulation of physical activity. Since a reduced physical activity level in patient with COPD may potentially have a behavioral aspect (43), behavioral interventions combined with the use of an activity monitor may be needed to obtain improvements in physical activity. Indeed, earlier reviews already demonstrated that activity monitors in combination with physical activity counseling programs are able to improve physical levels in older adults in an outpatient setting and in patients with Diabetes Mellitus type II (DMII) $(44,45)$. In chapter 7 we showed that activity monitor-based counseling is not only effective in improving physical activity in patients with DMII, but that it also has beneficial effects on health-related outcomes, such as hemoglobin A1c, systolic blood pressure, and body mass index. It can be assumed that activity monitorbased interventions in patients with COPD will have similar beneficial effects as in patients with DMII, however, the number and quality of the data studies are not sufficient to support this assumption. Indeed, only 3 studies were performed, showing contrary results (46-48).

Considering the mentioned benefits and the fact that interventions using an activity monitor in combination with counseling appear to be cost-effective in the general population (49), it is important to provide more evidence on the long-term effects of activity monitor-based counseling interventions on physical activity and generic and disease-specific health outcomes. Furthermore, the optimal embedment for these programs in the current healthcare needs to be established.

\section{Limitations and future directions}

The present thesis has some limitations that should be considered when interpreting the results. For obvious reasons, it was not possible to blind patients or the outcome assessor to the interventions in chapter 2, 3, 4 and 5. Because of the portable metabolic system, used in chapter 2,3 , and 4, we were not able to include COPD patients receiving long-term oxygen therapy. It can be assumed that these patients may experience even more problems during the performance of ADLs compared to those not receiving long-term oxygen therapy. In addition, we did not measure the impact of dynamic hyperinflation on the performance of ADLs, which contributes to an increased sensation of dyspnea and exercise intolerance. Indeed, it is known that dynamic hyperinflation occurs not only during maximal and submaximal cycle tests and six-minute walking test $(50,51)$, but also during ADLs (14-16).

In chapter 6 we used a longitudinal study design to determine the impact of changes in physical activity on all-cause mortality. Therefore, the effect of reverse causality will be limited, but might still be present. We showed an association between longitudinal changes in physical activity and mortality risk, however, we cannot draw a causal rela- 
tionship. Though, an earlier study showed that reported associations from the CCHS were not due to time-dependent confounding (52).

In addition, physical activity was measured using a questionnaire, which may represent a subjective level of physical activity. However, the large sample size of more than 10,000 subjects in this study compensates any degree of non-differential misclassification of subjects (53). Moreover, previously was shown that self-reported measures are fairly accurate of changes in physical activity in large epidemiological studies (54) and it is probably the only way to collect repeated data in such a large sample sizes during decades. Finally, the questionnaire used in the CCHS to assess physical activity fulfills the criteria of a patient-reported outcome questionnaire (55). Questions and answer options could easily be interpreted and completed by the participants, subjects' physical activity behavior was measured without interpretation from anyone else, and this questionnaire was able to detect clinically relevant changes in physical activity (56-58). As such, it provides important results to subjects with COPD and their healthcare providers in order to make proper, patient-centered treatment decisions, including lifestyle modifications (59).

Despite these methodological limitations, we can conclude that patients with COPD use a significantly higher metabolic load during the performance of simple domestic ADLs compared to healthy peers, already in the earliest stages of the disease. The use of a walking aid can be beneficial for improvement of walking, the most problematic ADL for patients with $\operatorname{COPD}(2)$. In addition, comprehensive pulmonary rehabilitation, including individually tailored occupational therapy, might be beneficial in reducing the burden of ADLs. However, the effects of such a program on the performance of ADLs have never been studied. So, future studies are needed, focusing on strategies aiming to reduce the burden of ADLs.

In addition, we demonstrated that a low physical activity level in patients with COPD was associated with an increased all-cause mortality risk, which cannot be reversed by increasing activity levels. Considering the negative consequences of a decline in physical activity level, it is of clinical importance that patients with COPD are encouraged to maintain an active lifestyle. Structured exercise programs seem to be beneficial in increasing physical activity, however, results are not uniform and long-term data are lacking (60). We showed that the use of an activity monitor as a feedback tool in combination with counseling has beneficial effects regarding physical activity. Considering the current developments, in which activity monitors can easily be connected to mobile phones or computers for even more feedback and counseling possibilities, such programs could be promising for improvement of physical activity in patients with COPD, not only during pulmonary rehabilitation, but also in their home setting. Future studies are necessary to explore strategies for enhancing or improving physical activity in COPD, already in the earliest stages of the disease, and to reduce the prevalence of sedentary lifestyles and the related adverse health-related consequences. Since physical activity is 
complex and multifactorial (61), interventions targeting determinants of physical activity at all levels (individual, interpersonal, environmental, policy) would offer the best chance for success. 


\section{REFERENCES}

1. Mannino DM, Buist AS. Global burden of COPD: risk factors, prevalence, and future trends. Lancet. 2007;370(9589):765-73.

2. Annegarn J, Meijer K, Passos VL, Stute K, Wiechert J, Savelberg HH, et al. Problematic activities of daily life are weakly associated with clinical characteristics in COPD. J Am Med Dir Assoc. 2012;13(3):284-90.

3. Watz H, Waschki B, Meyer T, Magnussen H. Physical activity in patients with COPD. Eur Respir J. 2009;33(2):262-72.

4. Pitta F, Troosters T, Spruit MA, Probst VS, Decramer M, Gosselink R. Characteristics of physical activities in daily life in chronic obstructive pulmonary disease. Am J Respir Crit Care Med. 2005;171(9):972-7.

5. Troosters T, Sciurba F, Battaglia S, Langer D, Valluri SR, Martino L, et al. Physical inactivity in patients with COPD, a controlled multi-center pilot-study. Respir Med. 2010;104(7):1005-11.

6. Hernandes NA, Teixeira Dde C, Probst VS, Brunetto AF, Ramos EM, Pitta F. Profile of the level of physical activity in the daily lives of patients with COPD in Brazil. Jornal brasileiro de pneumologia : publicacao oficial da Sociedade Brasileira de Pneumologia e Tisilogia. 2009;35(10):949-56.

7. Warburton DE, Nicol CW, Bredin SS. Health benefits of physical activity: the evidence. CMAJ. 2006;174(6):801-9.

8. Vorrink SN, Kort HS, Troosters T, Lammers JW. Level of daily physical activity in individuals with COPD compared with healthy controls. Respir Res. 2011;12:33.

9. Leidy NK, Hamilton A, Becker K. Assessing patient report of function: content validity of the Functional Performance Inventory-Short Form (FPI-SF) in patients with chronic obstructive pulmonary disease (COPD). Int J Chron Obstruct Pulmon Dis. 2012;7:543-54.

10. Williams $V$, Bruton A, Ellis-Hill C, McPherson K. What really matters to patients living with chronic obstructive pulmonary disease? An exploratory study. Chron Respir Dis. 2007;4(2):77-85.

11. Rodriguez Gonzalez-Moro JM, de Lucas Ramos P, Izquierdo Alonso JL, Lopez-Muniz Ballesteros B, Anton Diaz E, Ribera X, et al. Impact of COPD severity on physical disability and daily living activities: EDIP-EPOC I and EDIP-EPOC II studies. Int J Clin Pract. 2009;63(5):742-50.

12. Bendixen HJ, Ejlersen Waehrens E, Wilcke JT, Sorensen LV. Self-reported quality of ADL task performance among patients with COPD exacerbations. Scand J Occup Ther. 2014;21(4):313-20.

13. Rennard S, Decramer M, Calverley PM, Pride NB, Soriano JB, Vermeire PA, et al. Impact of COPD in North America and Europe in 2000: subjects' perspective of Confronting COPD International Survey. Eur Respir J. 2002;20(4):799-805.

14. Lahaije A, van Helvoort H, Dekhuijzen P, Heijdra Y. Physiologic limitations during daily life activities in COPD patients. Respir Med. 2010;104(8):1152-9.

15. Garcia-Rio F, Lores V, Mediano O, Rojo B, Hernanz A, Lopez-Collazo E, et al. Daily physical activity in patients with chronic obstructive pulmonary disease is mainly associated with dynamic hyperinflation. Am J Respir Crit Care Med. 2009;180(6):506-12.

16. Hannink JD, van Helvoort HA, Dekhuijzen PN, Heijdra YF. Dynamic hyperinflation during daily activities: does COPD global initiative for chronic obstructive lung disease stage matter? Chest. 2010;137(5):111621.

17. Sewell L, Singh SJ, Williams JE, Collier R, Morgan MD. Can individualized rehabilitation improve functional independence in elderly patients with COPD? Chest. 2005;128(3):1194-200.

18. Velloso M, Jardim JR. Study of energy expenditure during activities of daily living using and not using body position recommended by energy conservation techniques in patients with COPD. Chest. 2006;130(1):126-32.

19. Campbell EJ. Portable oxygen equipment and walking-aid in pulmonary emphysema. $\mathrm{Br}$ Med J. 1957;2(5060):1518-21.

20. Roomi J, Yohannes AM, Connolly MJ. The effect of walking aids on exercise capacity and oxygenation in elderly patients with chronic obstructive pulmonary disease. Age Ageing. 1998;27(6):703-6. 
21. Solway S, Brooks D, Lau L, Goldstein R. The short-term effect of a rollator on functional exercise capacity among individuals with severe COPD. Chest. 2002;122(1):56-65.

22. Probst VS, Troosters T, Coosemans I, Spruit MA, Pitta Fde O, Decramer M, et al. Mechanisms of improvement in exercise capacity using a rollator in patients with COPD. Chest. 2004;126(4):1102-7.

23. Hill K, Dolmage TE, Woon L, Brooks D, Goldstein RS. Rollator use does not consistently change the metabolic cost of walking in people with chronic obstructive pulmonary disease. Arch Phys Med Rehabil. 2012;93(6):1077-80.

24. Honeyman P, Barr P, Stubbing DG. Effect of a walking aid on disability, oxygenation, and breathlessness in patients with chronic airflow limitation. J Cardiopulm Rehabil. 1996;16(1):63-7.

25. Gupta R, Goldstein R, Brooks D. The acute effects of a rollator in individuals with COPD. J Cardiopulm Rehabil. 2006;26(2):107-11.

26. Gupta RB, Brooks D, Lacasse Y, Goldstein RS. Effect of rollator use on health-related quality of life in individuals with COPD. Chest. 2006;130(4):1089-95.

27. Holland AE, Hill CJ, Rasekaba T, Lee A, Naughton MT, McDonald CF. Updating the minimal important difference for six-minute walk distance in patients with chronic obstructive pulmonary disease. Arch Phys Med Rehabil. 2010;91(2):221-5.

28. Brandt A, Iwarsson S, Stahl A. Satisfaction with rollators among community-living users: a follow-up study. Disabil Rehabil. 2003;25(7):343-53.

29. Gitlin LN, Levine R, Geiger C. Adaptive device use by older adults with mixed disabilities. Arch Phys Med Rehabil. 1993;74(2):149-52.

30. Hill K, Goldstein R, Gartner EJ, Brooks D. Daily utility and satisfaction with rollators among persons with chronic obstructive pulmonary disease. Arch Phys Med Rehabil. 2008;89(6):1108-13.

31. Evans RA, Hill K, Dolmage TE, Blouin M, O'Hoski S, Brooks D, et al. Properties of self-paced walking in chronic respiratory disease: a patient goal-oriented assessment. Chest. 2011;140(3):737-43.

32. Garcia-Aymerich J, Lange P, Benet M, Schnohr P, Anto JM. Regular physical activity reduces hospital admission and mortality in chronic obstructive pulmonary disease: a population based cohort study. Thorax. 2006;61(9):772-8.

33. Waschki B, Kirsten A, Holz O, Muller KC, Meyer T, Watz H, et al. Physical activity is the strongest predictor of all-cause mortality in patients with COPD: a prospective cohort study. Chest. 2011;140(2):331-42.

34. Bijnen FC, Feskens EJ, Caspersen CJ, Nagelkerke N, Mosterd WL, Kromhout D. Baseline and previous physical activity in relation to mortality in elderly men: the Zutphen Elderly Study. Am J Epidemiol. 1999;150(12):1289-96.

35. Gregg EW, Cauley JA, Stone K, Thompson TJ, Bauer DC, Cummings SR, et al. Relationship of changes in physical activity and mortality among older women. JAMA. 2003;289(18):2379-86.

36. Lissner L, Bengtsson C, Bjorkelund C, Wedel H. Physical activity levels and changes in relation to longevity. A prospective study of Swedish women. Am J Epidemiol. 1996;143(1):54-62.

37. Nocon M, Hiemann T, Muller-Riemenschneider F, Thalau F, Roll S, Willich SN. Association of physical activity with all-cause and cardiovascular mortality: a systematic review and meta-analysis. Eur J Cardiovasc Prev Rehabil. 2008;15(3):239-46.

38. Spruit MA, Singh SJ, Garvey C, Zuwallack R, Nici L, Rochester C, et al. An official american thoracic society/european respiratory society statement: key concepts and advances in pulmonary rehabilitation. Am J Respir Crit Care Med. 2013;188(8):e13-64.

39. Lacasse Y, Goldstein R, Lasserson TJ, Martin S. Pulmonary rehabilitation for chronic obstructive pulmonary disease. Cochrane Database Syst Rev. 2006(4):CD003793.

40. Agusti A, Calverley PM, Celli B, Coxson HO, Edwards LD, Lomas DA, et al. Characterisation of COPD heterogeneity in the ECLIPSE cohort. Respir Res. 2010;11:122.

41. Sillen MJ, Franssen FM, Delbressine JM, Uszko-Lencer NH, Vanfleteren LE, Rutten EP, et al. Heterogeneity in clinical characteristics and co-morbidities in dyspneic individuals with COPD GOLD D: findings of the DICES trial. Respir Med. 2013;107(8):1186-94.

42. Pitta F, Troosters T, Probst VS, Spruit MA, Decramer M, Gosselink R. Quantifying physical activity in daily life with questionnaires and motion sensors in COPD. Eur Respir J. 2006;27(5):1040-55. 
43. Polkey MI, Rabe KF. Chicken or egg: physical activity in COPD revisited. Eur Respir J. 2009;33(2):227-9.

44. Bravata DM, Smith-Spangler C, Sundaram V, Gienger AL, Lin N, Lewis R, et al. Using pedometers to increase physical activity and improve health: a systematic review. JAMA. 2007;298(19):2296-304.

45. Tudor-Locke C, Craig CL, Aoyagi Y, Bell RC, Croteau KA, De Bourdeaudhuij I, et al. How many steps/day are enough? For older adults and special populations. Int J Behav Nutr Phys Act. 2011;8:80.

46. Hospes G, Bossenbroek L, Ten Hacken NH, van Hengel P, de Greef MH. Enhancement of daily physical activity increases physical fitness of outclinic COPD patients: results of an exercise counseling program. Patient Educ Couns. 2009;75(2):274-8.

47. de Blok BM, de Greef MH, ten Hacken NH, Sprenger SR, Postema K, Wempe JB. The effects of a lifestyle physical activity counseling program with feedback of a pedometer during pulmonary rehabilitation in patients with COPD: a pilot study. Patient Educ Couns. 2006;61(1):48-55.

48. Steele BG, Belza B, Cain KC, Coppersmith J, Lakshminarayan S, Howard J, et al. A randomized clinical trial of an activity and exercise adherence intervention in chronic pulmonary disease. Arch Phys Med Rehabil. 2008;89(3):404-12.

49. De Smedt D, De Cocker K, Annemans L, De Bourdeaudhuij I, Cardon G. A cost-effectiveness study of the community-based intervention '10 000 Steps Ghent'. Public Health Nutr. 2012;15(3):442-51.

50. O'Donnell DE, Revill SM, Webb KA. Dynamic hyperinflation and exercise intolerance in chronic obstructive pulmonary disease. Am J Respir Crit Care Med. 2001;164(5):770-7.

51. Callens E, Graba S, Gillet-Juvin K, Essalhi M, Bidaud-Chevalier B, Peiffer C, et al. Measurement of dynamic hyperinflation after a 6-minute walk test in patients with COPD. Chest. 2009;136(6):1466-72.

52. Garcia-Aymerich J, Lange P, Serra I, Schnohr P, Anto JM. Time-dependent confounding in the study of the effects of regular physical activity in chronic obstructive pulmonary disease: an application of the marginal structural model. Ann Epidemiol. 2008;18(10):775-83.

53. Szklo M, Nieto J. Epidemiology beyond the basics. Gaithersburg: Aspen publisher, Inc; 2000.

54. Shephard RJ. Limits to the measurement of habitual physical activity by questionnaires. Br J Sports Med. 2003;37(3):197-206; discussion

55. Saltin B, Grimby G. Physiological analysis of middle-aged and old former athletes. Comparison with still active athletes of the same ages. Circulation. 1968;38(6):1104-15.

56. Aires N, Selmer R, Thelle D. The validity of self-reported leisure time physical activity, and its relationship to serum cholesterol, blood pressure and body mass index. A population based study of 332,182 men and women aged 40-42 years. Eur J Epidemiol. 2003;18(6):479-85.

57. Petersen CB, Gronbaek M, Helge JW, Thygesen LC, Schnohr P, Tolstrup JS. Changes in physical activity in leisure time and the risk of myocardial infarction, ischemic heart disease, and all-cause mortality. Eur J Epidemiol. 2012;27(2):91-9.

58. Schnohr $\mathrm{P}$, Scharling $\mathrm{H}$, Jensen JS. Changes in leisure-time physical activity and risk of death: an observational study of 7,000 men and women. Am J Epidemiol. 2003;158(7):639-44.

59. Frei A, Williams K, Vetsch A, Dobbels F, Jacobs L, Rudell K, et al. A comprehensive systematic review of the development process of 104 patient-reported outcomes (PROs) for physical activity in chronically ill and elderly people. Health Qual Life Outcomes. 2011;9(1):116.

60. Cindy Ng LW, Mackney J, Jenkins S, Hill K. Does exercise training change physical activity in people with COPD? A systematic review and meta-analysis. Chron Respir Dis. 2012;9(1):17-26.

61. Bauman AE, Reis RS, Sallis JF, Wells JC, Loos RJ, Martin BW. Correlates of physical activity: why are some people physically active and others not? Lancet. 2012;380(9838):258-71. 

Chapter 9

Summary of this thesis

Samenvatting van dit proefschrift 



\section{SUMMARY}

COPD is characterized by persistent airflow limitation that is usually progressive and associated with an enhanced chronic inflammatory response in the airways and the lungs to noxious particles or gases. The chronic airflow limitation characteristic of COPD is caused by a mixture of small airways disease (obstructive bronchiolitis) and parenchymal destruction (emphysema). The characteristic symptoms of COPD are chronic and progressive dyspnea, cough and sputum production. However, it is increasingly recognized that COPD is associated with several extra-pulmonary manifestations, such as skeletal muscle dysfunction, osteoporosis, cardiovascular diseases, diabetes, anemia, and symptoms of anxiety and depression.

The prevalence of physical inactivity in patients with COPD is remarkably higher compared to healthy age-matched individuals, mainly determined by the perception of dyspnea. In addition, patients with COPD are limited in their ability to perform daily physical activities, even in the earliest stages of their disease. These lower levels of physical activity have a tremendous impact on many health related outcomes and also on the progression of the disease. This thesis focuses on the performance of daily physical activities, strategies to improve physical activity and the impact of changes in physical activity in patients with COPD.

The aim of chapter 2 was to evaluate differences in metabolic load and symptoms of dyspnea and fatigue during the performance of 5 domestic activities of daily life (e.g. getting dressed, folding towels, putting away groceries, washing up, sweeping the floor for 4 minutes) between patients with COPD and healthy elderly subjects. Patients with COPD used a higher task-related oxygen uptake and ventilation during the performance of domestic ADLs, accompanied by a higher degree of dyspnea and fatigue. These differences were already present in the earliest stages of the disease. Furthermore, patients in different body mass index (BMI) categories (underweight, normal, overweight or obese BMI) experienced similar functional limitations during the performance of domestic ADLs, as shown in chapter 3.

The aim of chapter 4 and 5 was to determine whether and to what extent the use of a walking aid could be useful in patients with COPD. In chapter 4 the effects of a rollator and draisine during indoor use were studied. Patients walked further while using the draisine, and the cost of transport was lower compared to the use of a rollator, indicat- 
ed by a lower oxygen uptake per meter. In chapter 5 the use of a rollator during selfpaced outdoor walking resulted in a significantly higher walk distance, time and speed compared to unaided walking. In addition, the use of a draisine had even a detrimental effect compared to rollator-aided or unaided walking. Therefore, the needs and daily use should be considered for the selection of a walking aid for patients with COPD.

Chapter 6 described longitudinal changes in the level of self-reported regular physical activity between subjects with and without COPD and their impact on all-cause mortality risk. Data from the Copenhagen City Heart Study showed that a decline in physical activity is significantly more common in patients with COPD compared to healthy subjects, and that determinants of these longitudinal changes in physical activity are different. Moreover, a longitudinal decline to a low physical activity level was associated with an increased all-cause mortality risk. In addition, findings suggest that once patients with COPD become physically low active, the high mortality risk cannot be reversed by increasing activity levels, showing the importance of encouraging an active lifestyle in patients with COPD.

Finally, in chapter 7, current literature on the effects of activity monitor-based counseling on physical activity in patients with DMII, COPD and CHF was systematically reviewed. Activity monitor-based counseling might not only be effective in improving physical activity in patients with DMII, but it has also beneficial effects on health-related outcomes. It can be assumed that activity monitor-based interventions in patients with COPD and CHF will have similar beneficial effects, however, the number and quality of the studies are not sufficient to support this assumption. 


\section{SAMENVATTING}

COPD is een aandoening die wordt gekarakteriseerd door een niet volledig reversibele luchtwegobstructie die in het algemeen progressief is en wordt veroorzaakt door een abnormale ontstekingsreactie in de luchtwegen en longen op schadelijke deeltjes en gassen. De luchtwegobstructie wordt gekenmerkt door een combinatie van een ontsteking van de kleine luchtwegen (obstructieve bronchiolitis) en parenchymschade (emfyseem).

De kenmerkende symptomen van COPD zijn chronische en progressieve kortademigheid, hoesten en slijmproductie. Er wordt echter steeds meer erkend dat COPD wordt geassocieerd met verschillende extra-pulmonale manifestaties, zoals verstoorde skeletspierfunctie, osteoporose, cardiovasculaire aandoeningen, diabetes, bloedarmoede en symptomen van angst en depressie.

De prevalentie van fysieke inactiviteit bij patiënten met COPD is aanzienlijk hoger dan bij gezonde controlepersonen, wat grotendeels wordt bepaald door de perceptie van kortademigheid. Patiënten met COPD zijn beperkt in de uitvoering van dagelijkse fysieke activiteiten, zelfs in de vroegste stadia van de aandoening. Deze lagere mate van fysiek actief zijn heeft een enorme impact op vele gezondheidsgerelateerde uitkomsten en ook op de progressie van de ziekte. Dit proefschrift richt zich op de uitvoering van dagelijkse fysieke activiteiten, strategieën om fysieke activiteit te verbeteren en het effect van veranderingen in fysieke activiteit bij patiënten met COPD.

Het doel van hoofdstuk 2 was om verschillen in metabole belasting en symptomen van kortademigheid en vermoeidheid tijdens de uitvoering van 5 huishoudelijke dagelijkse activiteiten (aankleden, handdoeken opvouwen, boodschappen opbergen, afwassen, en de vloer vegen gedurende 4 minuten) te evalueren bij patiënten met COPD en gezonde ouderen. Patiënten met COPD gebruikten een hogere proportie van hun maximale zuurstofopname en ventilatie tijdens de uitvoering van dagelijkse activiteiten, gepaard gaande met een hogere mate van kortademigheid en vermoeidheid. Deze verschillen waren al aanwezig in de vroege fase van de aandoening. Verder ervaarden patiënten in verschillende body mass index (BMI) categorieën (ondergewicht, normaal gewicht, overgewicht of obesitas) dezelfde functionele beperkingen bij het uitvoeren van dagelijkse activiteiten, zoals weergegeven in hoofdstuk 3. 
Het doel van hoofdstuk 4 en 5 was te bepalen of en in welke mate het gebruik van een loophulpmiddel nuttig kan zijn voor patiënten met COPD. In hoofdstuk 4 werd het gebruik van een rollator en draisine bestudeerd. Patiënten liepen verder met gebruik van een draisine, en de belasting was lager, aangeduid door een lagere zuurstofopname per meter. In hoofdstuk 5 resulteerde het gebruik van een rollator tijdens het buiten lopen in eigen tempo in een significant hogere loopafstand, -tijd en -snelheid vergeleken met lopen zonder loophulpmiddel. Daarnaast had het gebruik van een draisine een nadelig effect ten opzichte van lopen met een rollator of zonder loophulpmiddel. Bij de keuze voor een loophulpmiddel voor patiënten met COPD moeten daarom de behoeften en het dagelijks gebruik worden overwogen.

In hoofdstuk 6 werden longitudinale veranderingen in zelf-gerapporteerde fysieke activiteit en de impact hiervan op het algehele sterfterisico in personen met en zonder COPD bestudeerd. Gegevens van de Copenhagen City Heart Study toonden aan dat een daling in fysieke activiteit significant vaker voorkomt bij patiënten met COPD in vergelijking met gezonde personen, en dat determinanten van deze longitudinale veranderingen in fysieke activiteit verschillend zijn. Bovendien was een afname naar een laag fysiek activiteitenniveau geassocieerd met een verhoogd sterfterisico. Daarnaast suggereerden de bevindingen dat zodra patiënten met COPD laag fysiek actief zijn, het verhogen van de mate van fysiek actief zijn geen gunstig effect meer heeft op het sterfterisico. Dit toont het belang van het stimuleren van een actieve leefstijl bij patiënten met COPD aan.

Tenslotte werd in hoofdstuk 7 de huidige literatuur over de effecten van het gebruik van een activiteitenmeter in combinatie met counselling op de fysieke activiteit bij patiënten met DMII, COPD en CHF systematisch geëvalueerd. Counselling middels activiteitenmeters bleek niet alleen positieve effecten te hebben op de mate van fysieke activiteit, maar ook op gezondheidsgerelateerde uitkomstmaten. Er kan worden aangenomen dat interventies die gebruik maken van activiteitenmeters ook soortgelijke gunstige effecten hebben bij patiënten met COPD en CHF, echter het aantal en de kwaliteit van deze studies was onvoldoende om deze aanname te ondersteunen. 
Valorization addendum 



\section{Relevance}

COPD is a highly prevalent disease, which negatively affects patients daily functioning. It is known that COPD patients experience problems with performance of activities of daily life (ADLS) and that the prevalence of physical inactivity levels is remarkably higher compared to healthy controls. These lower levels of physical activity have a tremendous impact on many health related outcomes and progression of the disease. Since physical activity is an important modifiable risk factor, it can therefore be an important disease management target in COPD.

Although physical activity has been studied frequently in COPD, less is known about ADLs. Moreover, strategies for improving physical activity are rarely studied. The current thesis investigated the impact of COPD on the performance of ADLs, strategies to improve functional exercise performance, symptom burden and physical activity level and the impact of longitudinal changes in physical activity level. This thesis provided new evidence in this field of expertise:

First, our findings showed that patients with COPD experience more problems during the performance of domestic ADLs, as indicated by a higher task-related oxygen uptake and ventilation and a higher degree of dyspnea and fatigue. These differences were already present in the earliest stages of the disease. Furthermore, patients in different $\mathrm{BMI}$ categories (underweight, normal, overweight or obese BMI) experience similar functional limitations during the performance of domestic ADLs.

Second, our data indicate that walking aids can improve functional exercise performance not only indoors, but also during outdoor use. Though, clinicians should base the selection of a walking aid preferably on an exercise field test instead of an indoor $6 \mathrm{MWT}$, since test can be used to acquire more patient-meaningful information on walking ability and walking pattern and patients reported to use their walking aid mostly during outdoor activities. Moreover, patients' needs and daily use should also be taken into consideration.

Third, we demonstrated that a longitudinal decline in physical activity is significantly more common in subjects with COPD compared to healthy subjects, and that determinants of these longitudinal changes in physical activity are different. Moreover, a longitudinal decline to a low physical activity level was associated with an increased all-cause mortality risk. More important, findings suggest that once patients with COPD become physically low active, the high mortality risk cannot be reversed by increasing activity levels, showing the importance of encouraging an active lifestyle in patients with COPD. Fourth, we showed the promising effects of activity monitor-based counseling on improvement of physical activity and health-related outcomes in patients with DMII. It can be assumed that activity monitor-based interventions in patients with COPD and CHF will have similar beneficial effects, however, more research is needed. 


\section{Target groups}

Health care providers

The main target group of this thesis are health care providers involved in the care of patients with COPD. Our findings provided further insight why patients with COPD experience problems in the performance of ADLs, and highlight the consequences of a longitudinal decline in physical activity. This emphasizes the need to develop customized treatment of problematic ADLs valued by clients with COPD entering pulmonary rehabilitation, including physical exercise training and individually tailored occupational therapy. In addition, health care professionals, and occupational therapists in particular, may have an important role for considering walking aids in patients with COPD, which, as we have shown, can be beneficial for patients with COPD. Though, the choice of a walking aid should be based upon patients' needs and daily use, and in addition, the performance on an exercise field test and the degree of acceptance by the patient will also be important.

Finally, it is of clinical importance that healthcare professionals encourage patients with COPD to maintain an active lifestyle and caution them about the negative consequences of prolonged inactivity already in the earliest stages of the disease, since our findings demonstrated that a longitudinal decline to a low physical activity level was associated with an increased all-cause mortality risk, which was irreversible once patients became inactive. Since results of structured exercise programs are conflicting and long-term data are lacking, health care professionals should be aware of other strategies to increase physical activity in patients with COPD. For example, the use of an activity monitor as a feedback tool in combination with counseling has promising effects regarding physical activity, as shown in this thesis.

\section{COPD patients and their social network}

A better understanding of the problems patients experience in the performance of ADLs may not only be important for the patients themselves, but also for their families and other members of their social network, since problematic ADLS can result in a loss of independence, social isolation and therefore a reduction in quality of life.

Findings in this thesis demonstrate the importance of raising awareness in COPD patients about the impact and consequences of low physical activity levels, which may trigger patients to change their physical activity behavior. It is known that the family and social network op COPD patients play a major role in providing positive support and encouragement for physical activity to the patient, and should therefore also be involved in the treatment of the patients, including education and strategies to increase the level of physical activity. 
Industry

We demonstrated that a draisine can be beneficial for patients with COPD. Though, a high proportion of patients mentioned practical problems during its use, including 'too heavy', 'problems with placing the oxygen tank', 'balance problems' and 'steering problems'. The industry may have a role in improving the usability and accessibility of the draisine for patients with COPD.

This thesis showed the promising effects of activity monitor-based counseling on physical activity and health-related outcomes in patients with DMII, and it is reasonable to assume that similar beneficial effects apply to patients with COPD. Indeed, considering the current developments, in which activity monitors can easily be connected to mobile phones or computers for even more feedback and counseling possibilities, such programs could be promising in the near future. The industry can be important for the development of activity monitors which are easy to use and interpret for patients and in their home setting.

\section{Activities and products}

The findings presented in this thesis have led to several activities in the field of expertise. Results in chapter 2 to 6 were presented on the European Respiratory Society (ERS) Congress in 2010, 20112012 and 2013. Moreover, the results obtained in this thesis have led to original research articles, published in professional scientific journals in order to distribute the results to experts in this field of study. Therefore, the data obtained in this thesis can be the basis for further studies on daily physical activity in COPD.

In addition, the results are brought to the attention of health care professionals, stakeholders, patients and their families through national and regional newspapers and a magazine for COPD patients (Dagblad de Telegraaf, Dagblad de Limburger, Longwijzer). Moreover, results and practical issues of the use of a draisine (chapter 4 and 5) will be presented to different representatives of small- and medium-sized enterprises at the 'Maastricht Health Campus' organized by Limburg \& Co. 



\section{Acknowledgments}



En dan eindelijk het dankwoord! Ik had gedacht dat dit na alle voorgaande hoofdstukken wel makkelijk zou moeten zijn. Geen data-analyses, geen publicatiestress, en gewoon Nederlandstalig. Maar omdat dit hoofdstuk vaak als eerste en waarschijnlijk ook het meeste wordt gelezen, wil je natuurlijk wel een beetje je best doen om ook hier de juiste woorden op papier te krijgen en vooral ook om niemand te vergeten.

(Voor degene die direct naar deze bladzijde zijn doorgebladerd vind ik het toch even belangrijk om te vermelden dat er ruim 200 pagina's en bijna 33000 woorden aan dit dankwoord zijn vooraf gegaan)

Ik wil graag iedereen bedanken, die mij op welke wijze dan ook heeft geholpen bij het voltooien van dit proefschrift. Een aantal mensen wil ik graag in het bijzonder noemen.

Als eerste wil ik alle COPD patiënten en gezonde vrijwilligers bedanken die hebben meegedaan aan de onderzoeken beschreven in dit proefschrift.

Ik wil mijn (co)promotoren, Prof. Dr. Emiel Wouters, Dr. Martijn Spruit en Dr. Kenneth Meijer, heel erg bedanken voor hun begeleiding en de prettige samenwerking in de afgelopen jaren.

Prof. Wouters, ik wil u hartelijk danken voor uw waardevolle kritische blik en voor uw vertrouwen en begeleiding tijdens mijn promotieonderzoek. Uw expertise en wetenschappelijke enthousiasme is bewonderenswaardig en hebben me erg gemotiveerd.

Beste Martijn, bedankt voor je begeleiding, adviezen, enthousiasme en inzet gedurende de afgelopen jaren. Toen ik na mijn studies Bewegingswetenschappen en Fysiotherapie begon als fysiotherapeut in $\mathrm{CIRO}$ was ik vooral liever praktisch bezig, en was ik er vrij zeker van overtuigd dat promoveren echt niks voor mij zou zijn. Maar in de loop van de jaren ben ik mijn mening hierover toch iets gaan bijstellen. Ik ben je erg dankbaar dat je mij destijds de mogelijkheid hebt gegeven om mijn werkzaamheden als fysiotherapeut te combineren met dit promotieonderzoek. Jouw manier van werken heb ik als zeer prettig ervaren. Je hebt me veel vrijheid en verantwoordelijk, maar tegelijkertijd ook veel vertrouwen gegeven. Je was altijd beschikbaar voor vragen en je altijd snelle en kritische feedback was zeer waardevol.

Beste Kenneth, ik zal mijn eerste onderwijsgroep tijdens mijn studie bewegingswetenschappen niet snel vergeten. Een chaotisch groepje studenten met jou als tutor. Ik had toen nooit kunnen denken dat ik jou nog eens in mijn dankwoord zou gaan vermelden. Het was erg prettig om jouw betrokkenheid en rustige, duidelijke en enthousiaste begeleiding van destijds nu ook tijdens mijn promotieonderzoek te mogen ervaren. Bedankt hiervoor! 
De leden van de beoordelingscommissie, bestaande uit voorzitter Prof. dr. F.J.W.M. Smeenk, Prof. dr. R.A. de Bie, Prof. dr. F. Pitta, Dr. H. Savelberg en Prof. dr. A. SchmidtTrucksäss, dank ik voor hun kritische beoordeling en goedkeuring van het manuscript.

Al mijn co-auteurs wil ik hartelijk danken voor hun bijdrage en waardevolle feedback. Peter Schnohr, Peter Lange, Jørgen Vestbo and Jacob Marott, thank you for the opportunity to analyze parts of the impressive data from the Copenhagen City Heart Study. Judith and Martha, thank you for the possibility to come to Barcelona to work on the analysis plan. And Judith, your help with the statistical analyses and your thorough and critical feedback were always very useful.

Tevens wil ik Ingrid Augustin, lid van de Raad van Bestuur van $\mathrm{CIRO}$, bedanken voor de mogelijkheden om mijn promotieonderzoek binnen CIRO uit te voeren.

Een speciale dank gaat uit naar alle collega's van CIRO. De goede werksfeer en fijne collega's zijn bepalend voor het plezier dat ik in mijn werk ervaar. Bedankt voor de prettige samenwerking en de interesse in mijn onderzoek.

Een aantal collega's ontkomen er niet aan om specifiek benoemd te worden.

Mijn mede-onderzoekers en parttime kamergenoten, Carmen, Coby, Dionne B., Dionne S., Esther, Fiona, Jeannet, Nienke, Sarah, Wai-Yan, Rafael en Vasilis, bedankt voor de gezellige tijd!! Er was al die tijd (en nu nog steeds) een goede combinatie tussen gezelligheid, ontspanning en productiviteit. Er werd (gelukkig) heel veel gelachen, maar uiteraard ook erg serieus gewerkt, resulterend in verschillende hoogtepunten die gevierd moesten worden (hoewel sommige punten misschien iets minder hoog waren dan andere....). Bedankt voor jullie steun, medeleven, meedenken, meevieren, enz. En nog heel veel succes met het afronden van jullie eigen promotieonderzoeken.

En Jeannet, ik weet dat je niet graag in de belangstelling staat, maar toch een speciale vernoeming voor jou. Bedankt voor de hulp die je bij de verschillende onderzoeken in dit proefschrift hebt geleverd en ook nu nog steeds levert. Jouw enthousiasme, inzet, kritische blik en betrouwbaarheid zijn erg waardevol!

De overige leden van de onderzoeksgroep, Erica, Daisy, Lowie, Frits, Maurice, Miriam, Annie en Riny. Bedankt voor jullie getoonde interesse en fijne samenwerking. Maurice, bedankt voor de steun en hulp, vooral ook tijdens de laatste fase van mijn promotietraject. De tips en informatie die je als kersverse dr. gedurende de laatste maanden en weken hebt gegeven waren erg handig en waardevol. Miriam, bedankt voor jouw hulp bij mijn statistische vragen. Je was nooit te beroerd om zaken helemaal uit te pluizen en nam altijd uitgebreid de tijd om dit vervolgens duidelijk aan mij uit te leggen. En Lowie, het is me dan uiteindelijk toch gelukt om je voor te zijn. Gelukkig maar, want ik kan slecht tegen mijn verlies ;-) Succes nog met de laatste loodjes! 
Mijn collega's fysiotherapie en bewegingsagogie, Arjan, Chantal, Chris, Janneke, Jerôme, Maud, Remco, Sigrid, Sonja, Sylvia, Tatjana en Tom, bedankt voor de gezelligheid tijdens mijn fysiotherapeutische werkzaamheden. Hoe druk en chaotisch het soms ook was, altijd was er wel ergens een mogelijkheid te vinden voor een luchtig koffie, thee of cappuccinomomentje. Soms ook buiten de werktijden om (moeten we vaker plannen!!). Hoewel de meeste van jullie niets hebben met wetenschappelijk onderzoek, was er altijd interesse in mijn werkzaamheden en de voortgang van mijn onderzoek.

En Floor, officieel geen collega meer, maar toch vind ik dat ook jij hier een plaatsje verdient. Bedankt voor de fijne samenwerking het afgelopen jaar. Heel veel succes voor je verdere toekomst, en we komen elkaar vast nog tegen :-)

Mijn paranimfen, Fanny en Monique. Onze vriendschap gaat al zo ver terug. Veel belangrijke momenten in ons leven hebben we samen gedeeld. En hoe verschillend we ook zijn en hoe anders de keuzes die we maken, we zullen altijd betrokken blijven in elkaars levens. Ik vind het daarom heel speciaal dat jullie samen mijn paranimfen willen zijn en op deze bijzondere dag naast me willen staan.

Beste familie en vrienden, ik neem aan dat het voor de meeste van jullie nog steeds een raadsel is waar ik de afgelopen jaren mee bezig ben geweest en hoe dit boekwerk is ontstaan. Toch hebben velen van jullie geregeld interesse in mijn werkzaamheden getoond en geluisterd naar wat ik te melden had. Ik wil jullie graag bedanken omdat jullie er steeds voor me zijn en omdat ik altijd op jullie kan rekenen!

Beste Gijs en Roos, jullie schattige dochter Fiene heeft me de laatste weken behoorlijk van mijn werkzaamheden en voorbereidingen afgehouden. Maar een betere afleiding kon ik me niet bedenken!

Beste pap en mam, bedankt voor alle geboden kansen en jullie vertrouwen, steun en geduld. Zonder jullie was ik nooit zo ver gekomen en dankzij jullie ben ik geworden wie ik nu ben. Ik weet dat het hele traject ook voor jullie vaak vaag en onduidelijk was. Hoe vaak is me wel niet gevraagd wat ik nou eigenlijk precies aan het doen was en wat nu ook alweer het onderwerp van mijn promotieonderzoek was. Altijd enthousiast als er weer één van mijn artikelen was geaccepteerd voor publicatie, maar wat er eigenlijk precies in stond...? Toch weet ik dat jullie altijd trots op me zijn.

Lieve Frank, jij hebt ooit eens gezegd dat je toch wel een speciale vermelding in mijn boekje verwachtte. Niets groots, niets bijzonders, geen overdreven woorden.

Nou, zie hier...... Kort, simpel, eenvoudig. Het is dan misschien niet op de eerste bladzijde, maar op één van de laatste is misschien wel net zo speciaal, of niet? 

Curriculum vitae 

Anouk Vaes is geboren op 30 december 1982 in Weert. In 2000 behaalde zij het VWO diploma aan de Philips van Horne Scholengemeenschap te Weert. In hetzelfde jaar startte zij met de studie Gezondheidswetenschappen aan de Universiteit Maastricht, met als afstudeerrichting Bewegingswetenschappen. Tevens is zij in september 2003 gestart met de opleiding Fysiotherapie. Beide opleidingen werden in 2006 succesvol afgerond. Vanaf april 2006 is Anouk als fysiotherapeut werkzaam bij CIRO in Horn. Vanaf januari 2011 heeft ze deze werkzaamheden gecombineerd met haar promotieonderzoek onder leiding van prof. dr. Emiel F.M. Wouters, dr. Martijn A. Spruit en dr. Kenneth Meijer. De resultaten van dit promotieonderzoek werden gepresenteerd op verschillende internationale congressen en resulteerden in het winnen van de ERS Grant for best abstract on rehabilitation and chronic care 2010 en de Travel Grant for best abstracts on COPD 2013. 



\section{List of publications}





\section{ORIGINAL RESEARCH ARTICLES AND REVIEWS}

Vaes AW, Wouters EF, Franssen FM, Uszko-Lencer NH, Stakenborg KH, Westra M, Meijer K, Schols AM, Janssen PP, Spruit MA. Task-related oxygen uptake during domestic activities of daily life in patients with COPD and healthy elderly subjects. Chest. 2011;140(4):970-9..

Vaes AW, Annegarn J, Meijer K, Cuijpers MW, Franssen FM, Wiechert J, Wouters EF, Spruit MA. The effects of a "new" walking aid on exercise performance in patients with COPD: a randomized crossover trial. Chest. 2012;141(5):1224-32.

Vaes AW, Franssen FM, Meijer K, Cuijpers MW, Wouters EF, Rutten EP, Spruit MA. Effects of body mass index on task-related oxygen uptake and dyspnea during activities of daily life in COPD. PLoS ONE. 2012;7(7):e41078.

Vaes AW, Cheung A, Atakhorrami M, Groenen MT, Amft O, Franssen FM, Wouters EF, Spruit MA. Effect of 'activity monitor-based' counseling on physical activity and healthrelated outcomes in patients with chronic diseases: A systematic review and metaanalysis. Ann Med. 2013;45(5-6):397-412.

Spina G, Huang G, Vaes AW, Spruit MA, Amft O. COPDTrainer: a smartphone-based motion rehabilitation training system with real-time acoustic feedback. UbiComp. 2013:597-606.

Sillen MJ, Franssen FM, Delbressine JM, Vaes AW, Wouters EF, Spruit MA. Efficacy of lower-limb muscle training modalities in severely dyspnoeic individuals with COPD and quadriceps muscle weakness: results from the DICES trial. Thorax. 2014;69(6):525-31.

Vaes AW, Garcia-Aymerich J, Marott JL, Benet M, Groenen MT, Schnohr P, Franssen FM, Vestbo J, Wouters EF, Lange P, Spruit MA. Changes in physical activity and all-cause mortality in COPD. Eur Respir J. 2014;44(5):1199-209.

Sillen MJ, Franssen FM, Vaes AW, Delbressine JM, Wouters EF, Spruit MA. Metabolic load during strength training or NMES in individuals with COPD: results from the DICES trial. BMC Pulm Med. 2014;14:146.

Watz H, Pitta F, Rochester CL, Garcia-Aymerich J, ZuWallack R, Troosters T, Vaes AW, Puhan MA, Jehn M, Polkey MI, Vogiatzis I, Clini EM, Toth M, Gimeno-Santos E, Waschki B, Esteban C, Hayot M, Casaburi R, Porszasz J, McAuley E, Singh SJ, Langer D, Wouters $E F$, Magnussen H, Spruit MA. An official European Respiratory Society statement on physical activity in COPD. Eur Respir J. 2014. 
Vaes AW, Meijer K, Delbressine JM, Wiechert J, Willems P, Wouters EFM, Franssen FME, Spruit MA. Efficacy of walking aids on self-paced outdoor walking in individuals with COPD: A randomized cross-over trial. Submitted.

\section{BOOK CHAPTER}

Sillen MJ, Vaes AW, Franssen FME, Wouters EFM, Spruit MA. Trainingsstrategieën in revalidatieprogramma's bij patiënten met COPD. Jaarboek Fysiotherapie Kinesitherapie 2011. Houten: Bohn Stafleu van Loghum; 2011. 
